July 1999 • NREL/TP-580-26157

\title{
Lignocellulosic Biomass to Ethanol Process Design and Economics Utilizing Co-Current Dilute Acid Prehydrolysis and Enzymatic Hydrolysis Current and Futuristic Scenarios
}

Robert Wooley, Mark Ruth, John Sheehan, and Kelly Ibsen

Biotechnology Center for Fuels and Chemicals

Henry Majdeski and Adrian Galvez Delta-T Corporation
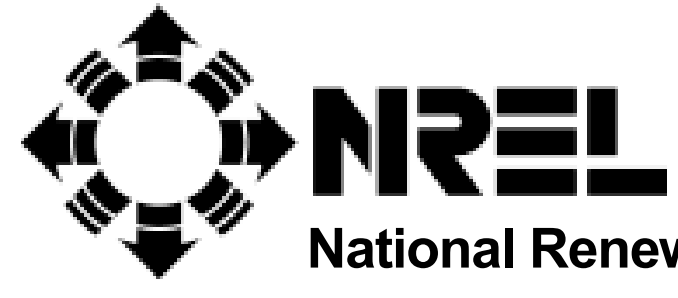

National Renewable Energy Laboratory

1617 Cole Boulevard

Golden, Colorado 80401-3393

NREL is a U.S. Department of Energy Laboratory

Operated by Midwest Research Institute $\bullet$ Battelle $\bullet$ Bechtel

Contract No. DE-AC36-98-G010337 


\section{Lignocellulosic Biomass to Ethanol Process Design and Economics Utilizing Co-Current Dilute Acid Prehydrolysis and Enzymatic Hydrolysis Current and Futuristic Scenarios}

Robert Wooley, Mark Ruth, John Sheehan, and Kelly Ibsen

Biotechnology Center for Fuels and Chemicals

Henry Majdeski and Adrian Galvez Delta-T Corporation

Prepared under Task No. BF992210

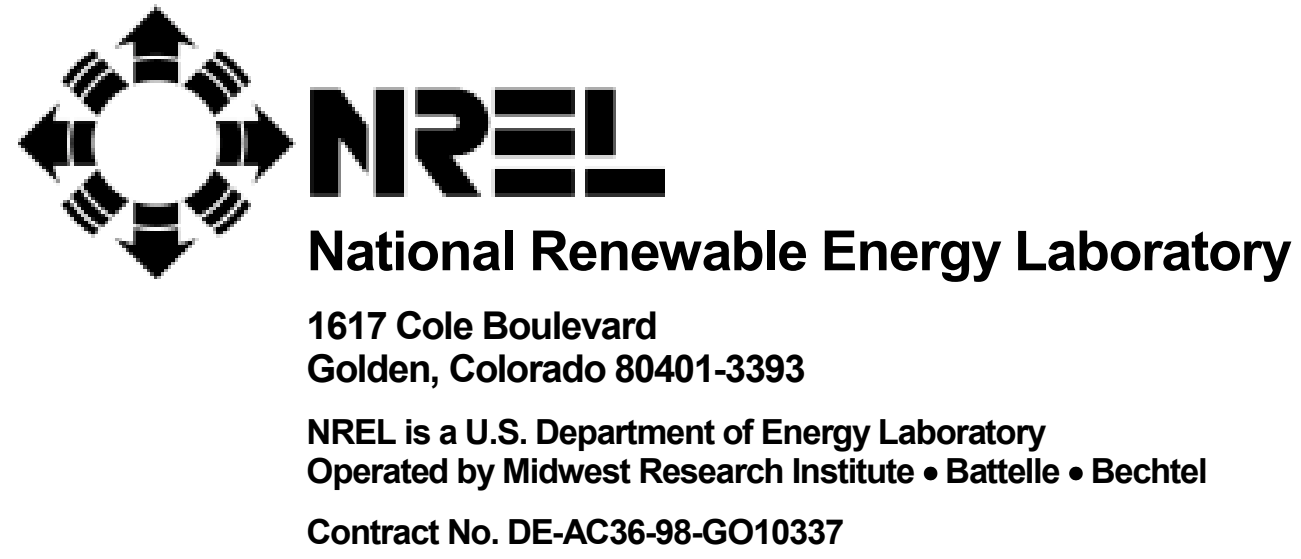




\section{NOTICE}

This report was prepared as an account of work sponsored by an agency of the United States government. Neither the United States government nor any agency thereof, nor any of their employees, makes any warranty, express or implied, or assumes any legal liability or responsibility for the accuracy, completeness, or usefulness of any information, apparatus, product, or process disclosed, or represents that its use would not infringe privately owned rights. Reference herein to any specific commercial product, process, or service by trade name, trademark, manufacturer, or otherwise does not necessarily constitute or imply its endorsement, recommendation, or favoring by the United States government or any agency thereof. The views and opinions of authors expressed herein do not necessarily state or reflect those of the United States government or any agency thereof.

Available to DOE and DOE contractors from:

Office of Scientific and Technical Information (OSTI)

P.O. Box 62

Oak Ridge, TN 37831

Prices available by calling 423-576-8401

Available to the public from:

National Technical Information Service (NTIS)

U.S. Department of Commerce

5285 Port Royal Road

Springfield, VA 22161

$703-605-6000$ or $800-553-6847$

or

DOE Information Bridge

http://www.doe.gov/bridge/home.html

Printed on paper containing at least $50 \%$ wastepaper, including $20 \%$ postconsumer waste 


\begin{abstract}
The National Renewable Energy Laboratory (NREL) has undertaken a complete review and update of the process design and economic model for the biomass-to-ethanol process based on co-current dilute acid prehydrolysis, along with simultaneous saccharification (enzymatic) and co-fermentation. The process design includes the core technologies being researched by the U.S. Department of Energy (DOE): prehydrolysis, simultaneous saccharification and co-fermentation, and cellulase enzyme production. In addition, all ancillary areas - feed handling, product recovery and purification, wastewater treatment lignin burner and boiler-turbogenerator, and utilities - are included. NREL engaged Delta-T Corporation to assist in the process design evaluation, the process equipment costing, and overall plant integration. The process design and costing for the lignin burner and boiler turbogenerator has been reviewed by Reaction Engineering Inc. and the wastewater treatment by Merrick \& Company. An overview of both reviews is included here.

The purpose of this update was to ensure that the process design and equipment costs were reasonable and consistent with good engineering practice for plants of this type using available technical data. For the non-research areas this means using equipment and process approaches as they are currently being used in industrial applications. For areas currently being researched by NREL, we used the best research estimates of near-term data to develop a process design and equipment specifications consistent with existing similar commercial operations.

This work has resulted in an economic model that can be used to predict the cost of producing ethanol from cellulosic biomass using this technology if a plant were to be built in the next few years. The model was also extended using technology improvements that are expected to be developed based on the current DOE research plan. Future process designs and cost estimates are given for the years 2005, 2010, and 2015.

The process design and economic model will also be useful for predicting the cost benefits of proposed research. Proposed research results can be translated into modifications of the process design and the economic impact assessed. This will allow DOE, NREL, and other researchers to set priorities on future research based on its potential to reduce the cost of producing ethanol.
\end{abstract}




\section{Table of Contents}

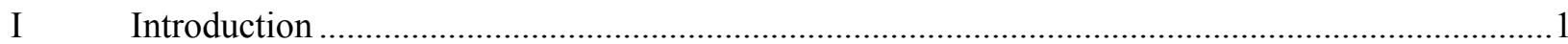

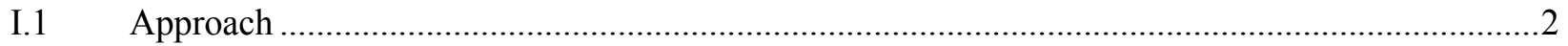

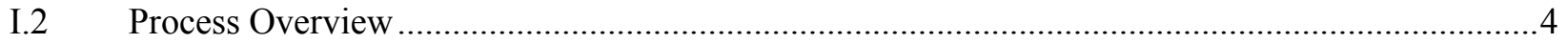

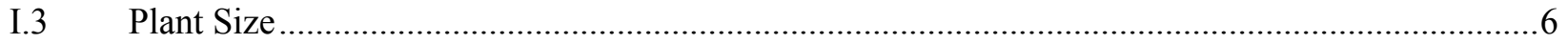

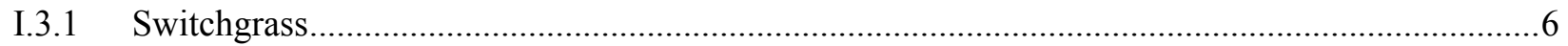

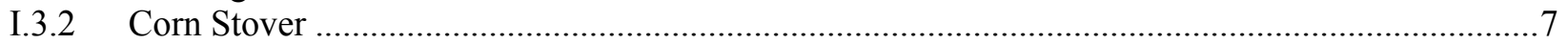

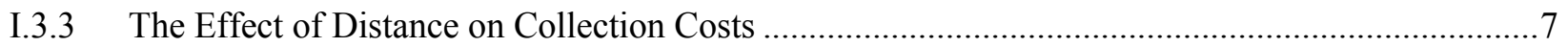

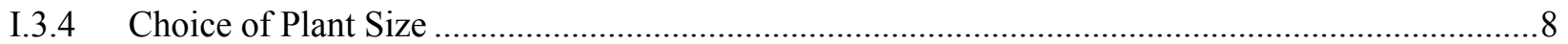

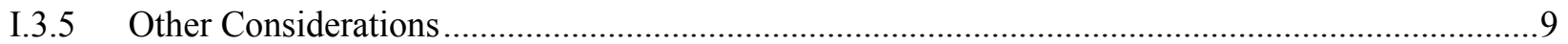

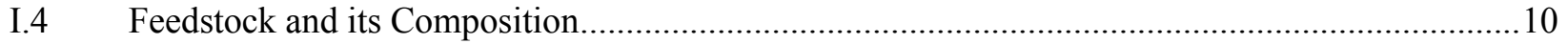

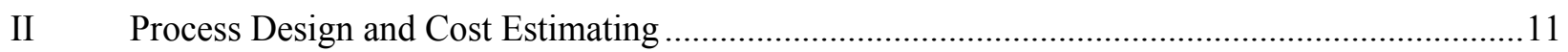

II.1 Feedstock Storage and Handling - Area 100 (PFD-P100-A101) ................................................

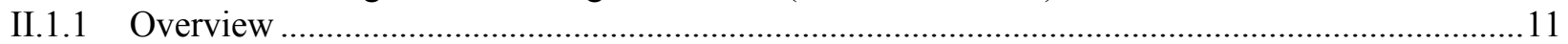

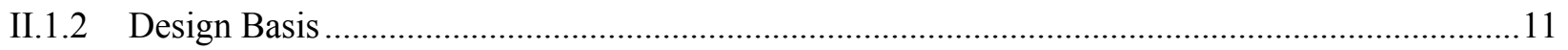

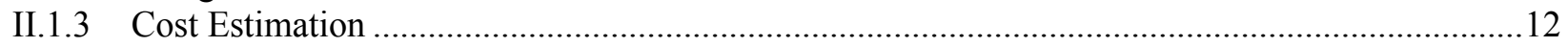

II.2 Pretreatment and Hydrolyzate Conditioning - Area 200 (PFD-P100-A201-3) ........................... 12

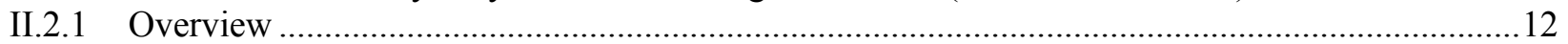

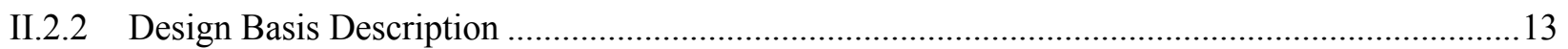

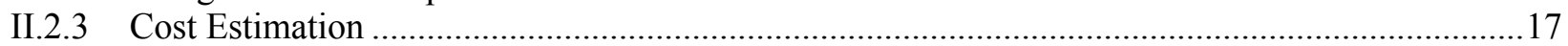

II.3 Simultaneous Saccharification and Co-Fermentation (SSCF) - Area 300 (PFD-P100-A301-2)...18

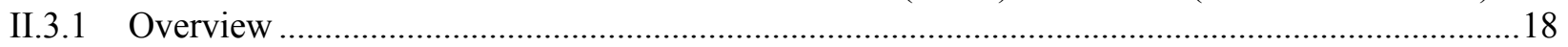

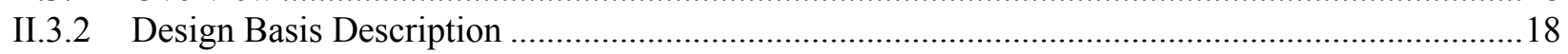

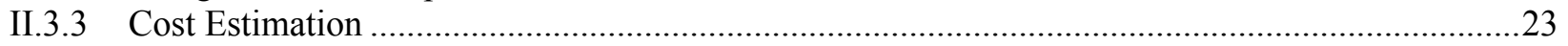

II.4 Enzyme Production - Area 400 (PFD-P100-A401-2) .......................................................23

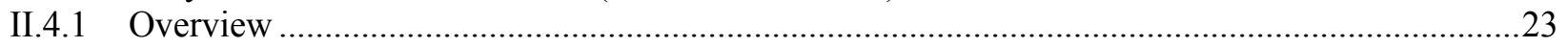

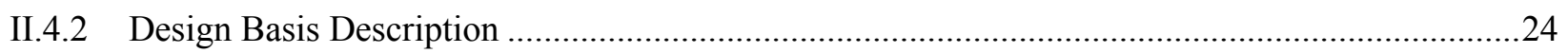

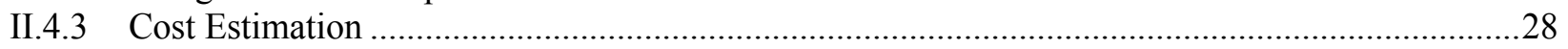

II.5 Product Recovery and Water Recovery (Distillation, Dehydration and Evaporation)

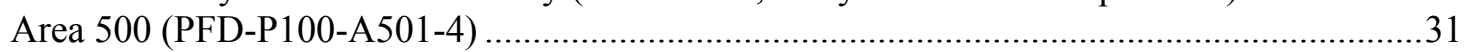

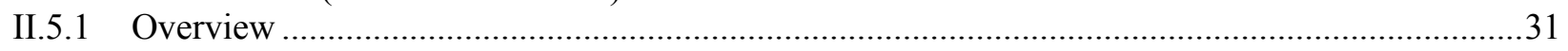

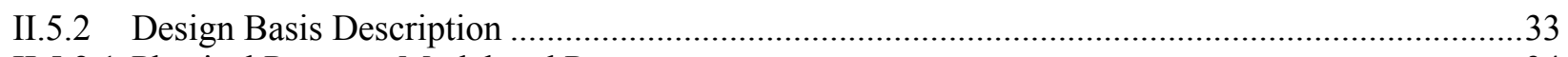

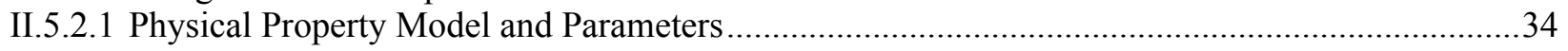

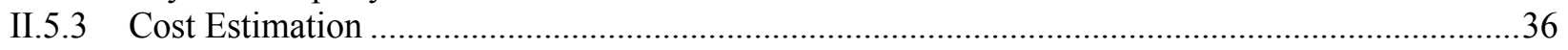

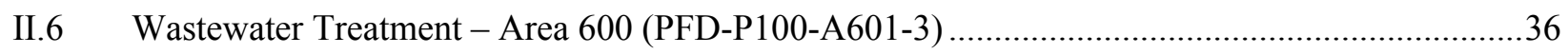

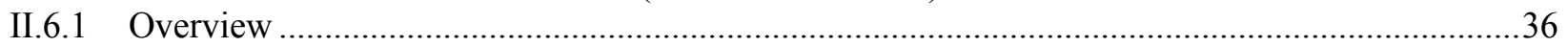

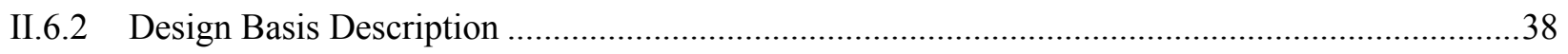

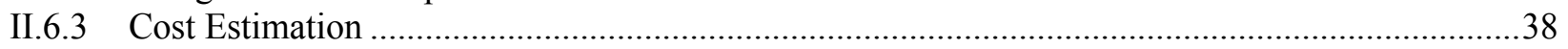

II.7 Product and Feed Chemical Storage - Area 700 (PFD-P100-A701) ..........................................39

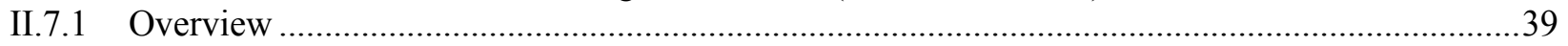

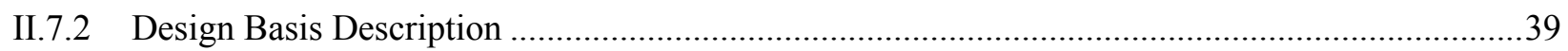

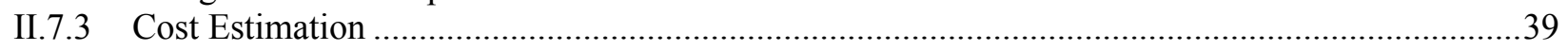

II.8 Burner, Boiler and Turbogenerator - Area 800 (PFD-P100-A801-3) .......................................40

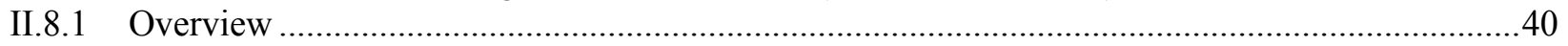

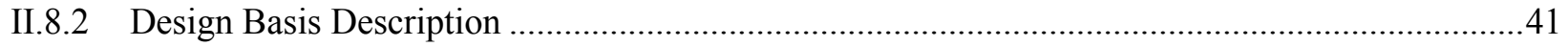




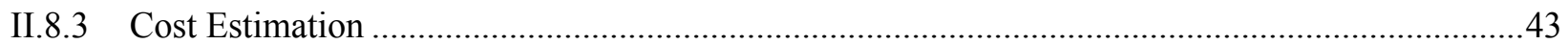

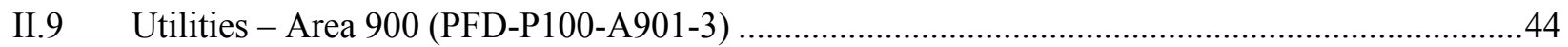

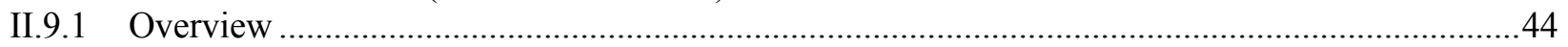

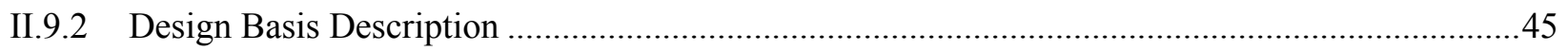

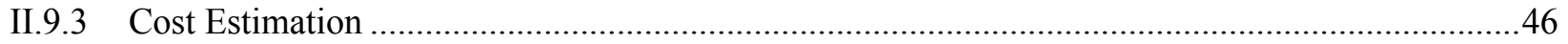

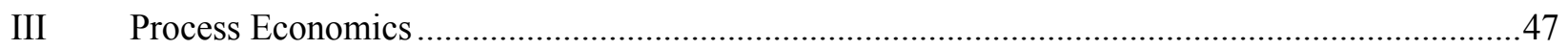

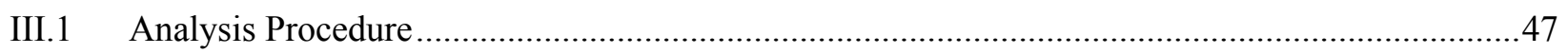

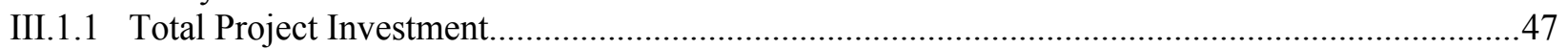

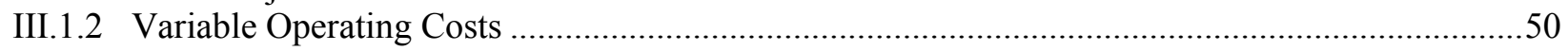

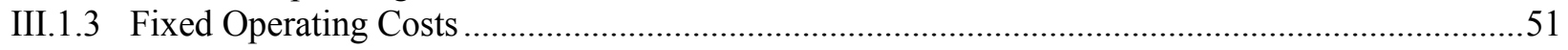

III.1.4 Discounted Cash Flow Analysis and the Selling Cost of Ethanol ...............................................53

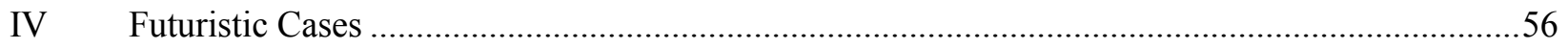

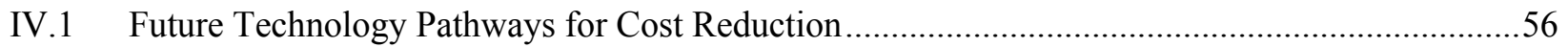

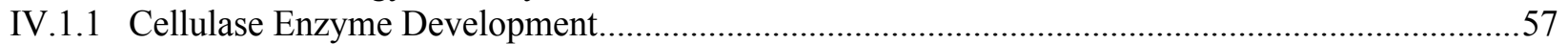

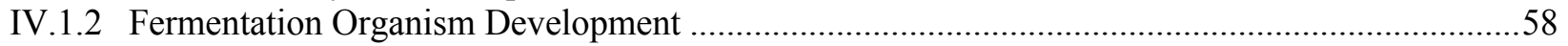

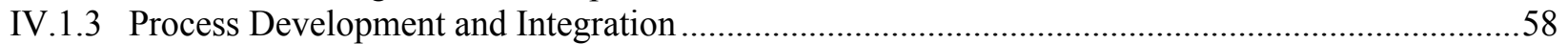

IV.1.4 Long Term Potential for Agricultural Biotechnology …..........................................................59

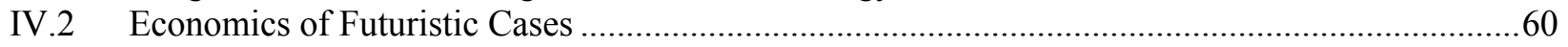

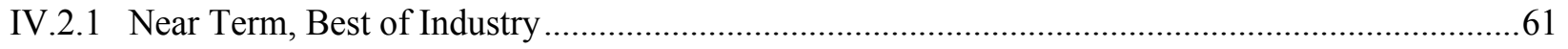

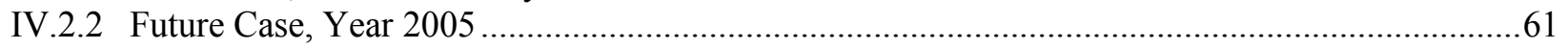

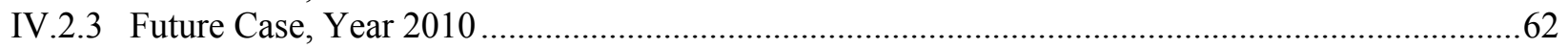

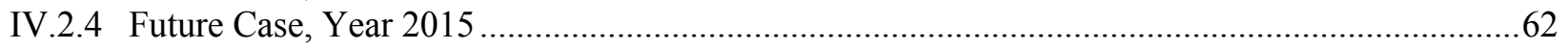

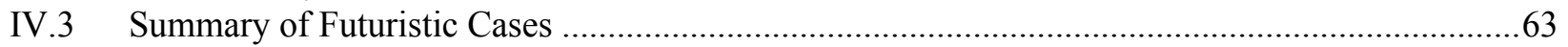

V. Improvements and Extension to the Model Planned or Currently Underway..............................66

V.1 Burner/Boiler Turbo-generator Model Improvements .........................................................66

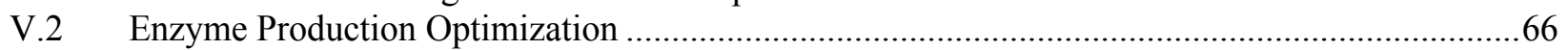

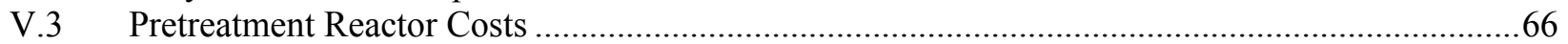

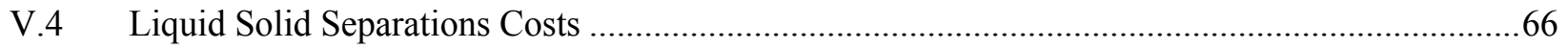

V.5 Lignin Gasification and Gas Turbine Power Generation .........................................................66

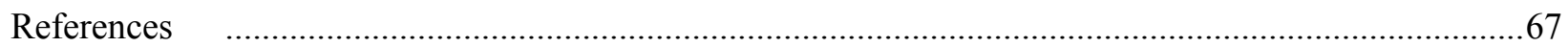

Appendix A - NREL Biofuels Process Design Database Description and Summary

Appendix B - Individual Equipment Costs Summary

Appendix C - Chemical Costs and Sources

Appendix D - Discounted Cash Flow Rate of Return Summary

Appendix E - Comparison of Experimentally Measured and Modeled Information

Appendix F - Other Summary Model Results

Appendix G - Process Flow Diagrams 


\section{Figures}

Fig. 1 NREL's Approach to Process Design and Economic Analysis ...................................................

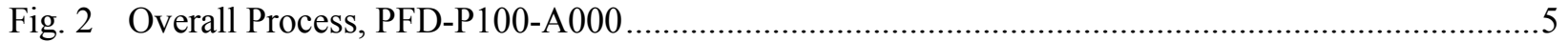

Fig. 3 Collection Distance as a Function of Plant Size for Switchgrass and Corn Stover......................... 7

Fig. 4 Hauling Charges for Corn Stover as a Function of Distance ....................................................

Fig. 5 The Effect of Plant Size on Incremental Feedstock Cost ..........................................................9

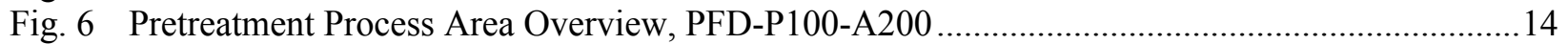

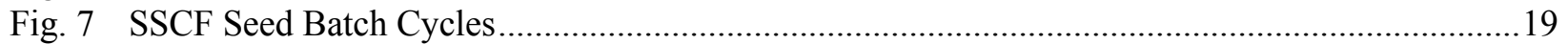

Fig. 8 Batch Cycles for Cellulase Seed and Production Fermentation ................................................25

Fig. 9 Required Cellulase Reactor Air Flow as a Function of Vessel H/D and Agitator Power .............29

Fig. 10 Required Cellulase Reactor Air Flow as a Function of Feed Oxygen Concentration ....................29

Fig. 11 Overall Ethanol Cost as a Function of Cellulase Reactor H/D ..................................................30

Fig. 12 Overall Ethanol Cost as a Function of Cellulase Feed Oxygen Concentration.............................30

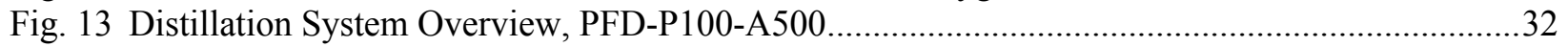

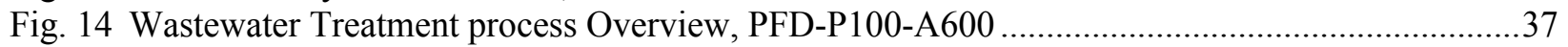

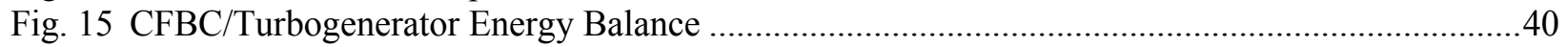

Fig. 16 Cost Contribution Details From Each Process Area.........................................56

Fig. 17 Future Projection of the Cost of Ethanol Production from Cellulosic Biomass............................63

Fig. 18 Cost Breakdown of Current and Future Cases......................................................64

Fig. 19 Future Projection of Ethanol Yield from Cellulosic Biomass .......................................................64

Fig. 20 Future Projection of the Cost of Ethanol as a Function of Feedstock Cost .................................65 


\section{Tables}

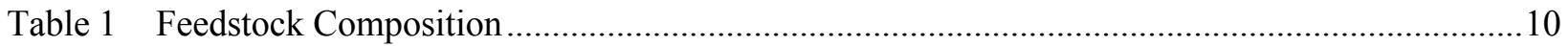

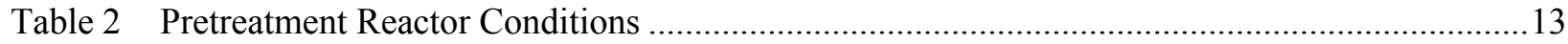

Table 3 Pretreatment Hydrolyzer Reactions and Conversions ......................................................... 15

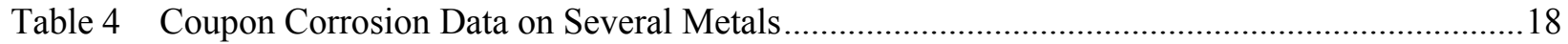

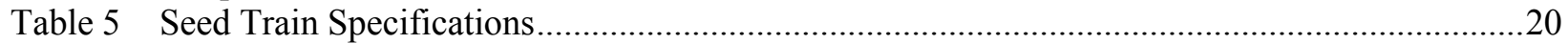

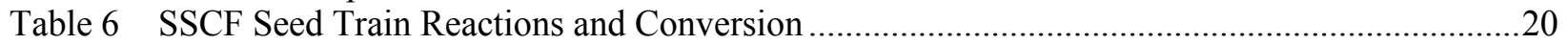

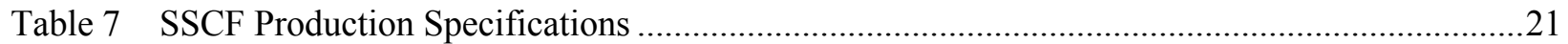

Table 8 Production SSCF Saccharification Reactions and Conversions..............................................21

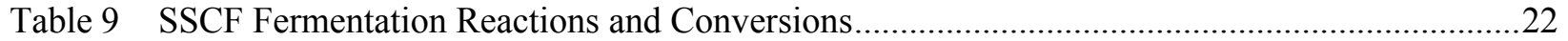

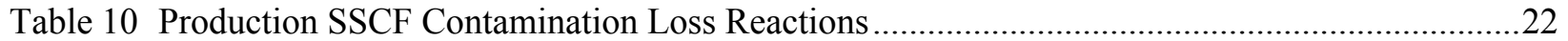

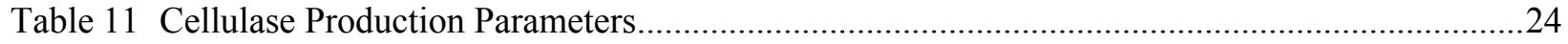

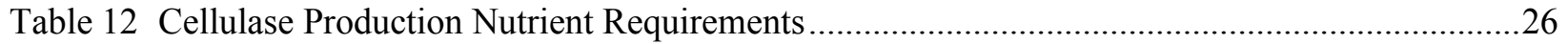

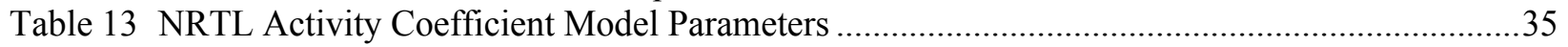

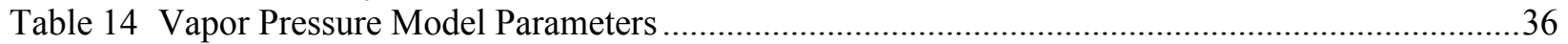

Table 15 Comparison of Sending Evaporator Syrup to the Burner or Wastewater Treatment...................38

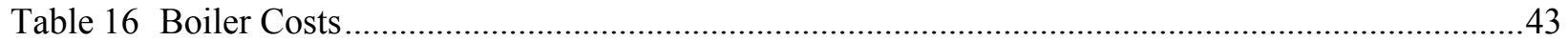

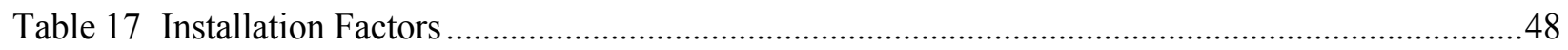

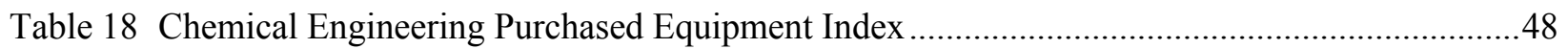

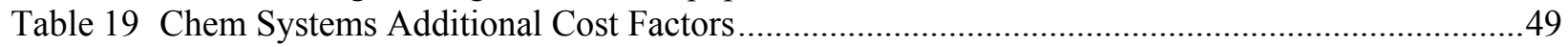

Table 20 Total Installed Equipment Costs by Process Area..............................................................50

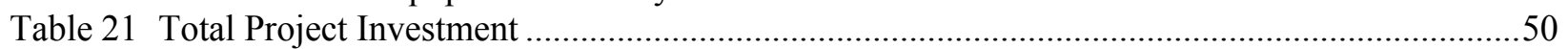

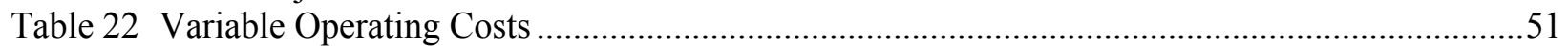

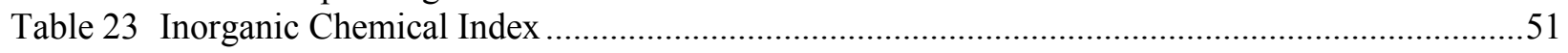

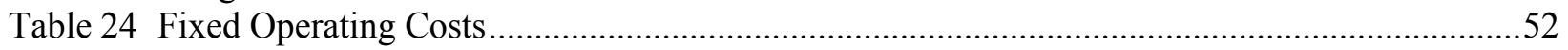

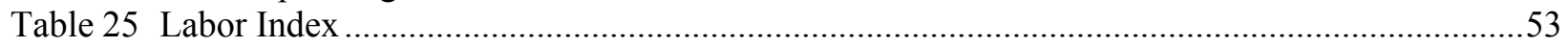

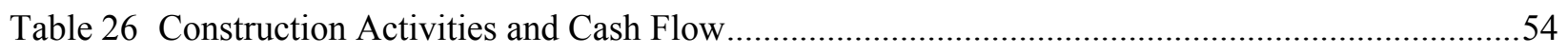

Table 27 Discounted Cash Flow Parameters.........................................................................................5

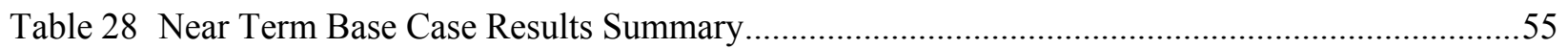

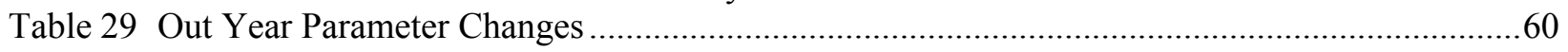

Table 30 Near Term, Best of Industry Improvements from Base Case ..............................................66

Table 31 Year 2005 Improvements from Best of Industry ................................................................62

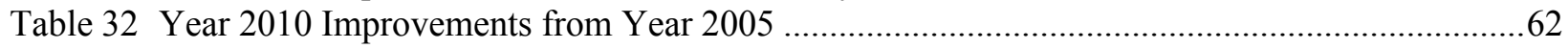

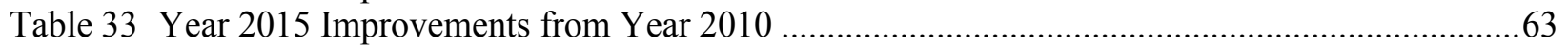




\section{I.0 Introduction}

The U.S. Department of Energy (DOE) is promoting the development of ethanol from lignocellulosic feedstocks as an alternative to conventional petroleum transportation fuels. Programs being sponsored by DOE range from basic research to develop better cellulose hydrolysis enzymes and ethanol-fermenting organisms, to engineering studies of potential processes, to co-funding initial ethanol from lignocellulosic biomass demonstration and production facilities. This research is conducted by various national laboratories, including the National Renewable Energy Laboratory (NREL) and Oak Ridge National Laboratory (ORNL), as well as by universities and private industry. Engineering and construction companies and operating companies are generally conducting the engineering work.

There are two primary reasons for NREL's Process Engineering team to investigate the complete process design and economics of these types of plants. First, this effort helps to direct research by developing a base case of the current process design and economics. Once the base case is developed, the proposed research and its anticipated results are translated into a new design, the economics (the anticipated results of proposed research) are determined, and this is compared to the base case. Following this process for several proposed research projects allows DOE to make funding decisions based on which projects have the greatest potential to lower the cost of ethanol production. Complete process design and economics are required for such studies, because a new proposal in one research area may have a large effect on another process area that is not generally part of the research program, such as product recovery or waste treatment. The impact on other areas of the process can have a significant impact on the economics of the proposed research.

Second, this investigation allowed us to develop an absolute cost of the production of ethanol based on process and plant design assumptions. In reviewing and establishing research directions, only relative cost differences are important. However, to be able to compare the economics of ethanol with other fuels, the baseline absolute cost is required. To that end, we are making the best possible attempt to develop cost estimates that are consistent with applicable engineering and construction practices for facilities of this type. To do so, the complete process, including newly researched areas and industry-available process components must be designed and their costs developed. For the current level of design, we consider the capital cost estimate to be at the conceptual level.

To improve the plant cost estimates that affect the absolute cost of ethanol production, NREL contracts with industry-knowledgeable turnkey companies such as Delta-T Corporation (Delta-T) to assist in preparing, reviewing, and estimating costs for the process design. Delta-T has worked with NREL process engineers over the last year to review all the process design and equipment costs (with the exclusion of wastewater treatment and the burner-boiler system, which were reviewed by Merrick Engineering $^{1}$ and Reaction Engineering, Inc. ${ }^{2}$ [REI], respectively). For the plant areas that are actively being investigated under DOE programs (e.g., prehydrolysis, cellulase enzyme production, and simultaneous saccharification and co-fermentation [SSCF]), Delta-T used the results of the DOEsponsored research to identify process design criteria and equipment requirements. These were used as a basis for sizing and costing major equipment components in the facility. The results of Merrick Engineering's work on wastewater treatment ${ }^{3}$ and REI's work on the burner/boiler ${ }^{4}$ is also included here. 


\section{I.1 Approach}

Developing a model that describes the technical process and its economics requires inputs from many different areas. Figure 1 describes the approach used here.

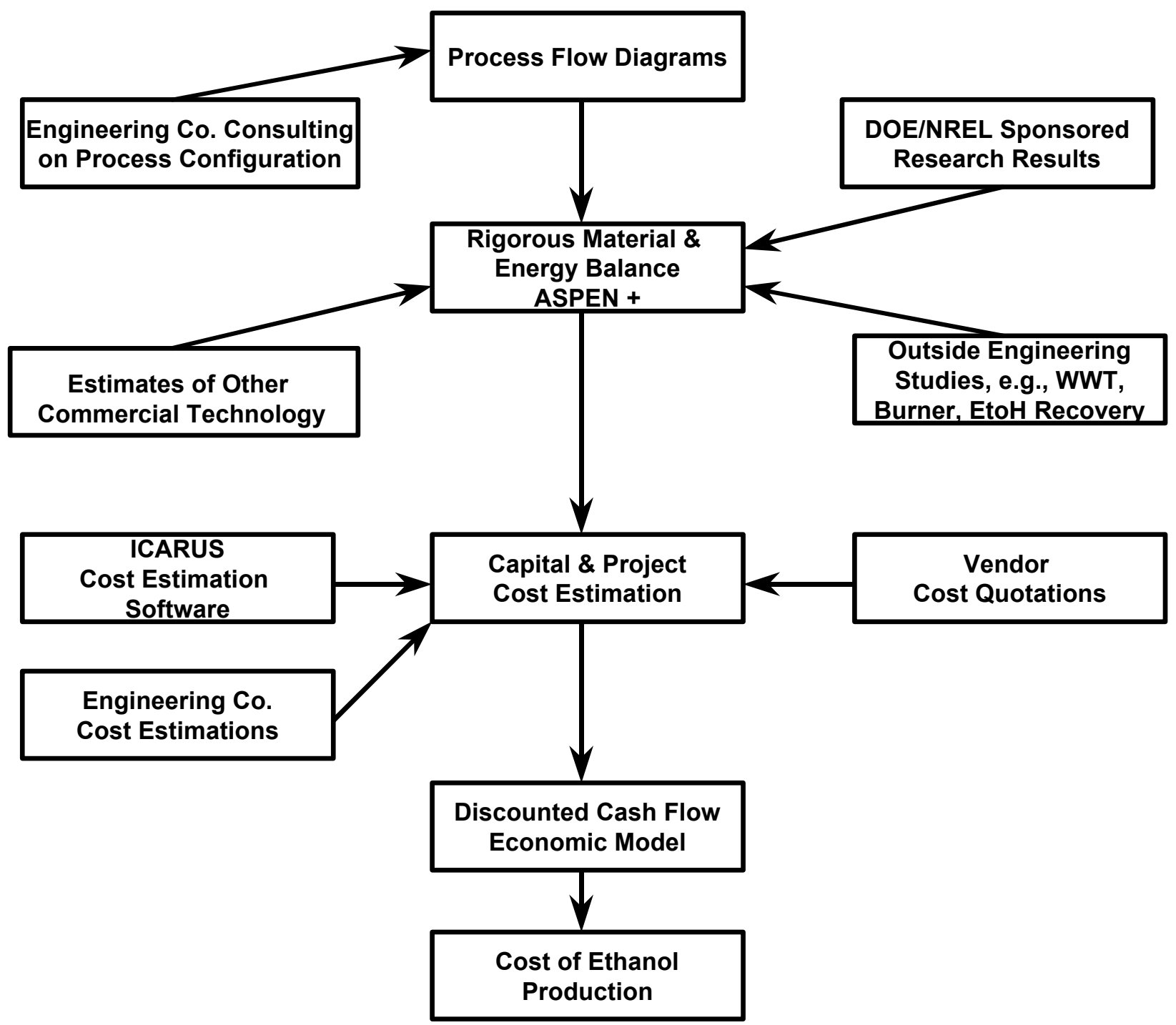

Figure 1. NREL's Approach to Process Design and Economic Analysis

The first step to any process design is to develop a set of process flow diagrams (PFDs). Appendix G contains the PFDs we used. Using the arrangement of the equipment shown, a mass and energy balance was developed within an ASPEN Plus ${ }^{5}$ model. This model consists of 144 unit operation blocks, 668 streams (462 material and 206 heat or work), 57 components, and 70 control blocks. The overall model is thermodynamically rigorous and uses built-in physical properties as well as properties developed at NREL $^{6}$. The individual unit models are thermodynamically consistent and can be either rigorous (for 
example, the simulation of the distillation) or simple. The reactors could be modeled with kinetic expressions, but because of the level of development of the experimental data, they were modeled as experimentally determined conversions of specific reactions. This type of model still satisfies the rigorous mass and energy balance. Other unit operations, such as liquid-solid separations, are typically modeled with a estimated fixed solids removal and liquid retention in the solids stream.

Using the PFDs, complete with the mass and energy balance information from the ASPEN model, we performed a detailed equipment design for each piece of equipment. This equipment design (and cost estimate) is detailed in the NREL process database (see Appendix A). Finally, from the detailed equipment design, we developed an individual purchase and installation cost.

Equipment costs were obtained from vendor quotations when possible, especially for uncommon equipment such as pretreatment reactors or ion exchange equipment. These costs reflect the base case for which the equipment was designed. If process changes are made and the equipment size changes, the equipment is not generally re-costed in detail. Using the following exponential scaling expression, the cost was determined by scaling based on the new size or some other characteristic related to the size.

New Cost $=$ Original Cost $\left(\frac{\text { New Size } *}{\text { Original Size }}\right)^{\frac{1}{\frac{\exp }{j}}}$

* or characteristic linearly related to the size

If the size of the equipment is known to change linearly with the inlet flow, that can be used for scaling. Another characteristic of the size might be the heat duty for a heat exchanger if the $\Delta \mathrm{T}$ is known not to change. Generally these related characteristics are easier to calculate and give the same result as resizing the equipment each time. For some equipment, nothing can be easily related to the size, so it must be resized with each process change.

The scaling exponent (exp) was obtained either from vendor quotes (if two quotes at different sizes were obtained) or from a standard reference, such as Garrett. ${ }^{7}$ The installation costs were taken from Delta-T's experience and are explained in more detail in the economic analysis section.

Once the scaled, installed equipment costs were determined, we applied various overhead and contingency factors to determine a total plant investment cost. That cost, along with the plant operating expenses (generally developed from the ASPEN model) was used in a discounted cash flow analysis to determine the cost of ethanol production, using a set discount rate. For the analysis done here, the ethanol production cost is the primary comparison tool.

Futuristic cases are developed in a fashion similar to evaluating research proposals. Scenarios, based on what might be developed after several years of research, are converted to process designs and the cost of ethanol production is evaluated. These projections are only as good as the estimation of the future technology developments.

Even though one aim of this work was to develop the absolute cost of ethanol for use in comparison to other fuels, it should be noted that ethanol and possibly electricity are the only products of these plants. Certainly, smaller volume niche products will emerge, products that can also be produced from the biomass-derived sugars and that will have a significantly higher profit margin. When these other products 
and their selling prices are figured into the analysis, the cost of ethanol will decrease, just as the cost of gasoline is lowered by the sale of other petroleum products of crude oil.

\section{I.2 Process Overview}

The process being analyzed here can be briefly described as using co-current dilute acid prehydrolysis of the lignocellulosic biomass with simultaneous enzymatic saccharification of the remaining cellulose and co-fermentation of the resulting glucose and xylose to ethanol. In addition to these unit operations, the process involves feedstock handling and storage, product purification, wastewater treatment, enzyme production, lignin combustion, product storage, and other utilities. In all, the process is divided into nine areas (see Figure 2).

The feedstock, in this case hardwood chips, is delivered to the feed handling (A100) area for storage and size reduction. From there the biomass is conveyed to pretreatment and detoxification (A200). In this area the biomass is treated with dilute sulfuric acid at a high temperature for a very short time, liberating the hemicellulose sugars and other compounds. Ion exchange and overliming is required to remove compounds liberated in the pretreatment that will be toxic to the fermenting organism. Detoxification is applied only to the liquid portion of the hydrolysis stream.

After detoxification, a portion of the hydrolyzate slurry is split off to enzyme production (A400). In enzyme production, seed inoculum is grown in a series of progressively larger aerobic batch fermenters. The inoculum is then combined with additional hydrolyzate slurry and nutrients in large-production aerobic fermenters to produce the enzyme needed for saccharification.

Simultaneous saccharification and co-fermentation (A300) of the detoxified hydrolyzate slurry is carried out in a series of continuous anaerobic fermentation trains. The fermenting organism Zymomonas mobilis is grown in progressively larger batch anaerobic fermentations. The inoculum, along with cellulase enzyme from area A400 and other nutrients, is added to the first fermenter. After several days of saccharification and fermentation, most of the cellulose and xylose will have been converted to ethanol. The resulting beer is sent to product recovery.

Product recovery (A500) consists of distilling the ethanol away from the water and residual solids. A mixture of nearly azeotropic water and ethanol is purified to pure ethanol using vapor-phase molecular sieves. Solids from the distillation bottoms are separated and sent to the boiler. Concentration of the distillation bottoms liquid is performed by evaporation, using waste heat. The evaporated condensate is returned to the process as fairly clean condensate and the concentrated syrup is sent to the burner.

Part of the evaporator condensate, along with other wastewater, is treated by anaerobic and aerobic digestion (A600). The biogas (high in methane) from the anaerobic digestion is sent to the burner for heat recovery. The treated water is considered suitable for recycle and is returned to the process.

The solids from distillation, the concentrated syrup from the evaporator, and biogas from anaerobic digestion are combusted in a fluidized bed combustor (A800) to raise steam for process heat. The majority of the steam demand is in the pretreatment reactor and distillation areas. Generally, the process produces excess steam that is converted to electricity for use in the plant and for sale to the grid. 


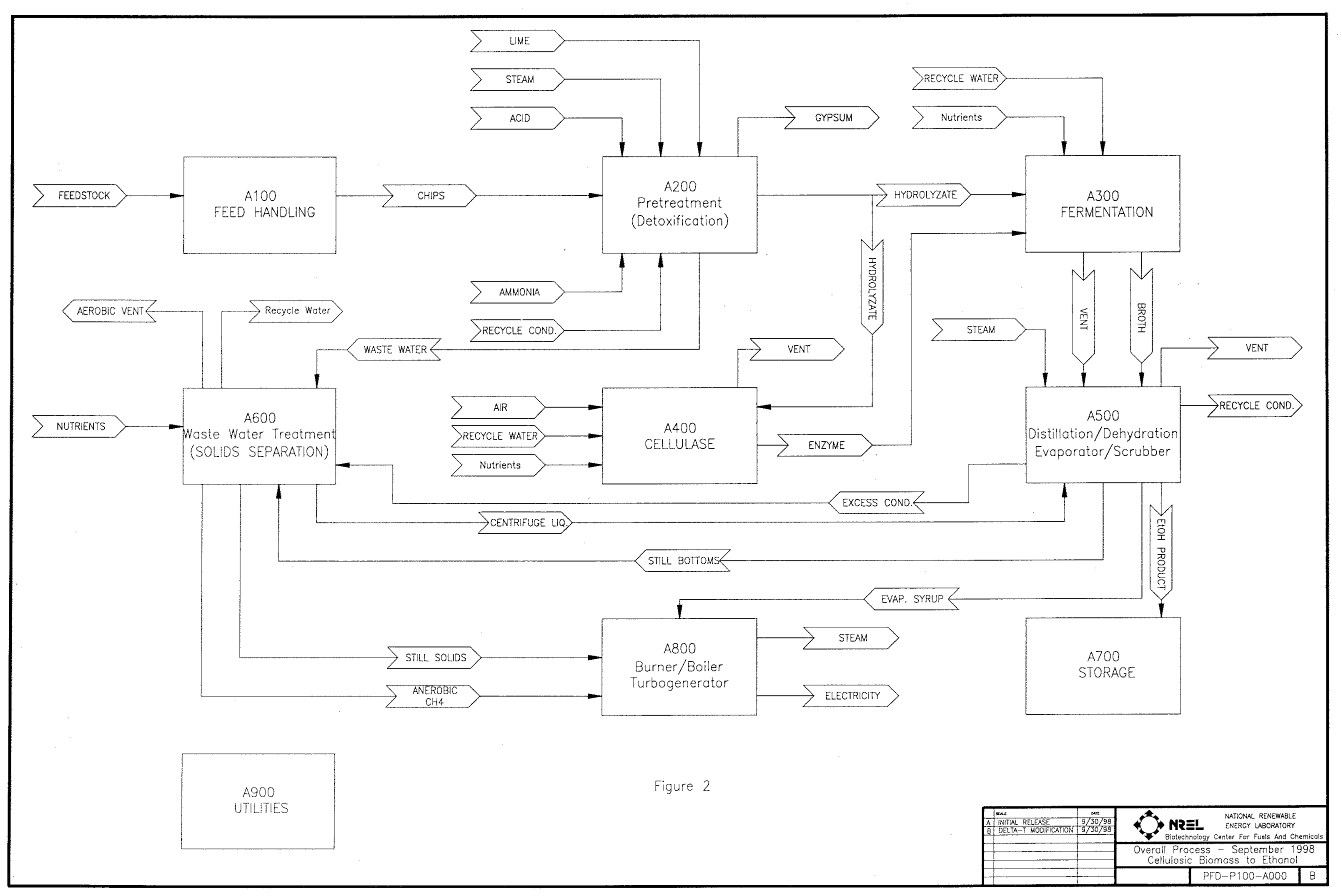




\section{I.3 Plant Size}

As can be seen from the scaling equation presented earlier, which shows that equipment costs do not linearly increase with equipment size, plant size is important in figuring the overall cost of making a product. Generally, equipment costs scale with an exponent of about 0.7. An exponent of 1 would translate to linear scaling. Anything less means that the capital cost per unit size decreases as the equipment becomes larger. This diminishes when the equipment is as large as possible and multiple pieces of equipment become necessary.

In establishing the appropriate size of an "nth" (the "nth" plant implies that many similar plants have already been built, thus minimizing design risk and uncertainty) ethanol plant, we must consider the effects of a number of tradeoffs. Savings resulting from economies of scale are offset by increased costs for feedstock collection. Put quite simply, the more feedstock a plant demands, the farther out it must go to get it. Collection distance for a plant is highly site specific. But a simple analysis can be done to determine if an assumption for the base case plant size is reasonable.

Such analysis for two of the key feedstocks currently targeted by the Biofuels Program - switchgrass and corn stover - has been completed. Switchgrass is a dedicated energy crop that could be in use as early as 2005, perhaps as a relatively small fraction of the total biomass used in an ethanol plant. Corn stover is a feedstock material available in high volume as a by-product from today's corn farmers.

\section{I.3.1 Switchgrass}

Oak Ridge National Laboratory has published a spreadsheet database that summarizes the cost, yield, and available acreage for producing energy crops. This database, known as ORECCL, ${ }^{8}$ provides county-level data on land availability and rents, energy crop yields, and production costs. We used this database to determine state-averaged estimates for switchgrass yields (in MT [metric ton]/acre/year), and estimated farm-gate cost of the switchgrass (in \$/MT). Our analysis of the database identified Alabama as the state with the lowest average cost for producing switchgrass. In Alabama, switchgrass could be produced for costs ranging from $\$ 28$ to $\$ 41 / \mathrm{MT}$ ( $\$ 25$ to $\$ 37 / \mathrm{ST}$ [short ton]), and averaging \$31/MT (\$28/ST) (in 1998 $\$$ ). The average yield of switchgrass in Alabama is estimated to be $6.15 \mathrm{MT} /$ acre/year (6.7 ST/acre/year).

To get a sense for the size of radius around the plant that must be included for feedstock collection, we made two more critical assumptions:

- Only $10 \%$ of the suitable acreage around the plant is actually used for switchgrass production

- Seventy-five percent of the land surrounding the plant is actual farmland.

The estimate of $10 \%$ dedication of acreage to switchgrass is conservative. An analysis of the cost data in the ORECCL database suggests that $30 \%$ of the suitable acreage in Alabama could produce switchgrass at a cost of $\$ 30$ or less per MT ( $\$ 27$ or less per ST). This cost estimate takes into account the effects of competition for land use in an indirect way by assigning land rent values on a county-by-county basis. Thus, for this analysis we assumed that only one-third of the land available at a switchgrass price of \$30/MT (\$27/ST) was actually assigned to switchgrass production. The second assumption said that $25 \%$ of the land around the plant was used for infrastructure (roads, buildings, and other rights of way). Using these assumptions, in conjunction with the average yield estimate for switchgrass, we calculated the radius of collection as a function of plant size (see Figure 3 ). 
These calculations show that a 2,000 MT/day (2205 ST/day) plant would require a collection radius of 64 $\mathrm{km}$ (40 miles) to meet its feedstock needs. Doubling the size of the plant to 4,000 MT per day (4409 ST/ day) would extend the collection radius to around $92 \mathrm{~km}$ (57 miles). (Note that the collection radius increased in proportion to the square root of the plant's feedstock demand rate.)

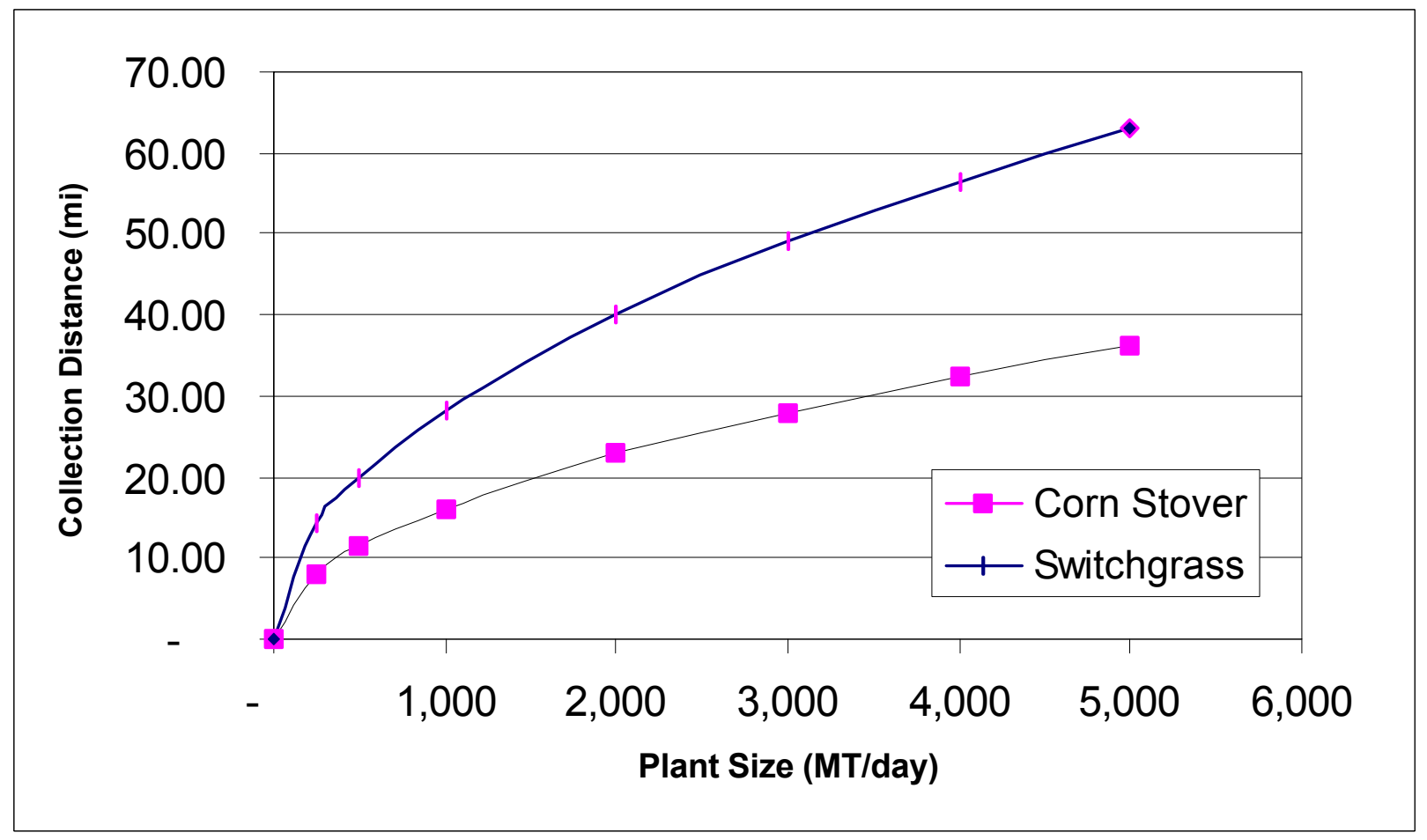

Figure 3. Collection Distance as a Function of Plant Size for Switchgrass and Corn Stover

\section{I.3.2 Corn Stover}

A similar analysis can be done for corn stover collection, using data from an ongoing corn stover collection project in Harlan, Iowa. In the second year of this demonstration project, researchers reported collecting 50,000 MT (55,100 ST) of corn stover from more than 30,000 acres of land. ${ }^{9}$ This amounts to around 1.67 MT (1.84 ST) of corn stover per acre. We assumed that $50 \%$ of the land around a Midwest facility would be dedicated to corn, and that the remaining $50 \%$ would be used for soybean production. This reflects the common practice of corn and soybean crop rotation. As with the switchgrass analysis, we assumed that $75 \%$ of the land around the plant was available for planting. Figure 3 shows that, under these assumptions, a 2,000 MT/day (2205 ST/day) corn stover to ethanol facility would have to collect its feedstock over $37 \mathrm{~km}$ (23-mile) radius from the plant. Doubling the plant size increases that radius by only $16 \mathrm{~km}(10 \mathrm{mi})$.

\section{I.3.3 The Effect of Distance on Collection Costs}

Collecting biomass for the plant has two main costs:

- The cost of harvesting and baling

- The cost of transportation from the farm to the plant gate. 
These costs must be added to the farmer's asking price for the feedstock. Costs for baling and transport of corn stover, based on the commercial demonstrations conducted in Harlan, Iowa, have recently been reported. ${ }^{9}$ Only transportation costs are directly affected by the size of the plant. ${ }^{10}$ These costs are shown in Figure 4 as a function of distance from the plant. Figure 5 combines the results from Figures 3 and 4 to show the effect of increased plant size on the incremental cost of feedstocks.

If plant size doubled from 1,000 MT (1102 ST) per day to 2,000 MT (2205 ST) per day, feedstock costs would rise by $\$ 2.11 / \mathrm{MT}(\$ 1.91 / \mathrm{ST})$ of switchgrass and only $\$ 1.21 / \mathrm{MT}(\$ 1.10 / \mathrm{ST})$ of corn stover. Doubling again from 2,000 to 4,000 MT (2205 to 4409 ST) per day would result in added costs of $\$ 1.63 / \mathrm{MT}(\$ 1.48 / \mathrm{ST})$ of switchgrass and \$0.93/MT (\$0.84/ST) of corn stover.

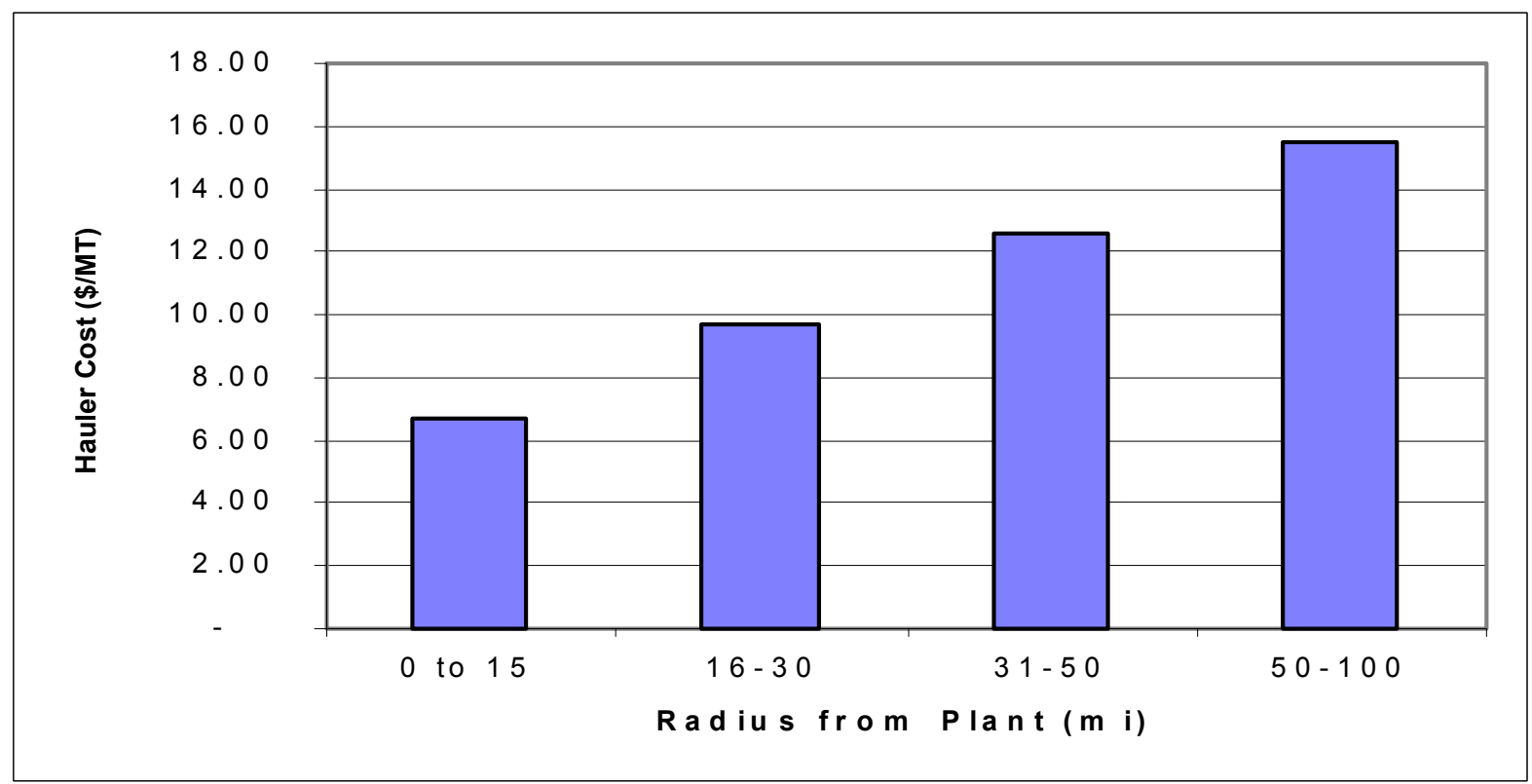

Figure 4. Hauling Charges for Corn Stover as a Function of Distance

\section{I.3.4 Choice of Plant Size}

The analyses presented in the previous two sections were not intended to definitively assess feedstock collection cost issues. We look to experts at ORNL and elsewhere for more complete evaluation of the logistics and costs of producing, harvesting, collecting, and transporting feedstocks. However, these analyses did give us a relative context for choosing plant size. Previous NREL process economics assumed a plant size of around 2,000 MT/day (2205 ST/day) of biomass. Recent concerns that this plant size is too large motivated us to reconsider this key assumption in our process analysis. The results of this simplified analysis suggested that the difference in feedstock costs between our 2,000 MT/day (2205 $\mathrm{ST} /$ day) plant and a plant twice this size is reasonable. To put this in context, consider that, for every dollar in added feedstock cost, the net effect on the cost of ethanol produced is on the order of 1 to 2 cents per gallon. We expect that the savings that result from the concomitant increased economy of scale may be an order of magnitude higher. We need to confirm these savings more rigorously. For corn stover collection, plants as large as 5,000 MT/day (5512 ST/day) could meet their demand for biomass within a 
40-mile radius. Switchgrass plants may be reaching out as far as 97 to $113 \mathrm{~km}$ (60 to 70 miles). These distances seem reasonable. For now, we are comfortable with cost projections based on a plant designed to process 2,000 MT/day (2205 ST/day). In fact, considering even larger plant sizes in the future may prove worthwhile.

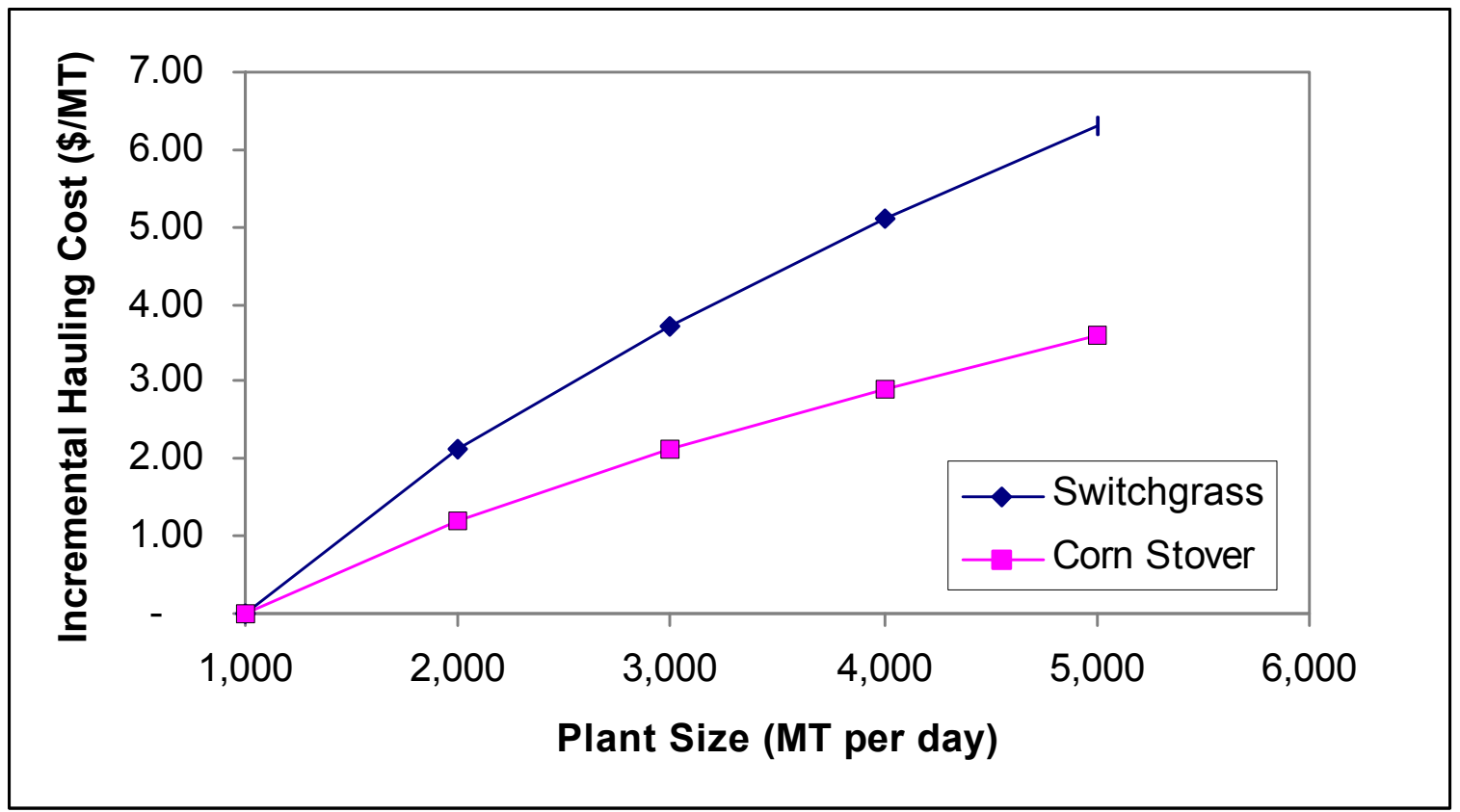

Figure 5. The Effect of Plant Size on Incremental Feedstock Cost

\section{I.3.5 Other Considerations}

It is important to keep in mind the purpose of our process analysis studies: to direct research and provide information on the cost of processing biomass to ethanol. Our concerns center on the impact of specific types of technology changes. Because of that focus, we tend not to dwell on external economic considerations such as feedstock costs. For example, our process economics assume a feedstock cost of $\$ 27.50 / \mathrm{MT}(\$ 25 / \mathrm{ST})$. As the previous analysis suggests, feedstock costs are likely to be higher than that. We treat these types of considerations by using sensitivity analyses to set a range on the cost estimates. For feedstock, we look at the effect of costs ranging from as low as $\$ 16.50 / \mathrm{MT}(\$ 15 / \mathrm{ST})$ to as high as \$44.10/MT (\$40/ST).

In addition, the perspective of our studies is that of "nth" plants using high-volume biomass sources. We assume that these plants are located in the best locations for access to these feedstocks. Switchgrass and corn stover are good examples of these kinds of feedstocks. In the near term, many of the pioneer plants will rely on niche feedstocks, which are often spread out over much larger distances. Such plants may indeed be much smaller in size than our base case design assumes. 


\section{I.4 Feedstock and its Composition}

The feedstock chosen for the process design has some impact on the overall analysis. However, it is important to use the feedstock for which most of the experimental work has been conducted in the analysis. In this case NREL has been using hardwood, typically yellow poplar, as its typical feedstock for research for the last several years. Therefore, we used yellow poplar hardwood as the feedstock for this process. Generally, the type of feedstock will have the biggest effect on the feedstock-handling portion of the process. Additionally, the feedstock composition certainly will have an impact on pretreatment yields and on how much ethanol is produced, as well as an effect on the efficiency of the fermenting organism (which depends on the presence or absence of toxic compounds).

The feedstock composition used for this analysis was typical yellow poplar. ${ }^{11}$ A feedstock analysis was converted to components that are used in the ASPEN model and normalized to $100 \%$. In general, the component analysis of carbohydrates was used directly.

Table 1 gives the feedstock composition used in this analysis.

Table 1: Feedstock Composition ${ }^{11}$

\begin{tabular}{|l|r|}
\hline \multicolumn{1}{|c|}{ Component } & \% Dry Basis \\
\hline Cellulose & 42.67 \\
\hline Xylan & 19.05 \\
\hline Arabinan & 0.79 \\
\hline Mannan & 3.93 \\
\hline Galactan & 0.24 \\
\hline Acetate* & 4.64 \\
\hline Lignin & 27.68 \\
\hline Ash & 1.00 \\
\hline Moisture & 47.90 \\
\hline $\begin{array}{l}\text { *Acetate is the acetate groups present in the } \\
\text { hemicellulose polymer. They are generally } \\
\text { converted to acetic acid in the prehydrolysis } \\
\text { reactor. }\end{array}$ \\
\hline \multicolumn{2}{|l}{} \\
\hline
\end{tabular}




\section{Process Design and Cost Estimating}

The following sections describe in detail the process design and cost estimation for a cellulose-tobiomass process based on core technology developed by NREL. Generally the data used for design have been demonstrated in the laboratory or pilot plant. In some cases, we extrapolated current experimental results to what should be possible to obtain in the next 1 or 2 years of continued research (these extrapolations are noted in the text). More details of the design and cost estimation can be found in the NREL Process Engineering equipment database, which contains all engineering calculations and results from any vendors or costing programs. The database is described and partially summarized in Appendix A.

The cost estimate is based on the assumption that this is the "nth" plant, meaning that several plants using this same technology will have already been built and are operating. This means that additional costs for risk financing, longer start-ups, and other costs associated with first-of-a-kind plants are not included.

The on-line time is $96 \%$, which allows for a little more than 2 weeks of downtime. Delta-T considered this quite reasonable for the "nth" operating plant.

In Section IV, we consider futuristic cases where the results of continued research on feedstocks, reactors, fermenting organisms, cellulase production, and effectiveness are compared to this "base case."

\section{II.1 Feedstock Storage and Handling - Area 100 (PFD-P100-A101)}

\section{II.1.1 Overview}

The plant receives wood chips by truck only. As these trucks are received, they are weighed and dumped. Upon dumping, the chips are conveyed to a storage pile. From the storage pile, bulldozers rearrange the pile and keep the reclaim hoppers filled. From the storage pile, the chips are transferred under a magnetic separator to remove metallic impurities and then moved on to chip washers. The chip washers remove other contaminants, such as dirt.

After washing, the chips are screened and the very large material is sent off to waste disposal. A second screener separates by material thickness. We expect that most material will pass through this screen and on to the pretreatment reactor system. The larger chips are sent to a disk refiner for size reduction and then on to the pretreatment area.

\section{II.1.2 Design Basis}

The continuous-process, wet-chip-feed requirement is $159,948 \mathrm{~kg} / \mathrm{hr}(352,625 \mathrm{lb} / \mathrm{hr}, 160 \mathrm{MT} / \mathrm{hr}, 176$ $\mathrm{ST} / \mathrm{hr}$ ). Limiting trucks to approximately $27 \mathrm{MT}$ (30 ST) for road considerations (this is less than their volumetric maximum capacity of 43 MT [47 ST]), it is necessary to unload 136 trucks per day, or 6 trucks every hour, 24 hours per day, 7 days per week. To allow for downtime, we assume that all unloading/dumping and transfer occurs in an 18-hr day and that one truck is unloaded every 20 minutes on each scale, requiring three operating dumps. In addition, one installed spare will be included because of the need to not delay the trucks' unloading.

Truck dumping will not be around the clock, so the size transfer conveyors to the chip pile are designed for $213 \mathrm{MT} / \mathrm{hr}(235 \mathrm{ST} / \mathrm{hr})$ of wet material. The remainder of the process-wood chip handling, 
reclaiming, washing, sizing, and feed to hydrolysis — is designed for the average capacity of $160 \mathrm{MT} / \mathrm{hr}$ $(176 \mathrm{ST} / \mathrm{hr})$ of wet material.

Vehicles will be weighed loaded and unloaded on a combination platform scale and hydraulic dumper (M-101), which can lift both truck and trailer to dump the load into a receiving hopper (T-101) that has a capacity of $176 \mathrm{~m}^{3}\left(6,200 \mathrm{ft}^{3}\right)$ or about three trucks. Each hopper is fitted with a vibrating feeder (C-101) that meters the chips onto a belt conveyor (C-102) at $109 \mathrm{MT} / \mathrm{hr}(120 \mathrm{ST} / \mathrm{hr})$, unloading the $27 \mathrm{MT}$ (30 ST) truck in 15 minutes. The belt conveyor discharges into a stacking conveyor (C-103) that delivers the chips to the storage pile at a rate of $213 \mathrm{MT} / \mathrm{hr}(235 \mathrm{ST} / \mathrm{hr})$. Bulldozers (M-102) move the chips to form a $12 \mathrm{~m}(40-\mathrm{ft})$ high pile with an area of approximately $2090 \mathrm{~m}^{2}\left(22,500 \mathrm{ft}^{2}\right)$ providing 7 days of storage. Two bulldozers are provided to allow for peak delivery, proper pile rotation, and maintenance. We anticipate that two operators will be required at all times in this area.

The bulldozers are used to push chips into two reclaim hoppers (T-102) with a capacity of $176 \mathrm{~m}^{3}(6,200$ $\mathrm{ft}^{3}$ ) or a combined total of about $2 \mathrm{hr}$ of surge time. Each hopper is fitted with a vibrating feeder (C-104) that meters the chips onto a transfer belt conveyor (C-105). Both have a capacity of $160 \mathrm{MT} / \mathrm{hr}(176$ $\mathrm{ST} / \mathrm{hr}$ ). The belt conveyor is fitted with a magnet (S-101) to remove tramp metal and with a tripper assembly to facilitate feeding to each of four chip washer surge bins $\left(\mathrm{T}-103,249 \mathrm{~m}^{3}\left(8,800 \mathrm{ft}^{3}\right)\right.$ each), with a total surge capacity of $7 \mathrm{hr}$. Each bin is fitted with a vibrating feeder (C-106) and feeds each of four chip washing systems (W-101) at $45 \mathrm{MT} / \mathrm{hr}(50 \mathrm{ST} / \mathrm{hr})$ (combined total of 182,000 kg/hr [401,000 $\mathrm{lb} / \mathrm{hr}]$ ). Four chip washer systems are used because each train consists of the largest commercially available components, $(19,000 \mathrm{~kg} / \mathrm{hr}(41,900 \mathrm{lb} / \mathrm{hr})$, dry). Washing of the chips aids in removing inert materials and water-soluble constituents in the raw chips, which might be detrimental to the process.

Chips from two washer units are collected on a common drag-chain conveyor (C-107) (two total for four washers), with a combined capacity of $181 \mathrm{MT} / \mathrm{hr}(200 \mathrm{ST} / \mathrm{hr})$. The chips are then passed to a scalper screen (S-102) to remove very large material and then onto to a chip thickness sizing screen (S-103). We assume that approximately $20 \%$ of the incoming material will be oversized and will require processing through a single disc refiner system (M-104). The disc refiner reduces oversized material to less than 19 $\mathrm{mm}(3 / 4 \mathrm{in}$.), suitable for the pretreatment reactors. A drag-chain conveyor (C-108) transfers processed material from the sizing screen and refiner to the pre-steaming hoppers of the pretreatment units (M-202) at $160 \mathrm{MT} / \mathrm{hr}(176 \mathrm{ST} / \mathrm{hr})$.

\section{II.1.3 Cost Estimation}

Most of the large equipment in this section - the hydraulic dump, all conveyors, screeners, washer system and disk refiner-was costed using vendor quotations. The other equipment (feeders and storage bins) was costed using the standard process cost estimation manual by Richardson ${ }^{12}$.

\section{II.2 Pretreatment and Hydrolyzate Conditioning - Area 200 (PFD-P100-A201-3)}

\section{II.2.1 Overview}

This process area converts, by hydrolysis reactions, most of the hemicellulose portion of the feedstock to soluble sugars, primarily xylose, mannose, arabinose, and galactose. A small portion of the cellulose is converted to glucose. This conversion is accomplished using dilute sulfuric acid and high temperature. These conditions also solubilize some of the lignin in the feedstock and "exposes" the cellulose for subsequent enzymatic hydrolysis. In addition, acetic acid is liberated from the hemicellulose hydrolysis. 
Degradation products of pentose sugars, primarily furfural, and hexose sugars, primarily hydroxymethyl furfural (HMF), are also formed.

Following the pretreatment reactor, the hydrolyzate liquid and solids are flash cooled, which vaporizes a large amount of water, much of the furfural and HMF, and a portion of the acetic acid (see Figure 6). Removal of these heterocyclic aldehydes is beneficial, as they can be detrimental to downstream fermentation.

In addition to flash removal of aldehydes, the acetic acid must be removed and other conditioning must be performed before fermentation. ${ }^{13}$ The acetic acid is removed from the liquid portion of the hydrolyzate using continuous ion exchange. After ion exchange, the liquid is "overlimed." This process, as we currently envision it, requires that the liquid hydrolyzate's $\mathrm{pH}$ be lowered (by adding sulfuric acid) after ion exchange, then raised to $\mathrm{pH} 10$ (by adding lime) and held for a period of time. Neutralization and precipitation of gypsum follow the overliming step. The gypsum is filtered out and the hydrolyzate is mixed with the solids (cellulose) and dilution water before being sent to fermentation (Area 300). What happens in the overliming process is not completely understood.

Research is currently under way to determine if the overliming process is removing, adding, or changing the form of a component, or a combination of all of these. ${ }^{14}$ A better understanding of the overliming process may allow it to be replaced with an operation that does not require lime addition and gypsum removal.

\section{II.2.2 Design Basis Description}

The milled wood chips are first steamed with low pressure steam in a feed bin (M-202) to about $100^{\circ} \mathrm{C}$ (see PFD-P100-A201). This steaming removes non-condensables and allows about one-third of the reactor heat load to be performed with low pressure steam. After steaming, acid is added in the impregnator section of M-202. Concentrated sulfuric acid is diluted with evaporator condensate (see evaporation section) and added to the reactor so that the total mixture constitutes $31 \%$ insoluble solids, before the steam addition. Concentrated acid is added until the mixture (the total water, including steam and acid) in the reactor is $0.5 \%$ sulfuric acid. The reactor is brought up to temperature by direct injection of $13 \mathrm{~atm}(191 \mathrm{psia})\left(192^{\circ} \mathrm{C}\right.$ saturation temperature and $76^{\circ} \mathrm{C}$ superheat) turbine extraction steam. Table 2 summarizes the conditions in the pretreatment reactor.

Table 2: Pretreatment Reactor Conditions ${ }^{15}$

\begin{tabular}{|l|l|}
\hline Acid Concentration & $0.5 \%$ \\
\hline Residence Time & 10 minutes \\
\hline Temperature & $190^{\circ} \mathrm{C}$ \\
\hline Solids in the Reactor & $22 \%$ \\
\hline
\end{tabular}




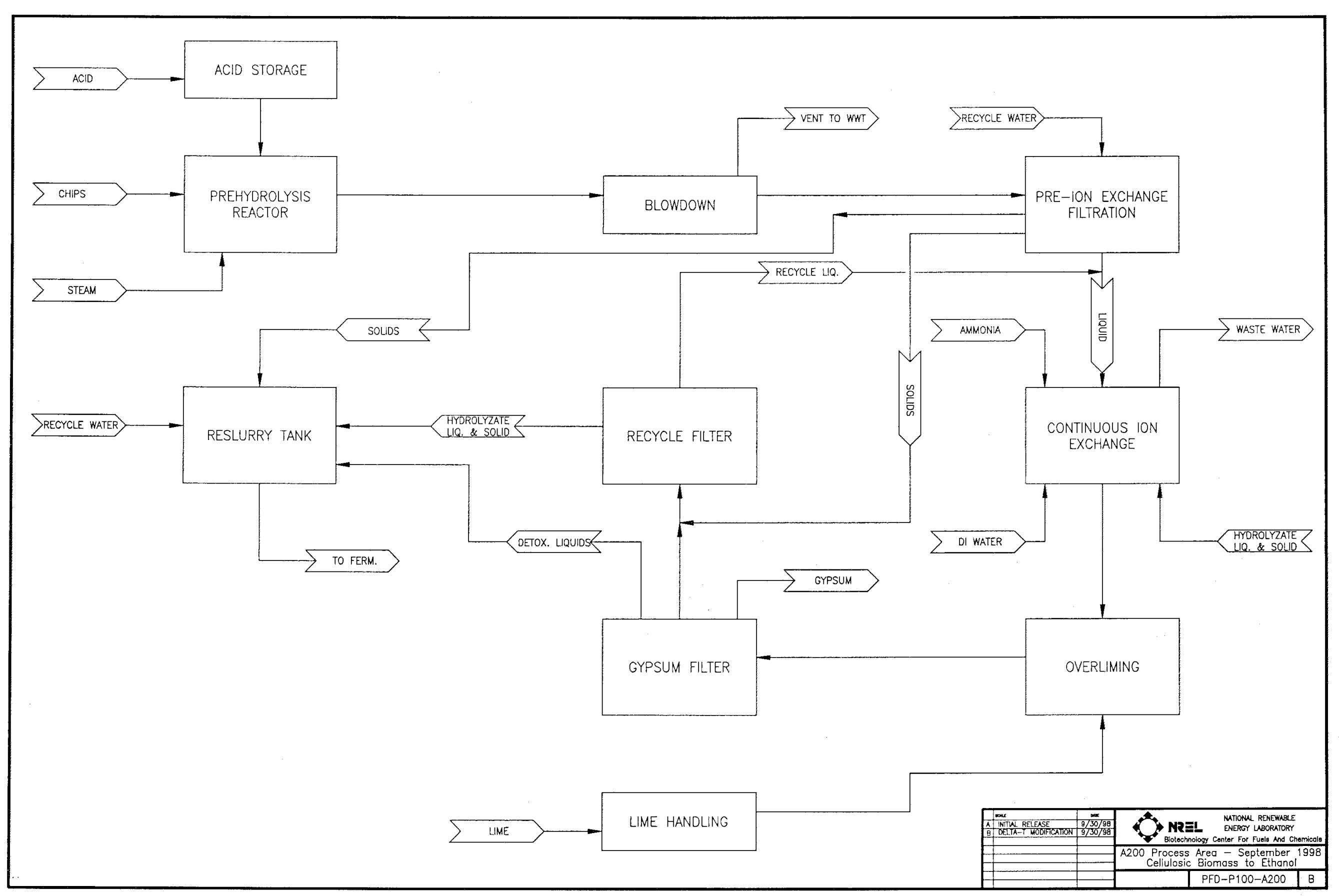


Table 3 summarizes the resulting reactions and the conversions that take place in the pretreatmenthydrolyzer. These reactions and conversions were taken from experiments conducted on yellow poplar hardwood in the NREL process development unit (PDU) Sunds reactor ${ }^{16}$ with adjustments made for expected near-term improvements ${ }^{17}$. We assumed that the results of the Sunds pilot unit would scale directly to the production-scale reactor. Also, we did not account for heat losses from the reactor in the energy balance calculations.

Table 3: Pretreatment Hydrolyzer Reactions and Conversions ${ }^{17}$

\begin{tabular}{|c|c|c|c|c|c|}
\hline \multicolumn{4}{|l|}{ Reaction } & \multicolumn{2}{|c|}{ Conversion } \\
\hline$(\text { Cellulose })_{\mathrm{n}}$ & + & $\mathrm{n} \mathrm{H}_{2} \mathrm{O}$ & $\rightarrow$ n Glucose & Cellulose & 0.065 \\
\hline$(\text { Cellulose })_{n}$ & + & $\mathrm{m} \mathrm{H}_{2} \mathrm{O}$ & $\rightarrow$ m Glucose Olig & Cellulose & 0.007 \\
\hline$(\text { Cellulose })_{n}$ & + & $1 / 2 \mathrm{n} \mathrm{H}_{2} \mathrm{O}$ & $\rightarrow 1 / 2 \mathrm{n}$ Cellobiose & Cellulose & 0.007 \\
\hline$(\text { Xylan })_{n}$ & + & $\mathrm{n} \mathrm{H}_{2} \mathrm{O}$ & $\rightarrow$ n Xylose & Xylan & 0.75 \\
\hline$(\text { Xylan })_{n}$ & + & $\mathrm{m} \mathrm{H}_{2} \mathrm{O}$ & $\rightarrow \mathrm{m}$ Xylose Olig & Xylan & 0.05 \\
\hline$(\text { Xylan })_{n}$ & & & $\rightarrow$ n Furfural & Xylan & 0.1 \\
\hline$(\text { Xylan })_{\mathrm{n}}$ & + & $\mathrm{n} \mathrm{H}_{2} \mathrm{O}$ & $\rightarrow(\text { Tar })_{\mathrm{n}}$ & Xylan & 0.05 \\
\hline (Mannan) $)_{\mathrm{n}}$ & + & $\mathrm{n} \mathrm{H}_{2} \mathrm{O}$ & $\rightarrow$ n Mannose & Mannan & 0.75 \\
\hline (Mannan) ${ }_{\mathrm{n}}$ & + & $\mathrm{m} \mathrm{H}_{2} \mathrm{O}$ & $\rightarrow$ m Mannose Olig & Mannan & 0.05 \\
\hline (Mannan) ${ }_{\mathrm{n}}$ & & & $\rightarrow$ n HMF & Mannan & 0.15 \\
\hline$(\text { Galactan })_{\mathrm{n}}$ & + & $\mathrm{n} \mathrm{H}_{2} \mathrm{O}$ & $\rightarrow$ n Galactose & Galactan & 0.75 \\
\hline$(\text { Galactan })_{\mathrm{n}}$ & + & $\mathrm{m} \mathrm{H}_{2} \mathrm{O}$ & $\rightarrow$ m Galactose Olig & Galactan & 0.05 \\
\hline$(\text { Galactan })_{\mathrm{n}}$ & & & $\rightarrow \mathrm{n} \mathrm{HMF}$ & Galactan & 0.15 \\
\hline$(\text { Arabinan })_{\mathrm{n}}$ & + & $\mathrm{n} \mathrm{H}_{2} \mathrm{O}$ & $\rightarrow$ n Arabinose & Arabinan & 0.75 \\
\hline$(\text { Arabinan })_{\mathrm{n}}$ & + & $\mathrm{m} \mathrm{H}_{2} \mathrm{O}$ & $\rightarrow \mathrm{m}$ Arabinose Olig & Arabinan & 0.05 \\
\hline$(\text { Arabinan })_{\mathrm{n}}$ & & & $\rightarrow$ Furfural & Arabinan & 0.1 \\
\hline$(\text { Arabinan })_{\mathrm{n}}$ & + & $\mathrm{n} \mathrm{H}_{2} \mathrm{O}$ & $\rightarrow(\text { Tar })_{\mathrm{n}}$ & Arabinan & 0.05 \\
\hline Acetate & & & $\rightarrow$ Acetic Acid & Acetate & 1.0 \\
\hline n Furfural & + & $3 \mathrm{n} \mathrm{H}_{2} \mathrm{O}$ & $\rightarrow(\text { Tar })_{\mathrm{n}}$ & Furfural & 1.0 \\
\hline n HMF & + & $3 \mathrm{n} \mathrm{H}_{2} \mathrm{O}$ & $\rightarrow 1.2(\text { Tar })_{\mathrm{n}}$ & HMF & 1.0 \\
\hline \multicolumn{6}{|c|}{$\begin{array}{l}\text { Xylose olig, mannose olig, galactose olig, and arabinose olig are soluble oligomers of their respective carbohydrate polymers. } \\
\text { Tar is an unknown final decomposition product of the carbohydrate polymers. }\end{array}$} \\
\hline \multicolumn{6}{|c|}{$\begin{array}{l}\text { Note: These reactions are modeled as occurring simultaneously. Therefore, products of one reaction, e.g., furfural, are not } \\
\text { considered a reactant in another reaction. Degradation of xylan all the way to tar is accounted for as a reaction of xylan to tar. } \\
\text { Degradation of furfural considers the furfural entering the reactor in the recycle water. }\end{array}$} \\
\hline
\end{tabular}

The pretreatment reactor (M-202) operates at 12.2 atm (179 psia) pressure and $190^{\circ} \mathrm{C}$. The exiting material is flash cooled to $1 \mathrm{~atm}$ (14.7 psia) in T-203. The flash vapor is modeled with the Hayden and $\mathrm{O}^{\prime}$ Connell ${ }^{18}$ equation of state to specifically model the vaporization of acetic acid. Acetic acid creates dimers in the vapor phase and this equation of state properly accounts for that. If the vapor phase dimerization of acetic acid is not accounted for, the loss of acetic acid in the vapor will be over estimated. In this flash, $6.5 \%$ of the acetic acid and $61 \%$ of the furfural and HMF are removed in the flash operation.

The flash vapor, about $45,000 \mathrm{~kg} / \mathrm{hr}(99,200 \mathrm{lb} / \mathrm{hr})$ of essentially $100^{\circ} \mathrm{C}$ steam, is used to preheat the beer column feed in $\mathrm{H}-201$. During this exchange, the beer column feed is heated to $95^{\circ} \mathrm{C}$ and most of the 
flash vapor from T-203 is condensed. The condensed flash vapor is sent to wastewater treatment (Area $600)$.

After a residence time of 15 minutes in the flash tank, the hydrolyzate slurry with $26 \%$ insoluble solids is conveyed to a washing belt filter press (S-202) for separation of the solids and the liquids (see PFDP100-202). The purpose of separating the liquids from the solids is to facilitate conditioning of the liquid portion to remove toxicity to the downstream fermentation.

Even a belt filter press will leave the solids portion with about $40 \%$ insoluble solids, removing $44 \%$ of the liquid. This leaves $56 \%$ of the toxic materials in the liquid portion of untreated solids. One way to remove more of the toxic materials from the solids is to wash with the water that must be added before fermentation. This will reduce the toxins left in liquid portion of the slurry to $30 \%$, but will affect the size of the liquid solid separator and the subsequent conditioning equipment. The other alternative is to remix the liquids and solids after conditioning, followed by another separation and recycling part of the liquid. This recycle stream needs to be quite large to accomplish the same acetic acid removal as this pre-ion exchange washing and requires a second liquid solid separator. In addition, by adding the fermentation dilution water before the ion exchange, there is an opportunity to remove acetic acid from this recycle water, so that it does not build up. Rearranging the original pilot plant flows minimizes the cost impact on ion exchange. The stream now is more dilute, but higher in flow.

NREL's understanding of the liquid solid separation is limited. Therefore, for this case we assumed that all the dilution water is used in a washing filter and that it is only a "single" stage of washing (S-202). Ideally, less wash water would probably be used and the operation may be more efficient (more removal of acetic acid into the liquid). If less than all of the dilution water is used, the ion exchange will be somewhat smaller and the remainder of the dilution water will be added just before fermentation. After filtering, the filtrate is cooled to $40^{\circ} \mathrm{C}$ in $\mathrm{H}-200$ using cooling water. This temperature is compatible with the next unit operation, ion exchange.

The ion exchange removal of acetic acid is accomplished in a continuous ion exchange unit known as an ISEP (S-221), from Advanced Separations Technology, Inc. (AST), in Lakeland, Florida. The separation used in this design employs Amberlyst A20 weak base resin from Rohm-Haas, regenerated with ammonia. Approximately $88 \%$ of the acetic acid and $100 \%$ of the sulfuric acid is removed. The sugar is completely $(100 \%)$ recovered and diluted with about $8 \%$ water. This dilution water is subtracted from the total that needs to be added for fermentation, so ion exchange essentially adds no additional water. The amount of ammonia used is 1.1 normal per normal of ions removed or $10 \%$ above the minimum. These conditions were determined in a pilot study conducted on an AST L100C pilot unit with 20-33 mm (1.3 in.) diameter by $1 \mathrm{~m}(3.3 \mathrm{ft})$ long columns. ${ }^{19}$ The scale-up is accomplished by keeping the liquid velocity in the columns the same as that used in the pilot plant. The eluant $\left(\mathrm{NH}_{3}\right)$ and water usage is in the same ratio to the feed as in the pilot plant.

After the ion exchange removal of acetic acid, the material is overlimed (see PFD-P100-A203). This is accomplished by reacidifying the liquid hydrolyzate to $\mathrm{pH} 2$ by addition of sulfuric acid using an in-line mixer (A-235). Lime is then added in tank T-209 to raise the $\mathrm{pH}$ to 10 and heated by direct steam injection to $50^{\circ} \mathrm{C}$. The residence time in T-209 is $1 \mathrm{hr}$ to allow for the overliming "reactions" to occur. ${ }^{20}$ Based on the experience of Delta-T, the agitation for this application is assumed to be $98.5 \mathrm{~W} / \mathrm{m}^{3}(0.5$ $\mathrm{hp} / 1000 \mathrm{gal})$. The liquid is then adjusted to the fermentation $\mathrm{pH}$ of $4.5 \mathrm{in}$ tank T-224 and held for $4 \mathrm{hr}$. This long residence time allows the resulting gypsum crystals to form in a size that can be readily separated by hydrocyclone and rotary drum filtration in series. ${ }^{21}$ Agitation in T-224 was taken as 98.5 
$\mathrm{w} / \mathrm{m}^{3}(0.5 \mathrm{hp} / 1000 \mathrm{gal})$, again based on Delta-T's experience. The filtration is assumed to remove $99.5 \%$ of the precipitated gypsum and the solids are assumed to contain $20 \%$ liquid. ${ }^{22}$ At $80 \%$ solids, gypsum can be handled as a dry solid. This approach was recommended by vendors and is typical of dewatering equipment used in the utility flue gas desulfurization industry to achieve high solids concentrations commercially.

After the gypsum is filtered, the conditioned hydrolyzate liquid is recombined with hydrolyzate solids (which were separated in S-202) in tank T-232 (see PFD-P100-A201). The residence time in this tank is minimal, 15 minutes, just long enough to afford good mixing. The agitation for this application is assumed to be $394 \mathrm{~W} / \mathrm{m}^{3}$ ( $2 \mathrm{hp} / 1000 \mathrm{gal}$ ) based on the experience of Delta-T. The resulting slurry, now conditioned, $\mathrm{pH}$-adjusted, and properly diluted, is pumped to fermentation (Area 300).

\section{II.2.3 Cost Estimation}

All pumps, tanks, screw conveyors, and agitators for this section were estimated using the ICARUS Process Evaluator. ${ }^{23}$ The material of construction for all equipment except the pretreatment reactor (M-202), continuous ion exchange (S-221) and flash tank (T-203) is 304SS, based on the experience of Delta-T. The material of construction of the flash tank is Carpenter 20 because additional acid resistance at temperatures higher than $100^{\circ} \mathrm{C}$ is necessary. Generally the ion exchange occurs at low temperature (about $40^{\circ} \mathrm{C}$ ) and the vessels are assumed to be rubber lined steel. The ISEP valve is polypropylene and 304SS, consistent with the material of construction use for low temperature equipment in this section.

We obtained the cost estimate of the ion exchange from the vendor, AST. Prices on two different size units were obtained so that an accurate scaling factor could be derived.

Sunds Defribractor, Inc. gave us quotes on the pretreatment reactor (M-202) and supporting equipment. We obtained prices on various temperatures and pressures. The materials of construction are assumed to be Hastelloy C-2000, based on work done at the Tennessee Valley Authority (TVA) ${ }^{24}$ (see Table 4). The quote from Sunds included a price for a stainless steel unit to be used at low temperature and on Hastelloy C-2000 to be used at high temperatures. The difference between these two was a factor of 3 to 4 . In further discussions with Sunds, we determined that the company had never built a large system of this type out of Hastelloy C-2000, and that this price included a contingency, along with development costs to build this "first-of-a kind-reactor". ${ }^{25}$ A first design is not the appropriate price for this estimate, which must consider the reactor to be the "nth" built and must assume that the manufacturer is comfortable with the design and fabrication of the unit. We feel that the Sunds quote for the lower temperature stainless steel reactor meets the criteria of an "nth" plant design and needs only to be adjusted for different conditions and materials of construction. Therefore, Delta-T used the cost estimate for a low temperature stainless steel unit and adjusted the cost to Hastelloy C-2000, accounting for higher pressure, as well as some increased engineering and fabrication costs (Hastelloy C-2000 is more difficult to fabricate than stainless steel). This analysis indicates that the cost of the stainless steel reactor will escalate by about $50 \%$. This is reasonable considering that not all of the material is Hastelloy C-2000 and that much of the equipment cost is in the mechanical complexity of the unit, which is unchanged by moving from stainless steel to Hastelloy C-2000. 
Table 4: Coupon Corrosion Data on Several Metals ${ }^{24}$

\begin{tabular}{|c|c|c|c|}
\hline & \multicolumn{3}{|c|}{ Corrosion, mm/yr (mils/yr) } \\
\hline Temperature, C & Carpenter 20 & Hastelloy B & Zirconium \\
\hline 100 & $0.013(0.5)$ & & \\
\hline 180 & $5.9(233)$ & $0.5(20)$ & $<0.007(<0.3)$ \\
\hline 200 & $23.4(923)$ & $0.8(32)$ & $<0.007(<0.3)$ \\
\hline Note: $2 \%(\mathrm{wt} / \mathrm{wt})$ Sulfuric Acid Solution & \\
\hline
\end{tabular}

The cost estimate for the liquid solid separators, S-202 and S-222 are based on vendor quotations from Komline Sanderson.

\section{II.3 Simultaneous Saccharification and Co-Fermentation (SSCF)-Area 300 (PFD-P100-A301-2)}

\section{II.3.1 Overview}

Two different operations are performed in this process area-saccharification of the remaining cellulose to glucose using cellulase enzymes, and fermentation of the resulting glucose and other sugars (from the dilute acid pretreatment of hemicellulose, Area 200) to ethanol. For fermentation, the recombinant $Z$. mobilis bacterium ${ }^{26}$ is used as the ethanologen. This form of $Z$. mobilis will ferment glucose and xylose to ethanol. It is assumed that no other sugars are fermented in the base case model. Futuristic cases or those using other ethanologens may convert other sugars.

Hydrolysis or saccharification occurs in the main fermentation vessels. Cellulase enzymes used in the saccharification are produced in Area 400 of the process and mixed with the hydrolysis raw material and nutrients directly in the fermenter.

The ethanologen must be "grown" in a seed fermentation train of vessels in this area. Detoxified hydrolyzate and nutrients are combined with an initial seed inoculum (grown in the laboratory) in a very small vessel. The result of each seed batch is used as the inoculum for the next size seed increment. This series of scale-ups is continued until the last step is large enough to support the production fermentation.

Finally the seed inoculum, cellulase enzyme, nutrients, and diluted, cooled, detoxified hydrolyzate are continuously added to the several continuous SSCF production lines. The number of fermenter tanks in a train or line will probably be about five or six, 1-million gallon fermenters, in three or four lines. The resulting ethanol broth is collected in a beer well (storage tank) to level out any surges or upsets before it is pumped to distillation.

\section{II.3.2 Design Basis Description}

Detoxified and diluted hydrolyzate is split to cellulase fermentations, Z. mobilis seed production, and SSCF fermenters. The hydrolyzate fed to the SSCF is about $20 \%$ total solids ${ }^{27}$ (soluble and insoluble solids) including the dilution that will occur when the cellulase stream is mixed in. The actual hydrolyzate feed stream will be closer to $22 \%$ total solids. The portion of hydrolyzate split off to cellulase production is a function of the cellulase yield on the xylose and cellulose present and the required loading of enzyme in the SSCF. 
The required inoculum volume has been experimentally determined to be $10 \%,{ }^{28}$ in the seed train and in the production train. The seed train is operated in a batch mode (see PFD-P100-A301). The batch time for each step is $24 \mathrm{hr}^{29}$ Delta-T decided two trains would be optimal using an assumed turn-around time for each seed fermenter of $12 \mathrm{hr}$ (see Figure 7). Using these conditions, a train will complete each $12 \mathrm{hr}$, skip $12 \mathrm{hr}$ and complete after $24 \mathrm{hr}$. Based on the production flow of about $8,700 \mathrm{~m}^{3} /$ day $(2.3$ million gallons/day), the seed volume to be produced each day is $870 \mathrm{~m}^{3}(230,000 \mathrm{gal})$, or $435 \mathrm{~m}^{3}(115,000$ gal $)$ every $12 \mathrm{hr}$. Referring to Figure 7, it is clear that each batch must be $655 \mathrm{~m}^{3}$ (173,000 gal) to satisfy the $12-\mathrm{hr}$ period that is skipped. If three trains were used, the maximum volume would be only $435 \mathrm{~m}^{3}$ $(115,000 \mathrm{gal})$, but because there would be three trains it would be more costly. Considering a $90 \%$ working volume, the maximum seed fermenter is $727 \mathrm{~m}^{3}$ (192,000 gal). Scaling down by a factor of 10 for each smaller stage results in four additional seed fermenters of $72.7,7.6,0.8$, and $0.08 \mathrm{~m}^{3}(19,200$, 2000,200 , and 20 gallons). The total amount of hydrolyzate split off to seed production is $10 \%$ (same as the inoculum level). Table 5 summarizes the seed train design specifications.

Figure 7. SSCF Seed Batch Cycles

\section{Summarized SSCF Seed Fermentation Sequence \\ 2 trains each...Stage $1 @ 0.08 \mathrm{~m}^{3}$ (20 gal) to Stage $5 @ 727 \mathrm{~m}^{3}(192,000$ gal) each train Basis: 24 hours growth each stage..12 hour clean-up and set-up}

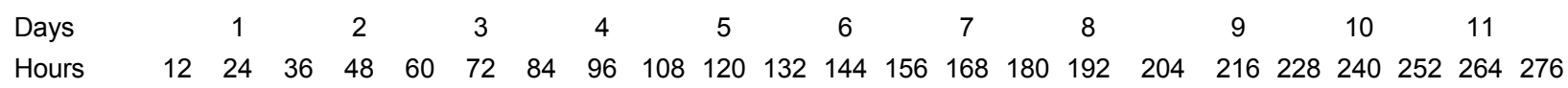

\begin{tabular}{l|l|lllll} 
& Stage 1 & Stage 2 & Stage 3 & Stage 4 & Stage 5 \\
Train A & & & & & \\
& Stage 1 & Stage 2 & Stage 3 & Stage 4 & Stage 5
\end{tabular}

Train $B$

Train A

$\begin{array}{lllll}\text { Stage } 1 & \text { Stage } 2 & \text { Stage } 3 & \text { Stage } 4 & \text { Stage } 5\end{array}$

Train $A$

Train B

$\begin{array}{lllll}\text { Stage } 1 & \text { Stage } 2 & \text { Stage } 3 & \text { Stage } 4 & \text { Stage } 5\end{array}$

Train A

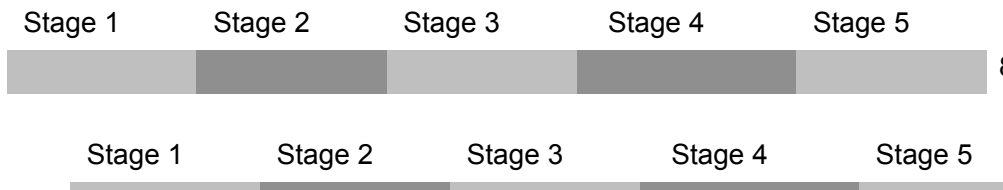

Train B

$\begin{array}{lllll}\text { Stage } 1 & \text { Stage } 2 & \text { Stage } 3 & \text { Stage } 4 & \text { Stage } 5\end{array}$

Values following each train indicate the inventory of seed at the end of seed batch in $\mathrm{m}^{3}$. 
Table 5: Seed Train Specifications ${ }^{27,28,29}$

\begin{tabular}{|l|l|}
\hline Inoculum Level & $10 \%$ of total \\
\hline Batch Time & $24 \mathrm{hr}$ \\
\hline Fermenter Turn-Around Time & $12 \mathrm{hr}$ \\
\hline Number of Trains & 2 \\
\hline Number of Fermenter Stages & 5 \\
\hline Maximum Fermenter Volume & $655 \mathrm{~m}^{3}(173,000 \mathrm{gal})$ \\
\hline
\end{tabular}

The two largest seed fermenters are large tanks (F-304 and F-305) with internal cooling coils (H-304 and H-305) and agitators (A-304 and A-305) that are costed separately. The small fermenters are package units (agitator and jacket included). The seed fermenters operate at $30^{\circ} \mathrm{C}$. The incoming hydrolyzate (about $60^{\circ} \mathrm{C}$ ) is cooled in $\mathrm{H}-301$ with cooling water to about $35^{\circ} \mathrm{C}$. Well water at $13^{\circ} \mathrm{C}$, supplemented with either cooling water or chilled water is used to maintain the fermenters at $30^{\circ} \mathrm{C}$. The well water is then used as make-up water to the process. The coil size was calculated using a tank coil correlation from $\mathrm{Kern}^{30}$. The agitators were sized based on Delta-T's experience with similar systems. The design numbers for agitation were $20 \mathrm{~W} / \mathrm{m}^{3}(0.1 \mathrm{hp} / 1000$ gal $)$ for F-305 $\left(727 \mathrm{~m}^{3}\right.$ [192,000 gal] $)$ and $60 \mathrm{~W} / \mathrm{m}^{3}$ $(0.3 \mathrm{hp} / 1000 \mathrm{gal})$ for F-304 $\left(72.7 \mathrm{~m}^{3}[19,200 \mathrm{gal}]\right)$. The three smaller seed fermenters $(\mathrm{F}-301-3)$ are designed as package-jacketed, agitated reactors $\left(0.08,0.8\right.$ and $7.6 \mathrm{~m}^{3}$ [20, 200, and 2000 gal], respectively). ICARUS ${ }^{23}$ was used to estimate the agitation powers of, $0.75 \mathrm{~kW}$ or $9.8 \mathrm{~kW} / \mathrm{m}^{3}(1 \mathrm{hp}$ or 50 $\mathrm{hp} / 1000 \mathrm{gal}$ ) for F-301, $3.7 \mathrm{~kW}$ or $4.9 \mathrm{~kW} / \mathrm{m}^{3}$ ( $5 \mathrm{hp}$ or $25 \mathrm{hp} / 1000$ gal) for F-302, and $18.6 \mathrm{~kW}$ ( $25 \mathrm{hp}$ ) or $2.5 \mathrm{~kW} / \mathrm{m}^{3}(13 \mathrm{hp} / 1000 \mathrm{gal})$ for the F-303.

Table 6: SSCF Seed Train Reactions and Conversion ${ }^{31}$

\begin{tabular}{|c|c|c|c|c|c|}
\hline \multicolumn{6}{|c|}{ Saccharification Reaction } \\
\hline \multicolumn{4}{|c|}{ Reaction } & \multicolumn{2}{|c|}{ Conversion } \\
\hline Cellulose $_{\mathrm{n}}$ & $+\mathrm{n} \mathrm{H}_{2} \mathrm{O}$ & $\rightarrow$ n Glucose & & Cellulose & 0.2 \\
\hline \multicolumn{6}{|c|}{ Fermentation Reactions } \\
\hline \multicolumn{4}{|l|}{ Reaction } & \multicolumn{2}{|c|}{ Conversion } \\
\hline Glucose & +2 Ethanol & $\rightarrow 2 \mathrm{CO}_{2}$ & & Glucose & 0.85 \\
\hline Glucose & $+1.2 \mathrm{NH}_{3}$ & $\rightarrow 6$ Z. mobilis & $+2.4 \mathrm{H}_{2} \mathrm{O}+0.3 \mathrm{O}_{2}$ & \begin{tabular}{|l|} 
Glucose \\
\end{tabular} & 0.04 \\
\hline Glucose & $+2 \mathrm{H}_{2} \mathrm{O}$ & $\rightarrow 2$ Glycerol & $+\mathrm{O}_{2}$ & Glucose & 0.002 \\
\hline Glucose & $+2 \mathrm{CO}_{2}$ & $\rightarrow 2$ Succinic Acid & $+\mathrm{O}_{2}$ & Glucose & 0.008 \\
\hline Glucose & & $\rightarrow 3$ Acetic Acid & & Glucose & 0.022 \\
\hline Glucose & & $\rightarrow 2$ Lactic Acid & & Glucose & 0.013 \\
\hline 3 Xylose & & $\rightarrow 5$ Ethanol & $+5 \mathrm{CO}_{2}$ & Xylose & 0.8 \\
\hline Xylose & $+\mathrm{NH}_{3}$ & $\rightarrow 5$ Z. mobilis & $+0.25 \mathrm{O}_{2}$ & Xylose & 0.03 \\
\hline 3 Xylose & $+5 \mathrm{H}_{2} \mathrm{O}$ & $\rightarrow 5$ Glycerol & $+2.5 \mathrm{O}_{2}$ & Xylose & 0.02 \\
\hline Xylose & $+\mathrm{H}_{2} \mathrm{O}$ & $\rightarrow$ Xylitol & $+9.5 \mathrm{O}_{2}$ & Xylose & 0.02 \\
\hline 3 Xylose & $+5 \mathrm{CO}_{2}$ & $\rightarrow 5$ Succinic Acid & $+2.5 \mathrm{O}_{2}$ & Xylose & 0.01 \\
\hline 2 Xylose & & $\rightarrow 5$ Acetic Acid & & Xylose & 0.01 \\
\hline 3 Xylose & & $\rightarrow 5$ Lactic Acid & & Xylose & 0.01 \\
\hline \multicolumn{6}{|c|}{$\begin{array}{l}\text { Note: The saccharification reaction is modeled to be in series with the fermentation reactions, so that glucose generated by saccharification } \\
\text { available for the subsequent fermentation reactions. } \\
\text { Ammonia is shown as a reactant for material balance purposes only. Corn steep liquor is the actual nitrogen source. }\end{array}$} \\
\hline
\end{tabular}


Table 6 gives the reactions and conversions used in the seed fermentations. The first reaction is the hydrolysis or saccharification reaction and the second set is the microorganism production.

Two high-capacity transfer pumps are used (P-302) to transfer the seed to the seed hold tank (T-301) in a timely fashion, approximately $2.5 \mathrm{hr}$. Two pumps are required because this is the maximum size of rotary lobe pump available from Waukesha Pump Company. A rotary lobe pump is used, to avoid damaging the seed by pump sheer.

The seed hold tank (T-301) is sized to hold 20\% more than the fifth seed reactor (F-305). A rotary lobe pump (P-301) is then used to continuously feed the seed to the production fermentation trains.

Production SSCF is conducted in trains of 950,000-gal vessels (see PFD-P100-A302). The residence time has been determined to be 7 days. ${ }^{32}$ In all, 17 vessels are required for this residence time. These are arranged in two continuous trains of six vessels each and one of five vessels. For a continuous fermentation, Delta- $\mathrm{T}$ felt that this was a reasonable train length.

Detoxified hydrolyzate slurry is first cooled to about $35^{\circ} \mathrm{C}$ in $\mathrm{H}-302$ using cooling water and then added directly to the first fermenter. In addition, inoculum from the seed train at a ratio of $1 / 10$ of the hydrolyzate is fed along with cellulase from Area 400. For the base case, cellulase is fed at the rate of 15 filter paper units (FPU)/g cellulose. ${ }^{33}$ Corn steep liquor is added as a nutrient at a rate of $0.25 \% .{ }^{34}$ Table 7 summarizes the design specifications used for SSCF production.

Table 7: SSCF Production Specifications $\mathbf{s}^{32,33,34}$

\begin{tabular}{|l|l|}
\hline Temperature & $30^{\circ} \mathrm{C}$ \\
\hline Initial Fermentation Solids Level & $20 \%$ \\
\hline Residence Time & 7 days \\
\hline Size of Vessels & $3596 \mathrm{~m}^{3}(950,000$ gal $)$ each \\
\hline Number of Vessels & 18 \\
\hline Number of Continuous Trains & 3 \\
\hline Inoculum Level & $10 \%$ \\
\hline Cellulase Loading & $15 \mathrm{FPU} / \mathrm{g}$ cellulose \\
\hline Corn Steep Liquor Level & $0.25 \%$ \\
\hline
\end{tabular}

The reactions and conversions used in the production SSCF fermenters are given in Tables 8 and 9. Saccharification or hydrolysis reactions are listed in Table 8; fermentation reactions are listed in Table 9. In the model, these reactions are carried out in series, meaning that any product of the hydrolysis reactions (Table 8) can be consumed as a reactant in the fermentation reactions (see Table 9).

Table 8: Production SSCF Saccharification Reactions and Conversions ${ }^{35}$

\begin{tabular}{|lll|ll|}
\hline Reaction & & Conversion & \\
\hline$(\text { Cellulose })_{\mathrm{n}}$ & $+\mathrm{m} \mathrm{H}_{2} \mathrm{O}$ & $\rightarrow \mathrm{m}$ Glucose Olig & Cellulose & 0.068 \\
\hline$(\text { Cellulose })_{\mathrm{n}}$ & $+1 / 2 \mathrm{n} \mathrm{H}_{2} \mathrm{O}$ & $\rightarrow \mathrm{1} / 2 \mathrm{n}$ Cellobiose & Cellulose & 0.012 \\
\hline (Cellulose $)_{\mathrm{n}}+\mathrm{n} \mathrm{H}_{2} \mathrm{O} \rightarrow \mathrm{n}$ Glucose & Cellulose & 0.8 \\
\hline Cellobiose & $+2 \mathrm{H}_{2} \mathrm{O} \rightarrow 2$ Glucose & Cellobiose & 1.0 \\
\hline
\end{tabular}


Table 9: SSCF Fermentation Reactions and Conversions ${ }^{35}$

\begin{tabular}{|c|c|c|c|c|c|}
\hline \multicolumn{4}{|l|}{ Reaction } & \multicolumn{2}{|c|}{ Conversion } \\
\hline Glucose & & $\rightarrow$ Ethanol & $+2 \mathrm{CO}_{2}$ & Glucose & 0.92 \\
\hline Glucose & $+1.2 \mathrm{NH}_{3}$ & $\rightarrow 6$ Z. mobilis & $+2.4 \mathrm{H}_{2} \mathrm{O}+0.3 \mathrm{O}_{2}$ & Glucose & 0.027 \\
\hline Glucose & $+2 \mathrm{H}_{2} \mathrm{O}$ & $\rightarrow 2$ Glycerol & $+\mathrm{O}_{2}$ & Glucose & 0.002 \\
\hline Glucose & $+2 \mathrm{CO}_{2}$ & $\rightarrow 2$ Succinic Acid & $+\mathrm{O}_{2}$ & Glucose & 0.008 \\
\hline Glucose & & $\rightarrow 3$ Acetic Acid & & Glucose & 0.022 \\
\hline Glucose & & $\rightarrow 2$ Lactic Acid & & Glucose & 0.013 \\
\hline 3 Xylose & & $\rightarrow 5$ Ethanol & $+5 \mathrm{CO}_{2}$ & Xylose & 0.85 \\
\hline Xylose & $+\mathrm{NH}_{3}$ & $\rightarrow 5$ Z. mobilis & $+0.25 \mathrm{O}_{2}$ & Xylose & 0.029 \\
\hline 3 Xylose & $+5 \mathrm{H}_{2} \mathrm{O}$ & $\rightarrow 5$ Glycerol & $+2.5 \mathrm{O}_{2}$ & Xylose & 0.002 \\
\hline Xylose & $+\mathrm{H}_{2} \mathrm{O}$ & $\rightarrow$ Xylitol & $+0.5 \mathrm{O}_{2}$ & Xylose & 0.006 \\
\hline 3 Xylose & $+5 \mathrm{CO}_{2}$ & $\rightarrow 5$ Succinic Acid & $+2.5 \mathrm{O}_{2}$ & Xylose & 0.009 \\
\hline 2 Xylose & & $\rightarrow 5$ Acetic Acid & & Xylose & 0.024 \\
\hline 3 Xylose & & $\rightarrow 5$ Lactic Acid & & Xylose & 0.014 \\
\hline $\begin{array}{r}\text { Note: The sa } \\
\text { availa } \\
\text { Amm }\end{array}$ & shown a & $\begin{array}{l}\text { modeled to be in series w } \\
\text { entation reactions. } \\
\text { or material balance purpos }\end{array}$ & $\begin{array}{l}\text { ion reactior } \\
\text { eep liquor is }\end{array}$ & $\begin{array}{l}\text { enerated b } \\
\text { source. }\end{array}$ & harifica \\
\hline
\end{tabular}

In addition to saccharification and fermentation to ethanol, loss to other products because of contaminating organisms occurs. This is modeled as a side stream (bypassing the SSCF) that reacts to lactic acid. This allows the model to simply assign a percent loss to contamination and the conversions in Table 9 do not have to be adjusted. The loss to other products by caused by Z. mobilis are given in the SSCF reactions in Table 9. Table 10 shows the contamination reactions. A total of $7 \%$ of the sugars available for fermentation are considered lost to contamination. ${ }^{36}$

Table 10: Production SSCF Contamination Loss

\begin{tabular}{|ll|ll|}
\multicolumn{2}{c}{ Reactions } \\
\hline \multicolumn{2}{|c|}{ Reaction } & \multicolumn{2}{c|}{ Conversion } \\
\hline Glucose & $\rightarrow$ 2 Lactic Acid & Glucose & 1.0 \\
\hline 3 Xylose & $\rightarrow$ 5 Lactic Acid & Xylose & 1.0 \\
\hline 3 Arabinose & $\rightarrow$ 5 Lactic Acid & Arabinose & 1.0 \\
\hline Galactose & $\rightarrow$ 2 Lactic Acid & Galactose & 1.0 \\
\hline Mannose & $\rightarrow$ 2 Lactic Acid & Mannose & 1.0 \\
\hline
\end{tabular}

The fermenters are cooled using a pump-around loop that consists of a centrifugal pump P-300 and heat exchanger, H-300. The heat exchanger is generally cooled with well water at $13^{\circ} \mathrm{C}$. When the well water is not sufficient for complete cooling, it is supplemented by either cooling or chilled water, depending on the time of year. See the utilities section (Area 900) for an explanation of the mix of cooling required. At the end of the fermentation train, a beer well collects the fermented beer and scrubber bottoms. With a residence time of $8 \mathrm{~min}$, this tank allows for some surge between fermentation and distillation. 


\section{II.3.3 Cost Estimation}

In general the material of construction for all equipment in this section is 304SS, which is the most costeffective material for the fermentation service.

We estimated all centrifugal pumps for this section using the ICARUS ${ }^{23}$ cost estimation software. Costs of the rotary lobe pumps (P-301 and P-302) were obtained as verbal quotations from Waukesha Pump Company.

The cost for the major agitators, those for the larger fermenters (A-300) and other large applications (A-301, A-305) were based on vendor (Lightnin Corp.) quotes that Delta-T had obtained for a different project. The large agitators are side-mounted. This minimizes additional structural steel required for topmounted agitator supports. These quotes were scaled using a scaling exponent from $\mathrm{Garrett}^{7}$ to fit the size required here. We used ICARUS to estimate the smaller agitators (A-304, A-306).

We obtained a quotation from Chattanooga Boiler and Tank Co. for the larger fermenters and tank (F-300, F-305, and T-301). The smaller seed fermenters (F-301, F-302 and F-303) were estimated with ICARUS as jacketed, agitated packages. The other, medium-size tanks (F-304, T-306) were estimated with ICARUS as stand-alone tanks.

Several plate and frame heat exchangers in this area (H-300, H-301, and H-302) were costed by Delta-T from previous jobs. In the case of H-300, the cost from ICARUS was exactly the same as Delta-T's number and is used here. The seed fermenter coil coolers (H-304 and H-305) were costed with ICARUS.

\section{II.4 Enzyme Production - Area 400 (PFD-P100-A401-2)}

\section{II.4.1 Overview}

Cellulase, a collection of enzymes that hydrolyze cellulose to form glucose, is produced in this process area. The enzyme is used in Area 300 (SSCF) where glucose is produced and then fermented into ethanol.

The enzymes that make up cellulase are: (1) endoglucanases, which attack randomly within the cellulose fiber reducing polymer size rapidly; (2) exoglucanases, which attack the ends of cellulose fibers, allowing it to hydrolyze highly crystalline cellulose; and (3) $\beta$-glucosidase, which hydrolyzes cellobiose to glucose. Several bacteria and fungi naturally produce these enzymes, including bacteria in ruminant and termite guts and white rot fungus. ${ }^{37}$ The most common organism used to produce cellulase industrially is Trichoderma reesei, so it was used for this analysis.

T. reesei is a fibrous fungus that can grow and produce cellulase in aerobic bioreactors. Eleven $1,000 \mathrm{~m}^{3}$ (264,000-gal) bioreactors make up the largest section of this area. The bioreactors are run batchwise, with eight in operation, one being drained, one being filled, and one being cleaned and sterilized at all times. The carbon source for the bioreactors is detoxified, pretreated biomass slurry that has been diluted. Whole corn steep liquor (CSL) and other trace nutrients are also added to the bioreactors. Ammonia is used to control $\mathrm{pH}$ and provides additional fixed nitrogen to the organisms. The bioreactors are sparged with compressed and cooled air and corn oil is used as an antifoam to prevent excessive foaming within the reactors. The reactors are cooled by chilled water flowing through internal coils. Inoculum is 
produced in three trains with three vessel sizes in each train. Each vessel in the seed trains is run batchwise and detoxified, pretreated biomass slurry, CSL, nutrients, dilution water, and ammonia are pumped to it. Air is also sparged through each of the seed vessels, which are cooled with chilled water.

\section{II.4.2 Design Basis Description}

Table 11 lists the primary parameters and NREL near-term goals for cellulase production .

Table 11: Cellulase Production Parameters

\begin{tabular}{|l|l|}
\hline Cellulase Requirement for SSCF & $15 \mathrm{FPU} / \mathrm{g}$ cellulose \\
\hline Yield & $200 \mathrm{FPU} /(\mathrm{g}$ cellulose + xylose $)$ \\
\hline Productivity & $75 \mathrm{FPU} /(\mathrm{L} \bullet \mathrm{hr})$ \\
\hline Initial Cellulose Concentration & $4 \%$ \\
\hline
\end{tabular}

Assuming that the specific activity of cellulase is $600 \mathrm{FPU} / \mathrm{g}$ protein, the yield is $0.33 \mathrm{~g}$ protein/(g initial cellulose + xylose $)$ and the productivity is $0.125 \mathrm{~g}$ protein/( $\bullet \bullet \mathrm{hr})$.

In an experiment ${ }^{38}$ completed on October 30, 1998, NREL researchers achieved a $168 \mathrm{hr}$ yield of approximately $250 \mathrm{FPU} / \mathrm{g}$ cellulose and a productivity of $85 \mathrm{FPU} /(\mathrm{L} \bullet \mathrm{hr})$. That experiment was run in a 5-L fermenter using 5\% Solka-Floc as the substrate and the dissolved oxygen concentration was kept at or above $50 \%$ saturated. These results have been achieved only once and are much higher than has been achieved on pretreated biomass, so the yield and productivity used in the model are slightly lower. The initial substrate concentration is also lower because of potential inhibitors in pretreated biomass.

We used ASPEN to calculate the flow of the feed stream to cellulase production and the number of required cellulase vessels to provide the required amount of enzyme to SSCF. The flows of cellulose plus xylose are calculated to provide $15 \mathrm{FPU} / \mathrm{g}$ cellulose to SSCF and sum to $2316 \mathrm{~kg} / \mathrm{hr}(5,106 \mathrm{lb} / \mathrm{hr})$. With a $200 \mathrm{FPU} / \mathrm{g}$ yield, a productivity of $75 \mathrm{FPU} /(\mathrm{L} \bullet \mathrm{hr})$, and a working volume of $80 \%$ the total fermentation volume required is $7,720 \mathrm{~m}^{3}(2,040,000$ gal.). The maximum allowable size of each cellulase production vessel has been estimated to be $1,000 \mathrm{~m}^{3}(264,000 \mathrm{gal})$ because cellulase production is an aerobic bioreaction. As mentioned previously, 11 cellulase production vessels are required. The flow from cellulase production (Stream 420) is $39,211 \mathrm{~kg} / \mathrm{hr}(86,445 \mathrm{lb} / \mathrm{hr}$ ) so the residence time of each batch production run is approximately $160 \mathrm{hr}$ and the filling/cleaning/draining time is $60 \mathrm{hr}$. Figure 8 shows the batch schedule.

Three trains of three seed fermenters provide inoculum to the production bioreactors. They are all sized to provide a $5 \%$ inoculum to the next scale; the smallest (F-401) is $125 \mathrm{~L}$ [33 gal.], which is $5 \%$ of the size of F-402 $\left(2.5 \mathrm{~m}^{3}\right.$ [660 gal.]), that is $5 \%$ of the size of F-403 $\left(50 \mathrm{~m}^{3}\right.$ [13,200 gal.]), that is $5 \%$ of the size of the production vessels $\left(1,000 \mathrm{~m}^{3}\right.$ [264,000 gal.]). The $5 \%$ inoculum size was chosen because it matches experimental work at NREL. ${ }^{38}$ These are all aerated at $0.577 \mathrm{vvm}$ (volume/min of air per volume of reactor) to match the main bioreactors. Three trains were chosen because each production fermenter has a batch time of $160 \mathrm{hr}$. Because 8 out of the 11 vessels are in use, inoculum is needed every $20 \mathrm{hr}$. With three trains each vessel gets a residence time of $40 \mathrm{hr}$, which NREL's experimental work has shown to be long enough to grow cell mass ${ }^{38}$ but not long enough to make enzyme. A cleaning/sterilization time of $20 \mathrm{hr}$ is also needed. 
Figure 8, Batch Cycles For Cellulase Seed and Production

\section{Seed Vessels}

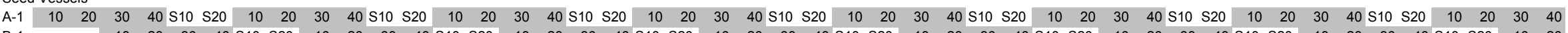

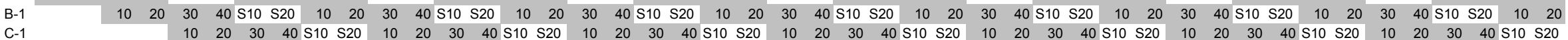

\begin{tabular}{l|lllllllllllllllllllllllllllllllllllll} 
A-2 & 10 & 20 & 30 & 40 & S10 S20 & 10 & 20 & 30 & 40 S10 S20 & 10 & 20 & 30 & 40 & S10 S20 & 10 & 20 & 30 & 40 & S10 S20 & 10 & 20 & 30 & 40 & S10 S20 & 10 & 20 & 30 & 40 & S10 S20 & 10 & 20 & 30 & 40 & S10 S20
\end{tabular}

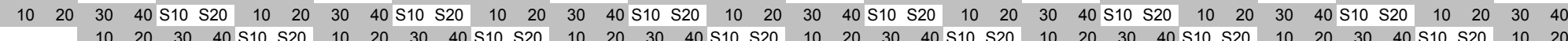

Production Vessels

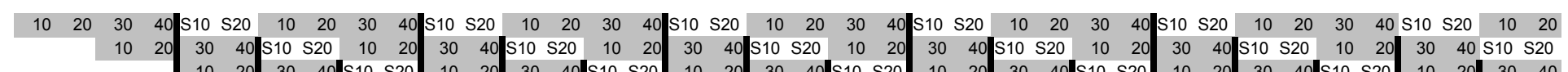

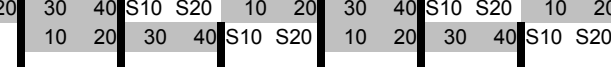

Shaded Cells Indicate Vessel is in Operation

Unshaded Cells Indicate Vessel is Draining (D), Sterilizing (S), or Filling (F)

Numbers Indicate the Number of Hours Vessel has been in or out of Operation

Three Seed Trains: A-1 inoculates A-2, which inoculates A-3

Likewise for Trains B \& C

Heavy Lines Link Final Seed Vessel to the Production Vessel it Inoculates 
Each batch cycle begins with cleaning and sterilizing a cellulase production tank as described in Area 900. The clean, sterile, empty vessel is filled with slurry from the mixed pretreated solids and conditioned liquor to a level where the final concentration, after all other additions are made, will be $4 \%$ cellulose. At the same time, recycle water flows into the vessel to dilute the slurry. Whole CSL is added to the vessel to reach a final concentration of $1 \%$ (after all additions are made). Nutrients are also added to the vessel. The required nutrient concentrations are from Schell et al. ${ }^{39}$, because updated information is not available. NREL researchers have not yet optimized nutrient requirements in cellulase production from pretreated biomass. The nutrient requirements from Tables 3-4 of Schell et al. ${ }^{39}$ are restated in Table 12. Corn oil is added as an antifoam to achieve a final batch concentration of $0.1 \%(\mathrm{vol} / \mathrm{vol})$. Once all additions are made, the batch cycle is allowed to run at $28^{\circ} \mathrm{C}$ for $160 \mathrm{hr}$.

Table 12: Cellulase Production Nutrient Requirements ${ }^{39}$

\begin{tabular}{|l|c|}
\hline Component & Amount $(\mathrm{g} / \mathrm{L})$ \\
\hline$\left(\mathrm{NH}_{4}\right)_{2} \mathrm{SO}_{4}$ & 1.4 \\
\hline $\mathrm{KH}_{2} \mathrm{PO}_{4}$ & 2.0 \\
\hline $\mathrm{MgSO}_{4} \bullet 7 \mathrm{H}_{2} \mathrm{O}$ & 0.3 \\
\hline $\mathrm{CaCl}_{2} \bullet 2 \mathrm{H}_{2} \mathrm{O}$ & 0.4 \\
\hline Tween 80 & 0.2 \\
\hline
\end{tabular}

Mass balances have not been done on cellulase production bioreactors so we used estimates of the reaction yields in the ASPEN model. In the modeled production bioreactors, $47 \%$ of the soluble sugars were converted using cell mass production stoichiometry, and $53 \%$ of the soluble sugars were converted using enzyme production stoichiometry. All the cellulose, insoluble mannan, and insoluble galactan were converted using enzyme production stoichiometry. Both stoichiometries consist of reacting the sugar with oxygen, ammonia, and sulfur dioxide to form water and carbon dioxide as well as the product (cell mass or enzyme protein). The reaction stoichiometry is defined to balance the reaction to form cell mass and enzyme with their defined elemental compositions. ${ }^{6}$

During the entire operation, the bioreactors are sparged with air at a rate of $0.577 \mathrm{vvm}$ after the air is compressed and cooled to $40^{\circ} \mathrm{C}$. The airflow rate was calculated to reach a target oxygen transfer rate (OTR) of $80 \mathrm{mmol} /(\mathrm{L} \bullet \mathrm{hr}){ }^{40}$ The OTR can be increased by increasing the height to diameter ratio of the vessel, increasing the bulk operating pressure, increasing the air flow rate, increasing the agitation power, improving the agitator design, or increasing the inlet oxygen concentration.

For cost optimization purposes, the OTR was calculated using the following equation:

$$
\text { OTR }=k_{l} a \frac{\left(C_{b}^{*}-C_{D}\right)-\left(C_{t}^{*}-C_{D}\right)}{\ln \left(\frac{C_{b}^{*}-C_{D}}{C_{t}^{*}-C_{D}} \frac{\frac{1}{\dot{\dot{j}}}}{\dot{j}}\right.}
$$

where $O T R$ is the oxygen transfer rate $(\mathrm{mmol} /(\mathrm{L} \bullet \mathrm{hr})), k_{l} a$ is the volumetric mass transfer coefficient $\left(\mathrm{hr}^{-1}\right), C_{b} *$ is the saturated dissolved oxygen concentration at the bottom of the vessel $(\mathrm{mmol} / \mathrm{L}), C_{t}^{*}$ is the saturated dissolved oxygen concentration at the top of the vessel $(\mathrm{mmol} / \mathrm{L})$, and $C_{D}$ is the desired dissolved oxygen concentration $(\mathrm{mmol} / \mathrm{L})$. The second term is the log mean of the oxygen concentration gradient (the difference between the saturated dissolved oxygen concentration and the desired dissolved oxygen concentration) at the top and bottom. The desired dissolved oxygen concentration is estimated to 
be $30 \%$ saturated at $1 \mathrm{~atm}$ absolute pressure $(0.063 \mathrm{mmol} / \mathrm{L})$. Most laboratory cellulase production work is run between $20 \%$ and $30 \%$ dissolved oxygen as measured, so the desired concentration is comparable to experiments and slightly conservative.

We used Henry's Law, described in the following equation, to calculate the concentration of saturated dissolved oxygen $\left(C_{b}{ }^{*}\right.$ and $\left.C_{t}{ }^{*}\right)$ :

$\pi=H^{*} C_{L}$

where $\pi$ is the partial pressure of the gas (i.e., oxygen) (atm), $H$ is Henry's coefficient $(\mathrm{atm} /(\mathrm{mmol} / \mathrm{L})$ ), and $C_{L}$ is the liquid concentration of the gas $(\mathrm{mmol} / \mathrm{L})$. Henry's coefficient was set equal to $1 \mathrm{~atm} /$ $(\mathrm{mmol} / \mathrm{L})$ for all work. ${ }^{41}$

The volumetric mass transfer coefficient was calculated using the following equation: $:^{42,43}$

$k_{l} a=0.026\left(\frac{P}{V_{L}} \frac{)^{\frac{1}{\dot{s}}}}{0.4} V_{G}^{0.5} * 3600(\mathrm{sec} / \mathrm{hr})\right.$

where $P$ is the impeller power consumption $(\mathrm{W}), \mathrm{V}_{\mathrm{L}}$ is the working volume $\left(\mathrm{m}^{3}\right)$, and $\mathrm{V}_{\mathrm{G}}$ is the superficial gas velocity $(\mathrm{m} / \mathrm{s})$. The equation is good for pure air/water systems with a maximum volume of $2.6 \mathrm{~m}^{3}$ (687 gal.) nd a power to volume ratio of 500 to $10,000 \mathrm{~W} / \mathrm{m}^{3}$ ( 2.5 to $51 \mathrm{hp} / 1000$ gal.). An equation (from the same references) is also available for ionic/coalescing systems. The above equation was chosen because it is slightly more conservative. We need to do more work to determine the proper equation and parameter values for use with this system and to determine if this equation form holds true for larger vessels.

Initially, we used the equations above to optimize aeration of the vessels by determining the least overall cost combination of agitation power, tank H/D ratio, and working pressure with air sparged into the vessel. Using the following methodology, we determined the required airflow to reach an OTR of 80 $\mathrm{mmol} /(\mathrm{L} \bullet \mathrm{hr})$ for many combinations of the four parameters listed above. The volumetric mass transfer coefficient $\left(k_{l} a\right)$ was calculated from the given tank geometry (working volume), air flow (air velocity), and agitation power. Next, the saturated oxygen concentration was calculated at the bottom of the vessel using the vessel's working pressure (the headspace pressure), the height of the broth in the vessel, and the oxygen concentration in air. The saturated oxygen concentration was then calculated at the top of the vessel using the vessel's working pressure and an initial estimate of oxygen concentration of the outlet gas. The oxygen concentration gradients at both the top and bottom of the vessel were calculated as well as their log means. Next, the OTR was calculated from the log mean oxygen concentration gradient and the $k_{l} a$ and the amount of oxygen absorbed in the vessel were calculated from the OTR. The amount of oxygen absorbed in the vessel was also calculated from the flow rate and the inlet and estimated outlet oxygen concentrations. The two were compared and the outlet concentration was modified until they were equal. Multiple air flows were tested for each agitation power, tank H/D ratio, and working pressure to find one close to and above an OTR of $80 \mathrm{mmol} /(\mathrm{L} \bullet \mathrm{hr})$.

Assuming that agitators could be designed to avoid problems associated with flooding or burping, we did not attempt to analyze these problems. 
Next, we calculated the economics of each combination of agitation power, tank H/D ratio, working pressure, and airflow. Tank, agitator, and air compressor costs from Delta-T's internal databases were added to determine the total capital cost. To annualize that capital cost, we multiplied it by 0.188 . The electricity used by the air compressor and the agitators were summed and costed at $\$ 0.042 /(\mathrm{kW} \bullet \mathrm{hr})$ to determine an annual electricity cost. The cooling water required by the air compressor and the air separation unit were summed and costed at $\$ 0.042 / \mathrm{m}^{3}$ ( $\$ 0.16 / 1000$ gal) to determine an annual cooling water cost. We then calculated the total annual cost as the sum of the annualized capital cost, the annual electricity cost, and the annual cooling water cost. Finally, we divided by the ethanol production rate of $206,660 \mathrm{~m}^{3} / \mathrm{yr}(54,594,000 \mathrm{gal} / \mathrm{yr})$ to determine a cost per gallon of ethanol.

The initial results from this study were used in the process design and economic model and showed that pressure vessels increased the cost of cellulase production over atmospheric vessels. The initial results also showed that an H/D ratio of 2 and an agitation power requirement of $500 \mathrm{~W} / \mathrm{m}^{3}(2.54 \mathrm{hp} /(1000$ gal $))$ would be the most cost-effective arrangement with atmospheric vessels and sparged air. To achieve an OTR greater than $80 \mathrm{mmol} /(\mathrm{L} \bullet \mathrm{hr})$ the airflow was set at $0.577 \mathrm{vvm}$. The OTR calculated for that set of conditions with the final model is $81 \mathrm{mmol} /(\mathrm{L} \bullet \mathrm{hr})$.

We also conducted a second preliminary analysis that included oxygen supplementation for enriched air. The results of the second analysis (shown in Figures 9-12) indicated that increasing the oxygen concentration reduces the cost of enzyme production. Figure 9 shows the required air flow to achieve the required OTR with different agitation powers and H/D ratios. As one would expect, at greater H/D ratios (i.e., taller and skinnier tanks) power becomes less important because the time that gas spends in the bioreactor is increased. Figure 10 shows the required gas flow to achieve the required OTR with different oxygen concentrations in the feed. As expected, the gas flow is reduced significantly with increased oxygen concentration. Figure 11 shows the cost, calculated using the method outlined above, of the enzyme area per gallon ethanol as a function of H/D ratio and mixing power. The cost decreases more significantly with less mixing than with more mixing and is minimized between $\$ 39.60 / \mathrm{m}^{3}$ and $\$ 52.80 / \mathrm{m}^{3}$ $(\$ 0.15 /$ gal and $\$ 0.20 / \mathrm{gal})$. Figure 12 shows the cost of the enzyme area as a function of oxygen concentration in the feed. The figure shows that when the oxygen concentration is above $50 \%$, the cost of cellulase production is less than the minimum cost with no oxygen supplementation. We will do more work to verify the economic assumptions, but it appears that oxygen supplementation may be the optimum process configuration.

Delta-T stated that it is proper to assume that heat loss from the bioreactors is equivalent to heat input from the agitator. Cooling coils $(\mathrm{H}-400)$ are designed to remove reaction heat. We used the method described in $\mathrm{Kern}^{44}$ to calculate the overall heat transfer coefficient with fouling.

\section{II.4.3 Cost Estimation}

Chattanooga Boiler and Tank Company quoted the production bioreactor (F-400) costs. The quote was for $1000 \mathrm{~m}^{3}$ (267,000 gal) vessels with an H/D ratio of 1 . To account for extra steel required (about 226.8 $\mathrm{kg}[500 \mathrm{lb}]$ ) for an $\mathrm{H} / \mathrm{D}$ ratio of 2 , we increased the quoted cost by $\$ 652 / \mathrm{vessel}$ Lightnin quoted the production agitator and motor (A-400) costs. The agitator was quoted as model $784 \mathrm{~S} 600$ with a $447 \mathrm{~kW}$ (600-hp) motor with dual A315 impellers rotating at $45.6 \mathrm{rpm}$. The $447 \mathrm{~kW}(600-\mathrm{hp})$ motor provides more than the required $400 \mathrm{~kW}(536 \mathrm{hp})$ to achieve the required $500 \mathrm{~W} / \mathrm{m}^{3}(2.5 \mathrm{hp} / 1000$ gal) mixing power. The tanks and agitators are constructed using 304SS. The cooling coils (H-400) were costed using ICARUS. ${ }^{23}$ 

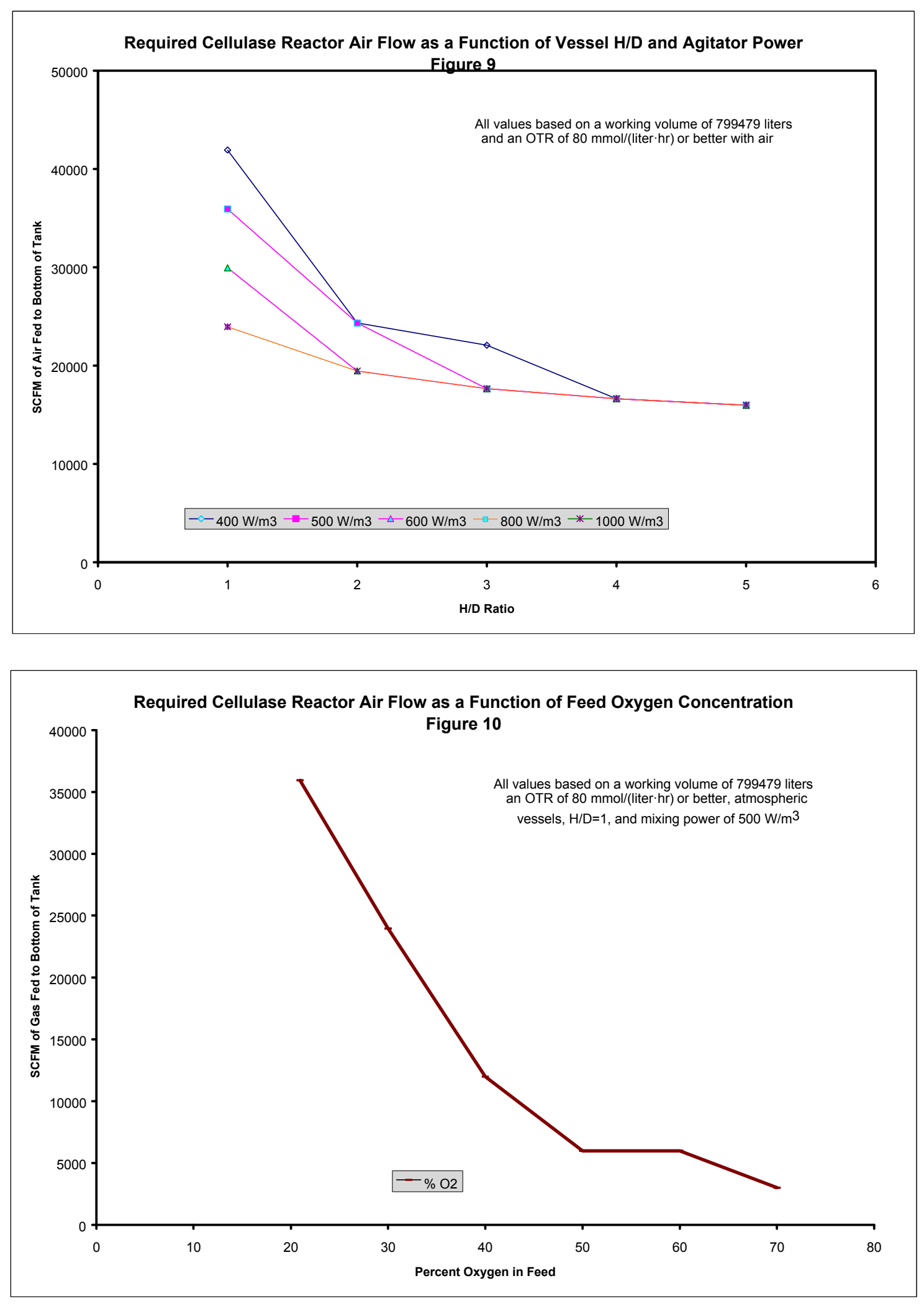

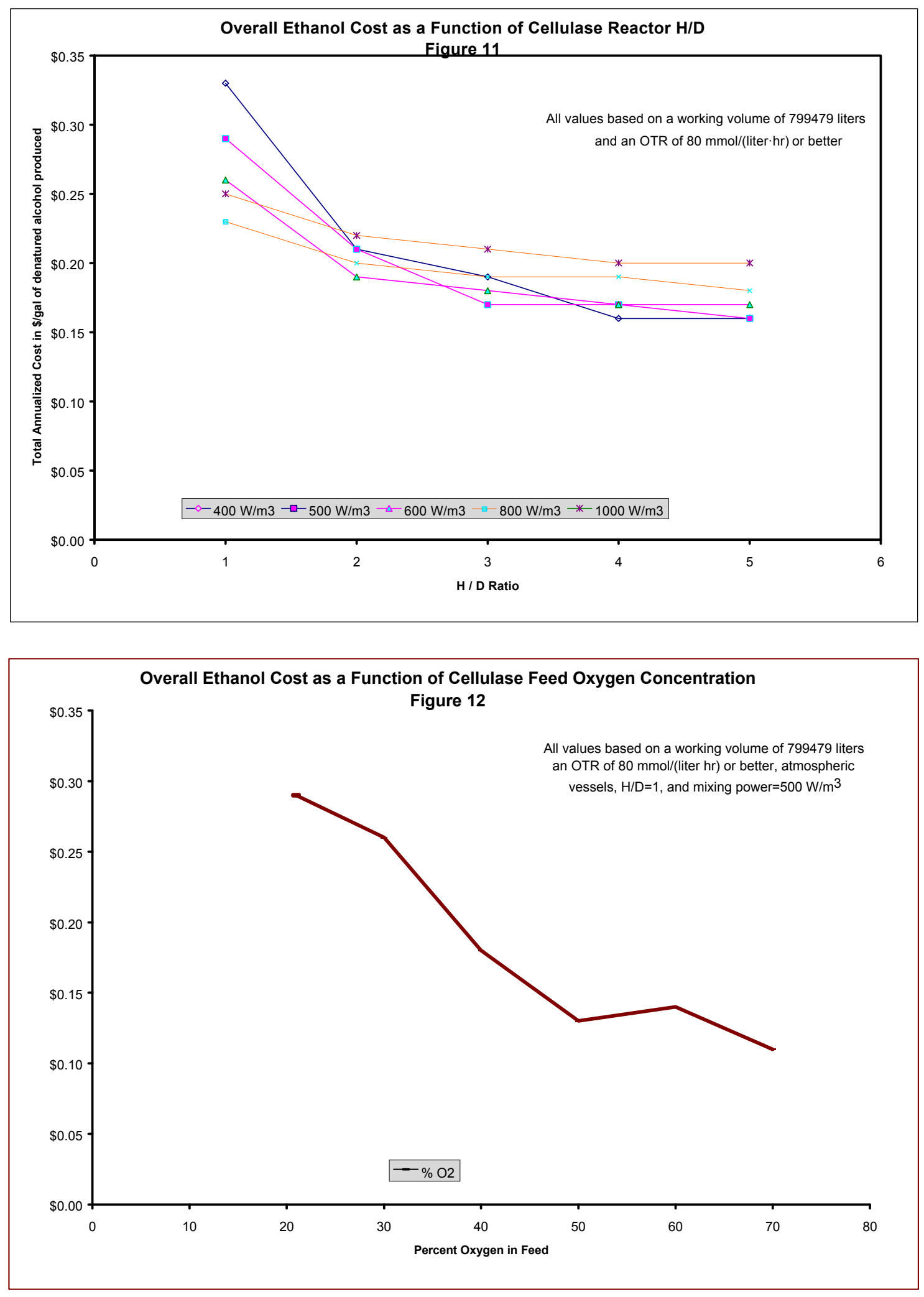
Using ICARUS, we costed the cellulase inoculum fermenters (F-401-3) as stirred stainless steel reactors. Their sizes are $0.125 \mathrm{~m}^{3}$ (33 gal), $2.5 \mathrm{~m}^{3}$ (660 gal), and $50 \mathrm{~m}^{3}$ (13,209 gal). Waukesha estimated the inoculum transfer pump cost for a rotary lobe pump and the cost was scaled to $16.5 \mathrm{~m}^{3} / \mathrm{hr}(72.5 \mathrm{gpm})$.

Ingersoll-Rand compressors (model 5CII250M2), which would provide sparge air to the system, were quoted. Each compressor has a capacity of $630.6 \mathrm{~m}^{3} / \mathrm{min}(22,271 \mathrm{SCFM})$ and a $2983 \mathrm{~kW}(4000-\mathrm{hp})$ motor.

The remaining pumps were all costed as centrifugal pumps using ICARUS. The cellulase transfer pump and media pump were specified as stainless steel and the antifoam pump was specified as carbon steel because of the lack of water in that stream. We used ICARUS to cost the media-prep tank as a mixed tank and costed the antifoam tank as a polyethylene tank from the McMaster ${ }^{45}$ catalog.

\section{II.5 Product Recovery and Water Recovery (Distillation, Dehydration, and Evaporation) - Area 500 (PFD-P100-A501-4)}

\section{II.5.1 Overview}

Distillation and molecular sieve adsorption are used to recover ethanol from the raw fermentation beer and produce very near $100 \%$ ethanol. Distillation is accomplished in two columns - the first removes the dissolved $\mathrm{CO}_{2}$ and most of the water, and the second concentrates the ethanol to a near azeotropic composition (see Figure 13).

All the water from the nearly azeotropic mixture is removed by vapor phase molecular sieve adsorption. Regeneration of the adsorption columns requires that an ethanol water mixture be recycled to distillation for recovery.

Fermentation vents (containing mostly $\mathrm{CO}_{2}$, but also some ethanol) as well as the beer column vent are scrubbed in a water scrubber, recovering nearly all of the ethanol. The scrubber effluent is fed to the first distillation column along with the fermentation beer.

The bottoms from the first distillation contains all the unconverted insoluble and dissolved solids. The insoluble solids are separated by centrifugation and sent to the burner (Area 800). The liquid from the centrifuge is concentrated using waste heat from the distillation. The concentrated syrup from the evaporator is sent to the burner and the evaporated condensate is used as clean recycle water to the process.

Because the amount of stillage water that can be recycled is limited, an evaporator is included in the process. The total amount of the water from the centrifuge that can be directly recycled is $25 \%$. Recycling too large a quantity of this material can result in levels of ionic strength and osmotic pressures that can be detrimental to the fermenting organism's efficiency. In a typical grain-to-ethanol facility, this recycle can be limited to as low as $10 \%$ of the centrifuge filtrate stream to minimize this effect. For the water that is not recycled, the evaporator concentrates the solids in syrup that can be sent to the burner, minimizing the load to wastewater treatment. 


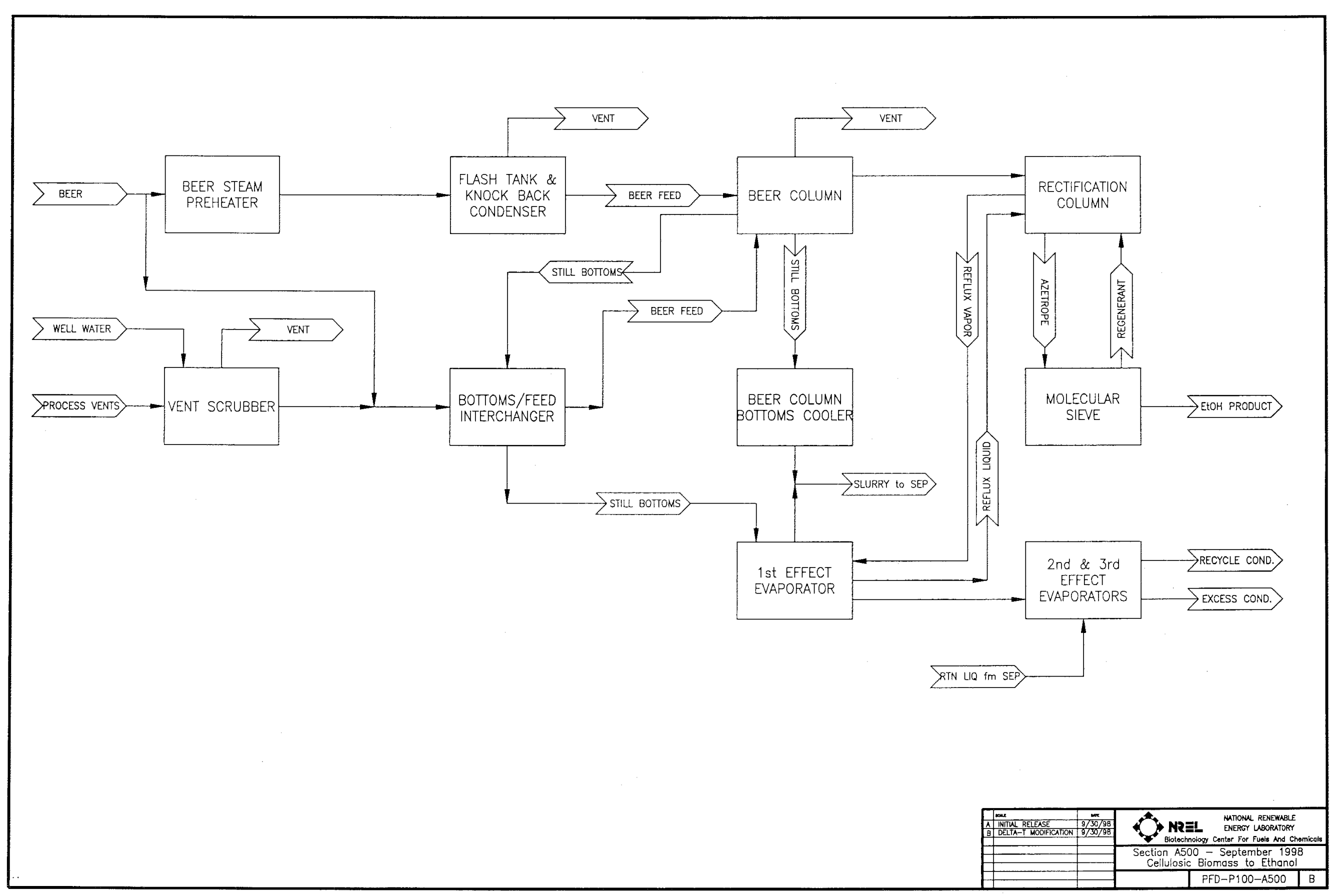




\section{II.5.2 Design Basis Description}

Beer from the fermentation area is first preheated with flash vapor from the pretreatment reactor (H-201). This feed to the beer column (PFD-P100-A501) is then further heated by interchange with the bottoms from the beer column in $\mathrm{H}-512$. The beer column (D-501) operates in a mode to remove the $\mathrm{CO}_{2}$ and as little ethanol as possible overhead, while removing about $90 \%$ of the water in the bottoms. The ethanol is removed as a vapor side draw from the column and fed directly to the rectification column (D-502).

This separation (D-501) is accomplished with 32 actual trays at $48 \%$ efficiency with the feed on actual tray 4 from the top. Nutter V-grid trays are used for this purpose. These trays have been found to tolerate the solids well and have a relatively good efficiency. Both columns D-501 and D-502 are operated at $1.77 \mathrm{~atm}$ (26 psia) overhead pressure. This relatively low pressure keeps the reboiler temperature down and minimizes fouling. The tray spacing is $0.61 \mathrm{~m}(24 \mathrm{in}$.) and the column diameter is $3.9 \mathrm{~m}(12.8 \mathrm{ft})$. The reflux ratio required is $6.1: 1$. The overheads are vented to the scrubber and contain $83.5 \% \mathrm{CO}_{2}, 12 \%$ ethanol, and $4.5 \%$ water. All the $\mathrm{CO}_{2}$ and only $0.4 \%$ of the ethanol is removed here. Most of the ethanol vented (99\%) will be recovered and recycled via the vent scrubber. In addition, about $0.8 \%$ of the ethanol fed is lost in the bottoms stream. Nearly $99 \%$ of the ethanol fed is removed as a $37.4 \% \mathrm{w} / \mathrm{w}$ mixture with water as a vapor side draw from the column at actual tray 8 . Heat is supplied to a forced recirculation reboiler (H-501) by low-pressure (4.4 atm [65 psia]) steam. A forced circulation reboiler is used in an effort to accommodate the solids present in the bottoms.

The vapor side draw from D-501 is fed directly to D-502, the rectification column (PFD-P100-A502). This column uses 60 Nutter V-Grid trays at a slightly higher efficiency of $57 \%$. The D-501 vapor is fed on tray 44 (from the top) and the recycle from adsorption, which is higher in ethanol $(72 \% \mathrm{w} / \mathrm{w}$ versus $37 \% \mathrm{w} / \mathrm{w}$ ) is fed on tray 19 (from the top). The column above tray 44 is $3.5 \mathrm{~m}(11.5 \mathrm{ft}$ ) in diameter;

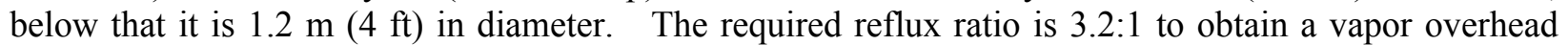
mixture of $92.5 \% \mathrm{w} / \mathrm{w}$ ethanol and a bottoms composition of $0.05 \% \mathrm{w} / \mathrm{w}$ ethanol. Only $0.1 \%$ of the ethanol from fermentation is lost in the bottoms. The composition of $7.5 \%$ water in the feed to the adsorption column represents only $0.6 \%$ of the water from entering distillation. Reflux condensing for this distillation is supplied by interchange with the evaporator, E-501. An ancillary condenser (H-505) is supplied for start-up. Heat is supplied to the column in a thermosyphon reboiler (H-502) with lowpressure (4.4 atm [65 psia]) steam.

As mentioned earlier, all ethanol-containing vents are collected and sent through a water scrubber (T-512). This is a packed column using Jaeger Tri-Pack plastic packing and recovers $98.7 \%$ of the ethanol with 4 theoretical stages and $7.6 \mathrm{~m}$ (25 ft) of packing. A flow rate of about $0.22 \mathrm{~m}^{3} / \mathrm{min}(60 \mathrm{gpm})$ of well water is used. The resulting effluent is $2.5 \% \mathrm{w} / \mathrm{w}$ ethanol and is sent to the beer well for feeding to D-501. The design basis is to adsorb $>98 \%$ ethanol in the vents and to vent no more than $36.3 \mathrm{MT}$ (40 ST) per year of organics for air pollution considerations.

Overhead vapor from D-502 is fed to the Delta-T molecular sieve adsorption unit (M-503). The design of this unit is generally proprietary to Delta-T, but the general arrangement is given on PFD-P100-A503. Saturated vapor from the distillation is first superheated and fed to one of two adsorption columns. The adsorption column removes all the water and a small portion of ethanol. The pure ethanol vapor is interchanged with regenerate condensate and finally condensed and pumped to storage. While one bed is adsorbing water, the other is regenerating. Regeneration is carried out by passing a very small slip stream 
of pure ethanol vapor back through the exhausted bed while a vacuum is applied. The water is stripped off the adsorbent. The mixture is then condensed and returned to the rectification column (D-502).

Finally, the beer column (D-501) bottoms are sent to the first effect evaporator (E-501). This effect is heated by both condensing the reflux vapor to the rectification column (D-502) and very low pressure steam (1.7 atm [25 psia]). This dual heating is accomplished using a split tubesheet evaporator that prevents the steam from mixing with the reflux. About $21 \%$ (37\% of the total evaporation) of the water entering this first effect is evaporated. In addition, the slurry is cooled from $117^{\circ} \mathrm{C}$ to $86^{\circ} \mathrm{C}$, a more suitable temperature for centrifugation. The slurry is sent to centrifugation (S-601, PFD-P100-A601) and the centrate is returned to the second evaporator effect (E-502). In the second effect, $44 \%(32 \%$ of the total evaporation) of the water entering is evaporated. A third stage of evaporation (E-502) is used to evaporate $78 \%$ of the remaining water (31\% of the total water evaporated). The final vapor is condensed in $\mathrm{H}-517$. Of the total feed to the evaporator/centrifuge system, $5 \%$ remains as syrup, $45 \%$ is removed as a wet cake in the centrifuge and $50 \%$ is evaporated. The final syrup (evaporator bottoms) is $60 \%$ water. Sixty-percent water is the maximum dissolved solids level that can be achieved without rapid fouling of the evaporator, so the flow of very low-pressure steam to the evaporator is set to achieve this parameter. This syrup is sent to the burner for disposal. The pressure of the third effect is set by the need to easily condense with cooling water at $0.2 \mathrm{~atm}(3 \mathrm{psia})$ or $62^{\circ} \mathrm{C}$. The system uses high circulation pumps to minimize fouling on the heat transfer surfaces caused by solids adhering to or plating out on the hot surfaces. The pressures of the first and second effects were adjusted to make all 5 evaporators the same size: two units each are used for the first and third effects and one unit for the second effect.

The clean-in-place system services equipment that handles stillage (beer column bottoms) by flushing with a hot caustic solution and recirculating the solution until heat transfer surfaces are clean. Manual acid cleaning, which must be performed occasionally, removes mineral scales. The frequency for this cleaning depends on the operating conditions.

\section{II.5.2.1 Physical Property Model and Parameters}

Physical property models and parameters are important throughout a rigorous mass and energy balance model such as the one used here. This is even truer for distillation calculations involving azeotropes such as the separation of ethanol from water. The physical property option ${ }^{46}$ selected for this ASPEN model uses the NRTL ${ }^{47}$ activity coefficient $\left(\gamma_{i}\right)$ model for the liquid phase fugacity, $f_{i}^{\ell}$, calculation. The vapor phase is modeled using the ideal gas law, which makes the vapor fugacity coefficient equal to one. The vapor phase fugacity coefficient is not nearly as important as the liquid phase fugacity because of the low pressure operation.

The liquid phase equation for liquid fugacity is:

$f_{i}^{\ell}=x_{i} \gamma_{i} f_{i}^{*, \ell}$

The pure component liquid fugacity, $f_{i}^{*}, \ell$, reduces to the pure component vapor pressure, $p_{i}^{*}, \ell$, at low pressures (the Poynting correction is unity). The NRTL activity coefficient model and vapor pressure models used by ASPEN are given below. Tables 13 and 14 give the ethanol and water parameters for those equations. 


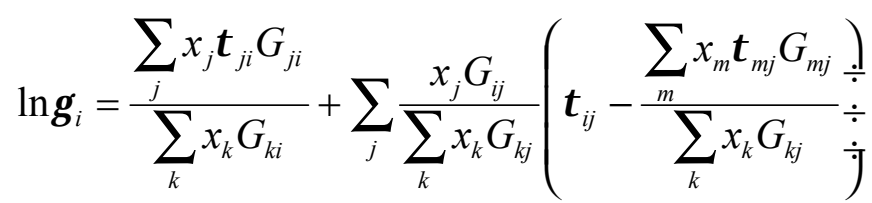

Where:

$G_{i j}=\exp \left(-\alpha_{i j} \tau_{i j}\right)$

$\tau_{i j}=a_{i j}+b_{i j} / T+e_{i j} \ln T+f_{i j} T$

$\alpha_{i j}=c_{i j}+d_{i j}(T-273.15)$

$\tau_{i i}=0$

$G_{i i}=1$

$a_{i j} \neq a_{j i}$

$b_{i j} \neq b_{j i}$

$c_{i j}=c_{j i}$

$d_{i j}=d_{j i}$

Vapor Pressure Correlation

$\ln p_{i}^{*, \ell}=C_{1 i}+\frac{C_{2 i}}{T+C_{3 i}}+C_{4 i} T+C_{5 i} \ln T+C_{6 i} T^{C_{7 i}}$

Table 13: NRTL Activity Coefficient Model Parameters $^{48}$

\begin{tabular}{|l|l|}
\hline aij & 0 \\
\hline aji & 0 \\
\hline bij & -55.1698 \\
\hline bji & 670.4442 \\
\hline cij & 0.3031 \\
\hline dij & 0 \\
\hline eij & 0 \\
\hline eji & 0 \\
\hline fij & 0 \\
\hline fji & 0 \\
\hline Lower Temperature Limit & 348.15 \\
\hline Upper Temperature Limit & 373.15 \\
\hline Note: i-ethanol, j-water \\
\hline
\end{tabular}


Table 14: Vapor Pressure Model Parameters ${ }^{48}$

\begin{tabular}{|l|l|l|}
\hline \multicolumn{1}{|c|}{ Eq. Parameters } & \multicolumn{1}{c|}{ Ethanol } & \multicolumn{1}{c|}{ Water } \\
\hline C1 & 74.475 & 73.649 \\
\hline C2 & -7164.3 & -7258.2 \\
\hline C3 & 0 & 0 \\
\hline C4 & 0 & 0 \\
\hline C5 & -7.3270 & -7.3037 \\
\hline C6 & $3.1340 \mathrm{E}-06$ & $4.1653 \mathrm{E}-06$ \\
\hline C7 & 2 & 2 \\
\hline Lower Temperature Limit & 159.05 & 273.16 \\
\hline Upper Temperature Limit & 513.92 & 647.13 \\
\hline $\begin{array}{l}\text { Temperature Units, Kelvins } \\
\text { Pressure Units, Pascals }\end{array}$ & & \\
\hline
\end{tabular}

\section{II.5.3 Cost Estimation}

The material of construction for the distillation is generally 304SS. We used a correlation from Aersten and Street ${ }^{49}$ to size the thermosyphon reboiler. The pumps, reflux drums, and the thermosyphon reboiler (H-502) were costed using ICARUS ${ }^{23}$. Delta-T used information and experience gained in other projects to cost the rest of the equipment. The cost of the first evaporator effect (E-501) was increased by $25 \%$ to account for the complexity of two vapor feeds. The molecular sieve package was quoted by Delta-T as the vendor of that equipment.

\section{II.6 Wastewater Treatment - Area 600 (PFD-P100-A601-3)}

\section{II.6.1 Overview}

The wastewater treatment was well studied by Merrick Engineering ${ }^{3}$. Merrick's engineers reviewed the design and cost estimation of the entire system.

In general, water is collected from the process and held in an equalization basis. From there the water is treated by anaerobic digestion (see Figure 14). During anaerobic digestion, $90 \%$ of the organic material present is converted to methane and carbon dioxide (biogas). This biogas is sent to the burner as medium BTU fuel. About $4.2 \mathrm{MM} \mathrm{BTU} / \mathrm{hr}(1231 \mathrm{~kW})$ or $8 \%$ of the fuel load to the burner is realized with the biogas. After anaerobic digestion the water is sent to an aerobic digestion lagoon, where another $90 \%$ of the remaining organics are removed. Aerobic sludge is also generated in this step and is then removed by clarification and filtration. The filtered sludge is sent to the burner/boiler for disposal. Water from the clarifier is now recycled to the process.

The evaporator syrup from area A500 contains about $60 \%$ water, so sending it to the burner might not be the most economical alternative. We considered the alternative of sending the evaporator syrup to wastewater treatment Table 15 summarizes the economic differences between the two options. 


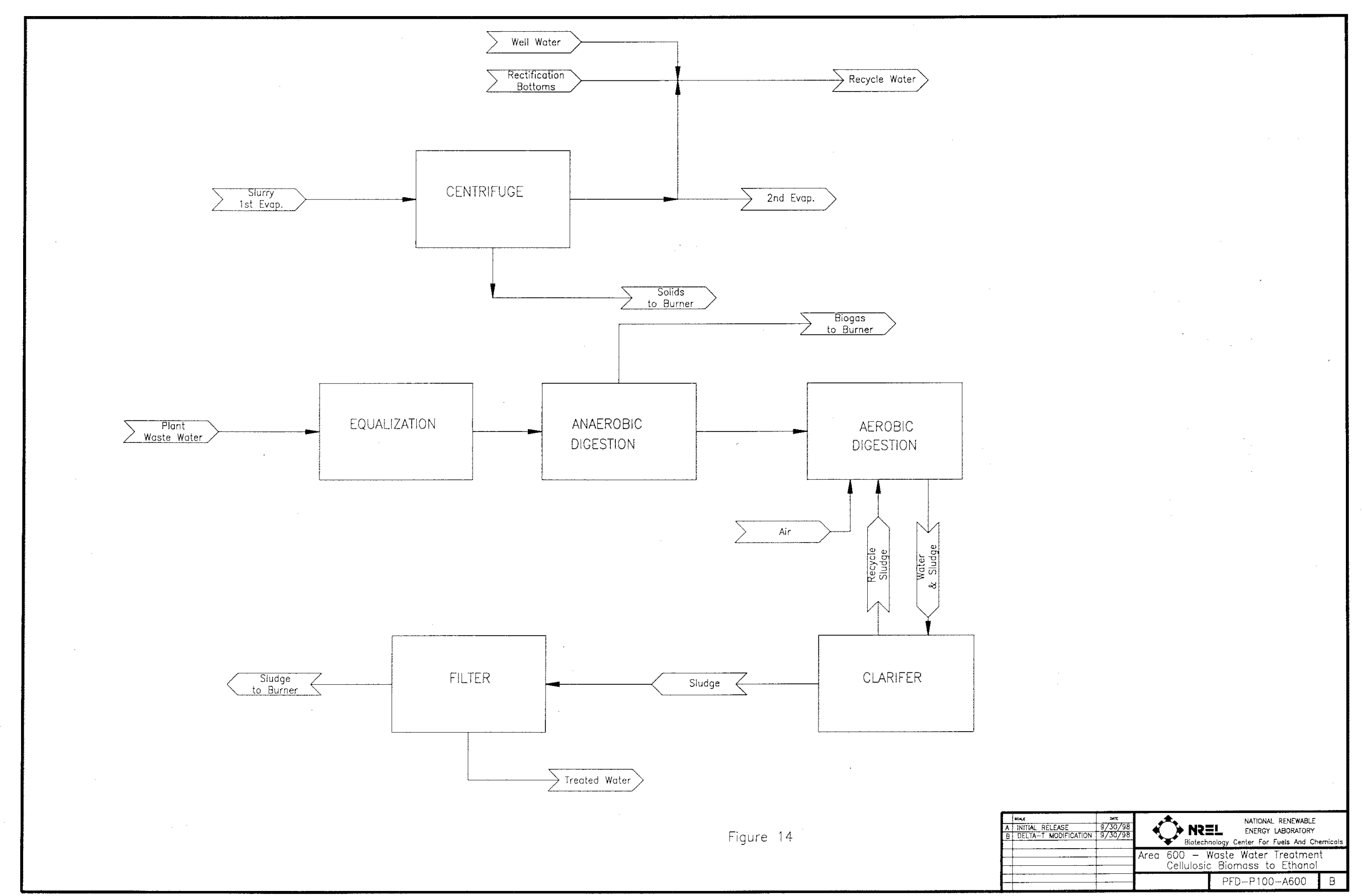


Table 15: Comparison of Sending Evaporator Syrup to the Burner or Wastewater Treatment (WWT)

\begin{tabular}{|c|c|c|c|}
\hline & \multicolumn{3}{|c|}{ Destination of Evaporator Syrup } \\
\hline & \begin{tabular}{l|l} 
Burner &
\end{tabular} & \begin{tabular}{|l|l} 
WWT & \\
\end{tabular} & Nowhere* \\
\hline Ethanol Production Cost per Gallon & $\$ 1.44$ & $\$ 1.50$ & $\$ 1.46$ \\
\hline Production Cost Breakdown & cents/gal & cents/gal & cents/gal \\
\hline Unchanged Costs & 37.0 & 37.0 & 37.0 \\
\hline Other Raw Materials & 17.1 & 18.1 & 17.0 \\
\hline Waste Disposal & 1.2 & 1.2 & 1.2 \\
\hline Electricity & -7.2 & -5.7 & -1.6 \\
\hline Fixed Costs & 14.3 & 14.7 & 14.0 \\
\hline Capital Recovery & 81.4 & 84.3 & 78.5 \\
\hline \multicolumn{4}{|l|}{ Capital Cost Breakdown } \\
\hline Unchanged Areas & $\$ 74,900,000$ & $\$ 74,900,000$ & $\$ 74,900,000$ \\
\hline WWT & $\$ 10,400,000$ & $\$ 16,200,000$ & $\$ 10,400,000$ \\
\hline Boiler/Turbogenerator & $\$ 44,500,000$ & $\$ 43,800,000$ & $\$ 39,700,000$ \\
\hline Utilities & $\$ 5,200,000$ & $\$ 5,200,000$ & $\$ 4,900,000$ \\
\hline Total Equipment Cost & $\$ 135,000,000$ & $\$ 140,100,000$ & $\$ 129,900,000$ \\
\hline Added Costs & $\$ 98,800,000$ & $\$ 102,200,000$ & $\$ 95,500,000$ \\
\hline Total Project Investment & $\$ 233,800,000$ & $\$ 242,300,000$ & $\$ 225,400,000$ \\
\hline Model & R9906A & W9906F & W9906G \\
\hline
\end{tabular}

As expected, the cost of wastewater treatment went up considerably when syrup was introduced because of the greatly increased COD (chemical oxygen demand) loading. This is counterbalanced somewhat by the increased biogas to the boiler, which results in higher electric generation and revenue (over the case of syrup to "Nowhere"). However, the overall economics as measured by the cost of ethanol production are more favorable when the syrup is sent to the boiler.

\section{II.6.2 Design Basis Description}

The design basis and alternatives are fully explained in the Merrick report. ${ }^{3}$

\section{II.6.3 Cost Estimation}

All cost estimation for this process was taken from the Merrick ${ }^{3}$ report. 


\section{II.7 Product and Feed Chemical Storage - Area 700 (PFD-P100-A701)}

\section{II.7.1 Overview}

This portion of the plant provides for the bulk storage of chemicals used in the process and product ethanol. Storage of the biomass feedstock is handled in Section A100 of the process. Feed chemicals stored in this area include ammonia, CSL, sulfuric acid, antifoam, diesel fuel (for feedstock handling bulldozers), and gasoline (used as a denaturant for the product ethanol). Water for fire suppression is also stored here.

\section{II.7.2 Design Basis Description}

Ethanol product storage is based on Delta-T's experience with fuel ethanol production facilities. The recommended amount of storage (T-701) corresponds to 7 days of production or $4,540 \mathrm{~m}^{3}(1.2$ million gal) in each of $22,270 \mathrm{~m}^{3}(600,000$-gal) carbon steel tanks.

Based on Delta-T's experience, we used 5 days of storage for sulfuric acid (T-703), which corresponds to about $72 \mathrm{~m}^{3}$ (19,000 gal). Stainless steel (SS316) is used as the material of construction because of the corrosive nature of sulfuric acid. SS316 is the industry standard for ambient temperature sulfuric acid.

Using a flow rate of $568 \mathrm{~m}^{3} / \mathrm{hr}(2500 \mathrm{gpm})$ of fire-fighting water (similar to another Delta-T project of about the same size), 2,270 $\mathrm{m}^{3}$ (600,000 gal) (T-704) will supply $4 \mathrm{hr}$ of operating time. This tank is of carbon steel construction.

Ammonia will most likely be delivered by rail. The largest tank car for this service is $131 \mathrm{~m}^{3}(34,500$ gallons). Using about $50 \%$ more for storage translates into $218 \mathrm{~m}^{3}$ (57,500 gallons) of storage (T-706). This is about 4.2 days of storage, requiring a rail car about every 3 days or 2 per week. This vessel will be of carbon steel construction and will require a design pressure $14.6 \mathrm{~atm}(200 \mathrm{psig})$.

Antifoam (corn oil) will be delivered in an $30.3 \mathrm{~m}^{3}$ (8,000-gal) truck. Using a tank that is $50 \%$ larger than this $\left(45.5 \mathrm{~m}^{3}\right.$ [12,000 gal], T-707) results in 7 days of storage.

Diesel fuel for the bulldozers will also be delivered in $30.3 \mathrm{~m}^{3}(8,000$ gal) trucks. The approximate consumption rate of diesel fuel is about $0.3 \mathrm{~m}^{3} / \mathrm{hr}$ ( $80 \mathrm{gph}$ ). A 12,000-gal tank (T-708) will give about 6 days of storage. This tank is made of carbon steel.

Gasoline is needed to dilute the ethanol being loaded for transportation away from the plant. Five percent gasoline (v/v) is added to the ethanol. The same storage time, 7 days, is used for the gasoline as for ethanol. This results in a $241 \mathrm{~m}^{3}(63,600$-gal) tank (T-710). Carbon steel is used for this tank.

The pumps in this section are generally sized for quickly loading trucks (P-701, P-710) or filling process day tanks (P-703, P-707, and P-720). The fire water pump is sized for $568 \mathrm{~m}^{3} / \mathrm{hr}(2,500 \mathrm{gpm})$. Other pumps are sized per the process requirements.

\section{II.7.3 Cost Estimation}

We used ICARUS to estimate the cost for all equipment in this section. ${ }^{23}$ 


\section{II.8 Burner, Boiler and Turbogenerator - Area 800 (PFD-P100-A801-4)}

\section{II.8.1 Overview}

The purpose of the burner, boiler and turbogenerator subsystem is to burn various by-product streams for steam generation. In turn, the steam is used to provide process heat and produce electricity. All of the lignin and some of the cellulose and hemicellulose from the feedstock will remain unconverted through the hydrolysis process. Wastewater from the process is concentrated to a syrup high in soluble solids. Anaerobic digestion of the wastewater produces a biogas high in methane. Aerobic digestion produces a small amount of waste biomass (sludge). Burning these by-product streams to generate steam and electricity for the process reduces solid waste disposal costs and is cheaper than purchasing the utilities.

Reaction Engineering Inc. (REI) ${ }^{4}$ investigated the combined system of combustion burner, boiler and turbogenerator. They contacted several vendors to obtain cost and operating information to identify a system suitable for the available feed and steam requirements. REI also obtained quotes for support equipment including a deaerator, baghouse and boiler feedwater pumps.

Three primary feed streams (centrifuge solids, biogas and evaporator syrup) are fed to a Circulating Fluidized Bed Combustor (CFBC). The small amount of waste biomass (sludge) from wastewater treatment is also sent to the burner. The solids' moisture content is reduced from $63 \%$ to $51 \%$ moisture via direct contact with flue gas exiting the burner cyclone in a drum dryer whereas the biogas and syrup enter the boiler at $4 \%$ and $60 \%$ moisture, respectively. The moisture of the combined feed to the boiler is $52 \%$. A fan moves air into the combustion chamber. Treated water enters the heat exchanger circuit in the combustor and is evaporated and superheated to $510^{\circ} \mathrm{C}\left(950^{\circ} \mathrm{F}\right)$ and 86 atm $(1265$ psia) producing $235,210 \mathrm{~kg} / \mathrm{hr}(518,550 \mathrm{lb} / \mathrm{hr})$ of steam. Boiler efficiency, defined as the percentage of the feed heat that is converted to steam heat, is $62 \%$ (see Figure 15). Flue gas from the dryer cyclone enters a baghouse to remove particulates, which are landfilled. The gas is exhausted through a stack.

A multistage turbine and generator are used to generate electricity. Steam is extracted from the turbine at 3 different conditions for injection into the pretreatment reactor and heat exchange in distillation and evaporation. The remaining steam is condensed with cooling water and returned to the boiler feedwater system along with condensate from the various heat exchangers in the process. Treated well water is used as makeup to replace steam used in direct injection.

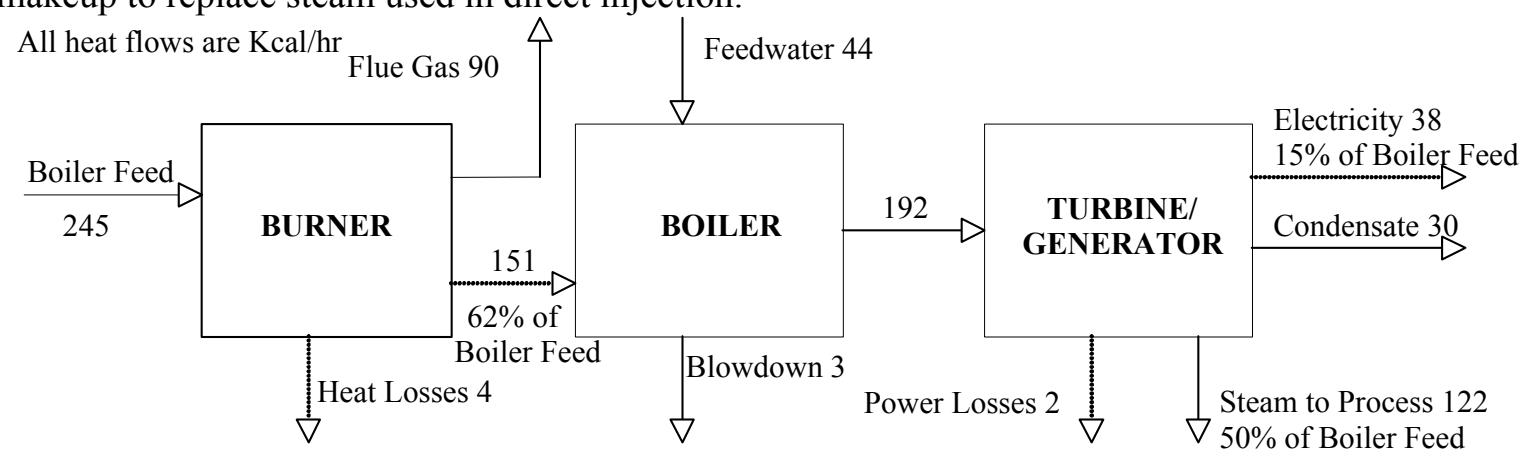

Figure 15 CFBC/Turbogenerator Energy Balance 
Makeup water and condensate are softened, deaerated, and preheated with steam to $177^{\circ} \mathrm{C}$. Chemicals for $\mathrm{pH}$ control, scale removal and oxygen removal are added. Boiler blowdown is $3 \%$ of steam production. Figure 15 shows the energy balance around the system; dashed lines are energy streams, solid lines are material streams.

\section{II.8.2 Design Basis Description}

The design of the combined burner/boiler/turbogenerator system is basically unchanged from an earlier design by Radian Corporation ${ }^{50}$. It includes a drum dryer that uses the hot flue gas to reduce the moisture in the solids. Alternately, steam could be used as a direct heat source, making a low-Btu vapor available for in-plant heating. Mechanical dewatering is also an option. When combined with maintaining a high solids content in the syrup, drying the solids helps to ensure a stable combustion bed temperature and improved boiler efficiency. Foster Wheeler Energy (FWE) suggested a maximum feed moisture of 50\%, other sources ${ }^{51}$ suggest $60 \%$ is acceptable. There is a wide range of values reported, primarily due to the various combinations of combustor designs and feeds being used. Because of heightened interest in using biomass, pulping wastes, and sewage sludge in place of fossil fuels, new methods of handling higher moisture feeds are being developed such as in-bed drying and staged combustion. Blending the wet feed with dry material or adding auxiliary fuel to maintain the combustion temperature are more traditional methods. A Lower Heating Value (LHV) of 1111-1389 kcal/kg (2000-2500 BTU/lb) is considered a minimum for maintaining combustion ${ }^{4}$ the combined feed to the burner has a LHV of $2302 \mathrm{kcal} / \mathrm{kg}(4144$ $\mathrm{Btu} / \mathrm{lb})$.

Foster Wheeler Energy confirmed the Radian design using a circulating fluidized bed combustor. This type of combustor is suitable for varying feeds and feed characteristics; however this flexibility is more expensive as compared to a grate or pile combustor. Because the bed material is returned to the combustor after the cyclone, CFBCs have little unburned carbon in the ash. Compared to coal, the combined feed in this process has significantly less ash and could require supplementation of the bed with sand to keep an adequate bed level. Two drawbacks to these units are the high power requirement for circulation and the potential for erosion due to high particulate velocities. Parameters for emissions, efficiency losses and air conditions were supplied by FWE.

Because the steam pressure required is not high (13 atm [191 psia]), NREL engineers originally envisioned a lower pressure system. FWE declined to quote on this system, citing it as non-standard due to the low operating pressure available to move the water/steam over the heating surfaces. After further study, FWE did state that a low-pressure system might be cost-effective because the lower materials cost may pay for the cost of added circuitry on the steam side.

Another option, gasification of the waste streams to produce steam and electricity, is being studied at NREL.

The turbogenerator, which consists of a multistage turbine with extraction ports, generator, and condenser is the other main portion of this system, producing lower pressure steam and electricity. A portion of the steam $(27 \%)$ is extracted from the turbine at 13 atm $\left(268^{\circ} \mathrm{C}\left[191 \mathrm{psia}, 514^{\circ} \mathrm{F}\right]\right)$, some at $4.4 \mathrm{~atm}\left(164^{\circ} \mathrm{C}\right.$ [65 psia, $\left.\left.327^{\circ} \mathrm{F}\right]\right)(46 \%)$, and some at $1.7 \mathrm{~atm}\left(115^{\circ} \mathrm{C}\right.$ [25 psia, $\left.\left.239^{\circ} \mathrm{F}\right]\right)(4 \%)$ for process needs. The remaining steam (23\%) is condensed at 0.1 atm (1.5 psia). ABB Power Generation Systems (ABB) provided cost, efficiency and design information, which were used in the model. ABB representatives, when asked about the low-pressure boiler discussed above, stated that the lower pressure option did not allow the most cost effective turbine system; higher-pressure systems supply more electricity on a power 
per capital cost basis. Badger, ${ }^{52}$ working with Turbodyne, came to the same conclusion, stating that "for larger turbines of $8000 \mathrm{~kW}$ upward steam inlet pressure has little effect on capital costs over the range 200-1600 psig". Per ABB, the turbine efficiency was set at $85 \%$; this represents an increase over the previously used value. For the base-case a total of $44 \mathrm{MW}$ of power is generated from this system. The process uses $33 \mathrm{MW}$, leaving $11 \mathrm{MW}$ that is sold to the grid.

V. Putsche confirmed the FWE and ABB design parameters using an ASPEN burner/boiler model showing good correlation of efficiencies, output flows, and temperatures. ${ }^{53}$

The boiler feedwater system includes a softener for the makeup and condensate water, a deaerator to remove air and other non-condensables, surge tanks and pumps. The boiler feedwater pumps produce 98 atm (1445 psia) pressure, requiring $895 \mathrm{~kW}(1200 \mathrm{hp})$ of power. Liquid hydrazine is injected into the deaerator to remove oxygen, which can pit the boiler surfaces. Ammonia, which volatizes with the steam, is added to control the $\mathrm{pH}$ and reduce the corrosive nature of the hot condensate. Phosphate is also added to control the formation of scale in the steam drum. The oxygen, $\mathrm{pH}$ and hardness control systems were designed by Badger ${ }^{52}$ and follow conventional practice. ${ }^{54}$ The amount of water treatment necessary depends on the incoming water quality, metallurgy of the boiler, and the ratio of makeup to condensate in the feedwater. The current system contains some redundancy; however, the control systems' costs are low compared to the replacement cost of the boiler or its components.

The power usage estimate for the baghouse cleaners $(176 \mathrm{~kW}$ [236 hp]) was obtained from the vendor, Hamon Research-Cottrell. For the flue gas dryer and its peripherals, power requirements were scaled from an existing dryer system in a corn ethanol facility (1422 kW [1907 hp]). One Induced Draft (ID) fan was used to move the flue gas from the burner cyclone through the dryer and baghouse; this may be insufficient. Power requirements for pumps and chemical handling systems were reviewed and except for minor corrections, are unchanged. Total power for this area is $2.8 \mathrm{MW}$, or $8.5 \%$ of the total plant requirement.

Pollutant generation values were taken from information provided by FWE. Baghouse efficiency of 98.8\% was taken from information supplied by the vendor. All of the emissions are below the current New Source Performance Standards (NSPS) $\operatorname{limits}^{53}$ so no control measures other than the baghouse were added to the process.

Sulfur dioxide is generated at a rate of $0.98 \mathrm{~kg} / \mathrm{Whr}(0.63 \mathrm{lb} / \mathrm{Mbtu})$. All of the sulfur into the burner is converted to sulfur dioxide; $1 \%$ of the generated sulfur dioxide is converted to sulfuric acid. The presence of this acid requires that the flue gas temperature be kept above the dewpoint to avoid corrosion. Sulfur comes from wastewater treatment (hydrogen sulfide), neutralization (sulfuric acid), and is present in the cellulase and biomass entering the boiler with the centrifuge and spent biomass solids, respectively. Limestone, if it is needed to control sulfur dioxide to a stricter standard, can be purchased for about $\$ 6$ per ton for quarter-inch particle size. ${ }^{4}$ The amount of sulfur in the feed is higher than untreated biomass, but lower than most coals.

Carbon monoxide is generated at a rate of $0.31 \mathrm{~kg} / \mathrm{Whr}(0.2 \mathrm{lb} / \mathrm{Mbtu}) .{ }^{4}$ Unburned carbon in the ash is low at $1 \%$, owing to the circulation of the unburned carbon back to the combustor bed from the cyclone.

$\mathrm{NO}_{\mathrm{x}}$ is generated at $0.31 \mathrm{~kg} / \mathrm{Whr}(0.2 \mathrm{lb} / \mathrm{Mbtu}){ }^{4}$ Nitrogen oxide, or $\mathrm{NO}_{\mathrm{x}}$, formation is a complicated mechanism, dependent on the feed, combustion temperatures, excess air rate, burner design and the presence of other control schemes like limestone injection for sulfur dioxide control. CFBCs are generally 
considered to have lower $\mathrm{NO}_{\mathrm{x}}$ emissions due to lower combustion temperatures compared to traditional pile or grate burners. ${ }^{51}$ The fate of the ammonia species in a burner is not well understood, but there is evidence to suggest that some of the ammonia is converted to nitrous oxide $\left(\mathrm{N}_{2} \mathrm{O}\right)$ while also acting to reduce $\mathrm{NO}_{\mathrm{x}}$ formation. ${ }^{55}$ Ammonia injection has long been a means of reducing $\mathrm{NO}_{\mathrm{x}}$ emissions. The nitrogen level in the combined feed is similar to coal when the ammonia species are included, more like untreated biomass when they are not.

\section{II.8.3 Cost Estimation}

The costs for the CFBC, turbogenerator, boiler feedwater pumps and deaerator are from vendor quotes. In addition, FWE and $\mathrm{ABB}$ provided scaling factor information. According to FWE, the $\mathrm{CFBC}$ should be scaled on steam production, but only for similar feed conditions, such as moisture content. The cost obtained from FWE compared well with a previous 1994 quote, shown in Table 16. Other quotes obtained over the last decade are also listed in this table. ABB provided scaling information based on steam entering the turbines rather than electricity generated, that represented a change in the costing methodology.

The flue gas dryer cost of $\$ 1.59 \mathrm{M}(1998 \$)$ is from an NREL report on biomass drying. ${ }^{56}$ A belt filter press system, quoted at $\$ 1.8 \mathrm{M}(1998 \$)$ by $\mathrm{Re}^{-\mathrm{Tec}^{4}}$ was investigated briefly by REI. The system, designed to reduce the solids moisture to $45 \%$, is an alternate method to drying.

Boiler feedwater softening equipment was costed using Richardson ${ }^{57}$, including the scaling factor. Other chemical treatment costs are from Chem Systems. ${ }^{58}$ ICARUS $^{23}$ was used to cost the remaining equipment including pumps, heat exchanger, and surge tanks.

For the baghouse, information on bag life and replacement cost from the vendor was incorporated into the capital costs.

Table 16: Boiler Costs

\begin{tabular}{|l|l|l|l|l|l|l|}
\hline Vendor/Requestor & Year & $\begin{array}{l}\text { Steam } \\
\text { Conditions } \\
\text { Pressure/Temp }\end{array}$ & $\begin{array}{l}\text { Steam } \\
\text { Production } \\
(\mathbf{1 0 0 0} \mathbf{~ l b} / \mathbf{h r})\end{array}$ & $\begin{array}{l}\text { Total Cost } \\
\mathbf{( \$ M M )}\end{array}$ & $\begin{array}{l}\text { Cost } \\
\mathbf{( \$ 9 8 / l b} \text { of } \\
\text { Steam }\end{array}$ & Scope \\
\hline FWEC/REI & & $\begin{array}{l}915-1265 \\
\mathrm{psia} / 950^{\circ} \mathrm{F}\end{array}$ & 752 & 24.9 & 33 & $\mathrm{CFB}$ \\
\hline FWEC/NREL $^{59}$ & 1994 & $1515 \mathrm{psia} / 950^{\circ} \mathrm{F}$ & 694 & 22.9 & 34.5 & $\mathrm{CFBC}$ \\
\hline $\begin{array}{l}\text { Ahlstrom } \\
\text { Pyropower/Radian }\end{array}$ & 1991 & $1515 \mathrm{psia} / 950^{\circ} \mathrm{F}$ & $279-385$ & $18-24$ & $70-68$ & $\mathrm{FBC}$ \\
\hline $\begin{array}{l}\text { ABB/Chem } \\
\text { Systems }\end{array}$ & 1990 & $1100 \mathrm{psia} / 875^{\circ} \mathrm{F}$ & 434 & 19.8 & 50 & $\begin{array}{l}\text { Dryer/ } \\
\text { FBC }\end{array}$ \\
\hline
\end{tabular}




\section{II.9 Utilities - Area 900 (PFD-P100-A901-3)}

\section{II.9.1 Overview}

This area provides all utilities required by the ethanol production facility except steam and electricity, which are provided by Area 800 . The utilities provided include cooling water, chilled water, plant and instrument air, process water, and clean-in-place (CIP) solution.

Cooling water is provided to the following equipment items:

- H-200 to cool the pretreated hydrolyzate liquor before it enters the ion exchange system

- H-301 to cool the detoxified hydrolyzate slurry before it flows into the SSCF seed train

- SSCF seed train vessels to remove the heat produced in them

- H-302 to cool the detoxified hydrolyzate slurry before it flows into the SSCF production train

- F-301-5 on an as-needed basis to remove heat in the SSCF seed train

- H-300 on an as-needed basis to remove heat produced in the SSCF production train

- M-401 to cool dried air before it is sparged into the cellulase production vessels

- H-504 to condense the beer column reflux

- H-505 to condense the rectification column reflux during start-up

- M-503 to provide some cooling and condensation in the molecular sieve

- H-517 to condense vapors from the third evaporator effect

- H-602 to cool wastewater before anaerobic digestion

- M-811 to condense the remaining steam after the steam turbine.

We assumed that cooling water can be kept at $28^{\circ} \mathrm{C}$ for most of the year, because the average summer wet bulb temperature in the United States is $24^{\circ} \mathrm{C}$, as described in Sheehan. ${ }^{61}$

Chilled water is provided to the cellulase seed and production vessels to cool them. Chilled water also cools the SSCF area (H-300, F-304, and F-305) when the cooling tower cannot keep the cooling water at $28^{\circ} \mathrm{C}$. Both the chilled and the cooling water systems were designed and costed to handle the entire remaining SSCF cooling load after well water provides initial cooling. However, we assumed that the chilled water system needs to handle the load only $20 \%$ of the time, so we calculated the operating costs with that specification.

The plant and instrument air systems provide compressed air for plant uses (pneumatic tools and clean up) and instrument operation.

The process water system mixes fresh well water with treated wastewater and provides water at a constant pressure to the facility. Water is provided to the chip washer system, the SSCF seed production, and the scrubber, to be mixed with recycle water for dilution before SSCF and cellulase production, boiler feed water, cooling tower make-up, and the clean-in-place (CIP) system. Process water is also used throughout the facility for cleaning on an as-needed basis.

The CIP system provides solution that can be heated and include cleaning and sterilization chemicals to SSCF production and seed vessels, cellulase production and seed vessels and the distillation system. 


\section{II.9.2 Design Basis Description}

The primary heat sources in this process are pretreatment, SSCF, cellulase production, distillation, wastewater treatment, and steam condensation after the turbogenerator. The cooling water system is designed at $28^{\circ} \mathrm{C}$ with a $9^{\circ} \mathrm{C}$ increase in coolers throughout the facility. We chose $28^{\circ} \mathrm{C}$ because the average summer wet bulb temperature ${ }^{61}$ in the southeastern part of the United States is $25^{\circ} \mathrm{C}$ and a $3^{\circ} \mathrm{C}$ approach is a reasonable design. The chilled water system is designed at $4^{\circ} \mathrm{C}$ with a $4^{\circ} \mathrm{C}$ increase in heat exchangers utilizing chilled water.

The cellulase production bioreactors are run too cold to use cooling water, so they require chilled water year round. Overliming, distillation, wastewater treatment, and steam condensation in the boiler are hot enough to utilize cooling water year round. The initial cooling source for SSCF is well water, which enters the facility at $13^{\circ} \mathrm{C}$ and is heated to $26^{\circ} \mathrm{C}$ by the SSCF before entering the process water system. The remaining heat is removed by cooling water or chilled water. SSCF is run at $30^{\circ} \mathrm{C}$ so it can only be cooled with cooling water when the weather permits the cooling tower to cool the cooling water to $28^{\circ} \mathrm{C}$ or less. We assumed that $28^{\circ} \mathrm{C}$ cooling water would be available $80 \%$ of the time throughout the year, so chilled water would be required the remaining $20 \%$ of the time.

Using ASPEN, we calculated the amount of cooling tower evaporation and assumed that windage would be $0.1 \%$ of the total flow to the tower. The tower blowdown is assumed to be equal to the evaporative loss plus the windage and $90 \%$ of the blowdown is recovered to the tower.

Approximately $14,060 \mathrm{~kW}$ (4,000 tons) of refrigeration is required from the chilled water units to provide cooling for cellulase production and SSCF (remaining heat requirements after cooling with well water during times when the cooling tower cannot provide cool enough water). Three 7,030 kW (2,000-ton) units are specified in the plant design - two on-line with one spare.

The plant and instrument air systems provide compressed air for plant uses (pneumatic tools and cleanup) and instrument operation. Delta-T recommended $1,530 \mathrm{~m}^{3} / \mathrm{hr}(900-\mathrm{SCFM})$ compressed air for plant operation. Three $875 \mathrm{~m}^{3} / \mathrm{hr}$ (515 CFM) screw compressors were specified - two on-line with one spare. An instrument air dryer and a surge tank were designed to provide clean dry air at a consistent pressure to the instrument air system. The surge tank was sized at $3.8 \mathrm{~m}^{3}$ (1,000 gal) to provide about $2.5 \mathrm{~L} / \mathrm{m}^{3} / \mathrm{hr}$ (1 gal per SCFM) of compressor capacity.

Fresh well water is used to cool the SSCF broth and is then split three ways, to provide clean water to the boiler feed water make-up system and the scrubber. The process water tank (T-914) mixes and holds the treated wastewater and the remaining fresh water before it is pumped throughout the facility. It is designed for an $8 \mathrm{hr}$. residence time. The process water pump (P-914), pumps water from the tank into the facility. It is designed to handle one-and-one-half times the process water flow requirement. Fresh process water is required by the chip washer system, SSCF seed production, and the scrubber, and fresh process water is mixed with recycle water for dilution before SSCF and cellulase production, boiler feed water, cooling tower make-up, and the CIP system.

The CIP system is designed to provide cleaning solution to all the fermentation vessels and heat exchangers, to the beer still (D-501), and to all the beer still mash heat exchangers. 
Process water for tank level make-up flows into the CIP system tanks and is heated by low-pressure steam. Two CIP tanks are needed in order to maintain the ability to clean a fermentation tank at the same time as a beer still mash component.

The washing sequence follows:

1) Process water is pumped at $454 \mathrm{~m}^{3} / \mathrm{hr}(2,000 \mathrm{gpm}$ ) (or at the equipment design flow) to the equipment being cleaned in order to flush the solids out of the equipment.

2) a. CIP solution is then pumped at $454 \mathrm{~m}^{3} / \mathrm{hr}(2,000 \mathrm{gpm})$ (or at the equipment design flow) through the equipment and returned to the CIP tank via the cyclone separator.

b. For tanks with sprayballs, CIP solution is pumped at $136 \mathrm{~m}^{3} / \mathrm{hr}(600 \mathrm{gpm})$ through the sprayballs in the tank. The solution is then pumped back to the CIP tanks by the 136 $\mathrm{m}^{3} / \mathrm{hr}(600 \mathrm{gpm})$ CIP return pump, via the cyclone separator.

3) The cyclone separator continuously discharges the sludge stream to the wastewater treatment area while the centrate is returned to the CIP tank for reuse.

4) The CIP cycle continues until the equipment has been cleaned.

\section{II.9.3 Cost Estimation}

We based the cooling system cost estimate on a verbal quote by Marley. It was quoted for a heat load of $148 \mathrm{MM} \mathrm{Kcal} / \mathrm{hr}(587 \mathrm{MMBtu} / \mathrm{hr}$ ) nd fiberglass construction for cost effectiveness and corrosion resistance. The quoted cooling tower is a 5 cell counterflow tower, $82.3 \mathrm{~m} \mathrm{x} 16.8 \mathrm{~m} \mathrm{(270} \mathrm{ft} \mathrm{x} 55 \mathrm{ft})$ frame, $82.6 \mathrm{~m} \times 18.6 \mathrm{~m}(271 \mathrm{ft} \times 61 \mathrm{ft})$ basin, with a $181 \mathrm{~kW}(243 \mathrm{HP})$ fan in each cell, and a total flow capacity of $16,125 \mathrm{~m}^{3} / \mathrm{hr}(71,000 \mathrm{gpm})$. The cooling tower circulation pumps were estimated using ICARUS. ${ }^{23}$ Their material of construction is carbon steel, chosen because of Delta T's experience.

The cost estimate for the chilled water system is for three 7,030 kW (2,000-ton) "off-the-shelf" chillers from YORK International Corp. The cost estimate includes pumps that can be used to circulate chilled water throughout the facility.

We used the Richardson manuals to estimate the plant and instrument air compressor and dryer costs ${ }^{12}$. The estimates are based on 125-psig rotary screw compressors and a dew point requirement of $-40^{\circ} \mathrm{C}$. We used ICARUS to estimate the plant air receiver tank cost as a horizontal vessel with a design pressure of $14.6 \mathrm{~atm}$ (200 psig).

The process water tank and pump costs were estimated using ICARUS. We estimated the tank cost using the atmospheric pressure carbon steel vertical vessel data and the pump cost using the carbon steel centrifugal pump data.

The CIP system was designed by Delta-T and the cost was estimated to be similar to the costs previously used by NREL for this system. The cost of the previous units totaled $\$ 95,000$ (1995). Scaling and installation factors were estimated. 


\section{Process Economics}

As mentioned earlier, one of the primary purposes for developing a detailed process design, model, and cost estimate is to determine the economics of ethanol production. The cost of ethanol production is used either to assess its potential in the marketplace with an absolute cost of production or to evaluate research proposals using a relative cost of production.

\section{III.1 Analysis Procedure}

The total project investment, based on total equipment cost, as well as variable and fixed operating costs, needs to be developed. With these costs, we will use a discounted cash flow analysis to determine the production cost of ethanol when the net present value of the project is zero. This section describes these three cost areas and the assumptions necessary to complete the discounted cash flow analysis.

\section{III.1.1 Total Project Investment}

Section II of this report describes the details of developing a process design and determining the purchase cost of all equipment required. The next step is to determine the installed cost of that equipment. The installation cost can be determined by a detailed study of everything required to install the required equipment and make it operational. This type of detail is not warranted for this level of estimate. When the process is much closer to construction and an estimate of $+/-5 \%$ accuracy is required for financing, more details will be necessary. This study is more of a $+25 \% /-10 \%$ accuracy, making a "factored" approach satisfactory. Many engineering texts such as Garrett ${ }^{7}$ or Peters and Timmerhaus ${ }^{62}$ list installation factors that can be applied to purchased equipment costs to determine the installed cost. The ICARUS Process Evaluator ${ }^{23}$ conducts a detailed estimate using its estimate of the piping and instrumentation required for each type of equipment. Although the ICARUS estimate is more detailed than a simple factored method, it, as well as the standard textbook factored methods, was developed for the chemical and petroleum industry, not an aqueous based biotechnology process. A better methodology is to use the actual experience that Delta-T has developed when actually installing these processes.

Delta-T reviewed the factors for direct installation costs suggested by Chem Systems ${ }^{63}$ in its 1994 study of this process (Chem Systems in turn took these installation factors from Walas ${ }^{64}$ ) These installation factors, given in Table 17, were applied to the equipment purchased costs. The overall installation "factor" was then calculated as the quotient of the sum of all purchased costs and the sum of all installed costs, excluding sections A600 and A800. Delta-T compared this ratio (1.42) to several projects that they have actually built, where the actual ratio was 1.46 . Therefore, these installation factors were accepted for most equipment except where other information, such as installation factors from vendors, was available. See Appendix B for a complete listing of the equipment, along with its purchased and installed costs.

Once the installed equipment cost has been determined from the purchased cost and the installation factor, it can be indexed to the project year being considered. In this case, we selected 1997 because the results of this work are being used in other studies that integrate these costs with petroleum costs projected by the Energy Information Administration (EIA), ${ }^{65}$ which happens to be in 1997 dollars. The purchase cost of each piece of equipment has a year associated with it. It might be 1998, if a vendor quote was obtained in that year, or it might be 1997 if ICARUS was used as its basis. The purchased cost year will be indexed to the year of interest using the Chemical Engineering Index ${ }^{66}$ Existing values for the index ranging from 
1990 to 1996 were regressed to a simple equation. The resulting equation was used to allow extrapolation to future years (known as "out years"). Table 18 gives the index as a function of date.

Table 17: Installation Factors ${ }^{67}$

\begin{tabular}{|l|c|}
\hline Equipment & Multiplier* \\
\hline Agitators - Carbon Steel & 1.3 \\
\hline Agitators - Stainless Steel & 1.2 \\
\hline Boilers & 1.3 \\
\hline Compressors (motor driven) & 1.3 \\
\hline Cooling Towers & 1.2 \\
\hline Distillation columns - Carbon Steel & 3.0 \\
\hline Distillation columns - Stainless Steel & 2.1 \\
\hline Filters & 1.4 \\
\hline Heat Exchangers (S\&T) - CS/SS & 2.1 \\
\hline Pumps - Lobe & 1.4 \\
\hline Pumps - Centrifugal, Carbon Steel & 2.8 \\
\hline Pumps - Centrifugal, Stainless Steel & 2.0 \\
\hline Pressure Vessels - Carbon Steel & 2.8 \\
\hline Pressure Vessels - Stainless Steel & 1.7 \\
\hline Tanks - Field Erected, Carbon Steel & 1.4 \\
\hline Tanks - Field Erected, Carbon Steel with Lining & 1.6 \\
\hline Tanks - Field Erected, Stainless Steel & 1.2 \\
\hline Solids Handling Equipment & $1.2-1.4$ \\
\hline Rotary Dryer & 1.6 \\
\hline Turbogenerator & 1.5 \\
\hline$*$ Installed cost = (purchased equipment cost) x (multiplier) \\
\hline
\end{tabular}

Table 18: Chemical Engineering Purchased Equipment Index ${ }^{66}$

\begin{tabular}{|l|l|l|l|}
\hline Year & Index & Year & Index \\
\hline 1990 & 357.6 & 1997 & 384.1 \\
\hline 1991 & 361.3 & 1998 & 388.5 \\
\hline 1992 & 358.2 & 1999 & 392.8 \\
\hline 1993 & 359.2 & 2000 & 397.2 \\
\hline 1994 & 368.1 & 2005 & 418.9 \\
\hline 1995 & 381.1 & 2010 & 440.7 \\
\hline 1996 & 281.7 & & \\
\hline & $\begin{array}{l}\text { Note: } 1990 \text { to 1996 represents actual data. } \\
\text { Beyond 1996 were extrapolated from the earlier data. }\end{array}$ \\
\hline
\end{tabular}

The total equipment cost in the year of interest has now been determined. To obtain the total project investment, we must add several other items. Chem Systems ${ }^{67}$ proposed the categories and amounts of additional factors listed in Table 19, which summarizes these additional costs. Delta-T reviewed the items and factors and determined that they were consistent with other projects the company has completed. 
Table 19: Chem Systems Additional Cost Factors ${ }^{67}$

\begin{tabular}{|c|c|c|}
\hline Item & Description & Amount \\
\hline Warehouse & & $\begin{array}{l}1.5 \% \text { of Total } \\
\text { Equipment Costs }\end{array}$ \\
\hline Site Development & $\begin{array}{l}\text { Site Development: Includes fencing, curbing, parking, lot, } \\
\text { roads, well drainage, rail system, soil borings, and general } \\
\text { paving. This factor allows for minimum site development } \\
\text { assuming a clear site, with no unusual problems such as right- } \\
\text { of-way, difficult land clearing, or unusual environmental } \\
\text { problems. } 9 \% \text { of the installed cost of process equipment (areas } \\
\text { A100, A200, A300, A400, and A500). }\end{array}$ & $\begin{array}{l}9 \% \text { of the } \\
\text { installed cost of } \\
\text { process } \\
\text { equipment (areas } \\
\text { A100, A200, } \\
\text { A300, A400, and } \\
\text { A500). }\end{array}$ \\
\hline Prorateable Costs & $\begin{array}{l}\text { This includes fringe benefits, burdens, and insurance of the } \\
\text { construction contractor. }\end{array}$ & $\begin{array}{l}10 \% \text { of Total } \\
\text { Installed Cost }\end{array}$ \\
\hline Field Expenses & $\begin{array}{l}\text { Consumables, small tool equipment rental, field services, } \\
\text { temporary construction facilities, and field construction } \\
\text { supervision. }\end{array}$ & $\begin{array}{l}10 \% \text { of Total } \\
\text { Installed Cost }\end{array}$ \\
\hline $\begin{array}{l}\text { Home Office and } \\
\text { Construction }\end{array}$ & Engineering plus incidentals, purchasing, and construction. & $\begin{array}{l}25 \% \text { of Total } \\
\text { Installed Cost }\end{array}$ \\
\hline $\begin{array}{l}\text { Project } \\
\text { Contingency }\end{array}$ & Small because of the detail included in the process design & $\begin{array}{l}3 \% \text { of Total } \\
\text { Installed Cost }\end{array}$ \\
\hline Other Costs & $\begin{array}{l}\text { Start-up and commissioning costs. } \\
\text { Land, rights-of-way, permits, surveys, and fees. } \\
\text { Piling, soil compaction/dewatering, unusual foundations. } \\
\text { Sales, use, and other taxes. } \\
\text { Freight, insurance in transit and import duties on equipment, } \\
\text { piping, steel, instrumentation, etc. } \\
\text { Overtime pay during construction. } \\
\text { Field insurance. } \\
\text { Project team. } \\
\text { Transportation equipment, bulk shipping containers, plant } \\
\text { vehicles, etc. } \\
\text { Escalation or inflation of costs over time. } \\
\text { Interest on construction loan. }\end{array}$ & $\begin{array}{l}10 \% \text { of Total } \\
\text { Capital } \\
\text { Investment }\end{array}$ \\
\hline
\end{tabular}

Table 20 summarizes the Total Equipment Cost. Table 21 illustrates the application of factors in Table 19 to obtain the Total Project Investment. 
Table 20: Total Installed Equipment Costs

\begin{tabular}{|l|r|}
\hline Process Area & Capital Cost \\
\hline Feed Handling & $\$ 4,900,000$ \\
\hline Pretreatment/Detox & $\$ 26,300,000$ \\
\hline SSCF & $\$ 13,400,000$ \\
\hline Cellulase Production & $\$ 15,500,000$ \\
\hline Distillation & $\$ 13,000,000$ \\
\hline WWT & $\$ 10,400,000$ \\
\hline Storage & $\$ 1,800,000$ \\
\hline Boiler/Turbogen & $\$ 44,500,000$ \\
\hline Utilities & $\$ 5,200,000$ \\
\hline Total Equipment Cost & $\$ 135,000,000$ \\
\hline Model R9906A 1997\$ \\
\hline
\end{tabular}

\begin{tabular}{|l|r|}
\hline \multicolumn{2}{|c|}{ Table 21: Total Project Investment } \\
\hline Total Equipment Costs (Table 20) & $\$ 135,000,000$ \\
Warehouse & $\$ 2,000,000$ \\
Site Development & $\$ 6,600,000$ \\
Total Installed Cost & $\$ 143,600,000$ \\
\hline Indirect Costs & \\
Field Expenses & $\$ 28,700,000$ \\
Home Office \& Construction Fee & $\$ 35,900,000$ \\
Project Contingency & $\$ 4,300,000$ \\
\hline Total Capital Investment & $\$ 212,500,000$ \\
\hline Other Costs & $\$ 21,300,000$ \\
\hline Total Project Investment & $\$ 233,800,000$ \\
\hline Model: R9906A, 1997 \$ & \\
\hline
\end{tabular}

\section{III.1.2 Variable Operating Costs}

Variable operating costs, which include raw materials, waste handling charges, and by-product credits, are incurred only when the process is operating. All raw material quantities used and wastes produced were determined using the ASPEN mass and energy balance model. Appendix C documents the sources of the costs of these items. Eventually, the documentation of raw material costs will be stored in the Process Basis database and linked to the economic model. The ASPEN mass and energy balance also calculates the gallons of ethanol produced. Therefore, each raw material's contribution to the cost of a gallon of ethanol can be determined. Table 22 summarizes these costs.

As with capital equipment, the costs for chemicals are associated with a particular year. To index the costs from the year in which they were obtained to the year the analysis is being performed, we use the Inorganic Chemical Index ${ }^{68}$ from SRI Consulting. Data for this index were available for years 1980 through 1996. These data were regressed to a simple equation and used to extrapolate to other years, as shown in Table 23. 
Table 22: Variable Operating Costs

\begin{tabular}{|c|c|c|c|c|}
\hline Raw Material & $\mathrm{kg} / \mathrm{hr}$ & $\begin{array}{l}\text { Cost } \\
\text { (\$/lb) }\end{array}$ & MM\$/yr & $\begin{array}{c}\text { \&/Gal } \\
\text { Ethanol }\end{array}$ \\
\hline Biomass Feedstock* & 159,948 & 0.006513 & 19.31 & 37.0 \\
\hline Sulfuric Acid & 1,867 & 0.012 & 0.41 & 0.8 \\
\hline Lime & 714 & 0.0335 & 0.44 & 0.9 \\
\hline Ammonia & 1,419 & 0.0837 & 2.20 & 4.3 \\
\hline Corn Steep Liquor & 1,977 & 0.072 & 2.63 & 5.1 \\
\hline Nutrients & 174 & 0.132 & 0.43 & 0.8 \\
\hline Ammonium Sulfate & 392 & 0.02 & 0.16 & 0.3 \\
\hline Antifoam (Corn Oil) & 227 & 0.2412 & 1.01 & 2.0 \\
\hline Diesel & 443 & 0.0588 & 0.48 & 0.9 \\
\hline Make-up Water & 186,175 & 0.00013 & 0.45 & 0.9 \\
\hline BFW Chemicals & 0.5 & 1.03 & 0.01 & 0.0 \\
\hline CW Chemicals & 5 & 1.00 & 0.10 & 0.2 \\
\hline WWT Nutrients & 230 & 0.11 & 0.45 & 0.9 \\
\hline WWT Chemicals & 0.76 & 2.39 & 0.03 & 0.1 \\
\hline Ash Disposal & 1,106 & 0.01 & 0.19 & 0.4 \\
\hline Gypsum Disposal & 2,433 & 0.01 & 0.42 & 0.8 \\
\hline Electricity Credit & $-10,942(\mathrm{~kW})$ & 0.04 & -3.68 & -7.2 \\
\hline
\end{tabular}

Table 23: Inorganic Chemical Index ${ }^{68}$

\begin{tabular}{|c|c|c|c|}
\hline Year & Index & Year & Index \\
\hline 1982 & 100 & 1993 & 108.9 \\
\hline 1983 & 95.1 & 1994 & 110.4 \\
\hline 1984 & 94.3 & 1995 & 117.2 \\
\hline 1985 & 96.7 & 1996 & 119.5 \\
\hline 1986 & 95.3 & 1997 & 119.0 \\
\hline 1987 & 94.5 & 1998 & 120.8 \\
\hline 1988 & 100.9 & 1999 & 122.5 \\
\hline 1989 & 108.9 & 2000 & 124.2 \\
\hline 1990 & 111.7 & 2005 & 131.2 \\
\hline 1991 & 112.5 & 2010 & 140.0 \\
\hline 1992 & 109.8 & & \\
\hline $\begin{array}{l}\text { Note: } 1990 \text { to } 1996 \text { represents actual data. } \\
\text { Beyond 1996 were extrapolated from the earlier data. }\end{array}$ \\
\hline
\end{tabular}

\section{III.1.3 Fixed Operating Costs}

Fixed operating costs are generally incurred whether or not the plant is producing at full capacity. These costs include labor and various overhead items. Delta-T recommended information on fixed operating costs using data from similar ethanol plant projects the company has been involved with (ranging up to 230 million L [60 million gal] annual production), as well as the standard reference of Peters and Timmerhaus. ${ }^{62}$ Table 24 contains the Delta-T recommendation. 
Salaries do not include benefits; they are covered in the general overhead category. General overhead is a factor of $60 \%$ applied to the total salaries and covers items such as safety, general engineering, general plant maintenance, payroll overhead (including benefits), plant security, janitor and similar services, phone, light, heat, and plant communications.

Annual maintenance materials, based on the same experience, were estimated as $2 \%$ of the total equipment cost as shown in Table 20. Additionally, insurance and taxes were estimated at $1.5 \%$ of the total installed cost using both Delta-T's in-house information and published information (Table 21).

It is important to note that the estimates provided for this section are based on a representative Midwest U. S. basis. The estimates can vary based on specific location.

Table 24: Fixed Operating Costs

\begin{tabular}{|c|c|c|c|c|}
\hline & Salary of Factor & Number & Total Cost & \\
\hline Plant Manager & $\$ 80,000$ & 1 & $\$ 80,000$ & \\
\hline Plant Engineer & $\$ 65,000$ & 1 & $\$ 65,000$ & \\
\hline Maintenance Supervisor & $\$ 60,000$ & 1 & $\$ 60,000$ & \\
\hline Lab Manager & $\$ 50,000$ & 1 & $\$ 50,000$ & \\
\hline Shift Supervisor & $\$ 37,000$ & 5 & $\$ 185,000$ & \\
\hline Lab Technician & $\$ 25,000$ & 2 & $\$ 50,000$ & \\
\hline Maintenance Technician & $\$ 28,000$ & 8 & $\$ 224,000$ & \\
\hline Shift Operators & $\$ 25,000$ & 20 & $\$ 500,000$ & \\
\hline Yard Employees & $\$ 20,000$ & 8 & $\$ 160,000$ & \\
\hline General Manager & $\$ 100,000$ & 1 & $\$ 100,000$ & \\
\hline Clerks \& Secretaries & $\$ 20,000$ & 5 & $\$ 100,000$ & \\
\hline Total Salaries (1998 \$) & & & $\$ 1,574,000$ & \\
\hline Total Salaries (1997 \$) & & & $\$ 1,532,000$ & \\
\hline Overhead/Maintenance & $60 \%$ & & $\$ 944,000$ & Of labor and supervision \\
\hline Maintenance & $2 \%$ & & $\$ 2,701,000$ & Of equipment cost \\
\hline Insurance \& Taxes & $1.5 \%$ & & $\$ 2,154,000$ & Of total installed cost \\
\hline
\end{tabular}

The salaries are on a 1998 basis and will need to be indexed to other cost years when appropriate. The index to adjust these costs is taken from the Bureau of Labor Statistics ${ }^{69}$ and is given in Table 25. As with the other indexes, data were available only up until 1996. The available data were regressed to a simple equation. The resulting regression equation was used to extrapolate to out years. 
Table 25: Labor Index ${ }^{69}$

\begin{tabular}{|c|r|c|c|}
\hline Year & \multicolumn{1}{|c|}{ Index } & Year & Index \\
\hline 1980 & 8.3 & 1992 & 14.51 \\
\hline 1981 & 9.12 & 1993 & 14.82 \\
\hline 1982 & 9.96 & 1994 & 15.13 \\
\hline 1983 & 10.58 & 1995 & 15.62 \\
\hline 1984 & 11.07 & 1996 & 16.17 \\
\hline 1985 & 11.56 & 1997 & 16.72 \\
\hline 1986 & 11.98 & 1998 & 17.17 \\
\hline 1987 & 12.37 & 1999 & 17.63 \\
\hline 1988 & 12.71 & 2000 & 18.08 \\
\hline 1989 & 13.09 & 2005 & 19.90 \\
\hline 1990 & 13.54 & 2010 & 22.18 \\
\hline 1991 & 14.04 & & \\
\hline $\begin{array}{l}\text { Note: 1990 to 1996 represents actual data. } \\
\text { Beyond 1996 information was extrapolated from the } \\
\text { earlier data. }\end{array}$ \\
\hline \multicolumn{4}{|l}{}
\end{tabular}

\section{III.1.4 Discounted Cash Flow Analysis and the Selling Cost of Ethanol}

Once the major three cost areas have been determined-(1) total project investment, (2) variable operating costs, and (3) fixed operating costs - a discounted cash flow analysis can be used to determine the minimum selling price per gallon of ethanol produced. The discounted cash flow analysis will iterate on the selling cost of ethanol until the net present value of the project is zero. This analysis requires that a discount rate be set. In addition, the depreciation method, along with income tax rates, plant life, construction, and start-up duration, will need to be determined. For this analysis, we assumed that the plant would be $100 \%$ equity financed. This, along with other financial assumptions made here, is subject to change for a specific project. For this analysis these parameters were chosen to be representative, but certainly not the final word in project financing.

The discount rate for this project is $10 \%$. This rate was selected based on the recommendation by Short et all $^{70}$ in his description of how to perform economic evaluations of renewable energy technologies for DOE. His view is that "In the absence of statistical data on discount rates used by industrial, transportation and commercial investors for investments with risks similar to those of conservation and renewable energy investments, it is recommended that an after tax discount rate of $10 \%$..." be used.

To determine the depreciation amount for the calculation of federal taxes to be paid, Short et al. ${ }^{71}$ recommends the use of the IRS Modified Accelerated Cost Recovery System (MARCS). Within the MARCS system is the General Depreciation System (GDS), which allows both the $200 \%$ and $150 \%$ declining balance (DB) methods of depreciation. This offers the shortest recovery period and the largest tax deductions. IRS publication 534 (IRS 1993) indicates that steam production plants should use a 20year recovery period. The IRS indicates that other property not specifically described in the publication should be depreciated using a 7-year recovery period. Short et al. ${ }^{72}$ indicates that property listed with a recovery period less than 10 years should use the $200 \%$ DB depreciation method and that a 20 -year recovery period property should use the $150 \%$ DB depreciation. 
State taxes are not considered, primarily because the location of the plant has not been determined and tax rates vary quite drastically, from $0 \%$ to $12 \%$. Short et al. ${ }^{70}$ suggests using the highest federal tax bracket, which is $39 \%$ for large corporations.

The construction time is important to the cash flow analysis because there is generally no income during construction and because huge sums of money are being expended. Perry and Green ${ }^{73}$ indicate that small projects (less than $\$ 10$ million investment) can be constructed in fewer than 18 months and that larger projects can take up to 42 months. An overview ${ }^{74}$ of petroleum refining economics indicates that large refineries (of the order of $\$ 1.5$ billion investment) can be constructed in 24 months. Certainly this process is much smaller than the refinery, so using a construction time of 24 months is conservative and fits within these references. Delta-T's experience with grain-to-ethanol plants indicates that it will require a little more than 2 years to complete a project of this size. An important difference between this type of facility and a refinery are the large number of field-erected vessels in this process. Their on-site construction in very close proximity to each other will cause the construction time to be a little longer. Table 26 summarizes the schedule for construction and the cash flow during that time.

Table 26: Construction Activities and Cash Flow

\begin{tabular}{|c|c|c|c|}
\hline $\begin{array}{l}\text { Project } \\
\text { Start } \\
\text { Month }\end{array}$ & $\begin{array}{l}\text { Project } \\
\text { End } \\
\text { Month }\end{array}$ & Activity Description & $\begin{array}{l}\text { \% of Project } \\
\text { Cost }\end{array}$ \\
\hline 0 & 6 & $\begin{array}{l}\text { Project plan and schedule established, conceptual and } \\
\text { basic design engineering, permitting completed. Major } \\
\text { equipment bid packages issued, engineering started on } \\
\text { selected sub-packages, P\&ID's complete, preliminary } \\
\text { plant and equipment arrangements complete. }\end{array}$ & $8.00 \%$ \\
\hline 6 & 18 & $\begin{array}{l}\text { All detailed engineering including foundations, structure, } \\
\text { piping, electrical, site, etc. complete; all equipment and } \\
\text { instrument components purchased and delivered; all site } \\
\text { grading, drainage, sewers, rail, fire pond, foundation, } \\
\text { and major structural installation complete; } 80 \% \text { of all } \\
\text { major process equipment set (all except longest lead } \\
\text { items), all field fabricated tanks built, and the majority } \\
\text { of piping and electrical materials procured. }\end{array}$ & $60.62 \%$ \\
\hline \multirow[t]{2}{*}{18} & 30 & $\begin{array}{l}\text { Complete process equipment setting, piping, and } \\
\text { instrumentation installation complete; all electrical } \\
\text { wiring complete; all building finishing and plumbing } \\
\text { complete; all landscaping complete; pre-commissioning } \\
\text { complete; and commissioning, start-up, initial } \\
\text { performance test complete. }\end{array}$ & $31.38 \%$ \\
\hline & & TOTAL & $100.00 \%$ \\
\hline \multicolumn{4}{|l|}{$\begin{aligned} & \text { Notes: } \\
& 1 . \\
& 2 .\end{aligned}$} \\
\hline
\end{tabular}

Perry and Green ${ }^{73}$ indicate that for a moderately complex plant start-up should be about $25 \%$ of the construction time or 6 months, in this case. Delta-T's experience with start-up demonstrates that a large 
grain-to-ethanol plant could be started in less time, but this is more complex than a grain ethanol plant. Considering that this design is for the "nth" operating plant, we assumed a start-up time of 6 months. The start-up period is not completely wasted, however. We expect that an average of $50 \%$ production could be achieved during that period with about $75 \%$ expenditure of variable expenses and $100 \%$ of fixed expenses. Certainly some start-up activities will also occur during construction. One of the additional cost factors accounts for additional man power to begin equipment testing and other start-up activities before construction is complete (see Table 19).

Working capital is money available to handle (1) raw materials and supplies in inventory, (2) finished product in storage, (3) accounts receivable, (4) cash on hand for monthly payments, (5) accounts payable, and (6) taxes payable. Peters and Timmerhaus ${ }^{62}$ indicate that this is usually $10 \%-20 \%$ of the capital investment. For this project, even $10 \%$ would be about $\$ 22$ million. One month's supply of raw materials and product inventory is only about $\$ 2$ million. Therefore, a lower number of $5 \%$ or about $\$ 10$ million is more reasonable.

Table 27 summarizes the parameters used in the discounted cash flow analysis.

Table 27: Discounted Cash Flow Parameters

\begin{tabular}{|l|l|}
\hline Plant Life & 20 years \\
\hline Discount Rate & $10 \%$ \\
\hline General Plant Depreciation & $200 \%$ DB \\
\hline General Plant Recovery Period & 7 years \\
\hline Steam Plant Depreciation & $150 \%$ DB \\
\hline Federal Tax Rate & $39 \%$ \\
\hline Financing & $100 \%$ equity \\
\hline Construction Period & 2.5 years \\
$1^{\text {st }}$ 6 Months Expenditures & $8 \%$ \\
Next 12 Months Expenditures & $61 \%$ \\
Last 12 Months Expenditures & $31 \%$ \\
\hline Working Capital & $5 \%$ of Total Project Investment \\
\hline Start-Up Time & 6 months \\
Revenues & $50 \%$ \\
Variable Costs & $75 \%$ \\
Fixed Costs & $100 \%$ \\
\hline
\end{tabular}

Using the discounted cash flow parameters in Table 27, plus the cost information in Tables 21, 22, and 24 , the resulting cost of pure ethanol is $\$ 1.44 /$ gal (see Table 28 and Appendix D). Using the capital cost estimate margin of $+25 \% /-10 \%$, the impact on the cost of ethanol would be a low of $\$ 1.36 /$ gal and a high of $\$ 1.64 /$ gal.

Table 28: Near-Term Base-Case Results Summary

\begin{tabular}{|l|l|}
\hline Production Cost of Ethanol & $\$ 1.44 /$ gal $(+\$ 0.20 /-\$ 0.08)$ \\
\hline Ethanol Yield & $68 \mathrm{gal} /$ ton \\
\hline Ethanol Production & $52.2 \mathrm{MM} \mathrm{gal} / \mathrm{yr}$ \\
\hline Total Project Investment (Capital) & $\$ 234 \mathrm{MM}$ \\
\hline $\begin{array}{l}\text { Note: } 1997 \$ \\
\text { Model: R9906A }\end{array}$ \\
\hline
\end{tabular}


The $\$ 1.44 /$ gal can be further broken down into the cost of each process area. Figure 16 illustrates the contribution to the overall cost by process area and capital, operations, and fixed costs.

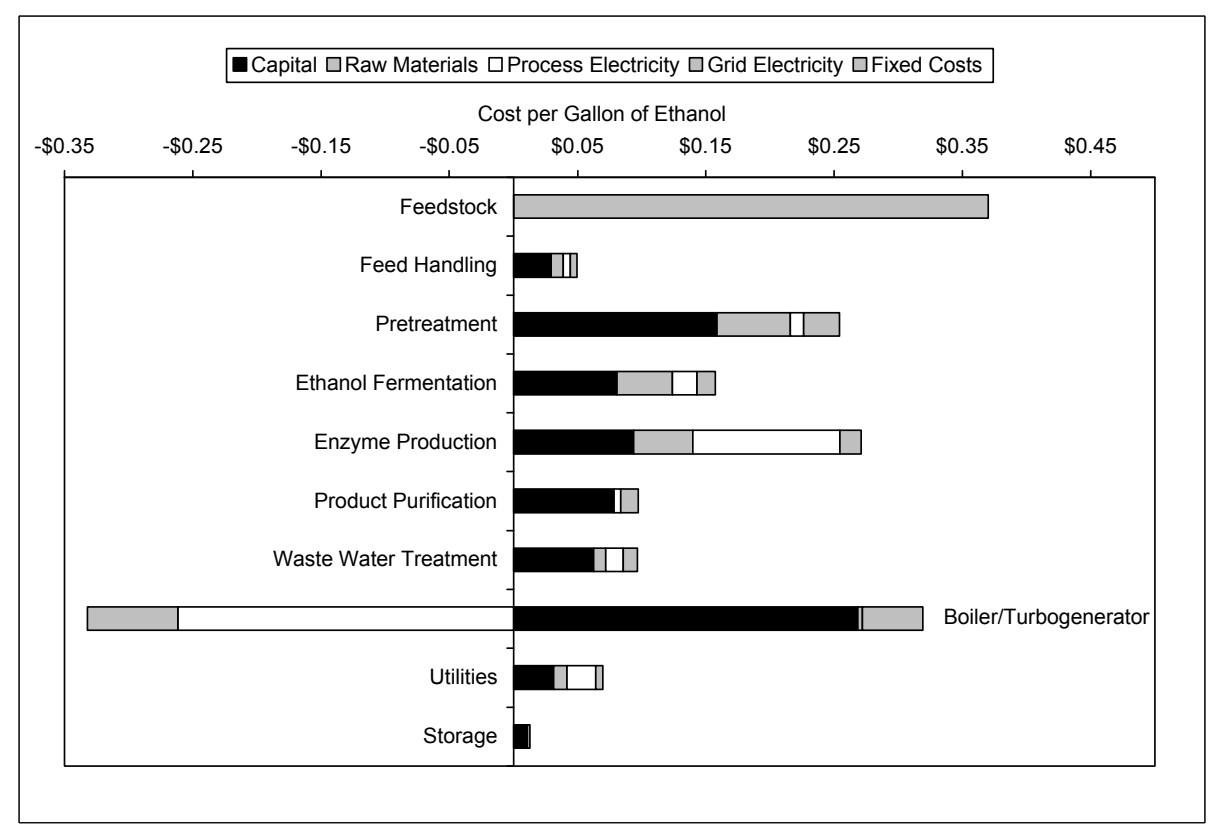

Figure 16: Cost Contribution Details From Each Process Area

\section{Futuristic Cases}

The cost of ethanol as determined in the previous section was derived using technology that has been developed or is currently close to completion. We expect that if a plant were to begin detailed engineering today, the expected costs would be as developed in Sections II and III. This cost is probably still a little high for a company to start constructing a grass roots plant based on this technology. Plants that are being engineered today all have some niche that allows them a special advantage in the short term for a small market segment. This could be feedstock costs (very low or negative for environmental wastes), used equipment (making use of related equipment that has been shut down), co-location with existing facilities (biomass burners and waste treatment facilities), or a combination of these. It is not expected that grass roots, large-scale cellulosic biomass-to-ethanol plants will be built for several more years. To help plan for those activities it is beneficial to explore the anticipated costs of producing ethanol in those out years. These futuristic costs are based on the expected results from continued research. The following sections introduce the ongoing research, its expected outcomes, and the economic result expected when that work is complete.

\section{IV.1 Future Technology Pathways for Cost Reduction}

The cost reductions shown in Figure 17 (on page 63) and discussed in the following sections for each out year case are based on the Biofuels Program's latest multi-year technical plan. The strategies for 
technology improvement as laid out in this plan are described in more detail elsewhere. ${ }^{75}$ They are described briefly here for each major aspect of the conversion technology.

\section{IV.1.1 Cellulase Enzyme Development}

Because of the importance of cellulase enzymes in the process, DOE and NREL sponsored a series of colloquies ${ }^{76}$ with experts and stakeholders in industry and academia. These dialogues were designed to determine what types of improvements in enzyme production and performance offer the greatest potential for success in the short term. There was a clear consensus in these discussions that the prospects for enzyme improvement through protein engineering are very good. We identified the following targets for protein engineering:

- Increased Thermal Stability. Simply by increasing the temperature at which these enzymes can operate, we can dramatically improve the rate of cellulose hydrolysis. The genetic pool available in our labs and in others around the world include thermotolerant, cellulase-producing organisms that represent a good starting point for engineering new enzymes.

- Improved Cellulose Binding Domain. Cellulase enzymes contain a catalytic domain and a binding domain. Improvements in the latter will lead to more efficient interaction between the soluble cellulase enzymes and the insoluble surface of the biomass.

- Improved Active Site. In addition to modifying the binding domain, we plan to modify amino acid sequences at the active site. Even minor modifications of the enzyme can lead to dramatic improvements in its catalytic activity.

- Reduced Non-Specific Binding. Enzyme that adsorbs on lignin is no longer available for hydrolysis. Genetic modifications of the enzyme will be geared toward adjusting its surface charge to minimize such unwanted binding.

We have identified two approaches for achieving these goals, both representing the state-of-the-art in biotechnology research. The first is a rational design approach known as site-directed mutagenesis. It uses sophisticated 3-D modeling tools to identify specific amino acids in the protein sequence that can affect the enzyme properties listed above. The second, more recent strategy is known among biotechnologists as "directed-evolution." It combines advanced genetic engineering techniques with highly automated laboratory robotics to randomly evolve new enzymes with the features required. The enzyme performance goals that are indicated in the future cases are based on the projected progress for these research strategies. By 2005, improvements in thermostability of the enzymes should yield a threefold improvement in specific activity. By 2010, enhancements in the cellulose binding domain, the active site, and the protein surface charge will lead to an increase in enzyme performance of ten-fold or more.

In parallel with the protein engineering work, our program plan calls for research aimed at improving the productivity of the enzyme expression systems. This includes:

- Developing microbial organisms for high productivity of enzymes

- Genetically engineered crops that contain high levels of cellulase enzymes harvested as feedstock

Developing improved organisms for enzyme production relies on industrial expertise and support, rather than on research actually carried out within the program. Higher efficiency microorganisms for use in submerged culture fermenters should be available by 2005. Work on genetically engineered crops is in the early stages of evaluation only. First, we need to establish the feasibility and potential benefits of producing enzymes in plants. 


\section{IV.1.2 Fermentation Organism Development}

Research in the past 10 years on ethanol-producing microorganisms has yielded microorganisms capable of converting hexose and pentose sugars to ethanol. These ethanol-producing microorganisms ferment xylose and glucose mixtures to ethanol with high efficiency. This represents a major advance in technology, as previous conversion of pentose sugars by natural yeasts was not industrially attractive. Furthermore, these new ethanologens have eliminated the need for separate pentose and hexose fermentation trains.

Substantial improvement in biomass conversion can be achieved by making the following additional improvements in ethanol-producing microorganisms:

- Ethanol-producing microorganisms capable of producing 5\% ethanol at temperatures greater than or equal to $50^{\circ} \mathrm{C}$

- Ethanol-producing microorganisms capable of converting cellulose to ethanol.

We have recently shown that a doubling of the rate of biomass hydrolysis for every $20^{\circ} \mathrm{C}$ increase in temperature of saccharification can be expected if $T$. reesei-like cellulases are used. The development of ethanologens capable of fermentation at temperatures greater than $50^{\circ} \mathrm{C}$ can potentially reduce the cost of cellulase enzyme by one-half. This is because the current ethanologens can only meet desired performance at temperatures of $30^{\circ}-33^{\circ} \mathrm{C}$.

The most advanced processing option is one in which all biologically mediated steps (e.g., enzyme production, enzymatic cellulose hydrolysis, and biomass sugar fermentation) occur in a single bioreactor. This process, also known as direct microbial conversion (DMC) or consolidated bioprocessing (CBP), can be carried out to various extents by a number of microorganisms, including fungi, such as Fusarium oxysporum and bacteria, such as Clostridia sp. However, known DMC strains often exhibit relatively low ethanol yields and have not yet been proven effective in handling high concentrations of biomass.

Our program plan calls for introducing a high-temperature ethanologen by 2005 . This new organism should be able to operate at $50^{\circ} \mathrm{C}$, while maintaining the best characteristics of the current ethanologens.

\section{IV.1.3 Process Development and Integration}

The cellulase enzymes and the fermenting organisms are the major thrusts of our applied research efforts. Integrating these into a complete process is critical to commercial success. Pilot and bench scale optimization of an integrated process is expected to lead to improvements such as:

- Optimal yields and operating conditions for the co-current pretreatment step

- Optimal yields and operating conditions for the simultaneous saccharification and co-fermentation step

- Testing of improved organisms and enzymes as they become available

An optimized and integrated process using cellulase enzymes and co-current pretreatment technology should be available by 2005 . 


\section{IV.1.4 Long-Term Potential for Agricultural Biotechnology}

Although still in its early stages, research on genetic engineering of agricultural crops holds great promise. We anticipate the need for a focused research effort to develop energy crops that contain higher levels of carbohydrates. Increased carbohydrate content provides a direct improvement in ethanol yield. Because the details of a research program targeted at higher carbohydrate content have not been worked out, we look at this as a long-term improvement. In our analysis, the fruits of such a research program are reflected in our year 2015 case study. 


\section{IV.2 Economics of Futuristic Cases}

Having reviewed the technology pathways for improving the production of ethanol, we can now apply those plans to the process design and economic model to quantify the expected results in the cost of ethanol. Using the model developed in the previous sections (the base case), we can make adjustments to the model to accommodate the improved technology described above. Years chosen for analysis are 2005, 2010, and 2015. Other investigators ${ }^{77}$ are exploring the costs of ethanol production in years beyond that. Table 29 summarizes the changes to key parameters in the model and the resulting cost of ethanol.

Table 29: Out Year Parameter Changes

\begin{tabular}{|c|c|c|c|c|c|c|}
\hline $\begin{array}{l}\text { Process } \\
\text { Area }\end{array}$ & Parameter & Base Case & \begin{tabular}{|l} 
Best of \\
Industry
\end{tabular} & Year 2005 & Year 2010 & Year 2015 \\
\hline Cost \$/gal & & $\$ 1.44$ & $\$ 1.16$ & $\$ 0.94$ & $\$ 0.82$ & $\$ 0.76$ \\
\hline \multirow[t]{6}{*}{ Feedstock } & Cellulose Fraction & $42.67 \%$ & $42.67 \%$ & $42.67 \%$ & $42.67 \%$ & $51.20 \%$ \\
\hline & Xylan Fraction & $19.05 \%$ & $19.05 \%$ & $19.05 \%$ & $19.05 \%$ & $22.86 \%$ \\
\hline & Arabinan Fraction & $0.79 \%$ & $0.79 \%$ & $0.79 \%$ & $0.79 \%$ & $0.95 \%$ \\
\hline & Mannan Fraction & $3.93 \%$ & $3.93 \%$ & $3.93 \%$ & $3.93 \%$ & $4.72 \%$ \\
\hline & Galactan Fraction & $0.24 \%$ & $0.24 \%$ & $0.24 \%$ & $0.24 \%$ & $0.29 \%$ \\
\hline & Lignin Fraction & $27.68 \%$ & $27.68 \%$ & $27.68 \%$ & $27.68 \%$ & $14.34 \%$ \\
\hline \multirow[t]{8}{*}{ Pretreatment } & Reactor Residence Time (min) & $10 \mathrm{~min}$ & $8 \mathrm{~min}$ & $8 \mathrm{~min}$ & $8 \mathrm{~min}$ & $8 \mathrm{~min}$ \\
\hline & Acid Concentration & $0.5 \%$ & $1.5 \%$ & $1.5 \%$ & $1.5 \%$ & $1.5 \%$ \\
\hline & Temperature $\left({ }^{\circ} \mathrm{C}\right)$ & 190 & 150 & 150 & 150 & 150 \\
\hline & Xylan to Xylose Yield & $75 \%$ & $85 \%$ & $85 \%$ & $85 \%$ & $85 \%$ \\
\hline & Mannan to Mannose Yield & $75 \%$ & $85 \%$ & $85 \%$ & $85 \%$ & $85 \%$ \\
\hline & Galactan to Galactose Yield & $75 \%$ & $85 \%$ & $85 \%$ & $85 \%$ & $85 \%$ \\
\hline & Arabinan to Arabinose Yield & $75 \%$ & $85 \%$ & $85 \%$ & $85 \%$ & $85 \%$ \\
\hline & Type of Conditioning & IX/OL & $\mathrm{IX} / \mathrm{OL}$ & OL only & OL only & OL only \\
\hline \multirow[t]{4}{*}{ Enzy. Prod. } & Enzyme Loading for SSCF & $15 \mathrm{FPU} / \mathrm{g}$ & $15 \mathrm{FPU} / \mathrm{g}$ & $15 \mathrm{FPU} / \mathrm{g}$ & $20 \mathrm{FPU} / \mathrm{g}$ & $20 \mathrm{FPU} / \mathrm{g}$ \\
\hline & Yield (FPU/g Cellulose+Xylose) & 200 & 200 & 600 & 2000 & 2000 \\
\hline & Productivity (FPU / L • hr) & 75 & 200 & 600 & 2000 & 2000 \\
\hline & Aeration (VVM) & 0.577 & 0.577 & 0.29 & 0.29 & 0.29 \\
\hline \multirow[t]{10}{*}{\begin{tabular}{|l|l|} 
SSCF \\
\end{tabular}} & Residence Time & 7 days & 7 days & 3.5 days & 2 days & 2 days \\
\hline & Cellulose to Glucose Yield & $80 \%$ & $80 \%$ & $80 \%$ & $90 \%$ & $90 \%$ \\
\hline & Glucose to Ethanol Yield & $92 \%$ & $92 \%$ & $92 \%$ & $95 \%$ & $95 \%$ \\
\hline & Xylose to Ethanol Yield & $85 \%$ & $85 \%$ & $85 \%$ & $95 \%$ & $95 \%$ \\
\hline & Arabinose to Ethanol Yield & $0 \%$ & $85 \%$ & $85 \%$ & $95 \%$ & $95 \%$ \\
\hline & Galactose to Ethanol Yield & $0 \%$ & $90 \%$ & $90 \%$ & $95 \%$ & $95 \%$ \\
\hline & Mannose to Ethanol Yield & $0 \%$ & $90 \%$ & $90 \%$ & $95 \%$ & $95 \%$ \\
\hline & Temperature $\left({ }^{\circ} \mathrm{C}\right)$ & 30 & 30 & 55 & 55 & 55 \\
\hline & Chilled Water Fraction & $20 \%$ & $20 \%$ & $0 \%$ & $0 \%$ & $0 \%$ \\
\hline & Contamination Loss & $7 \%$ & $7 \%$ & $5 \%$ & $3 \%$ & $3 \%$ \\
\hline \multirow[t]{3}{*}{ Utilities } & Biomass to Burn Flow (dry $\mathrm{kg} / \mathrm{hr}$ ) & 0 & 0 & 0 & 0 & 11,000 \\
\hline & Biomass to Burn (dry ton/day) & 0 & 0 & 0 & 0 & 275 \\
\hline & On-line Time (hr/yr) & 8,406 & 8,406 & 8,406 & 8,406 & 8,478 \\
\hline
\end{tabular}




\section{IV.2.1 Near-Term, Best of Industry}

Technologies in addition to that developed by NREL are available to the project developer. Specifically, it is thought that pretreatment can produce higher conversions of hemicellulosic sugars ${ }^{78}$ and that the current cellulase industry could provide a microorganism to produce the enzyme more efficiently ${ }^{76}$. Also, it is known that there are other ethanologens ${ }^{79}$ that will ferment the other hemicellulose sugars (arabinose, galactose, and mannose) to sugar. These improvements have been incorporated into the model (see Table $29)$. The result of this scenario is a reduction in the cost of ethanol production to $\$ 1.16 /$ gal (+\$0.15/$\$ 0.06)$.

Table 30: Near Term, Best of Industry Improvements from Base Case

\begin{tabular}{|l|l|}
\hline Production Cost of Ethanol Reduced & from $\$ 1.44 /$ gal to $\$ 1.16 /$ gal $(+\$ 0.15 /-\$ 0.06)$ \\
\hline Yield Increased & $12 \%$ to 76 gal/ton \\
\hline Production Increased & $12 \%$ to $58.8 \mathrm{MM}$ gal/yr \\
\hline Capital Reduced & $12 \%$ to $\$ 205 \mathrm{MM}$ \\
\hline $\begin{array}{l}\text { Note: } 1997 \$ \\
\text { Model: R9906B }\end{array}$ \\
\hline
\end{tabular}

\section{IV.2.2 Future Case, Year 2005}

We expect that continued research in the pretreatment area (A200) will lead to higher yields of xylose (hydrolysis of hemicellulose). This will be accomplished with lower temperatures, shorter residence times, and higher acid concentrations and will reduce the capital cost of the pretreatment reactors. We also anticipate that adapting the fermenting organism to function in the untreated hydrolyzate will eliminate the need for ion exchange removal of acetic acid. This will further reduce the capital by eliminating ion exchange and liquid/solid separating equipment.

In the fermentation area, we expect that the fermenting organism will be able to withstand a higher temperature. This will lead to increased fermenting kinetics, but more importantly increased enzymatic saccharification kinetics. These faster kinetics will reduce the SSCF residence time, reducing capital costs. This higher temperature will also reduce the contamination, as fewer competing organisms will be able to survive at these temperatures. Finally, the higher temperature will eliminate the need for any chilled water (currently used for part of the year) in this area. Table 31 lists the improved results in the year 2005 .

Cellulase enzyme activity in the SSCF fermenters will be improved by a factor of three times. This will reduce the need for enzyme production by that same amount, saving considerable capital. It is also expected that the new expression system used to grow the enzyme will require less air, thus reducing the need for air compression and capital cost.

The wastewater treatment area capital cost is also reduced, because ion exchange detoxification is eliminated. The ion exchange process has a large stream of organics from the regeneration of the resin. Without the ion exchange these organics ultimately end up in the syrup, which is sent to the burner and not to waste treatment. 
Table 31: Year 2005 Improvements from Best of Industry

\begin{tabular}{|l|l|}
\hline Production Cost of Ethanol Reduced & from \$1.16/gal to \$0.94/gal \\
\hline Yield Increased & $7 \%$ to 81 gal/ton \\
\hline Production Increased & $7 \%$ to $62.2 \mathrm{MM}$ gal/yr \\
\hline Capital Reduced & $18 \%$ to $\$ 169 \mathrm{MM}$ \\
\hline $\begin{array}{l}\text { Note: } 1997 \$ \\
\text { Model: R9906C }\end{array}$ \\
\hline
\end{tabular}

\section{IV.2.3 Future Case, Year 2010}

The overall improvements by the year 2010 are summarized in Table 32 . We expect that the yields of other hemicellulosic sugars (galactose, mannose, and arabinose) will be optimized in area A200 as a result of adjusting reactor conditions. The yield optimization will not directly affect the equipment costs.

In area (A300) an increased enzyme loading will result in a further reduction of the residence time in the SSCF fermenters. This increased enzyme load will also result in higher glucose yields. The fermenting organism will be optimized to increase the yields of ethanol and decrease contamination.

The cellulase enzyme activity will continue to be improved with a ten-fold improvement over that used in the base case. With such greater enzyme activities and subsequent reductions in the per gram cost of enzyme protein, it will be economical to increase the enzyme loading in the SSCF reactor to increase the conversion of cellulose to glucose.

At this point, the amount of boiler fuel is insufficient to meet the steam and electric demands of the process. Steam must be throttled from higher pressures to satisfy the heat demands of the process, lowering the amount of electricity produced. This is done rather than purchasing ancillary fuel to satisfy the steam demand and generating more excess electricity.

Table 32: Year 2010 Improvements from Year 2005 Case

\begin{tabular}{|l|l|}
\hline Production Cost of Ethanol Reduced & from $\$ 0.94 /$ gal to $\$ 0.82 /$ gal \\
\hline Yield Increased & $16 \%$ to 94 gal/ton \\
\hline Production Increased & $16 \%$ to $72.2 \mathrm{MM}$ gal $/ \mathrm{yr}$ \\
\hline Capital Reduced & $8 \%$ to $\$ 156 \mathrm{MM}$ \\
\hline $\begin{array}{l}\text { Note: } 1997 \$ \\
\text { Model: R9906D }\end{array}$ \\
\hline
\end{tabular}

\section{IV.2.4 Future Case, Year 2015}

By this time frame, we anticipate that the impacts of plant biotechnology improvements to the feedstock will begin to be realized. We are using a $20 \%$ carbohydrate increase as a model for the improvements achieved. As in the 2010 case, when more of the feedstock is converted to ethanol less boiler fuel will be available. In this case more biomass feedstock will need to be supplied directly to the boiler as fuel. Again, steam is throttled from higher pressures so that no excess electricity is generated and the minimum amount of feedstock is burned in the boiler. 
Table 33: Year 2015 Improvements from Year 2015 Case

\begin{tabular}{|l|l|}
\hline Production Cost of Ethanol Reduced & from $\$ 0.82 / \mathrm{gal}$ to $\$ 0.76 / \mathrm{gal}$ \\
\hline Yield Increased (Biomass to Plant)* & $5 \%$ to $99 \mathrm{gal} /$ ton \\
\hline Yield Increased (Biomass to Ethanol) & $19 \%$ to $112 \mathrm{gal} /$ ton \\
\hline Production Increased & $21 \%$ to $87.5 \mathrm{MM} \mathrm{gal} / \mathrm{yr}$ \\
\hline Capital Reduced & $-2 \%$ to $\$ 159 \mathrm{MM}$ \\
\hline $\begin{array}{l}\text { Note: } 1997 \$ \\
\text { Model: R9906E } \\
\text { * There is now a shortage of waste fuel for process steam and feedstock must be burned to generate } \\
\text { process steam. }\end{array}$ \\
\hline
\end{tabular}

\section{IV.3 Summary of Futuristic Cases}

The prospects for the future of producing ethanol from cellulosic biomass are very positive. Figure 17 shows the future reduction in ethanol production cost that will result from the continued research outlined in the previous sections. The cost of ethanol, with a feedstock cost of $\$ 25 /$ dry U.S. ton will be reduced from about $\$ 1.16 /$ gal (near-term best of industry) to about $\$ 0.76$ by the year 2015 - a reduction of $34 \%$. Considering only the cost of converting the biomass feedstock, the cost in the near term is about $\$ 0.83 / \mathrm{gal}$ (\$1.16/gal, less $\$ 0.33 /$ gal for the biomass feedstock). In 2015 , the cost of conversion will be only $\$ 0.51 /$ gal ( $\$ 0.76 /$ gal, less $\$ 0.25 /$ gal for the biomass feedstock).

The following figures show this reduction in cost over time. Figure 18 breaks the costs down into the contribution for capital, fixed, and operating costs.

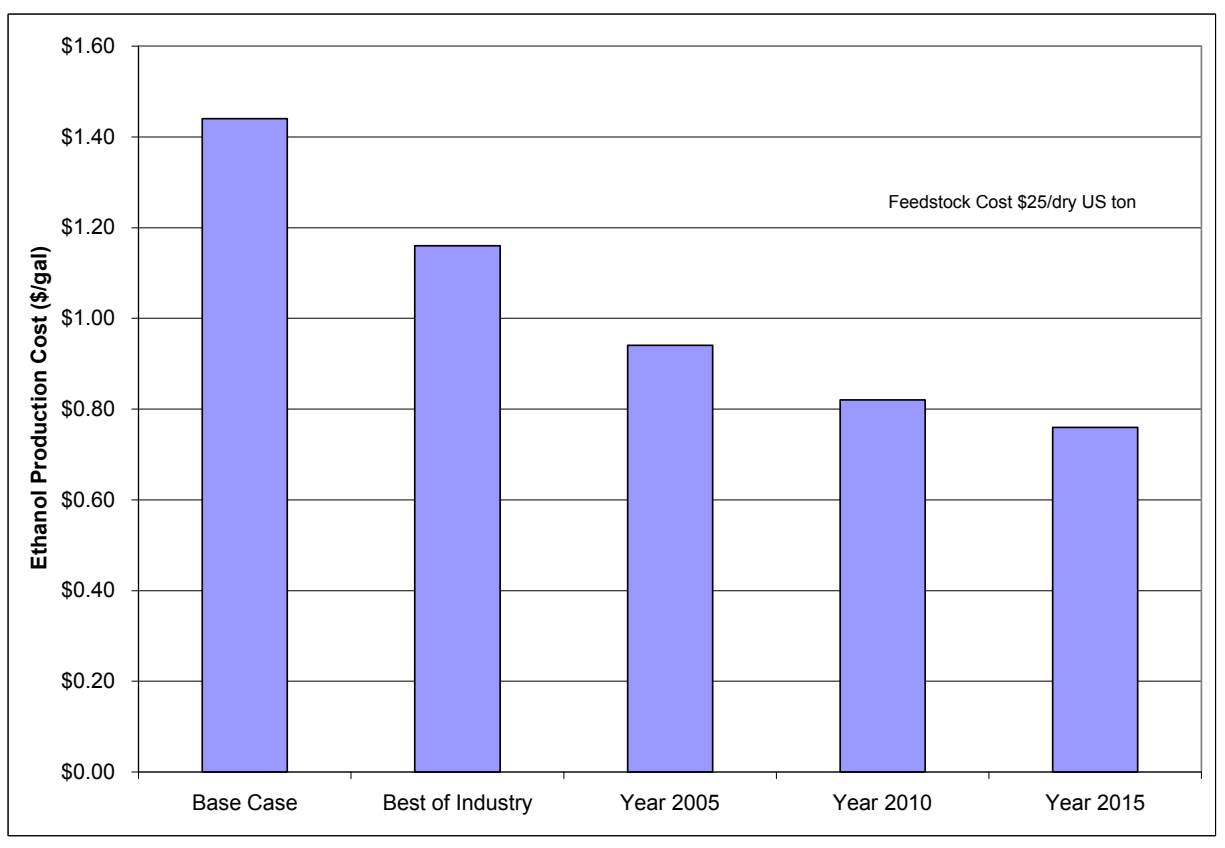

Figure 17, Future Projection of the Cost of Ethanol Production from Cellulosic Biomass 


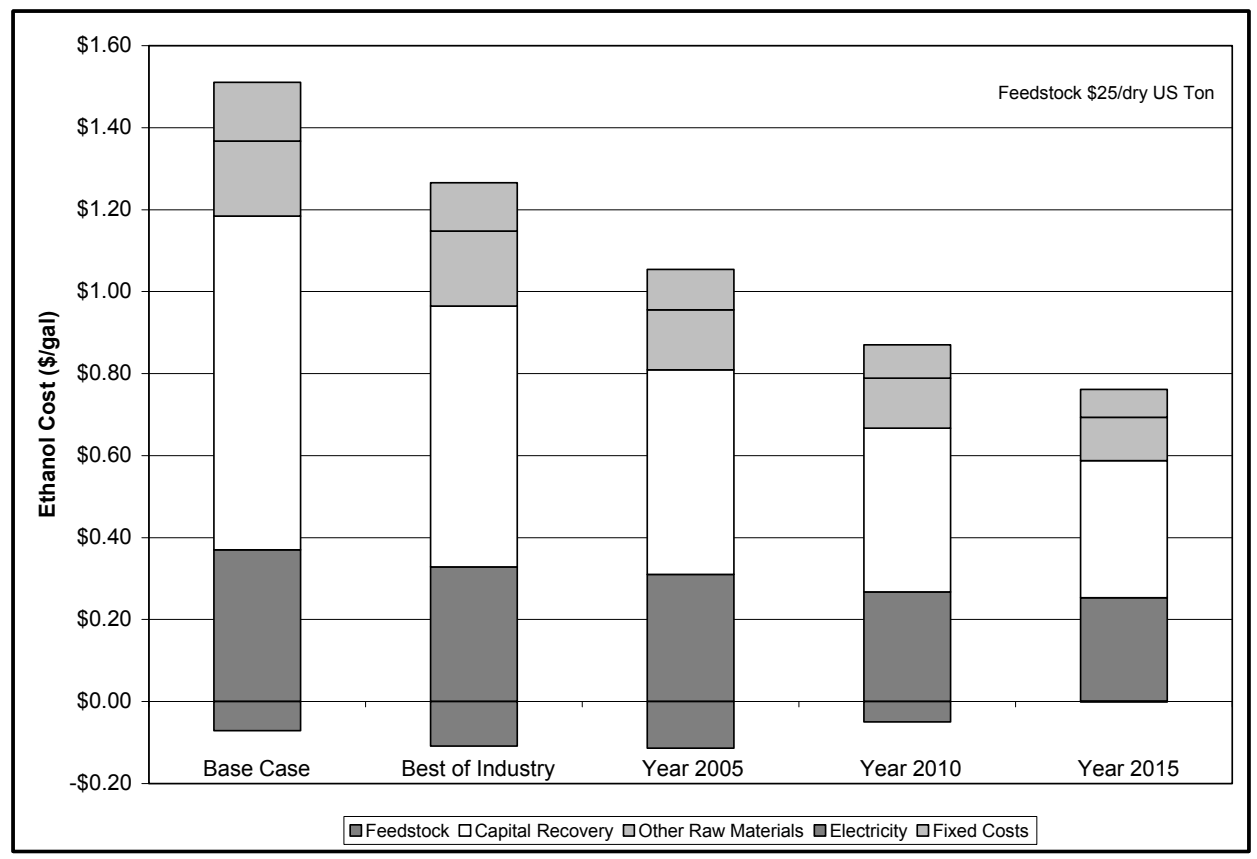

Figure 18, Cost Breakdown of Current and Future Cases

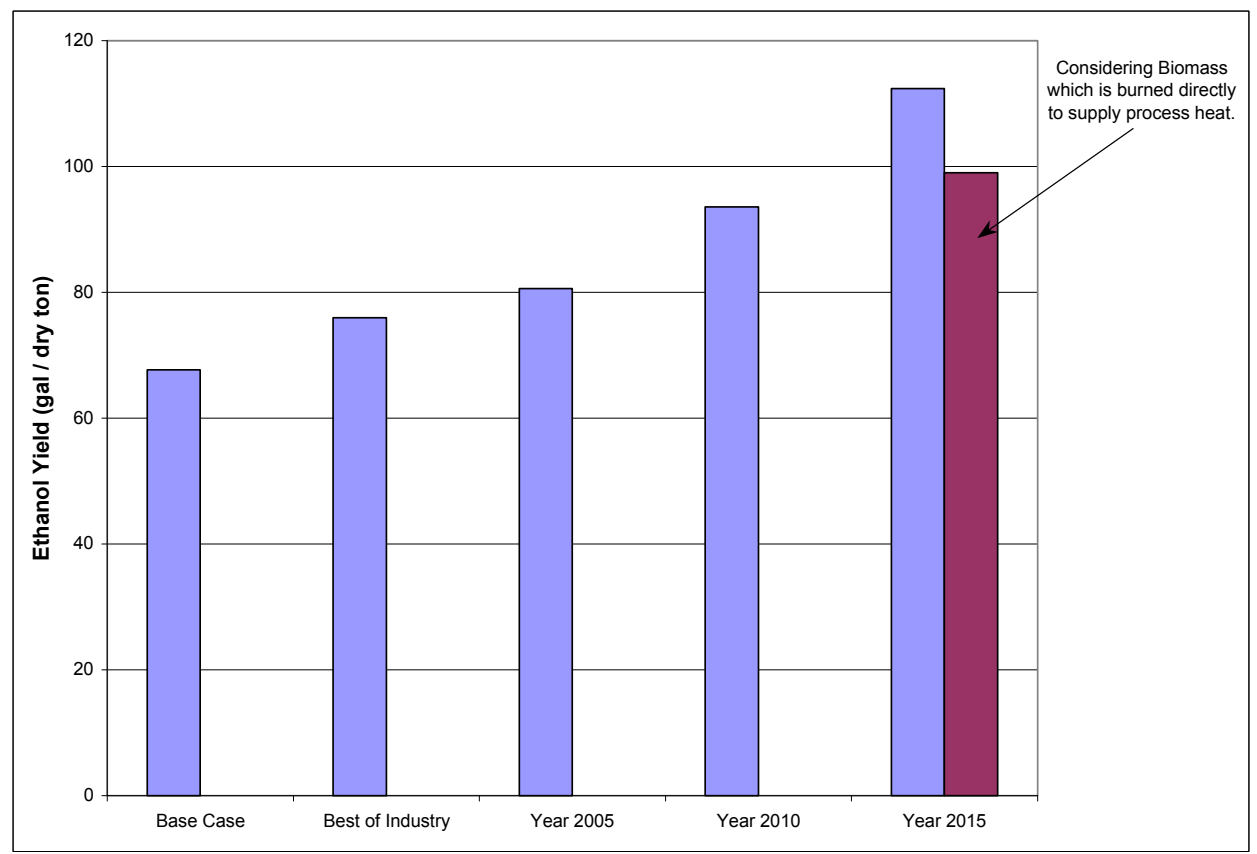

Figure 19, Ethanol Yield Improvements with Continued Development

During this time the yield of ethanol from feedstock will be increased (see Figure 19), as a result of better conversion in prehydrolysis (pretreatment), in enzymatic hydrolysis, and in actual fermentation of the 
available sugars to ethanol. Also, as the activity of the enzyme is improved, less sugars will be diverted to enzyme production. The process requires steam and electricity to operate, and the fuel to generate both is generally available in the unreacted carbohydrate and lignin. When both of these are reduced, as is the case in 2015, it is possible that they can no longer meet the energy (steam and electricity) demands of the process. In this case additional fuel would be required. Because there is already a biomass burner in the plant (to burn the lignin) and because biomass is the cheapest source of energy, it could be burned directly to supply the process energy required. If this additional biomass is considered, the overall yield is lowered to about what it was in 2010.

The capital cost will be reduced as the technology is improved, as shown in Figure 18. Capital costs will be reduced by decreasing the pretreatment temperatures, removing the hydrolyzate conditioning equipment, reducing the demand for enzyme (because of its greatly increased activity), and reducing the enzyme hydrolysis time (which subsequently reduces SSCF vessel size).

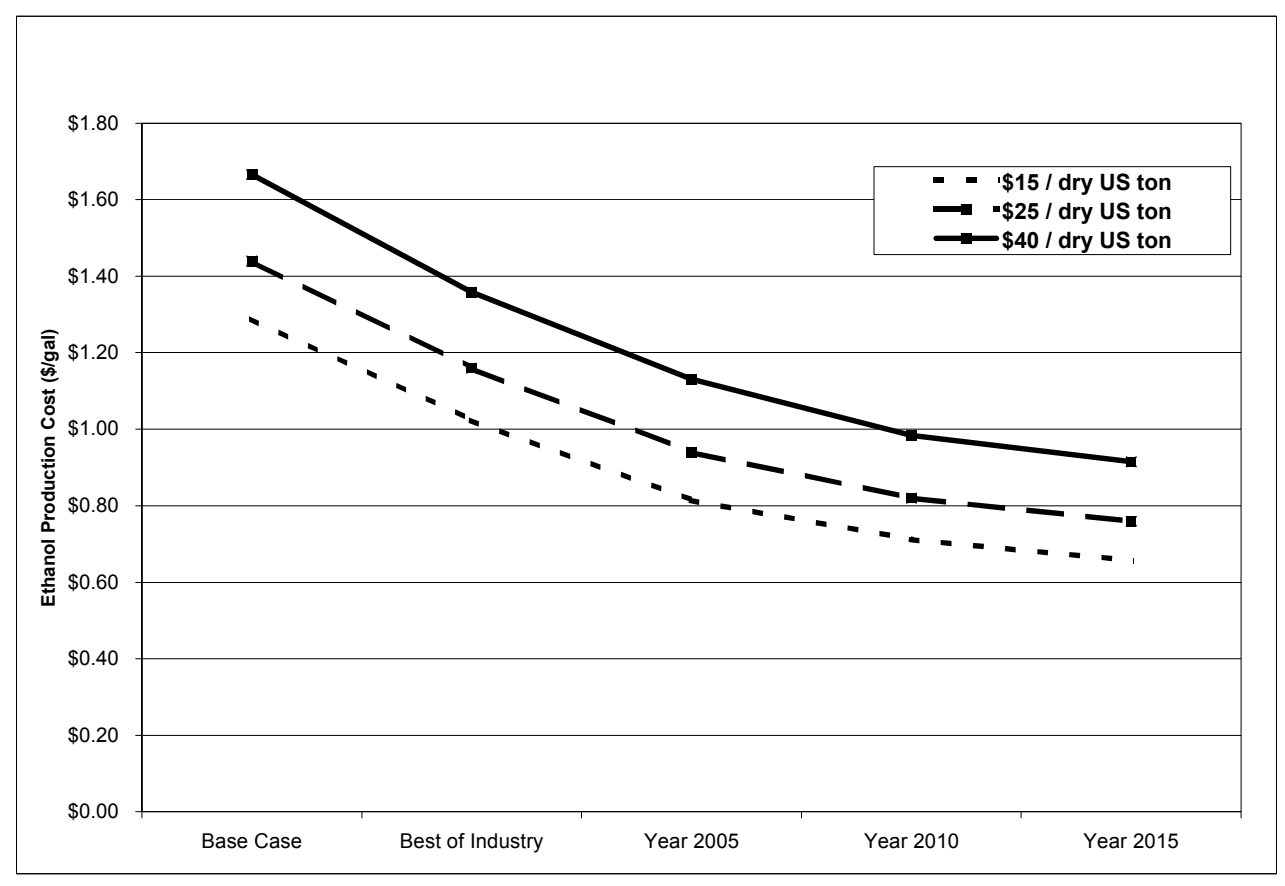

Figure 20, Future Projection of the Cost of Ethanol as a Function of Feedstock Cost

As mentioned earlier, DOE funds ORNL to project the cost of feedstocks, so only a sensitivity of the cost of ethanol to the feedstock cost will be given. Figure 20 illustrates the sensitivity of feedstock and the general reduction in the cost of ethanol production over the next several years. In the near term, at $\$ 25 /$ dry U.S. ton, the contribution to the ethanol cost from feedstock is $\$ 0.33 /$ gal. Yield improvements will reduce this cost to $\$ 0.22$ /gal by 2015 . If the feedstock is more or less expensive, the contribution to the ethanol cost will be correspondingly affected. 


\section{Improvements and Extension to the Model Planned or Currently Under Way}

The process design and economic model that we have described here is not a static tool. The information contained in the model will be continually improved, but the scope of technologies and the capabilities for calculation will also be expanded. The following gives a brief overview of the work currently going on or planned for the next year or so.

\section{V.1 Enzyme Production Optimization}

The preliminary investigation of using pure oxygen or enriched air for cellulase production was very encouraging. More work needs to be done to better determine the oxygen plant costs and to assess whether using oxygen or some oxygen mixed with air is the most cost-effective method of providing oxygen to the cellulase fermenters.

In addition, investigations will continue regarding the general design and costs of these fermenters giving consideration to the current state-of-the-art for large-scale aerobic fermentations.

\section{V.2 Pretreatment Reactor Costs}

The pretreatment reactor presents the largest uncertainty in capital costs. Delta-T had considerable difficulty obtaining quotations and assistance from vendors of this equipment. NREL plans to continue this work by developing a more detailed description of the needs and experimental work that has been performed on this equipment at NREL and elsewhere. Then, working with experienced engineers in the pulp and paper industry, we will attempt to buy design and costing information from equipment vendors. With this approach, we hope that within a year we will have better cost information on this very expensive piece of equipment.

\section{V.3 Liquid Solid Separations Costs}

Another area of concern is the liquid solid separations. Delta-T was able to get vendor quotations in this area, but the data on which those estimates were based were very minimal. NREL hopes to work with TVA and engineering firms to develop more data and subsequently more definitive cost information.

\section{V.5 Lignin Gasification and Gas Turbine Power Generation}

Another alternative to simply burning the lignin to generate steam and subsequently power generation is to gasify the lignin and use a gas turbine to generate power generation and subsequent steam generation. This technology is currently being pursued by the DOE Biomass Power Program for use on biomass feedstock. The current base case will be modified to incorporate this technology so that a comparison can be made between it and conventional lignin combustion. 
1 "Wastewater Treatment Options for the Biomass-To-Ethanol Process," NREL Subcontract AXE-818020-01, Merrick \& Company, Aurora, CO, February 24, 1998.

2 "Steam and Electricity Generation Options For the Biomass-To-Ethanol Process," NREL Subcontract ACO-8-18019-01, Reaction Engineering International, Salt Lake City, UT, March 16, 1998.

3 "Wastewater Treatment Options for the Biomass-To-Ethanol Process," NREL Subcontract AXE-818020-01 Final Report, Merrick \& Company, Aurora, CO, October 22, 1998.

4 "Energy Analysis of Biomass-to-Ethanol Processes", NREL Subcontract ACO-8-18019-01 Final Report, Reaction Engineering International, Salt Lake City, UT, February 1999.

5 ASPEN Plus ${ }^{T M}$, Release 9.2-1, Aspen Technology, Inc., Cambridge, MA, October 1995.

${ }^{6}$ Wooley, R.J. and V. Putsche, Development of an ASPEN PLUS Physical Property Database for Biofuels Components, NREL, Golden, CO, Report MP-425-20685, April 1996.

7 Garrett, D.E., Chemical Engineering Economics, Van Nostrand Reinhold, New York, 1989.

8 Graham, R.L., L. J. Allison and D.A. Becker, "The Oak Ridge Energy Crop County Level Database," December 20, 1996. Available at www.esd.ornl/bfdp/oreccl/database.html.

9 Glassner, D, J. Hettenhaus, and T. Schechinger, “Corn Stover Collection Project," in BioEnergy '98Expanding Bioenergy Partnerships: Proceedings, Volume 2, Madison, WI, pp. 1100-1110, 1998.

${ }^{10}$ This is not entirely true. In reality, a larger plant can have an effect on the market value of the feedstock in the local economy. In this analysis, some simplifying assumptions about the cost of the feedstock are made so that this market effect can be ignored.

${ }^{11}$ Partially reported as experiment 11 in Tucker, M.P., J.D. Farmer, F.A. Keller, D.J. Schell, and Q.A. Nguyen, "Comparison of Yellow Poplar Pretreatment Between NREL Digester and Sunds Hydrolyzer," Appl. Biochem. Biotechnol. 70-72:25-35. The NREL PDU run number was P960227SD and the total solids concentration was taken from measurements during the run. The carbohydrate concentrations were taken from CAT analysis \#96-042 and were corrected for hydrolysis and normalized to achieve $100 \%$ mass closure for the analysis.

${ }^{12}$ Process Plant Construction Estimating Standards, Volume 4, Process Equipment, Richardson Engineering Services, Inc., Mesa, AZ, 1993.

${ }^{13}$ Ranatunga, T.D., J. Jervis, R.F. Helm, J.D. McMillan, and C. Hatzis. "Identification of Inhibitory Components Toxic Toward Zymomonas mobilis CP4(pZB5) Xylose Fermentation," Appl. Biochem. Biotechnol. 67: 185-198, 1997.

${ }^{14}$ Ranatunga, T.D., J. Jervis, R.F. Helm, J.D. McMillan, and R.J. Wooley, "The overliming of dilute acid pretreated lignocellulosics, Part 1. The fate of inorganics, uronic acids and ether soluble organics", submitted to Enzyme and Microbial Technology, 1999.

${ }^{15}$ Partially reported as experiment 11 in Tucker, M.P., J.D. Farmer, F.A. Keller, D.J. Schell, and Q.A. Nguyen. "Comparison of Yellow Poplar Pretreatment Between NREL Digester and Sunds Hydrolyzer," Appl. Biochem. Biotechnol.70-72:25-35. The pretreatment run P960227SD (used for yields and composition) had the following conditions: $200^{\circ} \mathrm{C}, 4.6$ minute residence time, $0.33 \%$ acid concentration, $20.8 \%$ solids entering the Sunds. We believe that $190^{\circ} \mathrm{C}, 10$ minute, $0.5 \%$ acid 
conditions will result in better yields. The Sunds reactor has been pushed above $30 \%$ solids, so a solids concentration of $30.91 \%$ is used in the model.

16 Pretreatment conversions achieved in the pretreatment run P960227SD (Partially reported as experiment 11 in Tucker, M.P., J.D. Farmer, F.A. Keller, D.J. Schell, and Q.A. Nguyen. "Comparison of Yellow Poplar Pretreatment Between NREL Digester and Sunds Hydrolyzer," Appl. Biochem. Biotechnol. 70-72:25-35.). The measured conversions have been normalized so that $100 \%$ of each reactant is accounted for in the products.

${ }^{17}$ Pretreatment run P960227SD (partially reported as experiment 11 in Tucker, M.P., J.D. Farmer, F.A. Keller, D.J. Schell, and Q.A. Nguyen, 1998. "Comparison of Yellow Poplar Pretreatment Between NREL Digester and Sunds Hydrolyzer," Appl. Biochem. Biotechnol. 70-72:25-35) is the basis for the yields. However, some have changed to account for assumed near-term research improvements. See Appendix E for details.

${ }^{18}$ Hayden, J.G., and J.P. O’Connell, "A Generalized Method for Predicting Second Virial Coefficients," IEC Process. Des. Dev., 14(3), 209, 1975.

${ }^{19}$ R. Wooley, "Development of a Scaleable Detoxification Process Maximizing Fermentability," NREL Internal P-Milestone Report, June 30, 1997.

${ }^{20}$ Ranatunga, T.D., J. Jervis, R.F. Helm, J.D. McMillan, and C. Hatzis. "Identification of Inhibitory Components Toxic Toward Zymomonas mobilis CP4(pZB5) Xylose Fermentation," Appl. Biochem. Biotechnol. 67: 185-198, 1997 defines the hold time to be 30 minutes. The time is increased to $1 \mathrm{hr}$ in the model to allow for reduced heating rates and different reaction kinetics in a large continuous stirredtank reactor (CSTR).

${ }^{21} \mathrm{H}$. Majdeski, personal experience in the flue gas desulfurization industry, 1998.

${ }^{22}$ Letter to B. Bunner, Delta-T Corporation from A. Bowser, Komline-Sanderson Limited, August 1998.

${ }^{23}$ ICARUS Process Evaluator, Version 4.0, ICARUS Corporation, Rockville, MD, June 30, 1997.

${ }^{24}$ B. Platz, Sunds Defibrator, Inc., personal communication, April 1998. Results of experimental work conducted at TVA, Muscle Shoals Laboratories. Date of tests unknown.

${ }^{25}$ B. Platz, Sunds Defibrator, Inc., personal communication, August 1998.

${ }^{26}$ Zhang, M., C. Eddy, K. Deanda, M. Finkelstein, and S. Picataggio, "Metabolic Engineering of a Pentose Metabolism Pathway in Zymomonas mobilis." Science, 267:240-243, 1995.

${ }^{27}$ McMillan, J.D., M.P. Tucker, T.K. Hayward, C. Hatzis, and D. Glassner. "Process Qualifier Milestone", Internal Report, National Renewable Energy Laboratory, Golden, CO, 31 August 1996. Experiment PD 23 \#3. All SSCF data are from PD 23 \#3 except when noted. PD 23 \#3 was a batch SSCF run on pretreated yellow poplar (Pretreatment run P960227SD) that was conditioned by liquid/liquid extraction followed by overliming. It was run in a $400-\mathrm{mL}$ working volume fermenter with continuous $\mathrm{pH}$ control. Because of the small fermenter size, the effective solids concentration (initial total solids concentration) was only $14.7 \%$. It is believed that a larger fermenter with better mixing could be run with $20 \%$ effective solids.

${ }^{28}$ McMillan, J.D., M.P. Tucker, T.K. Hayward, C. Hatzis, and D. Glassner. "Process Qualifier Milestone", Internal Report, National Renewable Energy Laboratory, Golden, CO, 31 August 1996, Experiment PD 23 \#3. 
${ }^{29}$ McMillan, J.D., M.P. Tucker, T.K. Hayward, C. Hatzis, and D. Glassner. "Process Qualifier Milestone", Internal Report, National Renewable Energy Laboratory, Golden, CO, 31 August 1996, Experiment PD 23 \#3. PD 23 \#3 utilized a 24-hr residence time for seed production.

${ }^{30}$ Kern, D.Q., Process Heat Transfer, McGraw-Hill, New York, 1950, pp. 720-723.

${ }^{31}$ Full mass balances have not been attempted for conditions that favor cell growth as they would in the seed train. Therefore, the seed reaction yields were assumed to be the same as fermentation yields in SSCF (see note 26A), with increased cell mass production. Therefore the cell mass production was increased to $4 \%$ from both glucose and xylose and the xylose to products yield was reduced to allow more xylose to be converted to cell mass.

${ }^{32}$ McMillan, J.D., M.P. Tucker, T.K. Hayward, C. Hatzis, and D. Glassner. "Process Qualifier Milestone", Internal Report, National Renewable Energy Laboratory, Golden, CO, 31 August 1996, Experiment PD 23 \#3.

${ }^{33}$ McMillan, J.D., M.P. Tucker, T.K. Hayward, C. Hatzis, and D. Glassner. "Process Qualifier Milestone", Internal Report, National Renewable Energy Laboratory, Golden, CO, 31 August 1996. Experiment PD 23 \#3 was $12 \mathrm{FPU} / \mathrm{g}$ cellulose. That is much lower than has been achieved in any other experiment, so the loading used in the model was increased to $15 \mathrm{FPU} / \mathrm{g}$ cellulose.

${ }^{34}$ The CSL loading used in McMillan, J.D., M.P. Tucker, T.K. Hayward, C. Hatzis, and D. Glassner, Process Qualifier Milestone, August 31, 1996, experiment PD 23 \#3 was 1\% clarified CSL. The experiment titled Nutrient Screen \#2 for recombinant Zymo 39676pZB4L conducted by the Enzymatic Process Development (EPD) team during fiscal year 1998 showed that $0.25 \%$ CSL was as effective as $1 \%$ CSL, so $0.25 \%$ CSL is used in the model.

${ }^{35}$ McMillan, J.D., M.P. Tucker, T.K. Hayward, C. Hatzis, and D. Glassner. "Process Qualifier Milestone", Internal Report, National Renewable Energy Laboratory, Golden, CO, 31 August 1996. Experiment PD 23 \#3 is the basis for the yields. However, some have changed to account for assumed near-term research improvements. See Appendix E for details.

${ }^{36}$ A loss of $7 \%$ of the fermentable sugars to non-ethanol products, such as lactic acid, is estimated based on conversations with corn ethanol producers who indicate they are happy when contamination loss is less then 3\%. The estimated loss here is higher because of the longer fermentation residence time and the availability of a larger variety of sugars.

${ }^{37}$ Walker, L.P. and D.B. Wilson, "Enzymatic Hydrolysis of Cellulose: An Overview," Bioresource Technology 36:3-14, 1991.

${ }^{38}$ Hamilton, J., "Cellulase Production Experiment No. 36: Air/Oxygen 22 Factoral Design", Internal Report, NREL Enzymatic Process Development Team, Golden, CO, December 1998, Vessel \#3.

${ }^{39}$ Schell, D., C. Riley, P. Bergeron, and P. Walter, "Technical and Economic Analysis of an Enzymatic Hydrolysis Based Ethanol Plant - Draft”, Solar Energy Research Institute, Golden, CO, SERI Report TP-232-4295, 1991.

${ }^{40}$ K. Kadam and J. McMillan, NREL, personal conversations, June 1998.

${ }^{41}$ R. Landucci, "BEST Peripheral Module Development - Part One: Aeration and Agitation for Aerobic Fermentations", Internal Report, National Renewable Energy Laboratory, Golden, CO, undated. States that the Henry's law coefficient is approximately $1 \mathrm{~atm} /($

is $1 \mathrm{~atm} /(\mathrm{mmol} / \mathrm{L})$ at $13^{\circ} \mathrm{C}$ in pure water and $1.3 \mathrm{~atm} /(\mathrm{mmol} / \mathrm{L})$ 
at $25^{\circ} \mathrm{C}$. Solubility may be affected by the non-water components in the broth, so using a Henry's coefficient of 1 is a reasonable initial estimate.

42 Perry, R.H. and D. Green, eds., Perry's Chemical Engineers' Handbook, Sixth Edition, McGraw-Hill Book Company, New York, Equation 18-142, 1984.

${ }^{43}$ Bailey, J.E. and D. F. Ollis, Biochemical Engineering Fundamentals, McGraw-Hill Book Company, New York, Equation 8.71, 1986.

44 Kern, D.K., Process Heat Transfer, McGraw-Hill Book Company, New York, p. 722-726, 1950.

${ }^{45}$ McMaster-Carr Supply Company, Catalog 102, New Brunswick, NJ, p. 1266, 1996.

46 “ASPEN Plus ${ }^{\mathrm{TM}}$, Reference Manual-Volume 2, Physical Property Methods and Models," Release 9.3, Aspen Technology, Inc., Cambridge, MA, 1996.

${ }^{47}$ Renon, H., and J.M. Praustniz, "Local Composition in Thermodynamic Excess Functions for Liquid AIChE J., 14(1), 135, 1968.

48 “ASPEN Plus TM, Reference Manual-Volume 3, Physical Property Data,"Release 9.3, Aspen Technology, Inc., Cambridge, MA, 1996.

${ }^{49}$ Aersten, F., and G. Street, Applied Chemical Process Design, Plenum Press, New York, 1978.

50 "Biomass-To-Ethanol Total Energy Cycle Analysis", NREL Subcontract RCN 213-185-01-00 Final Report, Radian Corporation, Austin, TX, November 22, 1991.

51 Fluidized Bed Combustion and Gasification: A Guide for Biomass Waste Users, Southeastern Regional Biomass Energy Program, FBT, Inc and Tennessee Valley Authority, Muscle Shoals, AL, July 1994.

52 "Economic Feasibility Study of an Acid Hydrolysis-Based Ethanol Plant", NREL subcontract ZX-303096-2 Final Report, Badger Engineers, Inc., Cambridge, MA, April, 1987.

53 “ASPEN Modeling of the NREL Boiler/Turbogenerator Systems", NREL Consultant Agreement CXL8-18051-01, Final Report, V. Putsche, February 1998.

${ }^{54}$ Babcock \& Wilcox, 1978. Steam: It's Generation and Use Thirty-ninth Edition. Babcock \& Wilcox Company, New York, NY, p. 34/10-16.

${ }^{55}$ Phillippek, C. et al, 1997. " $\mathrm{NO}_{\mathrm{x}}$ Formation and Reduction During Combustion of Wet Sewage Sludge in the Circulating Fluidized Bed”, 1997 Fluidized Bed Combustion vol. 2, ASME 1997.

${ }^{56}$ Amos, W. , "Report on Biomass Drying Technology”, NREL Report NREL. TP-570-25885, November 1998, p. 20.

57 Process Plant Construction Estimating Standards, electronic version section 100-374, Richardson Engineering Services, Inc., Mesa, AZ, 1999.

58 "Biomass to Ethanol Process Evaluation", NREL Final Subcontract Report, Chem Systems, Tarrytown, NY, Appendix V, December 1994

59 W. Campbell, Foster Wheeler Corporation, Cost Quotation, Proposal 0-02-43731, to V. Putsche, NREL, September 30, 1994.

60 "Technical and Economic Evaluation: Wood to Ethanol Process", SERI Subcontract Report, Chem Systems, Tarrytown, NY, August, 1990. 
${ }^{61}$ Sheehan, J., "Analysis of Regional Conditions for Cooling Water Used in Ethanol Production , Internal Process Engineering Team Report, National Renewable Energy Laboratory, Golden, CO, January 26, 1998.

${ }^{62}$ Peters, M.S. and K.D. Timmerhaus, Plant Design and Economics for Chemical Engineers, 4th Edition, McGraw-Hill, Inc., New York, 1991.

63 "Biomass to Ethanol Process Evaluation", NREL Final Subcontract Report, Chem Systems, Tarrytown, NY, December 1994.

${ }^{64}$ Walas, S. M., Chemical Process Equipment Selection and Design, Butterworth Publishing, 1988.

${ }^{65}$ Energy Information Administration, Annual Energy Outlook 1999 with Projections to 2020. U.S. Department of Energy, Washington, DC, 1999.

66 “Chemical Engineering Plant Cost Index," Chemical Engineering, May 1997.

67 "Biomass to Ethanol Process Evaluation", NREL Final Subcontract Report, Chem Systems, Tarrytown, NY, p. VI-3, December 1994.

68 "U.S. Producer Price Indexes - Chemicals and Allied Products/Industrial Inorganic Chemicals Index," from the Chemical Economics Handbook, published by SRI Consulting, a division of SRI International, Menlo Park, CA, October 1997.

${ }^{69}$ Bureau of Labor Statistics Data Web site (www.stats.bls.gov), National Employment, Hours, and Earnings Catalog, Industry: Chemicals and Allied Products. Series ID: EEU32280006, Years: 1980 1996, annual average. Data extracted on December 29, 1997.

${ }^{70}$ Short, W., D.J. Packey, and T. Holt, "A Manual for the Economic Evaluation and Energy Efficiency and Renewable Energy Technologies", National Renewable Energy Laboratory, Golden, CO, Report TP-462-5173, p.7, March 1995.

${ }^{71}$ Short, W., D.J. Packey, and T. Holt, "A Manual for the Economic Evaluation and Energy Efficiency and Renewable Energy Technologies", National Renewable Energy Laboratory, Golden, CO, Report TP-462-5173, p. 19, March 1995.

72 Short, W., D.J. Packey, and T. Holt, “A Manual for the Economic Evaluation and Energy Efficiency and Renewable Energy Technologies", National Renewable Energy Laboratory, Golden, CO, Report TP-462-5173, pp. 20-21, March 1995.

${ }^{73}$ Perry, R. H., and D. W. Green, Perry's Chemical Engineers' Handbook, 7th Edition, McGraw-Hill, New York, pp. 9-76, 1997.

${ }^{74}$ Gary, J. H., and G. E. Handwerk, Petroleum Refining, Technology and Economics, 3rd Edition, Marcel Dekker, Inc., New York, 1994.

75 "Bioethanol Strategic Roadmap: A Planning Framework for Development of Biomass-to-Ethanol Technology", NREL, prepared for the Office of Fuels Development, Office of Transportation Technologies, U.S. DOE, Golden, CO, December 1998.

${ }^{76}$ Hettenhaus, J. and D. Glassner, "Enzyme Hydrolysis of Cellulose: Short Term Commercialization Prospects for Conversion of Lignocellulosics to Ethanol", Internal Report, National Renewable Energy Laboratory, Golden, CO, 1997. 
77 "Design, Analysis and Evaluation of Advanced Ethanol Production Technology with Comparison to other Alternative Fuels," NREL Subcontract XCG-8-18024-01, Dartmouth College, Hanover, NH, March 20, 1998, future work.

${ }^{78}$ R. Katzen, personal communication, January 1998.

${ }^{79}$ Ingram, L.O., T. Conway, D.P. Clark, G.W. Sewell, and J.F. Preston, "Genetic Engineering of Ethanol Production in Escherichia coli," Applied and Environmental Microbiology, Vol. 53, No. 10, 1987, pp 2420-2425. US Patent 5,000,000, "Ethanol production by Escherichia coli strains co-expressing Zymomonas PDC and ADH Genes,", Ingram, L.O., T. Conway, and F. Alterthum, issued March 19, 1991. 


\section{Appendix A}

\section{NREL Biofuels Process Design Database Description and Summary}


NREL's Process Engineering Team has developed a database of primary information on all of the equipment in the near term base case model. This database contains information about the cost, reference year, scaling factor, scaling characteristic, design information and back-up cost referencing. The information is stored in a secure database in the Alternative Fuels Data Center and can be directly linked to the economic portion of the model. In addition to having all of the cost information used by the model, it has the ability to store documents pertaining to the piece of equipment. These include sizing and costing calculations and vendor information when available.

The following summarizes the important fields of information contained in the database. A partial listing of the information is attached for each piece of equipment. Addition information from the database is contained in the equipment cost listing in Appendix B.

Equipment Number: ${ }^{\mathrm{AB}} \quad$ Unique identifier, the first letter indicates the equipment type and the first number represents the process area, e.g., P-301 is a pump in Area 300

Equipment Name: ${ }^{\mathrm{AB}}$ Descriptive Name of the piece of Equipment

Associated PFD: PFD number on which the piece of equipment appears, e.g., PFD-P100-A101

Equipment Category: ${ }^{\mathrm{A}}$ Code indicating the general type of equipment, e.g., PUMP

Equipment Type: ${ }^{\mathrm{A}}$ Code indicating the specific type of equipment, e.g., CENTRIFUGAL for a pump

Equipment Description: ${ }^{\mathrm{A}}$ Short description of the size or characteristics of the piece of equipment, e.g., 20 gpm, $82 \mathrm{ft}$ head, for a pump.

Number Required: ${ }^{\mathrm{B}}$ Number of duplicate pieces of equipment needed.

Number Spares: ${ }^{\mathrm{B}}$ Number of on-line spares.

Scaling Stream: Stream number or other characteristic variable from the ASPEN model by which

Base Cost: ${ }^{\mathrm{B}}$ the equipment cost will be scaled.

Cost Basis: ${ }^{\mathrm{A}}$ Equipment cost.

Cost Year: ${ }^{\mathrm{B}}$ Source of the equipment cost, e.g., ICARUS or VENDOR. Year for which the cost estimate is based.

Base for Scaling:

Base Type:

Base Units:

Installation Factor: ${ }^{\mathrm{B}}$ Value of the scaling stream or variable for which the equipment is based. Type of variable used for scaling, e.g., FLOW, DUTY, etc. Units of the scaling stream or variable, e.g., $\mathrm{KG} / \mathrm{HR}, \mathrm{CAL} / \mathrm{S}$.

Installation Factor Basis: ${ }^{\mathrm{A}}$ Source of installation factor value, e.g., ICARUS, VENDOR.

Scale Factor Exponent: ${ }^{\mathrm{B}} \quad$ Value for exponential scaling equation

Scale Factor Basis: ${ }^{\text {A }} \quad$ Source of scaling exponent value, e.g., GARRETT, VENDOR

Material of Construction: ${ }^{\mathrm{A}}$ Material of construction

Notes:

Any other important information about the design or cost.

Document: Complete, multi-page document containing design calculations, vendor literature and quotations and any other important information. This is stored as an electronic document and can be pages from a spreadsheet, other electronic sources or scanned information from vendors.

Design Date: Modified Date: Original date for the design of this piece of equipment. The system automatically marks the date in this field whenever a field is changed.

A These fields are listed for all pieces of equipment in this Appendix.

${ }^{B}$ These fields are part of the equipment cost listing in Appendix B. 


\begin{tabular}{|c|c|c|c|c|c|c|c|c|}
\hline & Eq. Category & Eq. Type & Equipment Description & Cost Basis & Install. Fact. Basis & Scale Fact. Basis & Material Const. \\
\hline \multirow{2}{*}{\multicolumn{9}{|c|}{ 24" $\times 44^{\prime \prime}$ electromechanical feeder. Rated at $175 \mathrm{TPH}$ for $50 \mathrm{lb} / \mathrm{cf}$ coal. }} \\
\hline & & CONVEYOR & VIBRATING-FEEDER & $24^{\prime \prime} \times 42^{\prime \prime}$ electromechanical feeder. Rated at $175 \mathrm{TPH}$ for $50 \mathrm{lb} / \mathrm{b}$ c coal. & RICHARDSON & DELTA-T98 & GARRETT & CS \\
\hline C-102 & Transfer Belt Conveyor & CONVEYOR & BELT & Inclined Belt Conveyor, $210 \mathrm{ft}$ long, 36 " wide, fully covered. & VENDOR & DELTA-T98 & GARRETT & CS \\
\hline C-103 & Radial Stacker Conveyor & CONVEYOR & BELT & Radial stacking conveyor, $150 \mathrm{ft}$ long, $36^{\prime \prime}$ wide, $125 \mathrm{ft}$ covered. & VENDOR & DELTA-T98 & GARRETT & CS \\
\hline C-104 & Reclaim Hopper Feeder & CONVEYOR & VIBRATING-FEEDER & $24^{\prime \prime} \times 42^{\prime \prime}$ electromechanical feeder. Rated at $175 \mathrm{TPH}$ for $50 \mathrm{lb} / \mathrm{bf}$ coal. & RICHARDSON & DELTA-T98 & GARRETT & CS \\
\hline C-105 & Reclaim Hopper Conveyor & CONVEYOR & BELT & Overhead belt conveyor, $450^{\prime}$ long, $36^{\prime \prime}$ wide. & VENDOR & DELTA-T98 & GARRETT & CS \\
\hline C-106 & Chip Washer Feeder & CONVEYOR & VIBRATING-FEEDER & $18^{\prime \prime} \times 30^{\prime \prime}$ electromechanical feeder. Rated at $100 \mathrm{TPH}$ for $50 \mathrm{lb} / \mathrm{bf}$ coal. & RICHARDSON & DELTA-T98 & GARRETT & CS \\
\hline C-107 & Scalper Screen Feeder & CONVEYOR & BELT & 42" horizontal drag chain conveyor. Capacity of $4800 \mathrm{tpd}$. & VENDOR & DELTA-T98 & GARRETT & CS \\
\hline C-108 & Pretreatment Feeder & CONVEYOR & BELT & Consists of two parts, a 18 " $\times 42$ " inclined chain belt and a $42 "$ horizontal unit. & VENDOR & DELTA-T98 & GARRETT & CS \\
\hline M-101 & Hydraulic Truck Dump with Scale & SCALE & TRUCK-SCALE & Hydraulic Truck Dumper with Scale & VENDOR & DELTA-T98 & DEFAULT & CS \\
\hline M-103 & Front End Loaders & VEHICLE & LOADER & Used diesel front end loaders. & DELTA-T98 & UNKNOWN & & \\
\hline M-104 & Disk Refiner System & SIZE-REDUCTION & & Disk type chip shredder, $50 "$ disk, capacity of 400-500 ODT/D. Includes chip surge bins and discharger. & VENDOR & DELTA-T98 & GARRETT & SS316 \\
\hline S-101 & Magnetic Separator & SEPARATOR & MAGNET & Tramp iron magnet separator. & VENDOR & DELTA-T98 & DEFAULT & \\
\hline S-102 & Scalper Screener & SEPARATOR & SCREEN & Screener removing gross oversize material. & VENDOR & DELTA-T98 & GARRETT & CS \\
\hline S-103 & Chip Thickness Screen & SEPARATOR & SCREEN & Screen for chip thickness. & VENDOR & DELTA-T98 & GARRETT & CS \\
\hline $\mathrm{T}-101$ & Dump Hopper & TANK & VERTICAL-VESSEL & $20^{\prime} \times 20^{\prime}$ Bin, Tapering to $3^{\prime} \times 3^{\prime}$ at Bottom. Capacity 6345 cf, two truck loads. & DELTA-T98 & DELTA-T98 & GARRETT & CS \\
\hline $\mathrm{T}-102$ & Reclaim Hopper & TANK & VERTICAL-VESSEL & $20^{\prime} \times 20^{\prime}$ bin tapering to $3^{\prime} \times 3^{\prime}$. Capacity $6345 \mathrm{cf}$, for a combined total of 1 hour residence time. & DELTA-T98 & DELTA-T98 & GARRETT & CS \\
\hline $\mathrm{T}-103$ & Washing/Refining Surge Bin & TANK & VERTICAL-VESSEL & $20^{\prime} \times 20^{\prime}$ bin tapering to $3^{\prime} \times 3^{\prime}$. Capacity of 8745 cf each for a residence time of 4 hours. & DELTA-T98 & DELTA-T98 & GARRETT & Cs \\
\hline $\mathrm{W}-101$ & Chip Washer System & SEPARATOR & MISCELLANEOUS & Capacity 500 to $600 \mathrm{ODT} / \mathrm{d}$. Scrap separator, screw drainer, circulation pump and cyclone separator. & VENDDOR & DELTA-T98 & NREL-ESTM & ss304;SS316 \\
\hline \multicolumn{9}{|c|}{ PFD-P100-A201,2,3 } \\
\hline $\mathrm{A}-201$ & In-line Sulfuric Acid Mixer & MIXER & STATIC & Static Mixer, $248 \mathrm{gpm}$ total flow. & ICARUS & DELTA-T98 & ICARUS & SS304 \\
\hline $\mathrm{A}-202$ & In-line NH3 Mixer & MIXER & STATIC & Static Mixer, $240 \mathrm{gpm}$ total flow & ICARUS & DELTA-T98 & ICARUS & SS304 \\
\hline $\mathrm{A}-209$ & Overliming Tank Agitator & AGITATOR & FIXED-PROP & Top Mounted, $1800 \mathrm{rpm}, 25 \mathrm{hp}$ & ICARUS & DELTA-T98 & GARRETT & ss \\
\hline $\mathrm{A}-224$ & Reacidification Tank Agitator & AGITATOR & FIXED-PROP & Top-Mounted, $1800 \mathrm{rpm}, 93 \mathrm{hp}$ & ICARUS & DELTA-T98 & GARRETT & ss \\
\hline $\mathrm{A}-232$ & Reslurrying Tank Agitator & AGITATOR & FIXED-PROP & Top-Mounted, $1800 \mathrm{rpm}, 50 \mathrm{hp}$ & ICARUS & DELTA-T98 & GARRETT & ss \\
\hline $\mathrm{A}-235$ & In-line Acidification Mixer & MIXER & STATIC & Static-Mixer, $720 \mathrm{gpm}$ total flow & ICARUS & \begin{tabular}{|l|} 
DELTA-T98 \\
\end{tabular} & NREL-ESTM & $304 \mathrm{SS}$ \\
\hline C-201 & Hydrolyzate Screw Conveyor & CONVEYOR & SCREW & 18" dia. X $33^{\prime}$ long, 7600 cfh max flow & ICARUS & DELTA-T98 & GARRETT & ss316 \\
\hline C-202 & Wash Solids Screw Conveyor & CONVEYOR & SCREW & 18" dia. X $16^{\prime}$ long, 7600 cfh max flow & ICARUS & ICARUS & MULTI-UNIT & SS304 \\
\hline $\mathrm{C}-225$ & Lime Solids Feeder & CONVEYOR & ROTARY-VALVE & 8" dia., $140 \mathrm{cfh}, 7000 \mathrm{lb} / \mathrm{hr}$ max flow & ICARUS & DELTA-T98 & & A285C \\
\hline $\mathrm{H}-200$ & Hydrolyzate Cooler & HEATX & SHELL-TUBE & Fixed Tube Sheet,1990 sf, 27" dia. X 20' long & ICARUS & DELTA-T98 & GARRETT & $304 \mathrm{SS} ; \mathrm{CS}$ \\
\hline $\mathrm{H}-201$ & Beer Column Feed Economizer & HEATX & SHELL-TUBE & Floating Head, 6266 sf, $48^{\prime \prime}$ dia x 23' long & ICARUS & DELTA-T98 & GARRETT & $304 \mathrm{SS}$ \\
\hline $\mathrm{M}-202$ & Prehydrolysis Reactor System & REACTOR & SCREW & Vertical Screw, 10 min residence time & VENDOR & CHEMSYST94 & GARRETT & HASTELLOY-C 200;SS316L \\
\hline $\mathrm{P}-201$ & Sulfuric Acid Pump & PUMPP & CENTRIFUGAL & $4 \mathrm{gpm}, 245 \mathrm{ft}$. head & ICARUS & \begin{tabular}{|l|l|} 
DELTA-T98 \\
\end{tabular} & GARRETT & Ss304 \\
\hline $\mathrm{P}-209$ & Overlimed Hydrolyzate Pump & PUMP & CENTRIFUGAL & $687 \mathrm{gpm}, 150 \mathrm{ft}$. head & ICARUS & \begin{tabular}{|l|} 
DELTA-T98 \\
\end{tabular} & GARRETT & $304 \mathrm{SS}$ \\
\hline $\mathrm{P}-222$ & Filtered Hydrolyzate Pump & PUMP & CENTRIFUGAL & $721 \mathrm{gpm}, 150 \mathrm{ft}$ head & ICARUS & DELTA-T98 & GARRETT & $304 \mathrm{SS}$ \\
\hline$P-223$ & Lime Unloading Blower & FAN & CENTRIFUGAL & $7425 \mathrm{cfm}, 6 \mathrm{psi}, 22275 \mathrm{lb} / \mathrm{hr}$ & DELTA-T98 & DELTA-T98 & GARRETT & C.S. \\
\hline$P-224$ & Fermentation Feed Pump & PUMP & ROTARY-LOBE & $737 \mathrm{gpm}, 200 \mathrm{ft}$ head & VENDOR & ICARUS & VENDOR & $304 \mathrm{SS}$ \\
\hline $\mathrm{P}-225$ & ISEP Elution Pump & PUMP & CENTRIFUGAL & $232 \mathrm{gpm}, 150 \mathrm{ft}$ head & ICARUS & DELTA-T98 & GARRETT & SS304 \\
\hline $\mathrm{P}-226$ & ISEP Reload Pump & PUMP & CENTRIFUGAL & $358 \mathrm{gpm}, 150 \mathrm{ft}$ head & ICARUS & \begin{tabular}{|l|} 
DELTA-T98 \\
\end{tabular} & GARRETT & SS304 \\
\hline P-227 & ISEP Hydrolyzate Feed Pump & PUMP & CENTRIFUGAL & $700 \mathrm{gpm}, 150 \mathrm{ft}$ head & ICARUS & DELTA-T98 & GARRETT & ss304 \\
\hline$P-239$ & Reacidified Liquor Pump & PUMP & CENTRIFUGAL & $720 \mathrm{gpm}, 100 \mathrm{ft}$ head & ICARUS & DELTA-T98 & GARRETT & SS304 \\
\hline S-202 & Pre-IX Belt Filter Press & SIL SEPARATOR & BELT-FILTER-PRESS & $181 \mathrm{gpm}$ slurry each, $16.7 \%$ insoluble solids & VENDOR & ICARUS & GARRETT & ss316 \\
\hline $\mathrm{S}-221$ & ISEP & SEPARATOR & CONT-IX & 20 chambers (39" dia. X 84" high), 4" dia. Valve - Weak Base Resin & VENDOR & NREL-ESTM & VENDOR & SS316;POLYPROP;RESIN-LINED- \\
\hline $\mathrm{S}-222$ & Hydroclone \& Rotary Drum Filter & SIL SEPARATOR & ROTARY-DRUM & Hydrocyclone and Vacuum Filter & VENDOR & DELTA-T98 & GARRETT & EPOXY LINED \\
\hline S-227 & LimeDust Vent Baghouse & SEPARATOR & FABRIC-FILTER & $8333 \mathrm{cfm}, 1389 \mathrm{sf}, 6 \mathrm{cfm} / \mathrm{sf}$ & ICARUS & DELTA-T98 & ICARUS & A285C;POLYESTER \\
\hline $\mathrm{T}-201$ & Sulfuric Acid Storage & TANK & VERTICAL-VESSEL & 6444 gall, $24 \mathrm{hr}$. residence time, $90 \% \mathrm{wv}$ & DELTA-T98 & DELTA-T98 & GARRETT & PLASTIC \\
\hline $\mathrm{T}-203$ & Blowdown Tank & TANK & VERTICAL-VESSEL & 14500 gal., $11^{\prime}$ dia $\times 30^{\prime}$ ' high, 10 min. res. time, $75 \%$ wv, 15 psig & ICARUS & ICARUS & GARRETT & ss316 \\
\hline $\mathrm{T}-209$ & Overliming Tank & TANK & VERTICAL-VESSEL & 46200 gal., $16^{\prime} \mathrm{di}$ & ICARUS & DELTA-T98 & GARRETT & SS304 \\
\hline $\mathrm{T}-220$ & Lime St & TANK & LIVE-BT & $4455 \mathrm{cf}, 14^{\prime}$ dia ? & ICARUS & DEL & ICARUS & CS \\
\hline $\mathrm{T}-224$ & Reacidification Tank & TANK & FLAT-BTM-STORAGE & 185200 gal., 32 ' dia $\times 32$ ' high, 4 hr. res. time, $90 \%$ wv, atmospheric & ICARUS & DELTA-T98 & GARRETT & $5 S 304$ \\
\hline $\mathrm{T}-232$ & Slurrying Tank & TANK & FLAT-BTM-STORAGE & 24770 gall, 13 ' dia. $\times 25^{\prime}$ high, 15 min. res. time, $90 \%$ wv, atmospheric & ICARUS & DELTA-T98 & GARRETT & ss304 \\
\hline
\end{tabular}




\begin{tabular}{|c|c|c|c|c|c|c|c|c|}
\hline Eguip. & Equipment Name & Eq. Category & Eq. Type & Equipment Description & Cost Basis & Install. Fact. Basis & Scale Fact. Basis & Material Const. \\
\hline PFD-P1 & 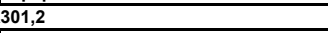 & & & & & & & \\
\hline $\mathrm{A}-300$ & SSCF Fermentor Agitators & AGITATOR & FIXED-PROP & Side Mounted, 2 per vessel, $75 \mathrm{hp}$ each, $0.15 \mathrm{hp} / 1000 \mathrm{gal}$ & DELTA-T98 & DELTA-T98 & & $\overline{S S 304}$ \\
\hline $\mathrm{A}-301$ & Seed Hold Tank Agitator & AGITATOR & FIXED-PROP & Top Mounted, $1800 \mathrm{rpm}, 23 \mathrm{hp}, 0.1 \mathrm{hp} / 1000 \mathrm{gal}$ & DELTA-T98 & DELTA-T98 & GARRETT & SS304 \\
\hline$A-304$ & 4th Seed Vessel Agitator & AGITATOR & FIXED-PROP & Top Mounted, $1800 \mathrm{rpm}, 6 \mathrm{hp}, 0.3 \mathrm{hp} / 1000 \mathrm{gal}$ & ICARUS & DELTA-T98 & GARRETT & SS \\
\hline $\mathrm{A}-305$ & 5th Seed Vessel Agitator & & FIXED-PROP & Top Mounted, $1800 \mathrm{rpm}, 19 \mathrm{hp}, 0.1 \mathrm{hp} / 1000 \mathrm{gal}$ & DELTA-T98 & DELTA-T98 & GARRETT & SS \\
\hline$A-306$ & Beer Surge Tank Agitator & AGITATOR & FIXED-PROP & Top Mounted, $1800 \mathrm{rpm}, 4 \mathrm{hp}, 0.3 \mathrm{hp} / 1000 \mathrm{gal}$ & ICARUS & DELTA-T98 & GARRETT & SS304 \\
\hline $\mathrm{F}-300$ & SSCF Fermentors & TANK & FLAT-BTM-STORAGE & 962,651 gal. each, 7 day residence total, $90 \%$ wv, APl, atmospheric & VENDOR & \begin{tabular}{|l|l|} 
DELTA-T98 \\
\end{tabular} & MULTI-UNIT & SS304 \\
\hline $\mathrm{F}-301$ & 1st SSCF Seed Fermentor & REACTOR & VERTICAL-VESSEL & 20 gal, jacketed, agitated, 1.3' dia., 2' high, 15 psig & ICARUS & DELTA-T98 & & $\overline{S S 304}$ \\
\hline $\mathrm{F}-302$ & 2nd SSCF Seed Fermentor & REACTOR & VERTICAL-VESSEL & 194 gal., jacketed, agitated, 3' dia., 4' high, 2.5 psig & ICARUS & ICARUS & & SS304 \\
\hline F-303 & 3rd SSCF Seed Fermentor & REACTOR & VERTICAL-VESSEL & 1950 gal., jacketed, agitated, $6.5^{\prime}$ dia, 8 ' high, 2.5 psig & ICARUS & DELTA-T98 & & ss304 \\
\hline $\mathrm{F}-304$ & 4th SSCF Seed Fermentor & REACTOR & FLAT-BTM-STORAGE & 19444 gal., 12' dia × 23' high, atmospheric & ICARUS & DELTA-T98 & GARRETT & ss304 \\
\hline F-305 & 5th SSCF Seed Fermentor & REACTOR & FLAT-BTM-STORAGE & 194500 gal., API, atmospheric & VENDOR & DELTA-T98 & GARRETT & ss304 \\
\hline $\mathrm{H}-300$ & Fermentation Cooler & HEATX & PLATE-FRAME & $2393 \mathrm{sf}, 300 \mathrm{BTU} / \mathrm{hr}$ sf F & ICARUS & DELTA-T98 & GARRETT & ss304 \\
\hline $\mathrm{H}-301$ & SSCF Seed Hydrolyzate Cooler & HEATX & PLATE-FRAME & $773 \mathrm{sf}, 300 \mathrm{BTU} / \mathrm{hr} \mathrm{sf} F$ & DELTA-T98 & DELTA-T98 & GARRETT & SS304 \\
\hline $\mathrm{H}-302$ & SSCF Hydrolyzate Cooler & HEATX & PLATE-FRAME & $3765 \mathrm{sf}$ total, $1255 \mathrm{sf}$ each, $300 \mathrm{BTU} / \mathrm{hr}$ sf F & DELTA-T98 & DELTA-T98 & GARRETT & $\mathrm{SS} 304$ \\
\hline $\mathrm{H}-304$ & 4TH Seed Fermentor Coils & HEATX & IIMMERSED-COIL & 27 sf, 1" sch 40 pipe, 105 BTU/hr sf F & ICARUS & DELTA-T98 & ICARUS & SS \\
\hline $\mathrm{H}-305$ & 5TH Seed Fermentor Coils & HEATX & IMMERSED-COIL & 307 sf, 3" sch 40 pipe, 92 BTU/hr sf F & ICARUS & DELTA-T98 & ICARUS & SS \\
\hline$P-300$ & SSCF Recirculation and Transfer Pump & PUMP & CENTRIFUGAL & $1060 \mathrm{gpm}, 150 \mathrm{ft}$ head & ICARUS & DELTA-T98 & GARRETT & ss304 \\
\hline$P-301$ & SSCF Seed Transfer Pump & PUMP & ROTARY-LOBE & $172 \mathrm{gpm}, 150 \mathrm{ft}$ head & VENDOR & CHEMSYST94 & VENDOR & SS304 \\
\hline $\mathrm{P}-302$ & Seed Transfer Pump & PUMP & ROTARY-LOBE & $1231 \mathrm{gpm}$ total, $615 \mathrm{gpm}$ each, $100 \mathrm{ft}$ head & VENDOR & CHEMSYST94 & VENDOR & sS304 \\
\hline P-306 & Beer Transfer Pump & PUMP & CENTRIFUGAL & $1632 \mathrm{gpm}$ each, $171 \mathrm{ft}$ head & ICARUS & DELTA-T98 & GARRETT & ss304 \\
\hline T-301 & SSCF Seed Hold Tank & TANK & FLAT-BTM-STORAGE & 233,333 gal., API atmospheric & \begin{tabular}{|l|l|l} 
VENDOR \\
\end{tabular} & \begin{tabular}{|l|l|} 
DELTA-T98 \\
\end{tabular} & GARRETT & SS304 \\
\hline $\mathrm{T}-306$ & Beer Storage Tank & TANK & FLAT-BTM-STORAGE & 15000 gal., 11 ' dia $\times 21^{\prime}$ high, 8 min res. Time, $90 \%$ wv, atmospheric & ICARUS & DELTA-T98 & GARRETT & ss304 \\
\hline PFD-P & $-401,2$ & & & & & & & \\
\hline $\mathrm{A}-400$ & Cellulase Fermentor Agitators & AGITATOR & |AXIAL-IMPELLER & $600 \mathrm{hp} /$ agitator -1 agitator/vessel & VENDOR & DELTA-T98 & & SS304 \\
\hline$F-400$ & Cellulase Fermentors & REACTOR & VERTICAL-VESSEL & 267,631 gal / 25 psig / Cooling coils in tank costed as $\mathrm{H} 400,37 \mathrm{ft}$. height, $36 \mathrm{ft}$. diameter & DELTA-T98 & DELTA-T98 & & SSS304L \\
\hline F-401 & 1st Cellulase Seed Fermentor & REACTOR & VERTICAL-VESSEL & 33 gal / 15 psig / Jacketed / Agitator & ICARUS & DELTA-T98 & GARRETT & SS304 \\
\hline F-402 & 2nd Cellulase Seed Fermentor & REACTOR & VERTICAL-VESSEL & 661 gal / 15 psig / Jacketed./Agitator & ICARUS & DELTA-T98 & GARRETT & SS304 \\
\hline F-403 & 3rd Cellulase Seed Fermentor & REACTOR & VERTICAL-VESSEL & 13210 gal / 15 psig / Jacketed./Agitator & ICARUS & DELTA-T98 & GARRETT & SS304 \\
\hline $\mathrm{H}-400$ & Cellulase Fermentation Cooler & HEATX & IMMERSED-COIL & Immersible Coil $613 \mathrm{ft} 2$ & ICARUS & DELTA-T98 & GARRETT & SS304 \\
\hline $\mathrm{M}-401$ & Fermentor Air Compressor Package & COMPRESSOR & CENTRIFUGAL & $22271 \mathrm{scfm}, 55$ psig outlet, $4000 \mathrm{hp}$ & \begin{tabular}{|l|l|} 
VENDOR \\
\end{tabular} & \begin{tabular}{|l|l|} 
DELTA-T98 \\
\end{tabular} & GARRETT & CS \\
\hline$P-400$ & Cellulase Transfer Pump & PUMP & CENTRIFUGAL & 175 GPM / 100 ft. head & ICARUS & \begin{tabular}{|l|} 
DELTA-T98 \\
\end{tabular} & GARRETT & ss \\
\hline $\mathrm{P}-401$ & Cellulase Seed Pump & PUMP & ROTARY-LOBE & $72.5 \mathrm{gpm} / 5 \mathrm{hp}$ & VENDOR & DELTA-T98 & & ss316 \\
\hline P-405 & \begin{tabular}{|l|} 
Media Pump \\
\end{tabular} & PUMP & CENTRIFUGAL & $62.5 \mathrm{Gpm} / 100 \mathrm{Ft} \mathrm{Head}$ & ICARUS & \begin{tabular}{|l|} 
DELTA-T98 \\
\end{tabular} & GARRETT & ss \\
\hline$\frac{P-403}{P-420}$ & Anti-foam Pump & PUMP & CENTRIFUGAL & \begin{tabular}{|l}
$11.2 \mathrm{gpm} / 75 \mathrm{ft} \mathrm{head}$ \\
\end{tabular} & ICARUS & \begin{tabular}{|l|} 
DELTA-T98 \\
\end{tabular} & \begin{tabular}{|l|l|} 
GARRETT \\
\end{tabular} & 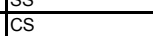 \\
\hline $\mathrm{T}-405$ & Media-Prep Tank & TANK & VERTICAL-VESSEL & $6250 \mathrm{Gal} / 1.17 \mathrm{hp}$ Agitator & ICARUS & \begin{tabular}{|l|} 
DELTA-T98 \\
\end{tabular} & GARRETT & SS304 \\
\hline $\mathrm{T}-420$ & Anti-foam Tank & TANK & VERTICAL-VESSEL & $200 \mathrm{gal}, 3 \mathrm{hr}$. residence time & DELTA-T98 & DELTA-T98 & UNKNOWN & POLYETHYLENE \\
\hline
\end{tabular}




\begin{tabular}{|c|c|c|c|c|c|c|c|c|}
\hline Eguip. $\mathrm{N}$ & Equipment Name & Eq. Category & Eq. Type & Equipment Description & Cost Basis & Install. Fact. Basis & Scale Fact. Basis & Material Const. \\
\hline PFD-P1C & $-501,2,3,4$ & & & & & & & \\
\hline D-501 & Beer Column & COLUMN & DISTILLATION & 13.5' dia, 32 Actual Trays, Nutter V-Grid Trays & DELTA-T98 & DELTA-T98 & JGARRETT & SS304 \\
\hline D-502 & Rectification Column & COLUMN & DISTILLATION & $11.5^{\prime}$ dia.(rect)., 4' dia. (strip) x 18" T.S., 60 act. Trays, $60 \%$ eff., Nutter V-Grid trays & DELTA-T98 & DELTA-T98 & GARRETT & SS \\
\hline $\mathrm{E}-501$ & 1st Effect Evaporation & HEATX & SHELL-TUBE & 22280 sf each., $135 \mathrm{BTT} / \mathrm{hr}$ sf F & DELTA-T98 & DELTA-T98 & GARRETT & SS316 \\
\hline $\mathrm{E}-502$ & 2nd Effect Evaporation & HEATX & SHELL-TUBE & 22278 sf., 170 BTU/hr sf F & DELTA-T98 & DELTA-T98 & GARRETT & SS316 \\
\hline $\mathrm{E}-503$ & 3rd Effect Evaporation & HEATX & SHELL-TUBE & 22278 sf each., 170 BTU/hr sf F & DELTA-T98 & DELTA-T98 & GARRETT & SS316 \\
\hline H-501 & Beer Column Reboiler & HEATX & SHELL-TUBE & Fixed TS, 13899 sf, 41" dia., 20' long, 178 BTU/hr sf F & \begin{tabular}{|l|l|} 
DELTA-T98 \\
\end{tabular} & DELTA-T98 & GARRETT & SS304;CS \\
\hline $\mathrm{H}-502$ & Rectification Column Reboiler & HEATX & SHELL-TUBE & Thermosyphon, 1089 sf, 20" dia., 20' long, 130 BTU/hr sf F & ICARUS & DELTA-T98 & GARRETT & SS304;CS \\
\hline $\mathrm{H}-504$ & Beer Column Condenser & HEATX & SHELL-TUBE & Floating Head, 880 sf, $20^{\prime \prime}$ dia., $22^{\prime}$ ' long, 92 BTU/hr sf F & DELTA-T98 & DELTA-T98 & GARRETT & SS304;CS \\
\hline $\mathrm{H}-505$ & Rectification Column Condenser & HEATX & SHELL-TUBE & Fixed TS, 4146 sf, 39" dia, 20' long, 157 BTU/hr sf F & DELTA-T98 & DELTA-T98 & GARRETT & SS304;CS \\
\hline $\mathrm{H}-512$ & Beer Column Feed Interchange & HEATX & PLATE-FRAME & $909 \mathrm{sf}, 200 \mathrm{BTU} / \mathrm{hr} \mathrm{sf} \mathrm{F}$ & DELTA-T98 & DELTA-T98 & GARRETT & ss \\
\hline $\mathrm{H}-517$ & Evaporator Condenser & HEATX & SHELL-TUBE & Fixed TS, 8223 sf, 39" dia., 20' long, 220 BTU/hr sf F & DELTA-T98 & DELTA-T98 & GARRETT & SS304;CS \\
\hline M-503 & Molecular Sieve (9 pieces) & MISCELLANEOUS & PACKAGE & Superheater, twin mole sieve columns, product cooler, condenser, pumps, vacuum source. & VENDOR & DELTA-T98 & & ss \\
\hline $\mathrm{P}-501$ & Beer Column Bottoms Pump & PUMP & CENTRIFUGAL & $5053 \mathrm{gpm}, 150 \mathrm{ft}$ head & ICARUS & ICARUS & GARRETT & ss \\
\hline $\mathrm{P}-503$ & Beer Column Reflux Pump & PUMP & CENTRIFUGAL & $12 \mathrm{gpm}, 140 \mathrm{ft}$ head & DELTA-T98 & DELTA-T98 & GARRETT & SS \\
\hline $\mathrm{P}-504$ & Rectification Column Bottoms Pump & PUMP & CENTRIFUGAL & $154 \mathrm{gpm}, 158 \mathrm{ft}$ head & DELTA-T98 & DELTA-T98 & GARRETT & SS \\
\hline $\mathrm{P}-505$ & Rectification Column Reflux Pump & PUMP & CENTRIFUGAL & $437 \mathrm{gpm}, 110 \mathrm{ft}$ head & DELTA-T98 & DELTA-T98 & GARRETT & SS \\
\hline P-511 & 1st Effect Pump & PUMP & CENTRIFUGAL & $2393 \mathrm{gpm}$ each, $110 \mathrm{ft}$ head & ICARUS & DELTA-T98 & GARRETT & SS \\
\hline P-512 & 2nd Effect Pump & PUMP & CENTRIFUGAL & $1261 \mathrm{gpm}, 110 \mathrm{ft}$ head & ICARUS & \begin{tabular}{|l|l|} 
DELTA-T98 \\
\end{tabular} & GARRETT & SS \\
\hline $\mathrm{P}-513$ & 3rd Effect Pump & PUMP & CENTRIFUGAL & $412 \mathrm{gpm}$ each, $110 \mathrm{ft}$ head & ICARUS & DELTA-T98 & GARRETT & sis \\
\hline $\mathrm{P}-514$ & Evaporator Condensate Pump & PUMP & CENTRIFUGAL & $617 \mathrm{gpm}, 125 \mathrm{ft}$ head & ICARUS & DELTA-T98 & GARRETT & SS304 \\
\hline $\mathrm{P}-515$ & Scrubber Bottoms Pump & PUMP & CENTRIFUGAL & $69 \mathrm{gpm}, 104 \mathrm{ft}$ head & DELTA-T98 & DELTA-T98 & GARRETT & ss \\
\hline $\mathrm{T}-503$ & Beer Column Relfux Drum & TANK & HORIZONTAL-VESSEL & 346 gal, 15 min res. Time, $50 \%$ wv, 3' dia., $6.5^{\prime}$ long, 25 psig & ICARUS & DELTA-T98 & GARRETT & SS304 \\
\hline T-505 & Rectification Column Reflux Drum & TANK & HORIZONTAL-VESSEL & 13106 gal, 15 min res time, 50\% wv, 9' dia, $27.5^{\prime}$ long, 25 psig & ICARUS & DELTA-T98 & GARRETT & SS304 \\
\hline $\mathrm{T}-512$ & Vent Scrubber & COLUMN & ABSORBER & 7' dia × $25^{\prime}$ high, 4 stages, plastic Jaeger Tri-Packing & \begin{tabular}{|l|l|} 
DELTA-T98 \\
\end{tabular} & DELTA-T98 & GARRETT & SS304;PLASTIC \\
\hline PFD-P1C & $601,2,3$ & & & & & & & \\
\hline A-602 & Equalization Basin Agitator & AGITATOR & FIXED-PROP & $38 \mathrm{hp}$ each, Fixed Prop, $0.1 \mathrm{hp} / 1000 \mathrm{gal}$ & IICARUS & DELTA-T98 & GARRETT & SS \\
\hline$A-606$ & Anaerobic Agitator & AGITATOR & FIXED-PROP & Fixed Prop, $41 \mathrm{hp}, 0.05 \mathrm{hp} / 1000 \mathrm{gal}$ & ICARUS & DELTA-T98 & GARRETT & ss \\
\hline$A-608$ & Aerobic Lagoon Agitators & AGITATOR & SURFACE-AERATOR & Twister Surface Aerators, $50 \mathrm{HP}$ ea & VENDOR & MERRICK98 & GARRETT & CS \\
\hline $\mathrm{A}-630$ & Recycled Water Tank Agitator & AGITATOR & FIXED-PROP & $5 \mathrm{hp}, 50 \mathrm{rpm}$, & VENDOR & DELTA-T98 & GARRETT & cs \\
\hline C-601 & Lignin Wet Cake Screw & CONVEYOR & SCREW & 14" Dia X 100' Long & ICARUS & DELTA-T98 & GARRETT & CS \\
\hline C-614 & Aerobic Sludge Screw & CONVEYOR & SCREW & 9" Dia X 25' Long & ICARUS & \begin{tabular}{|l|} 
DELTA-T98 \\
\end{tabular} & GARRETT & CS \\
\hline $\mathrm{H}-602$ & Anaerobic Digestor Feed Cooler & HEATX & SHELL-TUBE & TEMA BES Type, Floating Head & ICARUS & DELTA-T98 & VENDOR & ss316;CS \\
\hline M-604 & Nutrient Feed System & MISCELLANEOUS & PACKAGE & 5 Tanks and Pumps & VENDOR & VENDOR & & CS \\
\hline M-606 & Biogas Emergency Flare & MISCELLANEOUS & MISCELLANEOUS & Flare and Pilot & VENDOR & VENDOR & DEFAULT & ss \\
\hline $\mathrm{M}-612$ & Filter Precoat System & MISCELLANEOUS & MISCELLANEOUS & Tank, Agitator, Pump & MERRICK98 & & & CS \\
\hline$P-602$ & Anaerobic Reactor Feed Pump & PUMP & CENTRIFUGAL & $876 \mathrm{gpm}, 150 \mathrm{ft}$ head & ICARUS & DELTA-T98 & GARRETT & Cs \\
\hline P-606 & Aerobic Digestor Feed Pump & PUMP & CENTRIFUGAL & $830 \mathrm{gpm}, 150 \mathrm{ft}$ head & ICARUS & DELTA-T98 & GARRETT & CS \\
\hline $\mathrm{P}-608$ & Aerobic Sludge Recycle Pump & PUMP & SLURRY & $2.5 \mathrm{gpm}, 150 \mathrm{ft}$ head & ICARUS & \begin{tabular}{|l|} 
DELTA-T98 \\
\end{tabular} & GARRETT & ss316 \\
\hline P-610 & Aerobic Sludge Pump & PUMP & SLURRY & $25.3 \mathrm{gpm}, 150 \mathrm{ft}$ head & ICARUS & DELTA-T98 & GARRETT & ss316 \\
\hline$P-611$ & Aerobic Digestion Outlet Pump & PUMP & CENTRIFUGAL & $828 \mathrm{gpm}, 150^{\prime}$ head & ICARUS & DELTA-T98 & GARRETT & CS \\
\hline $\mathrm{P}-614$ & Sludge Filtrate Recycle Pump & PUMP & CENTRIFUGAL & $22 \mathrm{gpm}, 150^{\prime}$ head & ICARUS & DELTA-T98 & GARRETT & cs \\
\hline P-616 & Treated Water Pump & PUMP & CENTRIFUGAL & $803 \mathrm{gpm}, 100 \mathrm{ft}$ head & ICARUS & \begin{tabular}{|l|} 
DELTA-T98 \\
\end{tabular} & GARRETT & cs \\
\hline$P-630$ & Recycled Water Pump & PUMP & CENTRIFUGAL & $790 \mathrm{gpm}, 150 \mathrm{ft}$ head & ICARUS & DELTA-T98 & GARRETT & Cs \\
\hline S-600 & Bar Screen & SEPARATOR & SCREEN & $0.5^{\prime \prime}$ Mech. cleaned Screen & CH2MHL91 & DELTA-T98 & ASSUMED & CS \\
\hline S-601 & Beer Column Bottoms Centrifuge & SIL SEPARATOR & CENTRIFUGE & $36^{\prime \prime} X 12^{\prime \prime}, 550$ HP EACH & VENDOR & DELTA-T98 & GARRETT & 316SS \\
\hline S-614 & Belt Filter Press & SIL SEPARATOR & FILTER-PRESS & BELT THICKNESS & VENDOR & VENDOR & VENDOR & 304SS;BUNA N \\
\hline T-602 & Equalization Basin & TANK & FLAT-BTM-STORAGE & 377516 gal, Residence time $7.2 \mathrm{hr}$, & VENDOR & VENDOR & GARRETT & CONCRETE \\
\hline T-606 & Anaerobic Digestor & TANK & FLAT-BTM-STORAGE & 810250 gal each, space velocity $12 \mathrm{~g}$ COD/L/DAY & VENDOR & VENDOR & GARRETT & EPOXY-LINED \\
\hline$T-608$ & Aerobic Digestor & REACTOR & 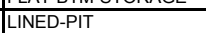 & 19500000 gal, 16.3 day residence time & MERRICK98 & MERRICK98 & & POLYMER LINED \\
\hline $\mathrm{T}-610$ & Clarifier & SEPARATOR & CLARIFIER & 195289 gal, Residence time $3.9 \mathrm{hr}$. & VENDOR & VENDOR & GARRETT & CONCRETE \\
\hline $\mathrm{T}-630$ & Recycled Water Tank & TANK & FLAT-BTM-STORAGE & $13218 \mathrm{gal}$, Residence time $20 \mathrm{~min}, 2.5 \mathrm{psig}$ & VENDOR & DELTA-T98 & VENDOR & CS \\
\hline
\end{tabular}




\begin{tabular}{|c|c|c|c|c|c|c|c|c|}
\hline \multirow{2}{*}{\multicolumn{2}{|c|}{ 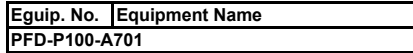 }} & Eq. Category & \multirow{2}{*}{ Eq. Type } & \multirow{2}{*}{ Equipment Description } & \multirow{2}{*}{ Cost Basis } & \multirow{2}{*}{ IInstall. Fact. Basis } & \multirow{2}{*}{ Scale Fact. Basis } & \multirow{2}{*}{ Material Const. } \\
\hline & & & & & & & & \\
\hline A-701 & Denaturant In-line Mixer & IMIXER & STATIC & Static Mixer, total flow $341 \mathrm{gpm}$ & ICARUS & DELTA-T98 & ICARUS & SS304 \\
\hline P-701 & Ethanol Product Pump & PUMP & $\begin{array}{l}\text { CENTRIFUGAL } \\
\end{array}$ & $324 \mathrm{gpm}, 112 \mathrm{ft}$ head & ICARUS & \begin{tabular}{|l|l|} 
DELTA-T98 \\
\end{tabular} & GARRETT & cs \\
\hline P-703 & Sulfuric Acid Pump & PUMPP & CENTRIFUGAL & $215 \mathrm{gpm}, 150 \mathrm{ft}$ head & ICARUS & DELTA-T98 & GARRETT & SS316 \\
\hline P-704 & Firewater Pump & PUMP & CENTRIFUGAL & $2500 \mathrm{gpm}, 50 \mathrm{ft}$ head & ICARUS & \begin{tabular}{|l} 
DELTA-T98 \\
DELA
\end{tabular} & GARRETT & cs \\
\hline P-706 & Ammonia Pump & PUMPP & CENTRIFUGAL & $8.5 \mathrm{gpm}, 22 \mathrm{ft}$ head & ICARUS & DELTA-T98 & GARRETT & cs \\
\hline P-707 & Antifoam Store Pump & PUMPP & CENTRIFUGAL & $1 \mathrm{gpm}, 92 \mathrm{ft}$ head & ICARUS & DELTA-T98 & GARRETT & Cs \\
\hline P-708 & Diesel Pump & PUMP & CENTRIFUGAL & $30 \mathrm{gpm}, 150 \mathrm{ft}$ head & ICARUS & \begin{tabular}{|l|} 
DELTA-T98 \\
\end{tabular} & & cs \\
\hline P-710 & Gasoline Pump & PUMP & CENTRIFUGAL & $17 \mathrm{gpm}, 200 \mathrm{ft}$ head & ICARUS & DELTA-T98 & GARRETT & cs \\
\hline $\mathrm{P}-720$ & \begin{tabular}{|l|l|} 
CSL Pump \\
\end{tabular} & PUMP & $\begin{array}{l}\text { CENTRIFUGAL } \\
\end{array}$ & $431 \mathrm{gpm}, 150 \mathrm{ft}$ head & ICARUS & \begin{tabular}{|l|l|} 
DELTA-T98 \\
\end{tabular} & GARRETT & cs \\
\hline T-701 & Ethanol Product Storage Tank & TANK & FLAT-BTM-STORAGE & 604,133 gal, 7 day res time total, $90 \% \mathrm{wv}, 51^{\prime}$ dia $\times 40^{\prime}$ high, atmospheric & ICARUS & DELTA-T98 & GARRETT & A285C \\
\hline $\mathrm{T}-703$ & Sulfuric Acid Storage Tank & TANK & FLAT-BTM-STORAGE & 18697 gal, 120 hr res time, $90 \%$ wv, 12' dia × 22' high, atmospheric & ICARUS & ICARUS & GARRETT & SS316 \\
\hline T-704 & Firewater Storage Tank & TANK & FLAT-BTM-STORAGE & 600,000 gal, $4 \mathrm{hr}$ res time, $51^{\prime}$ dia $\times 40^{\prime}$ ' high, atmospheric & ICARUS & DELTA-T98 & GARRETT & A285C \\
\hline T-706 & Ammonia Storage Tank & TANK & HORIZONTAL-STORAG & 197,500 gal, 4.2 day res time ( $1.5 \times$ rail car), $13^{\prime}$ dia $\times 60^{\prime}$ long, 260 psig & ICARUS & DELTA-T98 & GARRETT & A515 \\
\hline $\mathrm{T}-707$ & Antifoam Storage Tank & TANK & FLAT-BTM-STORAGE & 12,000 gal, 7 day res time, $90 \% \mathrm{wv}, 10.5^{\prime}$ dia $\times 18.5^{\prime}$ high, atmospheric & ICARUS & DELTA-T98 & GARRETT & A285C \\
\hline $\mathrm{T}-708$ & Diesel Storage Tank & TANK & FLAT-BTM-STORAGE & 10,667 gal, $120 \mathrm{hr}$ res time, $90 \%$ wv, $10^{\prime}$ dia $\times 18.2^{\prime}$ high, atmospheric & ICARUS & DELTA-T98 & & A285C \\
\hline $\mathrm{T}-710$ & Gasoline Storage Tank & TANK & FLAT-BTM-STORAGE & 63,593 gal, $168 \mathrm{hr}$ res time, $90 \%$ wv, $19^{\prime}$ dia $\times 32$ ' high, atmospheric & ICARUS & DELTA-T98 & GARRETT & A285C \\
\hline $\mathrm{T}-720$ & CSL Storage Tank & TANK & FLAT-BTM-STORAGE & $71,918 \mathrm{gal}, 120 \mathrm{hr}$ res time, $90 \% \mathrm{wv}, 20^{\prime}$ dia $\times 322^{\prime}$ high, atmospheric & IICARUS & ICARUS & GARRETT & Sss304 \\
\hline \multicolumn{9}{|c|}{ PFD-P100-801,2,3,4 } \\
\hline $\mathrm{H}-811$ & BFW Preheater & HEATX & SHELL-TUBE & Floating Head, $500 \mathrm{SF}$ & JICARUS & DELTA-T98 & GARRETT & SS304 \\
\hline M-801 & Solid Feed Rotary Dryer & DRYER & ROTARY-DRUM & Rotary Drum Dryer & VENDOR & CHEMSYST94 & GARRETT & \\
\hline $\mathrm{M}-803$ & Fluidized Bed Combustion Reactor & MISCELLANEOUS & MISCELLANEOUS & 900 to $1250 \mathrm{psig} / 950 \mathrm{~F}$ Circ. Fluid Bed & VENDOR & DELTA-T98 & VENDOR & CS \\
\hline M-804 & Combustion Gas Baghouse & SEPARATOR & FABRIC-FILTER & Pulse Shaker, $545000 \mathrm{cfm}, 135,135 \mathrm{SF}$ & VENDOR & VENDOR & MULTI-UNIT & A285C;FABRIC \\
\hline M-811 & Turbine/Generator & GENERATOR & STEAM-TURBINE & $52-61 \mathrm{MW} ; 281000 \mathrm{KG} / \mathrm{HR}$ STEAM & VENDOR & DELTA-T98 & VENDOR & \\
\hline M-820 & Hot Process Water Softener System & MISCELLANEOUS & PACKAGE & $1000 \mathrm{gpm}$ flow, 24 " dia softener. Includes filters, chemical feeders, piping, valves & RICHARDSON & NREL-ESTM & MULTI-UNIT & \\
\hline $\mathrm{M}-830$ & Hydrazine Addition Pkg. & MISCELLANEOUS & PACKAGE & 150 gal tank, agitator, 2 metering pumps & CHEMSYST94 & CHEMSYST94 & DEFAULT & \\
\hline M-832 & Ammonia Addition Pkg & MISCELLANEOUS & PACKAGE & 150 gal tank, agitator, 2 metering pumps & CHEMSYST94 & CHEMSYST94 & DEFAULT & \\
\hline M-834 & Phosphate Addition Pkg. & MISCELLANEOUS & PACKAGE & 150 gal tank, agitator, 2 metering pumps & CHEMSYST94 & CHEMSYST94 & DEFAULT & \\
\hline $\mathrm{P}-804$ & Condensate Pump & PUMP & CENTRIFUGAL & $272 \mathrm{gpm} 150^{\circ}$ head & ICARUS & DELTA-T98 & GARRETT & Ss316 \\
\hline $\mathrm{P}-811$ & Turbine Condensate Pump & PUMP & CENTRIFUGAL & $175 \mathrm{gpm}, 150 \mathrm{ft}$ head. & ICARUS & DELTA-T98 & GARRETT & SS304 \\
\hline $\mathrm{P}-824$ & Deaerator Feed Pump & PUMP & CENTRIFUGAL & $650 \mathrm{gpm}, 115 \mathrm{ft}$ head. & ICARUS & DELTA-T98 & GARRETT & ss304 \\
\hline $\mathrm{P}-826$ & BFW Pump & PUMP & CENTRIFUGAL & $500 \mathrm{gpm}, 2740 \mathrm{fth}$ head. & VENDOR & DELTA-T98 & GARRETT & ss316 \\
\hline $\mathrm{P}-828$ & Blowdown Pump & PUMP & CENTRIFUGAL & $29 \mathrm{gpm}, 150$ ' head & ICARUS & DELTA-T98 & GARRETT & cs \\
\hline $\mathrm{P}-830$ & Hydrazine Transfer Pump & PUMP & CENTRIFUGAL & $5 \mathrm{gpm}, 75 \mathrm{ft}$ head & DELTA-T98 & DELTA-T98 & GARRETT & cs \\
\hline $\mathrm{T}-804$ & Condensate Collection Tank & TANK & VERTICAL-VESSEL & 1600 gal, Residence time 1.5 minutes, atmospheric & ICARUS & DELTA-T98 & GARRETT & A285C \\
\hline $\mathrm{T}-824$ & Condensate Surge Drum & TANK & HORIZONTAL-VESSEL & 11,400 gal, 24' $\times$ 9'dia, 15psig, Residence time 11 min. & ICARUS & DELTA-T98 & GARRETT & ss304 \\
\hline $\mathrm{T}-826$ & Deaerator & TANK & HORIZONTAL-VESSEL & 18,170 gal hold tank, 150 psig design pressure, 10 min residence time & VENDOR & CHEMSYST94 & GARRETT & CS;SS316 \\
\hline $\mathrm{T}-828$ & Blowdown Flash Drum & TANK & HORIZONTAL-VESSEL & 424 gal, $4.5^{\prime} \times 4^{\prime}$ 'dia, 15 psig & ICARUS & DELTA-T98 & GARRETT & cs \\
\hline $\mathrm{T}-830$ & Hydrazine Drum & TANK & VERTICAL-VESSEL & 260 gal, $4.9^{\prime} \times 3^{\prime}$ 'dia., $10 \mathrm{psig}$ & ICARUS & DELTA-T98 & GARRETT & ss316 \\
\hline \multicolumn{9}{|c|}{ PFD-P100-A901,2,3 } \\
\hline M-902 & Cooling Tower System & COOLING-TOWER & INDUCED-DRAFT & $71000 \mathrm{gpm}, 147.8$ x E6 kcal/hr, 5 cell & DELTA-T98 & DELTA-T98 & GARRETT & FIBERGLASS \\
\hline M-904 & Plant Air Compressor & COMPRESSOR & RECIPROCATING & $450 \mathrm{cfm}, 125$ psig outlet & ICARUS & DELTA-T98 & GARRETT & Cs \\
\hline M-908 & Chilled Water Package & COMPRESSOR & CENTRIFUGAL & 2000 tons each, $1200 \mathrm{kw}$ & ICARUS & DELTA-T98 & GARRETT & Cs \\
\hline M-910 & CIP System & MISCELLANEOUS & MISCELLANEOUS & Designed by Delta-T. Same cost as sum of previous units. & DELTA-T98 & DELTA-T98 & NREL-ESTM & Cs \\
\hline $\mathrm{P}-902$ & Cooling Water Pumps & PUMP & CENTRIFUGAL & $41000 \mathrm{gpm}, 70 \mathrm{ft}$ head. & ICARUS & DELTA-T98 & GARRETT & cs \\
\hline$P-912$ & Make-up Water Pump & PUMP & CENTRIFUGAL & $1083 \mathrm{gpm}, 75 \mathrm{ft}$. head & ICARUS & DELTA-T98 & GARRETT & CS \\
\hline P-914 & Process Water Circulating Pump & PUMP & CENTRIFUGAL & $1199 \mathrm{gpm}$ ea, $75 \mathrm{ft}$. head & ICARUS & DELTA-T98 & GARRETT & cs \\
\hline S-904 & Instrument Air Dryer & DRYER & PACKAGE & 400 SCFM Air Dryer, -40F Dewpoint & RICHARDSON & \begin{tabular}{|l|l|} 
DELTA-T98 \\
\end{tabular} & DEFAULT & cs \\
\hline T-904 & Plant Air Receiver & TANK & HORIZONTAL-VESSEL & 900 gal., 200 psig & ICARUS & DELTA-T98 & GARRETT & CS \\
\hline $\mathrm{T}-914$ & Process Water Tank & TANK & FLAT-BTM-STORAGE & 756000 gal. 8 hr res time & IICARUS & DELTA-T98 & GARRETT & Cs \\
\hline
\end{tabular}


Appendix B

\section{Individual Equipment Costs Summary}




\begin{tabular}{|c|c|c|c|c|c|c|c|c|c|c|c|c|c|}
\hline Equip No. & $\begin{array}{c}\text { No. } \\
\text { Req'd }\end{array}$ & $\begin{array}{c}\text { No. } \\
\text { Spares }\end{array}$ & Equip Name & Scaled On & $\begin{array}{c}\text { Size Ratio } \\
\text { (Base/ } \\
\text { Current) }\end{array}$ & $\begin{array}{c}\text { Original } \\
\text { Equip Cost } \\
\text { (per unit) }\end{array}$ & $\begin{array}{l}\text { Base } \\
\text { Year }\end{array}$ & $\begin{array}{c}\text { Total Original } \\
\text { Equip Cost } \\
\text { (Req'd \& } \\
\text { Spare) in } \\
\text { Base Year }\end{array}$ & $\begin{array}{l}\text { Scaling } \\
\text { Exponent }\end{array}$ & $\begin{array}{c}\text { Scaled Cost } \\
\text { in Base Year }\end{array}$ & $\begin{array}{c}\text { Installation } \\
\text { Factor }\end{array}$ & $\begin{array}{c}\text { Installed } \\
\text { Cost in Base } \\
\text { Year }\end{array}$ & $\begin{array}{c}\text { Installed } \\
\text { Cost in } \\
1997 \$\end{array}$ \\
\hline C-101 & 3 & 1 & Hopper Feeder & Flow & 1.00 & $\$ 8,000$ & 1999 & $\$ 32,000$ & 0.76 & $\$ 32,000$ & 1.3 & $\$ 41,600$ & $\$ 40,679$ \\
\hline $\mathrm{C}-102$ & 1 & & Transfer Belt Conveyor & Flow & 1.00 & $\$ 78,120$ & 1999 & $\$ 78,120$ & 0.76 & $\$ 78,120$ & 1.3 & $\$ 101,556$ & $\$ 99,307$ \\
\hline $\mathrm{C}-103$ & 1 & & Radial Stacker Conveyor & Flow & 1.00 & $\$ 200,100$ & 1999 & $\$ 200,100$ & 0.76 & $\$ 200,100$ & 1.3 & $\$ 260,130$ & $\$ 254,369$ \\
\hline C-104 & 2 & & Reclaim Hopper Feeder & Flow & 1.00 & $\$ 8,000$ & 1999 & $\$ 16,000$ & 0.76 & $\$ 16,000$ & 1.3 & $\$ 20,800$ & $\$ 20,339$ \\
\hline $\mathrm{C}-105$ & 1 & & Reclaim Hopper Conveyor & Flow & 1.00 & $\$ 172,976$ & 1999 & $\$ 172,976$ & 0.76 & $\$ 172,976$ & 1.3 & $\$ 224,869$ & $\$ 219,889$ \\
\hline C-106 & 4 & & Chip Washer Feeder & Flow & 1.00 & $\$ 5,500$ & 1999 & $\$ 22,000$ & 0.76 & $\$ 22,000$ & 1.3 & $\$ 28,600$ & $\$ 27,967$ \\
\hline C-107 & 2 & & Scalper Screen Feeder & Flow & 1.00 & $\$ 13,392$ & 1998 & $\$ 26,784$ & 0.76 & $\$ 26,784$ & 1.3 & $\$ 34,819$ & $\$ 34,429$ \\
\hline $\mathrm{C}-108$ & 1 & & Pretreatment Feeder & Flow & 1.00 & $\$ 95,255$ & 1998 & $\$ 95,255$ & 0.76 & $\$ 95,255$ & 1.3 & $\$ 123,832$ & $\$ 122,445$ \\
\hline $\mathrm{M}-101$ & 3 & 1 & Hydraulic Truck Dump with Scale & Flow & 1.00 & $\$ 80,000$ & 1998 & $\$ 320,000$ & 0.6 & $\$ 320,000$ & 1.3 & $\$ 416,000$ & $\$ 411,342$ \\
\hline$M-103$ & 2 & & Front End Loaders & None & & $\$ 156,000$ & 1998 & $\$ 312,000$ & & $\$ 312,000$ & 1 & $\$ 312,000$ & $\$ 308,506$ \\
\hline $\mathrm{M}-104$ & 1 & & Disk Refiner System & Flow & 1.00 & $\$ 382,500$ & 1997 & $\$ 382,500$ & 0.62 & $\$ 382,500$ & 1.3 & $\$ 497,250$ & $\$ 497,250$ \\
\hline $\mathrm{S}-101$ & 1 & & Magnetic Separator & Flow & 1.00 & $\$ 13,863$ & 1998 & $\$ 13,863$ & 0.6 & $\$ 13,863$ & 1.3 & $\$ 18,022$ & $\$ 17,820$ \\
\hline S-102 & 2 & & Scalper Screener & Flow & 1.00 & $\$ 29,554$ & 1998 & $\$ 59,108$ & 0.75 & $\$ 59,108$ & 1.3 & $\$ 76,840$ & $\$ 75,980$ \\
\hline S-103 & 1 & & Chip Thickness Screen & Flow & 1.00 & $\$ 218,699$ & 1998 & $\$ 218,699$ & 0.75 & $\$ 218,699$ & 1.3 & $\$ 284,309$ & $\$ 281,125$ \\
\hline $\mathrm{T}-101$ & 3 & 1 & Dump Hopper & Flow & 1.00 & $\$ 28,327$ & 1998 & $\$ 113,308$ & 0.71 & $\$ 113,308$ & 1.4 & $\$ 158,631$ & $\$ 156,855$ \\
\hline $\mathrm{T}-102$ & 2 & & Reclaim Hopper & Flow & 1.00 & $\$ 28,327$ & 1998 & $\$ 56,654$ & 0.51 & $\$ 56,654$ & 1.4 & $\$ 79,316$ & $\$ 78,427$ \\
\hline $\mathrm{T}-103$ & 4 & & Washing/Refining Surge Bin & Flow & 1.00 & $\$ 36,103$ & 1998 & $\$ 144,412$ & 0.51 & $\$ 144,412$ & 1.4 & $\$ 202,177$ & $\$ 199,913$ \\
\hline W-101 & 4 & & Chip Washer System & Flow & 1.00 & $\$ 400,000$ & 1998 & $\$ 1,600,000$ & 0.6 & $\$ 1,600,000$ & 1.3 & $\$ 2,080,000$ & $\$ 2,056,710$ \\
\hline
\end{tabular}




\begin{tabular}{|c|c|c|c|c|c|c|c|c|c|c|c|c|c|}
\hline Equip No. & $\begin{array}{c}\text { No. } \\
\text { Req'd }\end{array}$ & $\begin{array}{c}\text { No. } \\
\text { Spares }\end{array}$ & Equip Name & Scaled On & $\begin{array}{c}\text { Size Ratio } \\
\text { (Base/ } \\
\text { Current) }\end{array}$ & $\begin{array}{c}\text { Original } \\
\text { Equip Cost } \\
\text { (per unit) }\end{array}$ & $\begin{array}{l}\text { Base } \\
\text { Year }\end{array}$ & $\begin{array}{c}\text { Total Original } \\
\text { Equip Cost } \\
\text { (Req'd \& } \\
\text { Spare) in } \\
\text { Base Year }\end{array}$ & $\begin{array}{c}\text { Scaling } \\
\text { Exponent }\end{array}$ & $\begin{array}{c}\text { Scaled Cost } \\
\text { in Base Year }\end{array}$ & $\begin{array}{c}\text { Installation } \\
\text { Factor }\end{array}$ & $\begin{array}{c}\text { Installed } \\
\text { Cost in Base } \\
\text { Year }\end{array}$ & $\begin{array}{c}\text { Installed } \\
\text { Cost in } \\
1997 \$\end{array}$ \\
\hline A-201 & 1 & & In-line Sulfuric Acid Mixer & Flow & 0.88 & $\$ 1,900$ & 1997 & $\$ 1,900$ & 0.48 & $\$ 1,785$ & 1 & $\$ 1,785$ & $\$ 1,785$ \\
\hline $\mathrm{A}-202$ & 1 & & In-line NH3 Mixer & Flow & 1.25 & $\$ 1,500$ & 1997 & $\$ 1,500$ & 0.48 & $\$ 1,669$ & 1 & $\$ 1,669$ & $\$ 1,669$ \\
\hline A-209 & 1 & & Overliming Tank Agitator & Flow & 1.30 & $\$ 19,800$ & 1997 & $\$ 19,800$ & 0.51 & $\$ 22,663$ & 1.3 & $\$ 29,462$ & $\$ 29,462$ \\
\hline A-224 & 1 & & Reacidification Tank Agitator & Flow & 1.30 & $\$ 65,200$ & 1997 & $\$ 65,200$ & 0.51 & $\$ 74,629$ & 1.2 & $\$ 89,555$ & $\$ 89,555$ \\
\hline A-232 & 1 & & Reslurrying Tank Agitator & Flow & 1.01 & $\$ 36,000$ & 1997 & $\$ 36,000$ & 0.51 & $\$ 36,200$ & 1.2 & $\$ 43,441$ & $\$ 43,441$ \\
\hline $\mathrm{A}-235$ & 1 & & In-line Acidification Mixer & Flow & 1.30 & $\$ 2,600$ & 1997 & $\$ 2,600$ & 0.48 & $\$ 2,953$ & 1 & $\$ 2,953$ & $\$ 2,953$ \\
\hline C-201 & 1 & & Hydrolyzate Screw Conveyor & Flow & 1.00 & $\$ 59,400$ & 1997 & $\$ 59,400$ & 0.78 & $\$ 59,356$ & 1.3 & $\$ 77,163$ & $\$ 77,163$ \\
\hline C-202 & 4 & & Wash Solids Screw Conveyor & Flow & 0.75 & $\$ 23,700$ & 1997 & $\$ 94,800$ & 1 & $\$ 70,920$ & 1.3 & $\$ 92,196$ & $\$ 92,196$ \\
\hline $\mathrm{C}-225$ & 1 & & Lime Solids Feeder & None & & $\$ 3,900$ & 1997 & $\$ 3,900$ & & $\$ 3,900$ & 1.3 & $\$ 5,070$ & $\$ 5,070$ \\
\hline $\mathrm{H}-200$ & 1 & & Hydrolyzate Cooler & Area & 1.31 & $\$ 45,000$ & 1997 & $\$ 45,000$ & 0.51 & $\$ 51,558$ & 2.1 & $\$ 108,271$ & $\$ 108,271$ \\
\hline $\mathrm{H}-201$ & 2 & 1 & Beer Column Feed Economizer & Area & 1.02 & $\$ 132,800$ & 1997 & $\$ 398,400$ & 0.68 & $\$ 403,256$ & 2.1 & $\$ 846,837$ & $\$ 846,837$ \\
\hline M-202 & 1 & & Prehydrolysis Reactor System & Flow & 1.00 & $\$ 12,461,841$ & 1998 & $\$ 12,461,841$ & 0.78 & $\$ 12,462,882$ & 1.5 & $\$ 18,694,322$ & $\$ 18,485,000$ \\
\hline $\mathrm{P}-201$ & 1 & 1 & Sulfuric Acid Pump & Flow & 1.13 & $\$ 4,800$ & 1997 & $\$ 9,600$ & 0.79 & $\$ 10,598$ & 2.8 & $\$ 29,673$ & $\$ 29,673$ \\
\hline $\mathrm{P}-209$ & 1 & 1 & Overlimed Hydrolyzate Pump & Flow & 1.30 & $\$ 10,700$ & 1997 & $\$ 21,400$ & 0.79 & $\$ 26,380$ & 2.8 & $\$ 73,863$ & $\$ 73,863$ \\
\hline $\mathrm{P}-222$ & 1 & 1 & Filtered Hydrolyzate Pump & Flow & 1.33 & $\$ 10,800$ & 1997 & $\$ 21,600$ & 0.79 & $\$ 27,057$ & 2.8 & $\$ 75,760$ & $\$ 75,760$ \\
\hline $\mathrm{P}-223$ & 1 & & Lime Unloading Blower & Flow & 1.31 & $\$ 47,600$ & 1998 & $\$ 47,600$ & 0.5 & $\$ 54,382$ & 1.4 & $\$ 76,134$ & $\$ 75,282$ \\
\hline $\mathrm{P}-224$ & 2 & 1 & Fermentation Feed Pump & Flow & 1.01 & $\$ 61,368$ & 1998 & $\$ 184,104$ & 0.7 & $\$ 185,512$ & 2.8 & $\$ 519,435$ & $\$ 513,618$ \\
\hline $\mathrm{P}-225$ & 1 & 1 & ISEP Elution Pump & Flow & 1.25 & $\$ 7,900$ & 1997 & $\$ 15,800$ & 0.79 & $\$ 18,826$ & 2.8 & $\$ 52,714$ & $\$ 52,714$ \\
\hline $\mathrm{P}-226$ & 1 & 1 & ISEP Reload Pump & Flow & 1.30 & $\$ 8,700$ & 1997 & $\$ 17,400$ & 0.79 & $\$ 21,450$ & 2.8 & $\$ 60,061$ & $\$ 60,061$ \\
\hline $\mathrm{P}-227$ & 1 & 1 & ISEP Hydrolyzate Feed Pump & Flow & 1.31 & $\$ 10,700$ & 1997 & $\$ 21,400$ & 0.79 & $\$ 26,456$ & 2.8 & $\$ 74,078$ & $\$ 74,078$ \\
\hline P-239 & 1 & 1 & Reacidified Liquor Pump & Flow & 1.30 & $\$ 10,800$ & 1997 & $\$ 21,600$ & 0.79 & $\$ 26,627$ & 2.8 & $\$ 74,555$ & $\$ 74,555$ \\
\hline S-202 & 8 & & Pre-IX Belt Filter Press & Feed Solids & 1.03 & $\$ 200,000$ & 1998 & $\$ 1,600,000$ & 0.39 & $\$ 1,619,536$ & 1.4 & $\$ 2,267,351$ & $\$ 2,241,963$ \\
\hline S-221 & 1 & & ISEP & Flow & 1.00 & $\$ 2,058,000$ & 1997 & $\$ 2,058,000$ & 0.33 & $\$ 2,056,875$ & 1.2 & $\$ 2,468,250$ & $\$ 2,468,250$ \\
\hline S-222 & 1 & & Hydroclone \& Rotary Drum Filter & Flow & 0.47 & $\$ 165,000$ & 1998 & $\$ 165,000$ & 0.39 & $\$ 122,738$ & 1.4 & $\$ 171,833$ & $\$ 169,909$ \\
\hline S-227 & 1 & & LimeDust Vent Baghouse & Flow & 1.30 & $\$ 32,200$ & 1997 & $\$ 32,200$ & 1 & $\$ 41,952$ & 1.5 & $\$ 62,928$ & $\$ 62,928$ \\
\hline T-201 & 1 & & Sulfuric Acid Storage & Flow & 1.13 & $\$ 5,760$ & 1996 & $\$ 5,760$ & 0.71 & $\$ 6,295$ & 1.4 & $\$ 8,813$ & $\$ 8,870$ \\
\hline $\mathrm{T}-203$ & 1 & & Blowdown Tank & Flow & 1.00 & $\$ 64,100$ & 1997 & $\$ 64,100$ & 0.93 & $\$ 64,048$ & 1.2 & $\$ 76,857$ & $\$ 76,857$ \\
\hline T-209 & 1 & & Overliming Tank & Flow & 1.30 & $\$ 71,000$ & 1997 & $\$ 71,000$ & 0.71 & $\$ 85,687$ & 1.4 & $\$ 119,962$ & $\$ 119,962$ \\
\hline $\mathrm{T}-220$ & 1 & & Lime Storage Bin & Flow & 1.30 & $\$ 69,200$ & 1997 & $\$ 69,200$ & 0.46 & $\$ 78,155$ & 1.3 & $\$ 101,602$ & $\$ 101,602$ \\
\hline $\mathrm{T}-224$ & 1 & & Reacidification Tank & Flow & 1.30 & $\$ 147,800$ & 1997 & $\$ 147,800$ & 0.51 & $\$ 169,174$ & 1.2 & $\$ 203,009$ & $\$ 203,009$ \\
\hline T-232 & 1 & & Slurrying Tank & Flow & 1.01 & $\$ 44,800$ & 1997 & $\$ 44,800$ & 0.71 & $\$ 45,148$ & 1.2 & $\$ 54,177$ & $\$ 54,177$ \\
\hline
\end{tabular}




\begin{tabular}{|c|c|c|c|c|c|c|c|c|c|c|c|c|c|}
\hline Equip No. & $\begin{array}{c}\text { No. } \\
\text { Req'd }\end{array}$ & \begin{tabular}{|c|} 
No. \\
Spares
\end{tabular} & Equip Name & Scaled On & $\begin{array}{c}\text { Size Ratio } \\
\text { (Base/ } \\
\text { Current) }\end{array}$ & $\begin{array}{c}\text { Original } \\
\text { Equip Cost } \\
\text { (per unit) }\end{array}$ & $\begin{array}{l}\text { Base } \\
\text { Year }\end{array}$ & $\begin{array}{c}\text { Total Original } \\
\text { Equip Cost } \\
\text { (Req'd \& } \\
\text { Spare) in } \\
\text { Base Year }\end{array}$ & $\begin{array}{l}\text { Scaling } \\
\text { Exponent }\end{array}$ & $\begin{array}{l}\text { Scaled Cost } \\
\text { in Base Year }\end{array}$ & $\begin{array}{c}\text { Installation } \\
\text { Factor }\end{array}$ & $\begin{array}{c}\text { Installed } \\
\text { Cost in Base } \\
\text { Year }\end{array}$ & $\begin{array}{c}\text { Installed } \\
\text { Cost in } \\
1997 \$\end{array}$ \\
\hline A-300 & 34 & & SSCF Fermentor Agitators & & & $\$ 19,676$ & 1996 & $\$ 668,984$ & & $\$ 668,984$ & 1.2 & $\$ 802,781$ & $\$ 807,919$ \\
\hline$A-301$ & 1 & & Seed Hold Tank Agitator & Flow & 0.91 & $\$ 12,551$ & 1996 & $\$ 12,551$ & 0.51 & $\$ 11,958$ & 1.2 & $\$ 14,350$ & $\$ 14,442$ \\
\hline A-304 & 2 & & 4th Seed Vessel Agitator & Flow & 0.91 & $\$ 11,700$ & 1997 & $\$ 23,400$ & 0.51 & $\$ 22,295$ & 1.2 & $\$ 26,754$ & $\$ 26,754$ \\
\hline A-305 & 2 & & 5th Seed Vessel Agitator & Flow & 0.91 & $\$ 10,340$ & 1996 & $\$ 20,680$ & 0.51 & $\$ 19,704$ & 1.2 & $\$ 23,644$ & $\$ 23,796$ \\
\hline A-306 & 1 & & Beer Surge Tank Agitator & Flow & 1.00 & $\$ 10,100$ & 1997 & $\$ 10,100$ & 0.51 & $\$ 10,080$ & 1.2 & $\$ 12,096$ & $\$ 12,096$ \\
\hline F-300 & 17 & & SSCF Fermentors & None & & $\$ 493,391$ & 1998 & $\$ 8,387,647$ & & $\$ 8,387,647$ & 1.2 & $\$ 10,065,176$ & $\$ 9,952,475$ \\
\hline F-301 & 2 & & 1st SSCF Seed Fermentor & None & & $\$ 14,700$ & 1997 & $\$ 29,400$ & & $\$ 29,400$ & 2.8 & $\$ 82,320$ & $\$ 82,320$ \\
\hline $\mathrm{F}-302$ & 2 & & 2nd SSCF Seed Fermentor & None & & $\$ 32,600$ & 1997 & $\$ 65,200$ & & $\$ 65,200$ & 2.8 & $\$ 182,560$ & $\$ 182,560$ \\
\hline F-303 & 2 & & 3rd SSCF Seed Fermentor & None & & $\$ 81,100$ & 1997 & $\$ 162,200$ & & $\$ 162,200$ & 2.8 & $\$ 454,160$ & $\$ 454,160$ \\
\hline $\mathrm{F}-304$ & 2 & & 4th SSCF Seed Fermentor & Flow & 0.91 & $\$ 39,500$ & 1997 & $\$ 79,000$ & 0.93 & $\$ 72,331$ & 1.2 & $\$ 86,798$ & $\$ 86,798$ \\
\hline F-305 & 2 & & 5th SSCF Seed Fermentor & Flow & 0.91 & $\$ 147,245$ & 1998 & $\$ 294,490$ & 0.51 & $\$ 280,587$ & 1.2 & $\$ 336,704$ & $\$ 332,934$ \\
\hline $\mathrm{H}-300$ & 17 & 1 & Fermentation Cooler & Heat Duty & 1.33 & $\$ 4,000$ & 1997 & $\$ 72,000$ & 0.78 & $\$ 89,761$ & 2.1 & $\$ 188,499$ & $\$ 188,499$ \\
\hline $\mathrm{H}-301$ & 1 & & SSCF Seed Hydrolyzate Cooler & Area & 0.91 & $\$ 15,539$ & 1998 & $\$ 15,539$ & 0.78 & $\$ 14,414$ & 2.1 & $\$ 30,270$ & $\$ 29,931$ \\
\hline $\mathrm{H}-302$ & 3 & & SSCF Hydrolyzate Cooler & Area & 0.98 & $\$ 25,409$ & 1998 & $\$ 76,227$ & 0.78 & $\$ 75,201$ & 2.1 & $\$ 157,922$ & $\$ 156,154$ \\
\hline $\mathrm{H}-304$ & 1 & & 4TH Seed Fermentor Coils & Heat Duty & 0.92 & $\$ 3,300$ & 1997 & $\$ 3,300$ & 0.83 & $\$ 3,066$ & 1.2 & $\$ 3,679$ & $\$ 3,679$ \\
\hline $\mathrm{H}-305$ & 1 & & 5TH Seed Fermentor Coils & Heat Duty & 0.92 & $\$ 18,800$ & 1997 & $\$ 18,800$ & 0.98 & $\$ 17,234$ & 1.2 & $\$ 20,681$ & $\$ 20,681$ \\
\hline $\mathrm{P}-300$ & 17 & 1 & SSCF Recirculation and Transfer Pump & Heat Duty & 1.33 & $\$ 8,000$ & 1997 & $\$ 144,000$ & 0.79 & $\$ 180,205$ & 2.8 & $\$ 504,574$ & $\$ 504,574$ \\
\hline P-301 & 1 & 1 & SSCF Seed Transfer Pump & Flow & 0.91 & $\$ 22,194$ & 1998 & $\$ 44,388$ & 0.7 & $\$ 41,537$ & 1.4 & $\$ 58,152$ & $\$ 57,501$ \\
\hline P-302 & 2 & & Seed Transfer Pump & Flow & 0.91 & $\$ 54,088$ & 1998 & $\$ 108,176$ & 0.7 & $\$ 101,228$ & 1.4 & $\$ 141,720$ & $\$ 140,133$ \\
\hline$P-306$ & 1 & 1 & Beer Transfer Pump & Flow & 1.00 & $\$ 17,300$ & 1997 & $\$ 34,600$ & 0.79 & $\$ 34,493$ & 2.8 & $\$ 96,581$ & $\$ 96,581$ \\
\hline T-301 & 1 & & SSCF Seed Hold Tank & Flow & 0.91 & $\$ 161,593$ & 1998 & $\$ 161,593$ & 0.51 & $\$ 153,964$ & 1.2 & $\$ 184,757$ & $\$ 182,688$ \\
\hline T-306 & 1 & & Beer Storage Tank & Flow & 1.00 & $\$ 34,900$ & 1997 & $\$ 34,900$ & 0.71 & $\$ 34,803$ & 1.2 & $\$ 41,764$ & $\$ 41,764$ \\
\hline
\end{tabular}

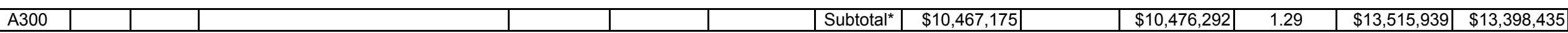




\begin{tabular}{|c|c|c|c|c|c|c|c|c|c|c|c|c|c|}
\hline Equip No. & $\begin{array}{l}\text { No. } \\
\text { Req'd }\end{array}$ & $\begin{array}{c}\text { No. } \\
\text { Spares }\end{array}$ & Equip Name & Scaled On & $\begin{array}{c}\text { Size Ratio } \\
\text { (Base/ } \\
\text { Current) }\end{array}$ & $\begin{array}{c}\text { Original } \\
\text { Equip Cost } \\
\text { (per unit) }\end{array}$ & $\begin{array}{l}\text { Base } \\
\text { Year }\end{array}$ & $\begin{array}{c}\text { Total Original } \\
\text { Equip Cost } \\
\text { (Req'd \& } \\
\text { Spare) in } \\
\text { Base Year }\end{array}$ & $\begin{array}{l}\text { Scaling } \\
\text { Exponent }\end{array}$ & $\begin{array}{c}\text { Scaled Cost } \\
\text { in Base Year }\end{array}$ & $\begin{array}{c}\text { Installation } \\
\text { Factor }\end{array}$ & $\begin{array}{c}\text { Installed } \\
\text { Cost in Base } \\
\text { Year }\end{array}$ & $\begin{array}{c}\text { Installed } \\
\text { Cost in } \\
1997 \$\end{array}$ \\
\hline A-400 & 11 & & Cellulase Fermentor Agitators & None & & $\$ 550,000$ & 1998 & $\$ 6,050,000$ & & $\$ 6,050,000$ & 1.2 & $\$ 7,260,000$ & $\$ 7,178,709$ \\
\hline $\mathrm{F}-400$ & 11 & & Cellulase Fermentors & None & & $\$ 179,952$ & 1998 & $\$ 1,979,472$ & & $\$ 1,979,472$ & 1 & $\$ 1,979,472$ & $\$ 1,957,308$ \\
\hline $\mathrm{F}-401$ & 3 & & 1st Cellulase Seed Fermentor & Flow & 0.92 & $\$ 22,500$ & 1997 & $\$ 67,500$ & 0.93 & $\$ 62,772$ & 2 & $\$ 125,545$ & $\$ 125,545$ \\
\hline F-402 & 3 & & 2nd Cellulase Seed Fermentor & Flow & 0.92 & $\$ 54,100$ & 1997 & $\$ 162,300$ & 0.93 & $\$ 150,933$ & 2 & $\$ 301,866$ & $\$ 301,866$ \\
\hline $\mathrm{F}-403$ & 3 & & 3rd Cellulase Seed Fermentor & Flow & 0.92 & $\$ 282,100$ & 1997 & $\$ 846,300$ & 0.93 & $\$ 787,028$ & 2 & $\$ 1,574,055$ & $\$ 1,574,055$ \\
\hline $\mathrm{H}-400$ & 11 & & Cellulase Fermentation Cooler & Heat Duty & 1.00 & $\$ 34,400$ & 1997 & $\$ 378,400$ & 0.78 & $\$ 378,222$ & 2.1 & $\$ 794,266$ & $\$ 794,266$ \\
\hline $\mathrm{M}-401$ & 2 & 1 & Fermentor Air Compressor Package & Flow & 3.10 & $\$ 596,342$ & 1998 & $\$ 1,789,026$ & 0.34 & $\$ 2,626,951$ & 1.3 & $\$ 3,415,036$ & $\$ 3,376,798$ \\
\hline $\mathrm{P}-400$ & 1 & 1 & Cellulase Transfer Pump & Flow & 0.97 & $\$ 9,300$ & 1997 & $\$ 18,600$ & 0.79 & $\$ 18,118$ & 2.8 & $\$ 50,730$ & $\$ 50,730$ \\
\hline $\mathrm{P}-401$ & 1 & 1 & Cellulase Seed Pump & Flow & 0.92 & $\$ 12,105$ & 1998 & $\$ 24,210$ & 0.7 & $\$ 22,922$ & 1.2 & $\$ 27,507$ & $\$ 27,199$ \\
\hline $\mathrm{P}-405$ & 1 & 1 & Media Pump & Flow & 0.99 & $\$ 8,300$ & 1997 & $\$ 16,600$ & 0.79 & $\$ 16,469$ & 2.8 & $\$ 46,115$ & $\$ 46,115$ \\
\hline$P-420$ & 1 & 1 & Anti-foam Pump & Flow & 1.00 & $\$ 5,500$ & 1997 & $\$ 11,000$ & 0.79 & $\$ 10,997$ & 2.8 & $\$ 30,792$ & $\$ 30,792$ \\
\hline T-405 & 1 & & Media-Prep Tank & Flow & 0.99 & $\$ 64,600$ & 1997 & $\$ 64,600$ & 0.71 & $\$ 64,143$ & 1.2 & $\$ 76,972$ & $\$ 76,972$ \\
\hline$T-420$ & 1 & & Anti-foam Tank & Flow & 1.00 & $\$ 402$ & 1998 & $\$ 402$ & 0.71 & $\$ 402$ & 1.2 & $\$ 482$ & $\$ 477$ \\
\hline A400 & & & & & & & Subtotal ${ }^{*}$ & $\$ 11,408,410$ & & $\$ 12,168,430$ & 1.29 & $\$ 15,682,838$ & $\$ 15,540,831$ \\
\hline
\end{tabular}




\begin{tabular}{|c|c|c|c|c|c|c|c|c|c|c|c|c|c|}
\hline Equip No. & $\begin{array}{c}\text { No. } \\
\text { Req'd }\end{array}$ & $\begin{array}{c}\text { No. } \\
\text { Spares }\end{array}$ & Equip Name & Scaled On & $\begin{array}{c}\text { Size Ratio } \\
\text { (Base/ } \\
\text { Current) }\end{array}$ & $\begin{array}{c}\text { Original } \\
\text { Equip Cost } \\
\text { (per unit) }\end{array}$ & $\begin{array}{l}\text { Base } \\
\text { Year }\end{array}$ & $\begin{array}{c}\text { Total Original } \\
\text { Equip Cost } \\
\text { (Req'd \& } \\
\text { Spare) in } \\
\text { Base Year }\end{array}$ & $\begin{array}{l}\text { Scaling } \\
\text { Exponent }\end{array}$ & $\begin{array}{c}\text { Scaled Cost } \\
\text { in Base Year }\end{array}$ & $\begin{array}{c}\text { Installation } \\
\text { Factor }\end{array}$ & $\begin{array}{c}\text { Installed } \\
\text { Cost in Base } \\
\text { Year }\end{array}$ & $\begin{array}{c}\text { Installed } \\
\text { Cost in } \\
1997 \$\end{array}$ \\
\hline D-501 & 1 & & Beer Column & Deameter & 0.94 & $\$ 636,976$ & 1996 & $\$ 636,976$ & 0.78 & $\$ 604,672$ & 2.1 & $\$ 1,269,811$ & $\$ 1,277,938$ \\
\hline $\mathrm{D}-502$ & 1 & & Rectification Column & Flow & 0.99 & $\$ 525,800$ & 1996 & $\$ 525,800$ & 0.78 & $\$ 521,461$ & 2.1 & $\$ 1,095,069$ & $\$ 1,102,077$ \\
\hline$E-501$ & 2 & & 1st Effect Evaporation & Area & 1.23 & $\$ 544,595$ & 1996 & $\$ 1,089,190$ & 0.68 & $\$ 1,256,849$ & 2.1 & $\$ 2,639,383$ & $\$ 2,656,275$ \\
\hline$E-502$ & 1 & & 2nd Effect Evaporation & Area & 1.23 & $\$ 435,650$ & 1996 & $\$ 435,650$ & 0.68 & $\$ 502,710$ & 2.1 & $\$ 1,055,690$ & $\$ 1,062,446$ \\
\hline $\mathrm{E}-503$ & 2 & & 3rd Effect Evaporation & Area & 1.23 & $\$ 435,650$ & 1996 & $\$ 871,300$ & 0.68 & $\$ 1,005,419$ & 2.1 & $\$ 2,111,380$ & $\$ 2,124,893$ \\
\hline $\mathrm{H}-501$ & 1 & & Beer Column Reboiler & Heat Duty & 0.99 & $\$ 158,374$ & 1996 & $\$ 158,374$ & 0.68 & $\$ 157,438$ & 2.1 & $\$ 330,619$ & $\$ 332,735$ \\
\hline $\mathrm{H}-502$ & 1 & & Rectification Column Reboiler & Heat Duty & 0.99 & $\$ 29,600$ & 1997 & $\$ 29,600$ & 0.68 & $\$ 29,355$ & 2.1 & $\$ 61,646$ & $\$ 61,646$ \\
\hline $\mathrm{H}-504$ & 1 & & Beer Column Condenser & Heat Duty & 0.89 & $\$ 29,544$ & 1996 & $\$ 29,544$ & 0.68 & $\$ 27,278$ & 2.1 & $\$ 57,283$ & $\$ 57,650$ \\
\hline $\mathrm{H}-505$ & 1 & & Rectification Column Condenser & Heat Duty & 0.99 & $\$ 86,174$ & 1996 & $\$ 86,174$ & 0.68 & $\$ 85,460$ & 2.1 & $\$ 179,466$ & $\$ 180,615$ \\
\hline $\mathrm{H}-512$ & 1 & 1 & Beer Column Feed Interchange & Area & 1.00 & $\$ 19,040$ & 1996 & $\$ 38,080$ & 0.68 & $\$ 38,034$ & 2.1 & $\$ 79,872$ & $\$ 80,383$ \\
\hline $\mathrm{H}-517$ & 1 & 1 & Evaporator Condenser & Heat Duty & 1.18 & $\$ 121,576$ & 1996 & $\$ 243,152$ & 0.68 & $\$ 271,888$ & 2.1 & $\$ 570,965$ & $\$ 574,620$ \\
\hline M-503 & 1 & & Molecular Sieve (9 pieces) & Flow & 0.91 & $\$ 2,700,000$ & 1998 & $\$ 2,700,000$ & 0.7 & $\$ 2,519,007$ & 1 & $\$ 2,519,007$ & $\$ 2,490,801$ \\
\hline $\mathrm{P}-501$ & 1 & 1 & Beer Column Bottoms Pump & Flow & 1.00 & $\$ 42,300$ & 1997 & $\$ 84,600$ & 0.79 & $\$ 84,767$ & 2.8 & $\$ 237,347$ & $\$ 237,347$ \\
\hline $\mathrm{P}-503$ & 1 & 1 & Beer Column Reflux Pump & Heat Duty & 0.89 & $\$ 1,357$ & 1998 & $\$ 2,714$ & 0.79 & $\$ 2,474$ & 2.8 & $\$ 6,926$ & $\$ 6,849$ \\
\hline $\mathrm{P}-504$ & 1 & 1 & Rectification Column Bottoms Pump & Flow & 0.98 & $\$ 4,916$ & 1998 & $\$ 9,832$ & 0.79 & $\$ 9,682$ & 2.8 & $\$ 27,109$ & $\$ 26,805$ \\
\hline $\mathrm{P}-505$ & 1 & 1 & Rectification Column Reflux Pump & Heat Duty & 0.99 & $\$ 4,782$ & 1998 & $\$ 9,564$ & 0.79 & $\$ 9,471$ & 2.8 & $\$ 26,518$ & $\$ 26,221$ \\
\hline $\mathrm{P}-511$ & 2 & 1 & 1st Effect Pump & Flow & 0.97 & $\$ 19,700$ & 1997 & $\$ 59,100$ & 0.79 & $\$ 57,534$ & 2.8 & $\$ 161,095$ & $\$ 161,095$ \\
\hline $\mathrm{P}-512$ & 1 & 1 & 2nd Effect Pump & Flow & 0.83 & $\$ 13,900$ & 1997 & $\$ 27,800$ & 0.79 & $\$ 24,082$ & 2.8 & $\$ 67,430$ & $\$ 67,430$ \\
\hline $\mathrm{P}-513$ & 2 & 1 & 3rd Effect Pump & Flow & 0.51 & $\$ 8,000$ & 1997 & $\$ 24,000$ & 0.79 & $\$ 14,049$ & 2.8 & $\$ 39,337$ & $\$ 39,337$ \\
\hline $\mathrm{P}-514$ & 1 & 1 & Evaporator Condensate Pump & Flow & 1.18 & $\$ 12,300$ & 1997 & $\$ 24,600$ & 0.79 & $\$ 27,943$ & 2.8 & $\$ 78,239$ & $\$ 78,239$ \\
\hline $\mathrm{P}-515$ & 1 & & Scrubber Bottoms Pump & Flow & 0.88 & $\$ 2,793$ & 1998 & $\$ 2,793$ & 0.79 & $\$ 2,529$ & 2.8 & $\$ 7,082$ & $\$ 7,003$ \\
\hline $\mathrm{T}-503$ & 1 & & Beer Column Relfux Drum & Heat Duty & 0.89 & $\$ 11,900$ & 1997 & $\$ 11,900$ & 0.93 & $\$ 10,669$ & 2.1 & $\$ 22,406$ & $\$ 22,406$ \\
\hline $\mathrm{T}-505$ & 1 & & Rectification Column Reflux Drum & Heat Duty & 0.99 & $\$ 45,600$ & 1997 & $\$ 45,600$ & 0.72 & $\$ 45,194$ & 2.1 & $\$ 94,908$ & $\$ 94,908$ \\
\hline $\mathrm{T}-512$ & 1 & & Vent Scrubber & Flow & 1.00 & $\$ 99,000$ & 1998 & $\$ 99,000$ & 0.78 & $\$ 98,640$ & 2.1 & $\$ 207,145$ & $\$ 204,825$ \\
\hline
\end{tabular}

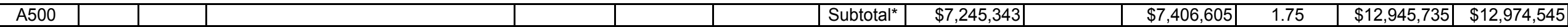




\begin{tabular}{|c|c|c|c|c|c|c|c|c|c|c|c|c|c|}
\hline Equip No. & $\begin{array}{c}\text { No. } \\
\text { Req'd }\end{array}$ & $\begin{array}{c}\text { No. } \\
\text { Spares }\end{array}$ & Equip Name & Scaled On & $\begin{array}{c}\text { Size Ratio } \\
\text { (Base/ } \\
\text { Current) }\end{array}$ & $\begin{array}{c}\text { Original } \\
\text { Equip Cost } \\
\text { (per unit) }\end{array}$ & $\begin{array}{l}\text { Base } \\
\text { Year }\end{array}$ & $\begin{array}{c}\text { Total Original } \\
\text { Equip Cost } \\
\text { (Req'd \& } \\
\text { Spare) in } \\
\text { Base Year }\end{array}$ & $\begin{array}{l}\text { Scaling } \\
\text { Exponent }\end{array}$ & $\begin{array}{l}\text { Scaled Cost } \\
\text { in Base Year }\end{array}$ & $\begin{array}{c}\text { Installation } \\
\text { Factor }\end{array}$ & $\begin{array}{c}\text { Installed } \\
\text { Cost in Base } \\
\text { Year }\end{array}$ & $\begin{array}{l}\text { Installed } \\
\text { Cost in } \\
1997 \$\end{array}$ \\
\hline A-602 & 1 & & Equalization Basin Agitator & Flow & 0.95 & $\$ 28,400$ & 1997 & $\$ 28,400$ & 0.51 & $\$ 27,716$ & 1.2 & $\$ 33,259$ & $\$ 33,259$ \\
\hline A-606 & 4 & & Anaerobic Agitator & Volume & 1.02 & $\$ 30,300$ & 1997 & $\$ 121,200$ & 0.51 & $\$ 122,516$ & 1.2 & $\$ 147,019$ & $\$ 147,019$ \\
\hline $\mathrm{A}-608$ & 16 & & Aerobic Lagoon Agitators & Power & 1.02 & $\$ 31,250$ & 1998 & $\$ 500,000$ & 0.51 & $\$ 505,650$ & 1.4 & $\$ 707,910$ & $\$ 699,983$ \\
\hline$A-630$ & 1 & & Recycled Water Tank Agitator & Flow & 0.95 & $\$ 5,963$ & 1998 & $\$ 5,963$ & 0.51 & $\$ 5,819$ & 1.3 & $\$ 7,565$ & $\$ 7,480$ \\
\hline C-601 & 1 & & Lignin Wet Cake Screw & Flow & 0.99 & $\$ 31,700$ & 1997 & $\$ 31,700$ & 0.78 & $\$ 31,470$ & 1.4 & $\$ 44,058$ & $\$ 44,058$ \\
\hline C-614 & 1 & & Aerobic Sludge Screw & Flow & 0.94 & $\$ 5,700$ & 1997 & $\$ 5,700$ & 0.78 & $\$ 5,424$ & 1.4 & $\$ 7,594$ & $\$ 7,594$ \\
\hline $\mathrm{H}-602$ & 1 & & Anaerobic Digestor Feed Cooler & Area & 0.98 & $\$ 128,600$ & 1997 & $\$ 128,600$ & 0.74 & $\$ 126,409$ & 2.1 & $\$ 265,459$ & $\$ 265,459$ \\
\hline $\mathrm{M}-604$ & 1 & & Nutrient Feed System & None & & $\$ 31,400$ & 1998 & $\$ 31,400$ & & $\$ 31,400$ & 2.58 & $\$ 81,012$ & $\$ 80,105$ \\
\hline $\mathrm{M}-606$ & 1 & & Biogas Emergency Flare & Flow & 1.02 & $\$ 20,739$ & 1998 & $\$ 20,739$ & 0.6 & $\$ 21,028$ & 1.68 & $\$ 35,326$ & $\$ 34,931$ \\
\hline $\mathrm{M}-612$ & 1 & & Filter Precoat System & None & & $\$ 3,000$ & 1998 & $\$ 3,000$ & & $\$ 3,000$ & 1.4 & $\$ 4,200$ & $\$ 4,153$ \\
\hline P-602 & 1 & 1 & Anaerobic Reactor Feed Pump & Flow & 0.95 & $\$ 11,400$ & 1997 & $\$ 22,800$ & 0.79 & $\$ 21,955$ & 2.8 & $\$ 61,474$ & $\$ 61,474$ \\
\hline P-606 & 1 & 1 & Aerobic Digestor Feed Pump & Flow & 0.95 & $\$ 10,700$ & 1997 & $\$ 21,400$ & 0.79 & $\$ 20,592$ & 2.8 & $\$ 57,657$ & $\$ 57,657$ \\
\hline P-608 & 1 & & Aerobic Sludge Recycle Pump & Flow & 0.94 & $\$ 11,100$ & 1997 & $\$ 11,100$ & 0.79 & $\$ 10,574$ & 1.4 & $\$ 14,804$ & $\$ 14,804$ \\
\hline P-610 & 1 & & Aerobic Sludge Pump & Flow & 0.94 & $\$ 11,100$ & 1997 & $\$ 11,100$ & 0.79 & $\$ 10,574$ & 1.4 & $\$ 14,804$ & $\$ 14,804$ \\
\hline $\mathrm{P}-611$ & 1 & 1 & Aerobic Digestion Outlet Pump & Flow & 0.95 & $\$ 10,700$ & 1997 & $\$ 21,400$ & 0.79 & $\$ 20,571$ & 2.8 & $\$ 57,599$ & $\$ 57,599$ \\
\hline P-614 & 1 & 1 & Sludge Filtrate Recycle Pump & Flow & 0.94 & $\$ 6,100$ & 1997 & $\$ 12,200$ & 0.79 & $\$ 11,625$ & 2.8 & $\$ 32,551$ & $\$ 32,551$ \\
\hline P-616 & 1 & 1 & Treated Water Pump & Flow & 0.95 & $\$ 10,600$ & 1997 & $\$ 21,200$ & 0.79 & $\$ 20,385$ & 2.8 & $\$ 57,078$ & $\$ 57,078$ \\
\hline$P-630$ & 1 & 1 & Recycled Water Pump & Flow & 0.95 & $\$ 10,600$ & 1997 & $\$ 21,200$ & 0.79 & $\$ 20,413$ & 2.8 & $\$ 57,156$ & $\$ 57,156$ \\
\hline S-600 & 1 & & Bar Screen & Flow & 0.95 & $\$ 117,818$ & 1991 & $\$ 117,818$ & 0.3 & $\$ 116,140$ & 1.2 & $\$ 139,368$ & $\$ 148,180$ \\
\hline S-601 & 3 & & Beer Column Bottoms Centrifuge & Flow & 0.96 & $\$ 659,550$ & 1998 & $\$ 1,978,650$ & 0.6 & $\$ 1,928,354$ & 1.2 & $\$ 2,314,025$ & $\$ 2,288,115$ \\
\hline S-614 & 1 & & Belt Filter Press & COD & 1.02 & $\$ 650,223$ & 1998 & $\$ 650,223$ & 0.72 & $\$ 660,062$ & 1.8 & $\$ 1,188,111$ & $\$ 1,174,807$ \\
\hline $\mathrm{T}-602$ & 1 & & Equalization Basin & Flow & 0.95 & $\$ 350,800$ & 1998 & $\$ 350,800$ & 0.51 & $\$ 342,350$ & 1.42 & $\$ 486,137$ & $\$ 480,693$ \\
\hline $\mathrm{T}-606$ & 4 & & Anaerobic Digestor & Volume & 1.02 & $\$ 881,081$ & 1998 & $\$ 3,524,324$ & 0.51 & $\$ 3,562,594$ & 1.04 & $\$ 3,705,098$ & $\$ 3,663,612$ \\
\hline $\mathrm{T}-608$ & 1 & & Aerobic Digestor & Volume & 0.95 & $\$ 635,173$ & 1998 & $\$ 635,173$ & 1 & $\$ 606,356$ & 1 & $\$ 606,356$ & $\$ 599,566$ \\
\hline $\mathrm{T}-610$ & 1 & & Clarifier & Flow & 0.95 & $\$ 174,385$ & 1998 & $\$ 174,385$ & 0.51 & $\$ 170,104$ & 1.96 & $\$ 333,403$ & $\$ 329,670$ \\
\hline T-630 & 1 & & Recycled Water Tank & Flow & 0.95 & $\$ 14,515$ & 1998 & $\$ 14,515$ & 0.745 & $\$ 14,006$ & 1.4 & $\$ 19,609$ & $\$ 19,389$ \\
\hline
\end{tabular}

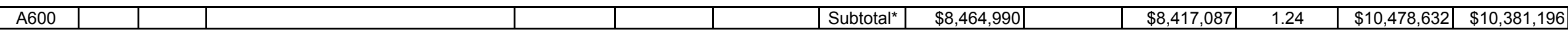




\begin{tabular}{|c|c|c|c|c|c|c|c|c|c|c|c|c|c|}
\hline Equip No. & $\begin{array}{l}\text { No. } \\
\text { Req'd }\end{array}$ & $\begin{array}{c}\text { No. } \\
\text { Spares }\end{array}$ & Equip Name & Scaled On & $\begin{array}{c}\text { Size Ratio } \\
\text { (Base/ } \\
\text { Current) }\end{array}$ & $\begin{array}{c}\text { Original } \\
\text { Equip Cost } \\
\text { (per unit) }\end{array}$ & $\begin{array}{l}\text { Base } \\
\text { Year }\end{array}$ & $\begin{array}{c}\text { Total Original } \\
\text { Equip Cost } \\
\text { (Req'd \& } \\
\text { Spare) in } \\
\text { Base Year }\end{array}$ & $\begin{array}{c}\text { Scaling } \\
\text { Exponent }\end{array}$ & $\begin{array}{c}\text { Scaled Cost } \\
\text { in Base Year }\end{array}$ & $\begin{array}{c}\text { Installation } \\
\text { Factor }\end{array}$ & $\begin{array}{c}\text { Installed } \\
\text { Cost in Base } \\
\text { Year }\end{array}$ & $\begin{array}{c}\text { Installed } \\
\text { Cost in } \\
1997 \$\end{array}$ \\
\hline A-701 & 1 & & Denaturant In-line Mixer & Flow & 1.00 & $\$ 1,900$ & 1997 & $\$ 1,900$ & 0.48 & $\$ 1,899$ & 1 & $\$ 1,899$ & $\$ 1,899$ \\
\hline P-701 & 2 & 1 & Ethanol Product Pump & Flow & 1.00 & $\$ 7,500$ & 1997 & $\$ 22,500$ & 0.79 & $\$ 22,508$ & 2.8 & $\$ 63,022$ & $\$ 63,022$ \\
\hline P-703 & 1 & 1 & Sulfuric Acid Pump & Flow & 1.13 & $\$ 8,000$ & 1997 & $\$ 16,000$ & 0.79 & $\$ 17,663$ & 2.8 & $\$ 49,456$ & $\$ 49,456$ \\
\hline P-704 & 1 & 1 & Firewater Pump & Flow & 1.00 & $\$ 18,400$ & 1997 & $\$ 36,800$ & 0.79 & $\$ 36,811$ & 2.8 & $\$ 103,072$ & $\$ 103,072$ \\
\hline P-706 & 1 & 1 & Ammonia Pump & Flow & 1.20 & $\$ 5,000$ & 1997 & $\$ 10,000$ & 0.79 & $\$ 11,581$ & 2.8 & $\$ 32,427$ & $\$ 32,427$ \\
\hline P-707 & 1 & 1 & Antifoam Store Pump & Flow & 1.00 & $\$ 5,700$ & 1997 & $\$ 11,400$ & 0.79 & $\$ 11,397$ & 2.8 & $\$ 31,912$ & $\$ 31,912$ \\
\hline P-708 & 1 & 1 & Diesel Pump & Flow & 1.00 & $\$ 6,100$ & 1997 & $\$ 12,200$ & 0.79 & $\$ 12,201$ & 2.8 & $\$ 34,162$ & $\$ 34,162$ \\
\hline P-710 & 1 & 1 & Gasoline Pump & Flow & 0.98 & $\$ 4,500$ & 1997 & $\$ 9,000$ & 0.79 & $\$ 8,833$ & 2.8 & $\$ 24,732$ & $\$ 24,732$ \\
\hline P-720 & 1 & 1 & CSL Pump & Flow & 0.97 & $\$ 8,800$ & 1997 & $\$ 17,600$ & 0.79 & $\$ 17,178$ & 2.8 & $\$ 48,100$ & $\$ 48,100$ \\
\hline $\mathrm{T}-701$ & 2 & & Ethanol Product Storage Tank & Flow & 1.00 & $\$ 165,800$ & 1997 & $\$ 331,600$ & 0.51 & $\$ 331,675$ & 1.4 & $\$ 464,345$ & $\$ 464,345$ \\
\hline $\mathrm{T}-703$ & 1 & & Sulfuric Acid Storage Tank & Flow & 1.13 & $\$ 42,500$ & 1997 & $\$ 42,500$ & 0.51 & $\$ 45,301$ & 1.2 & $\$ 54,361$ & $\$ 54,361$ \\
\hline $\mathrm{T}-704$ & 1 & & \begin{tabular}{|l} 
Firewater Storage Tank \\
\end{tabular} & Flow & 1.00 & $\$ 166,100$ & 1997 & $\$ 166,100$ & 0.51 & $\$ 166,146$ & 1.4 & $\$ 232,604$ & $\$ 232,604$ \\
\hline $\mathrm{T}-706$ & 1 & & Ammonia Storage Tank & Flow & 1.20 & $\$ 287,300$ & 1997 & $\$ 287,300$ & 0.72 & $\$ 328,423$ & 1.4 & $\$ 459,792$ & $\$ 459,792$ \\
\hline T-707 & 1 & & Antifoam Storage Tank & Flow & 1.00 & $\$ 14,400$ & 1997 & $\$ 14,400$ & 0.71 & $\$ 14,397$ & 1.4 & $\$ 20,155$ & $\$ 20,155$ \\
\hline $\mathrm{T}-708$ & 1 & & Diesel Storage Tank & Flow & 1.00 & $\$ 14,400$ & 1997 & $\$ 14,400$ & 0.51 & $\$ 14,400$ & 1.4 & $\$ 20,161$ & $\$ 20,161$ \\
\hline $\mathrm{T}-710$ & 1 & & Gasoline Storage Tank & Flow & 0.98 & $\$ 43,500$ & 1997 & $\$ 43,500$ & 0.51 & $\$ 42,977$ & 1.4 & $\$ 60,167$ & $\$ 60,167$ \\
\hline $\mathrm{T}-720$ & 1 & & CSL Storage Tank & Flow & 0.97 & $\$ 88,100$ & 1997 & $\$ 88,100$ & 0.79 & $\$ 85,990$ & 1.4 & $\$ 120,386$ & $\$ 120,386$ \\
\hline A700 & & & & & & & Subtotal $^{\star}$ & $\$ 1,125,300$ & & $\$ 1,169,380$ & 1.56 & $\$ 1,820,753$ & $\$ 1,820,753$ \\
\hline
\end{tabular}




\begin{tabular}{|c|c|c|c|c|c|c|c|c|c|c|c|c|c|}
\hline Equip No. & $\begin{array}{l}\text { No. } \\
\text { Req'd }\end{array}$ & $\begin{array}{c}\text { No. } \\
\text { Spares }\end{array}$ & Equip Name & Scaled On & $\begin{array}{c}\text { Size Ratio } \\
\text { (Base/ } \\
\text { Current) }\end{array}$ & $\begin{array}{c}\text { Original } \\
\text { Equip Cost } \\
\text { (per unit) }\end{array}$ & $\begin{array}{l}\text { Base } \\
\text { Year }\end{array}$ & \begin{tabular}{|c|} 
Total Original \\
Equip Cost \\
(Req'd \& \\
Spare) in \\
Base Year
\end{tabular} & $\begin{array}{c}\text { Scaling } \\
\text { Exponent }\end{array}$ & $\begin{array}{c}\text { Scaled Cost } \\
\text { in Base Year }\end{array}$ & $\begin{array}{c}\text { Installation } \\
\text { Factor }\end{array}$ & $\begin{array}{c}\text { Installed } \\
\text { Cost in Base } \\
\text { Year }\end{array}$ & $\begin{array}{l}\text { Installed } \\
\text { Cost in } \\
1997 \$\end{array}$ \\
\hline $\mathrm{H}-811$ & 1 & & BFW Preheater & Area & 1.03 & $\$ 58,400$ & 1997 & $\$ 58,400$ & 0.68 & $\$ 59,609$ & 2.1 & $\$ 125,178$ & $\$ 125,178$ \\
\hline $\mathrm{M}-801$ & 1 & & Solid Feed Rotary Dryer & Flow & 1.00 & $\$ 1,620,000$ & 1998 & $\$ 1,620,000$ & 0.45 & $\$ 1,621,871$ & 1.6 & $\$ 2,594,994$ & $\$ 2,565,938$ \\
\hline $\mathrm{M}-803$ & 1 & & Fluidized Bed Combustion Reactor & Flow & 0.69 & $\$ 24,900,000$ & 1998 & $\$ 24,900,000$ & 0.75 & $\$ 18,835,267$ & 1.3 & $\$ 24,485,847$ & $\$ 24,211,676$ \\
\hline M-804 & 1 & & Combustion Gas Baghouse & Flow & 0.22 & $\$ 2,536,300$ & 1998 & $\$ 2,536,300$ & 0.58 & $\$ 1,061,116$ & 1.5 & $\$ 1,591,674$ & $\$ 1,573,852$ \\
\hline $\mathrm{M}-811$ & 1 & & Turbine/Generator & Flow & 0.84 & $\$ 10,000,000$ & 1998 & $\$ 10,000,000$ & 0.71 & $\$ 8,809,671$ & 1.5 & $\$ 13,214,507$ & $\$ 13,066,543$ \\
\hline M-820 & 1 & & Hot Process Water Softener System & Flow & 0.96 & $\$ 1,381,300$ & 1999 & $\$ 1,381,300$ & 0.82 & $\$ 1,334,444$ & 1.3 & $\$ 1,734,777$ & $\$ 1,696,358$ \\
\hline $\mathrm{M}-830$ & 1 & & Hydrazine Addition Pkg. & Flow & 1.06 & $\$ 19,000$ & 1994 & $\$ 19,000$ & 0.6 & $\$ 19,645$ & 1 & $\$ 19,645$ & $\$ 20,501$ \\
\hline $\mathrm{M}-832$ & 1 & & Ammonia Addition Pkg & Flow & 1.06 & $\$ 19,000$ & 1994 & $\$ 19,000$ & 0.6 & $\$ 19,645$ & 1 & $\$ 19,645$ & $\$ 20,501$ \\
\hline M-834 & 1 & & Phosphate Addition Pkg. & Flow & 1.06 & $\$ 19,000$ & 1994 & $\$ 19,000$ & 0.6 & $\$ 19,645$ & 1 & $\$ 19,645$ & $\$ 20,501$ \\
\hline P-804 & 2 & & Condensate Pump & Flow & 2.36 & $\$ 7,100$ & 1997 & $\$ 14,200$ & 0.79 & $\$ 28,010$ & 2.8 & $\$ 78,427$ & $\$ 78,427$ \\
\hline $\mathrm{P}-811$ & 2 & & Turbine Condensate Pump & Flow & 1.40 & $\$ 7,800$ & 1997 & $\$ 15,600$ & 0.79 & $\$ 20,401$ & 2.8 & $\$ 57,123$ & $\$ 57,123$ \\
\hline $\mathrm{P}-824$ & 2 & & Deaerator Feed Pump & Flow & 0.74 & $\$ 9,500$ & 1997 & $\$ 19,000$ & 0.79 & $\$ 14,940$ & 2.8 & $\$ 41,833$ & $\$ 41,833$ \\
\hline$P-826$ & 5 & & BFW Pump & Flow & 0.43 & $\$ 52,501$ & 1998 & $\$ 262,505$ & 0.79 & $\$ 134,639$ & 2.8 & $\$ 376,988$ & $\$ 372,767$ \\
\hline $\mathrm{P}-828$ & 2 & & Blowdown Pump & Flow & 1.10 & $\$ 5,100$ & 1997 & $\$ 10,200$ & 0.79 & $\$ 10,999$ & 2.8 & $\$ 30,796$ & $\$ 30,796$ \\
\hline $\mathrm{P}-830$ & 1 & & Hydrazine Transfer Pump & Flow & 1.06 & $\$ 5,500$ & 1997 & $\$ 5,500$ & 0.79 & $\$ 5,747$ & 2.8 & $\$ 16,091$ & $\$ 16,091$ \\
\hline $\mathrm{T}-804$ & 1 & & Condensate Collection Tank & Flow & 0.63 & $\$ 7,100$ & 1997 & $\$ 7,100$ & 0.71 & $\$ 5,141$ & 1.4 & $\$ 7,198$ & $\$ 7,198$ \\
\hline $\mathrm{T}-824$ & 1 & & Condensate Surge Drum & Flow & 0.97 & $\$ 49,600$ & 1997 & $\$ 49,600$ & 0.72 & $\$ 48,668$ & 1.7 & $\$ 82,736$ & $\$ 82,736$ \\
\hline $\mathrm{T}-826$ & 1 & & Deaerator & Flow & 0.91 & $\$ 165,000$ & 1998 & $\$ 165,000$ & 0.72 & $\$ 154,281$ & 2.8 & $\$ 431,986$ & $\$ 427,149$ \\
\hline $\mathrm{T}-828$ & 1 & & Blowdown Flash Drum & Flow & 1.11 & $\$ 9,200$ & 1997 & $\$ 9,200$ & 0.72 & $\$ 9,908$ & 2.8 & $\$ 27,743$ & $\$ 27,743$ \\
\hline $\mathrm{T}-830$ & 1 & & Hydrazine Drum & Flow & 1.06 & $\$ 12,400$ & 1997 & $\$ 12,400$ & 0.93 & $\$ 13,058$ & 1.7 & $\$ 22,199$ & $\$ 22,199$ \\
\hline A800 & & & & & & & Subtotal $^{\star}$ & $\$ 41,123,305$ & & $\$ 32,226,704$ & 1.40 & $\$ 44,979,031$ & $\$ 44,465,109$ \\
\hline
\end{tabular}




\begin{tabular}{|c|c|c|c|c|c|c|c|c|c|c|c|c|c|}
\hline Equip No. & $\begin{array}{l}\text { No. } \\
\text { Req'd }\end{array}$ & $\begin{array}{c}\text { No. } \\
\text { Spares }\end{array}$ & Equip Name & Scaled On & $\begin{array}{c}\text { Size Ratio } \\
\text { (Base/ } \\
\text { Current) }\end{array}$ & $\begin{array}{c}\text { Original } \\
\text { Equip Cost } \\
\text { (per unit) }\end{array}$ & $\begin{array}{l}\text { Base } \\
\text { Year }\end{array}$ & $\begin{array}{c}\text { Total Original } \\
\text { Equip Cost } \\
\text { (Req'd \& } \\
\text { Spare) in } \\
\text { Base Year }\end{array}$ & $\begin{array}{c}\text { Scaling } \\
\text { Exponent }\end{array}$ & $\begin{array}{l}\text { Scaled Cost } \\
\text { in Base Year }\end{array}$ & $\begin{array}{c}\text { Installation } \\
\text { Factor }\end{array}$ & $\begin{array}{c}\text { Installed } \\
\text { Cost in Base } \\
\text { Year }\end{array}$ & $\begin{array}{c}\text { Installed } \\
\text { Cost in } \\
1997 \$\end{array}$ \\
\hline M-902 & 1 & & Cooling Tower System & Flow & 0.79 & $\$ 1,659,000$ & 1998 & $\$ 1,659,000$ & 0.78 & $\$ 1,374,359$ & 1.2 & $\$ 1,649,231$ & $\$ 1,630,764$ \\
\hline M-904 & 2 & 1 & Plant Air Compressor & Flow & 1.00 & $\$ 60,100$ & 1997 & $\$ 180,300$ & 0.34 & $\$ 180,299$ & 1.3 & $\$ 234,389$ & $\$ 234,389$ \\
\hline M-908 & 3 & & Chilled Water Package & Flow & 0.96 & $\$ 380,000$ & 1997 & $\$ 1,140,000$ & 0.8 & $\$ 1,104,036$ & 1.2 & $\$ 1,324,844$ & $\$ 1,324,844$ \\
\hline M-910 & 1 & & CIP System & Flow & 1.00 & $\$ 95,000$ & 1995 & $\$ 95,000$ & 0.6 & $\$ 95,036$ & 1.2 & $\$ 114,043$ & $\$ 114,954$ \\
\hline P-902 & 1 & 1 & Cooling Water Pumps & Flow & 0.76 & $\$ 332,300$ & 1997 & $\$ 664,600$ & 0.79 & $\$ 533,245$ & 2.8 & $\$ 1,493,085$ & $\$ 1,493,085$ \\
\hline $\mathrm{P}-912$ & 1 & 1 & Make-up Water Pump & Flow & 0.76 & $\$ 10,800$ & 1997 & $\$ 21,600$ & 0.79 & $\$ 17,392$ & 2.8 & $\$ 48,698$ & $\$ 48,698$ \\
\hline $\mathrm{P}-914$ & 2 & 1 & Process Water Circulating Pump & Flow & 0.78 & $\$ 11,100$ & 1997 & $\$ 33,300$ & 0.79 & $\$ 27,307$ & 2.8 & $\$ 76,460$ & $\$ 76,460$ \\
\hline S-904 & 1 & 1 & Instrument Air Dryer & Flow & 1.00 & $\$ 15,498$ & 1999 & $\$ 30,996$ & 0.6 & $\$ 30,996$ & 1.3 & $\$ 40,294$ & $\$ 39,402$ \\
\hline $\mathrm{T}-904$ & 1 & & Plant Air Receiver & Flow & 1.00 & $\$ 13,000$ & 1997 & $\$ 13,000$ & 0.72 & $\$ 13,000$ & 1.3 & $\$ 16,900$ & $\$ 16,900$ \\
\hline $\mathrm{T}-914$ & 1 & & Process Water Tank & Flow & 0.78 & $\$ 195,500$ & 1997 & $\$ 195,500$ & 0.51 & $\$ 171,996$ & 1.4 & $\$ 240,795$ & $\$ 240,795$ \\
\hline
\end{tabular}

\begin{tabular}{|l|l|l|l|l|l|l|l|l|}
\hline & & & & & & & Subtotal $^{*}$ & $\$ 4,033,296$ \\
\hline
\end{tabular}




\section{Appendix C}

Chemical Costs and Sources 


\begin{tabular}{|c|c|c|}
\hline Raw Material & Cost $(\$ / l b)$ & Reference \\
\hline $\mathrm{H} 2 \mathrm{SO} 4$ & $\$ 0.0125$ & \$25/ton -- tanks, works, Chemical Marketing Reporter 2 Nov 98 \\
\hline Lime & $\$ 0.035$ & \$70/ton -- bulk, fob plants, Chemical Marketing Reporter 2 Nov 98 \\
\hline $\mathrm{NH3}$ & $\$ 0.0875$ & $\$ 175 /$ ton -- anhydrous, fertilizer grade, wholesale tanks, Delivered to Midwest Terminals, Chemical Marketing Reporter 2 Nov 98 \\
\hline Corn Steep Liq & $\$ 0.075$ & Analysis of CSL market -- Ruth, M. Report to Process Engineering Team, 5 June 1998 \\
\hline Nutrients & $\$ 0.124$ & Schell, 1991. P. 48 \\
\hline Ammonium Sulfate & $\$ 0.0225$ & \$45/ton -- standard commercial, fob works, Chemical Marketing Reporter 2 Nov 98 \\
\hline Antifoam & $\$ 0.249$ & Corn Oil -- crude, tank cars, fob Decatur, US Dept. of Agriculture, Agricultural Statistics 1998 Table 3-56 \\
\hline Gasoline & $\$ 0.0898$ & $\$ 0.515 / \mathrm{gal}$-- Density of $0.6875 \mathrm{~g} / \mathrm{mL}$, DOE Energy Information Administration Average Cost of Wholesale Unleaded Gasoline in July 1997 \\
\hline Diesel & $\$ 0.0615$ & $\$ 0.426$ / gal -- Density of $0.83 \mathrm{~g} / \mathrm{mL}$, DOE Energy Information Administration Average Cost of Wholesale \#2 Diesel in July 1998 \\
\hline Makeup Water & $\$ 0.00012$ & $\$ 1 / 1000$ gal: Middle of Range $\$ 0.35-\$ 1.50 / 1000$ gal Peters \& Timmerhaus, p 815 \\
\hline BFW Chemicals & $\$ 0.97$ & Radian Report, Cases \\
\hline CW Chemicals & $\$ 1.00$ & Unknown \\
\hline WWT Nutrients & $\$ 0.11$ & Merrick Report Appendix G \\
\hline WWT Chemicals & $\$ 2.50$ & Merrick Report Appendix G \\
\hline \multicolumn{3}{|l|}{ Utility } \\
\hline Solid Disposal & $\$ 0.01$ & \$20/ton -- Chem Systems Report 1993 \\
\hline
\end{tabular}




\section{Appendix D Discounted Cash Flow Rate of Return Summary}




\begin{tabular}{|c|c|c|c|c|c|c|c|c|c|c|c|c|c|c|}
\hline \multirow{2}{*}{$\begin{array}{l}\text { Year } \\
\text { Fixed Capital Investment } \\
\text { Working Capital }\end{array}$} & & & -1 & $\overline{0}$ & 1 & \multirow[t]{2}{*}{2} & \multirow{2}{*}{3} & \multirow{2}{*}{4} & \multirow{2}{*}{5} & \multirow{2}{*}{6} & \multirow{2}{*}{7} & \multirow[t]{2}{*}{8} & \multirow{2}{*}{9} & \multirow{2}{*}{10} \\
\hline & & $\$ 18,706,738$ & $\$ 140,300,534$ & $\begin{array}{l}\$ 74,826,951 \\
\$ 11,691,711\end{array}$ & & & & & & & & & & \\
\hline Ethanol Sales & & & & & $\$ 56,344,666$ & $\$ 75,126,221$ & $\$ 75,126,221$ & $\$ 75,126,221$ & $\$ 75,126,221$ & $\$ 75,126,221$ & $\$ 75,126,221$ & $\$ 75,126,221$ & $\$ 75,126,221$ & $\$ 75,126,221$ \\
\hline By-Product Credit & & & & & $\$ 2,801,911$ & $\$ 3,735,882$ & $\$ 3,735,882$ & $\$ 3,735,882$ & $\$ 3,735,882$ & $\$ 3,735,882$ & $\$ 3,735,882$ & $\$ 3,735,882$ & $\$ 3,735,882$ & $\$ 3,735,882$ \\
\hline Total Annual Sales & & & & & $\$ 59,146,578$ & $\$ 78,862,103$ & $\$ 78,862,103$ & $\$ 78,862,103$ & $\$ 78,862,103$ & $\$ 78,862,103$ & $\$ 78,862,103$ & $\$ 78,862,103$ & $\$ 78,862,103$ & $\$ 78,862,103$ \\
\hline \multicolumn{15}{|l|}{ Annual Manufacturing Cost } \\
\hline Raw Materials & & & & & $\$ 16,894,022$ & $\$ 19,307,454$ & $\$ 19,307,454$ & $\$ 19,307,454$ & $\$ 19,307,454$ & $\begin{array}{l}\$ 19,307,454 \\
\$ 16,376\end{array}$ & $\$ 19,307,454$ & $\$ 19,307,454$ & $\$ 19,307,454$ & $\$ 19,307,454$ \\
\hline Baghouse Bags & & & & & $\$ 341,730$ & & & & & $\$ 341,730$ & & & & \\
\hline Other Variable Costs & & & & & $\$ 8,367,094$ & $\$ 9,562,393$ & $\$ 9,562,393$ & $\$ 9,562,393$ & $\$ 9,562,393$ & $\$ 9,562,393$ & $\$ 9,562,393$ & $\$ 9,562,393$ & $\$ 9,562,393$ & $\$ 9,562,393$ \\
\hline Fixed Operating Costs & & & & & $\$ 7,484,090$ & $\$ 7,484,090$ & $\$ 7,484,090$ & $\$ 7,484,090$ & $\$ 7,484,090$ & $\$ 7,484,090$ & $\$ 7,484,090$ & $\$ 7,484,090$ & $\$ 7,484,090$ & $\$ 7,484,090$ \\
\hline Total Product Cost & & & & & $\$ 33,803,313$ & $\$ 36,353,937$ & $\$ 36,353,937$ & $\$ 36,353,937$ & $\$ 36,353,937$ & $\$ 37,412,043$ & $\$ 36,353,937$ & $\$ 36,353,937$ & $\$ 36,353,937$ & $\$ 36,353,937$ \\
\hline Annual Depreciation & & & & & & & & & & & & & & \\
\hline General Plant & & & & & & & & & & & & & & \\
\hline DDB & & & & & $\$ 44,808,645$ & $\$ 32,006,175$ & $\$ 22,861,553$ & $\$ 16,329,681$ & $\$ 11,664,058$ & $\$ 8,331,470$ & $\$ 5,951,050$ & & & \\
\hline SL & & & & & $\$ 22,404,322$ & $\$ 18,670,269$ & $\$ 16,003,087$ & $\$ 14,288,471$ & $\$ 13,608,067$ & $\$ 13,608,067$ & $\$ 13,608,067$ & & & \\
\hline Remaining Value & & & & & $\$ 112,021,612$ & $\$ 80,015,437$ & $\$ 57,153,883$ & $\$ 40,824,202$ & $\$ 29,160,145$ & $\$ 20,828,675$ & $\$ 14,877,625$ & & & \\
\hline Actual & & & & & $\$ 44,808,645$ & $\$ 32,006,175$ & $\$ 22,861,553$ & $\$ 16,329,681$ & $\$ 13,608,067$ & $\$ 13,608,067$ & $\$ 13,608,067$ & & & \\
\hline Steam Plant & & & & & & & & & & & & & & \\
\hline DDB & & & & & $\$ 5,775,298$ & $\$ 5,342,150$ & $\$ 4,941,489$ & $\$ 4,570,877$ & $\$ 4,228,061$ & $\$ 3,910,957$ & $\$ 3,617,635$ & $\$ 3,346,312$ & $\$ 3,095,339$ & $\$ 2,863,189$ \\
\hline SL & & & & & $\$ 3,850,198$ & $\$ 3,748,877$ & $\$ 3,660,362$ & $\$ 3,585,002$ & $\$ 3,523,385$ & $\$ 3,476,406$ & $\$ 3,445,367$ & $\$ 3,432,115$ & $\$ 3,432,115$ & $\$ 3,432,115$ \\
\hline Remaining Value & & & & & $\$ 71,228,669$ & $\$ 65,886,519$ & $\$ 60,945,030$ & $\$ 56,374,153$ & $\$ 52,146,092$ & $\$ 48,235,135$ & $\$ 44,617,500$ & $\$ 41,271,187$ & $\$ 38,175,848$ & $\$ 35,312,659$ \\
\hline Actual & & & & & $\$ 5,775,298$ & $\$ 5,342,150$ & $\$ 4,941,489$ & $\$ 4,570,877$ & $\$ 4,228,061$ & $\$ 3,910,957$ & $\$ 3,617,635$ & $\$ 3,432,115$ & $\$ 3,432,115$ & $\$ 3,432,115$ \\
\hline Taxable Income & & & & & $-\$ 25,240,677$ & $\$ 5,159,842$ & $\$ 14,705,124$ & $\$ 21,607,608$ & $\$ 24,672,038$ & $\$ 23,931,036$ & $\$ 25,282,464$ & $\$ 39,076,051$ & $\$ 39,076,051$ & $\$ 39,076,051$ \\
\hline Income Tax & & & & & $\$ 0$ & $\$ 2,012,338$ & $\$ 5,734,998$ & $\$ 8,426,967$ & $\$ 9,622,095$ & $\$ 9,333,104$ & $\$ 9,860,161$ & $\$ 15,239,660$ & $\$ 15,239,660$ & $\$ 15,239,660$ \\
\hline Annual Cash Income & & & & & $\$ 25,343,265$ & $\$ 40,495,828$ & $\$ 36,773,168$ & $\$ 34,081,199$ & $\$ 32,886,072$ & $\$ 32,116,956$ & $\$ 32,648,006$ & $\$ 27,268,507$ & $\$ 27,268,507$ & $\$ 27,268,507$ \\
\hline Discount Factor & & 1.21 & 1.10 & 1.00 & 0.91 & 0.83 & 0.75 & 0.68 & 0.62 & 0.56 & 0.51 & 0.47 & 0.42 & 0.39 \\
\hline Annual Present Value & $\$ 261,746,504$ & & & & $\$ 23,039,332$ & $\$ 33,467,627$ & $\$ 27,628,226$ & $\$ 23,277,918$ & $\$ 20,419,663$ & $\$ 18,129,184$ & $\$ 16,753,589$ & $\$ 12,720,960$ & $\$ 11,564,509$ & $\$ 10,513,190$ \\
\hline Total Capital Investment + Interest & & $\$ 22,635,153$ & $\$ 154,330,587$ & $\$ 86,518,663$ & & & & & & & & & & \\
\hline Net Present Worth & & & & 8 & & & & & & & & & & \\
\hline$\overline{\text { Year }}$ & & & & & 11 & $\overline{12}$ & 13 & $\overline{14}$ & $\overline{15}$ & $\overline{16}$ & 17 & 18 & 19 & $\overline{20}$ \\
\hline Fixed Capital Investment & & & & & & & & & & & & & & \\
\hline Working Capital & & & & & & & & & & & & & & $-\$ 11,691,711$ \\
\hline Ethanol Sales & & & & & $\$ 75,126,221$ & $\$ 75,126,221$ & $\$ 75,126,221$ & $\$ 75,126,221$ & $\$ 75,126,221$ & $\$ 75,126,221$ & $\$ 75,126,221$ & $\$ 75,126,221$ & $\$ 75,126,221$ & $\$ 75,126,221$ \\
\hline By-Product Credit & & & & & $\$ 3,735,882$ & $\$ 3,735,882$ & $\$ 3,735,882$ & $\$ 3,735,882$ & $\$ 3,735,882$ & $\$ 3,735,882$ & $\$ 3,735,882$ & $\$ 3,735,882$ & $\$ 3,735,882$ & $\$ 3,735,882$ \\
\hline Total Annual Sales & & & & & $\$ 78,862,103$ & $\$ 78,862,103$ & $\$ 78,862,103$ & $\$ 78,862,103$ & $\$ 78,862,103$ & $\$ 78,862,103$ & $\$ 78,862,103$ & $\$ 78,862,103$ & $\$ 78,862,103$ & $\$ 78,862,103$ \\
\hline Annual Manufacturing Cost & & & & & & & & & & & & & & \\
\hline Raw Materials & & & & & $\$ 19,307,454$ & $\$ 19,307,454$ & $\$ 19,307,454$ & $\$ 19,307,454$ & $\$ 19,307,454$ & $\$ 19,307,454$ & $\$ 19,307,454$ & $\$ 19,307,454$ & $\$ 19,307,454$ & $\$ 19,307,454$ \\
\hline lon Exchange Resin & & & & & $\$ 716,376$ & & & & & $\$ 716,376$ & & & & \\
\hline Baghouse Bags & & & & & $\$ 341,730$ & & & & & $\$ 341,730$ & & & & \\
\hline Other Variable Costs & & & & & $\$ 9,562,393$ & $\$ 9,562,393$ & $\$ 9,562,393$ & $\$ 9,562,393$ & $\$ 9,562,393$ & $\$ 9,562,393$ & $\$ 9,562,393$ & $\$ 9,562,393$ & $\$ 9,562,393$ & $\$ 9,562,393$ \\
\hline Fixed Operating Costs & & & & & $\$ 7,484,090$ & $\$ 7,484,090$ & $\$ 7,484,090$ & $\$ 7,484,090$ & $\$ 7,484,090$ & $\$ 7,484,090$ & $\$ 7,484,090$ & $\$ 7,484,090$ & $\$ 7,484,090$ & $\$ 7,484,090$ \\
\hline Total Product Cost & & & & & $\$ 37,412,043$ & $\$ 36,353,937$ & $\$ 36,353,937$ & $\$ 36,353,937$ & $\$ 36,353,937$ & $\$ 37,412,043$ & $\$ 36,353,937$ & $\$ 36,353,937$ & $\$ 36,353,937$ & $\$ 36,353,937$ \\
\hline Annual Depreciation & & & & & & & & & & & & & & \\
\hline General Plant & & & & & & & & & & & & & & \\
\hline DDB & & & & & & & & & & & & & & \\
\hline SL & & & & & & & & & & & & & & \\
\hline Remaining Value & & & & & & & & & & & & & & \\
\hline Actual & & & & & & & & & & & & & & \\
\hline Steam Plant & & & & & & & & & & & & & & \\
\hline DDB & & & & & $\$ 2,648,449$ & $\$ 2,449,816$ & $\$ 2,266,080$ & $\$ 2,096,124$ & $\$ 1,938,914$ & $\$ 1,793,496$ & $\$ 1,658,984$ & $\$ 1,534,560$ & $\$ 1,419,468$ & $\$ 1,313,008$ \\
\hline SL & & & & & $\$ 3,432,115$ & $\$ 3,432,115$ & $\$ 3,432,115$ & $\$ 3,432,115$ & $\$ 3,432,115$ & $\$ 3,432,115$ & $\$ 3,432,115$ & $\$ 3,432,115$ & $\$ 3,432,115$ & $\$ 3,432,115$ \\
\hline Remaining Value & & & & & $\$ 32,664,210$ & $\$ 30,214,394$ & $\$ 27,948,315$ & $\$ 25,852,191$ & $\$ 23,913,277$ & $\$ 22,119,781$ & $\$ 20,460,797$ & $\$ 18,926,238$ & $\$ 17,506,770$ & $\$ 16,193,762$ \\
\hline Actual & & & & & $\$ 3,432,115$ & $\$ 3,432,115$ & $\$ 3,432,115$ & $\$ 3,432,115$ & $\$ 3,432,115$ & $\$ 3,432,115$ & $\$ 3,432,115$ & $\$ 3,432,115$ & $\$ 3,432,115$ & $\$ 3,432,115$ \\
\hline Taxable Income & & & & & $\$ 38,017,945$ & $\$ 39,076,051$ & $\$ 39,076,051$ & $\$ 39,076,051$ & $\$ 39,076,051$ & $\$ 38,017,945$ & $\$ 39,076,051$ & $\$ 39,076,051$ & $\$ 39,076,051$ & $\$ 39,076,051$ \\
\hline Income Tax & & & & & $\$ 14,826,998$ & $\$ 15,239,660$ & $\$ 15,239,660$ & $\$ 15,239,660$ & $\$ 15,239,660$ & $\$ 14,826,998$ & $\$ 15,239,660$ & $\$ 15,239,660$ & $\$ 15,239,660$ & $\$ 15,239,660$ \\
\hline Annual Cash Income & & & & & $\$ 26,623,062$ & $\$ 27,268,507$ & $\$ 27,268,507$ & $\$ 27,268,507$ & $\$ 27,268,507$ & $\$ 26,623,062$ & $\$ 27,268,507$ & $\$ 27,268,507$ & $\$ 27,268,507$ & $\$ 27,268,507$ \\
\hline Discount Factor & & & & & 0.35 & 0.32 & 0.29 & 0.26 & 0.24 & 0.22 & 0.20 & 0.18 & 0.16 & 0.15 \\
\hline Annual Present Value & & & & & $\$ 9,331,221$ & $\$ 8,688,587$ & $\$ 7,898,715$ & $\$ 7,180,650$ & $\$ 6,527,864$ & $\$ 5,793,954$ & $\$ 5,394,929$ & $\$ 4,904,481$ & $\$ 4,458,619$ & $\$ 4,053,290$ \\
\hline Total Capital Investment + Interest & & & & & & & & & & & & & & $-\$ 1,737,898$ \\
\hline
\end{tabular}




\section{Ethanol Production Process Engineering Analysis}

NREL Year 2000 Case Co-Current Pretreatment \& Enzymatic Hydrolysis

All Values in $1997 \$$

\section{Ethanol Production Cost $\$ 1.44$}

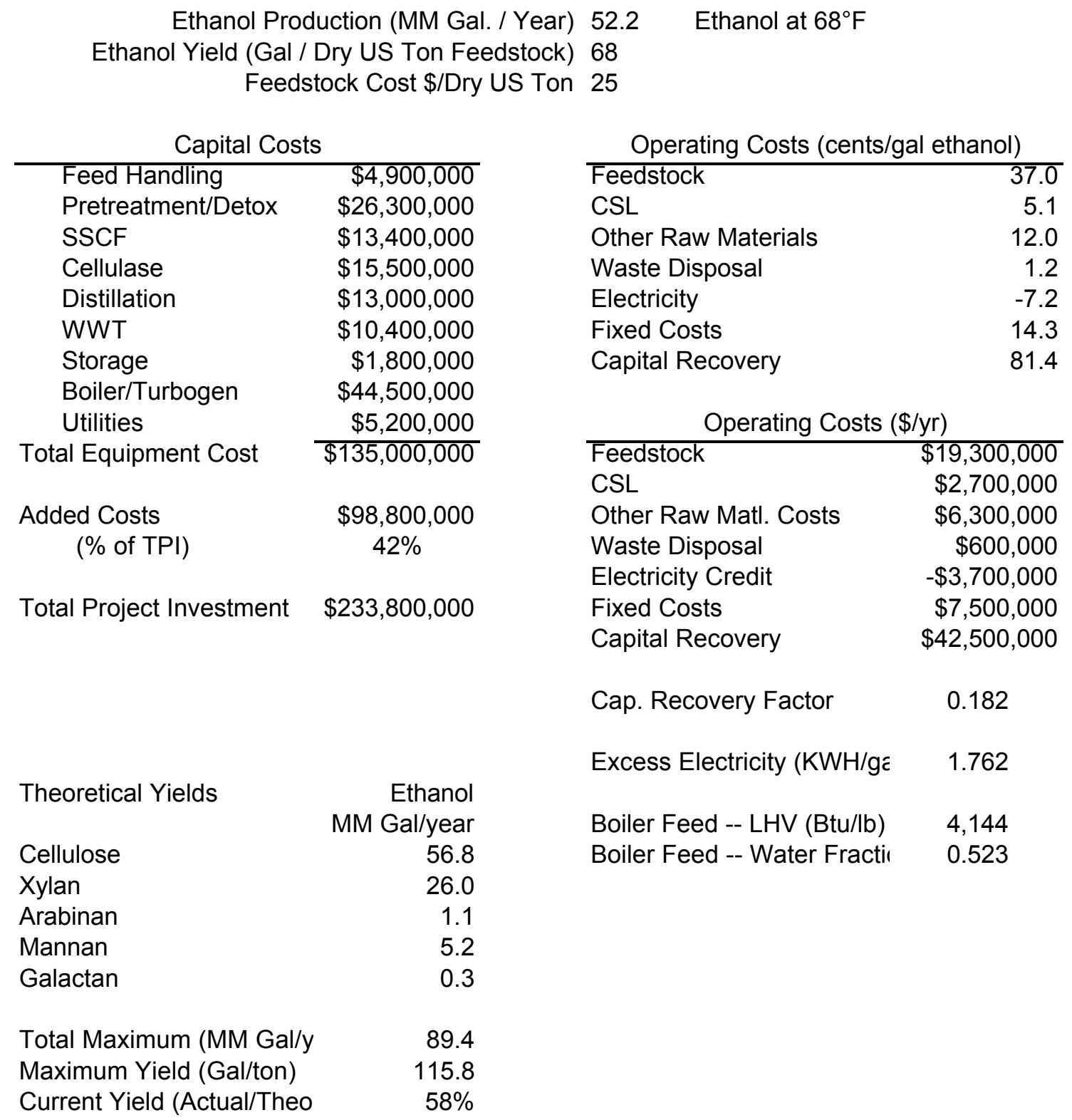

File: r9906a.xls 


\begin{tabular}{|c|c|c|c|c|c|c|c|c|c|c|c|}
\hline $\begin{array}{l}\text { Ethanol } \\
\text { Production Rate } \\
(\mathrm{MM} \text { gal/yr) }\end{array}$ & 52.20 & 18,557 & \begin{tabular}{|l|} 
Feedstock \\
Dry \\
Tons/yr
\end{tabular} & 772165 & & & & & & & \\
\hline & & & gal/ton & 68 & & & & & & & \\
\hline $\begin{array}{l}\text { Operatıng } \\
\text { Hours per Year }\end{array}$ & 8,406 & & & & & & & & & & \\
\hline Resin Charge & Stream No. & $\begin{array}{l}\text { Acetic } \\
\text { Acid }\end{array}$ & & $\begin{array}{l}\text { Sulfuric } \\
\text { Acid }\end{array}$ & $\begin{array}{l}\text { Base } \\
\text { Resin,CF }\end{array}$ & $\begin{array}{l}\text { Base } \\
\text { Acetic }\end{array}$ & Base H2SO4 & $\begin{array}{l}\text { Required, } \\
\text { CF }\end{array}$ & & & \\
\hline & ACET220A & 3,803 & SULF220 & 921 & 2500 & 1,748 & 357 & 5731 & & & \\
\hline \multicolumn{2}{|c|}{ Variable Operating Costs } & & & & & & & & & & \\
\hline Raw Material & Stream No. & kg/hr & $\mathbf{l b} / \mathbf{h r}$ & $\begin{array}{l}1995 \\
\text { Cost } \\
(\$ / 1 b)\end{array}$ & \$/hour & $\begin{array}{c}\text { MM\$ } / \mathbf{y r} \\
\text { (1995) }\end{array}$ & $\begin{array}{c}\text { Cents/Gailon } \\
\text { Ethanol } \\
(1995)\end{array}$ & $\begin{array}{c}\text { MM\$/yr } \\
(1997)\end{array}$ & $\begin{array}{c}\text { Cents/Gallon } \\
\text { Ethanol } \\
\text { (1997) }\end{array}$ & & \\
\hline Feedstock & STRM0101 & 159,948 & 352,685 & 0.006513 & 2,297 & 19.31 & 36.99 & 19.31 & 36.99 & & \\
\hline $\mathrm{H} 2 \mathrm{SO} 4$ & STRM0710 & 1,867 & 4,116 & 0.0120 & 49 & 0.41 & 0.79 & 0.42 & 0.80 & & \\
\hline Lime & STRM0745 & 714 & 1,574 & 0.0335 & 53 & 0.44 & 0.85 & 0.45 & 0.86 & & \\
\hline NH3 & STRM0717 & 1,419 & 3,128 & 0.0837 & 262 & 2.20 & 4.22 & 2.23 & 4.28 & & \\
\hline Corn Steep L1q & STRMU/35 & $1, \mathrm{YTT}$ & 4,360 & $0.0 / 2$ & 313 & 2.63 & 5.04 & $2.6 \%$ & 5.12 & & \\
\hline Nutrients & STRM0415 & 174 & 385 & 0.132 & 51 & 0.43 & 0.82 & 0.43 & 0.83 & & \\
\hline Ammonium & STRM0420 & 392 & 865 & 0.02 & 19 & 0.16 & 0.30 & 0.16 & 0.301 & $1.4 \mathrm{~g} / \mathrm{L}$ is calculated in Nutrien & 11.4 \\
\hline Antifoam & STRM0417 & 227 & 500 & 0.2412 & 121 & 1.01 & 1.94 & 1.03 & 1.97 & & \\
\hline Diesel & STRM0723 & 443 & 977 & 0.0588 & 57 & 0.48 & 0.93 & 0.49 & 0.94 & & \\
\hline Makeup Water & STRM0903 & 185,593 & 409,232 & \#\#\#\#\#\# & 53 & 0.45 & 0.85 & 0.45 & 0.87 & & \\
\hline BFW & STRM0921 & 0 & 1 & 1.49 & 2 & 0.01 & 0.02 & 0.01 & $0.02 \$$ & $\$ 1.40 /$ lb avg cost in Radian re & eport, 199 \\
\hline CW Chemicals & STRM0922 & 5 & 12 & 1.00 & 12 & 0.10 & 0.19 & 0.10 & 0.19 & & \\
\hline WWT Nutrients & STRM0630 & 230 & 508 & 0.11 & 53 & 0.45 & 0.86 & 0.46 & 0.87 & & \\
\hline WWT & STRM0631 & 0.76 & 1.68 & 2.39 & 4 & 0.03 & 0.06 & 0.03 & 0.07 & & \\
\hline Subtotal & & & & & 3,345 & 28.12 & 53.86 & 28.25 & 54.12 & & \\
\hline & & & & & & & & & & & \\
\hline \multicolumn{12}{|l|}{ Waste Streams } \\
\hline Solids Disposal & STRM0809 & 1,106 & 2,438 & 0.01 & 23 & 0.19 & 0.36 & 0.19 & & \\
\hline Solids Disposal & STRM0229 & 2,433 & 5,364 & 0.01 & 50 & 0.42 & 0.80 & 0.42 & \multicolumn{2}{|c|}{\begin{tabular}{l|l}
$0.320 /$ metric ton in CSI report, 1993 \\
0.81 & $\mathbf{\$ 2 0}$ /metric ton in CSI report, 1993
\end{tabular}} & \\
\hline Subtotal & & & & & 72 & 0.61 & 1.17 & 0.62 & 1.18 & & \\
\hline $\begin{array}{l}\text { By-Product } \\
\text { Credits }\end{array}$ & & KW & & & & & & & & & \\
\hline Electricity & WRKWKN & 10,942 & na & 0.040 & 438 & 3.68 & 7.05 & 3.74 & 7.16 & & \\
\hline \multicolumn{12}{|l|}{ Subtotal } \\
\hline $\begin{array}{l}\text { Total Variable } \\
\text { Operating }\end{array}$ & & & & & 2,979 & 25.05 & 47.98 & 25.13 & 48.15 & & \\
\hline & & & & & & & & & & & \\
\hline & & & & & & & & & & & \\
\hline \multicolumn{12}{|l|}{\begin{tabular}{|l} 
Fixed \\
Operating
\end{tabular}} \\
\hline Plant Manager & 80000 & 1 & 80,000 & & & & & & & & \\
\hline Plant Engineer & 65000 & 1 & 65,000 & & & & & & & & \\
\hline Supr & 60000 & 1 & 60,000 & & & & & & & & \\
\hline Lab Manager & 50000 & 1 & 50,000 & & & & & & & & \\
\hline Shift Supervisor & 37000 & 5 & 185,000 & & & & & & & & \\
\hline Lab Technician & 25000 & 2 & 50,000 & & & & & & & & \\
\hline Tech & 28000 & 8 & 224,000 & & & & & & & & \\
\hline Shift Operators & 25000 & 20 & 500,000 & & & & & & & & \\
\hline Employees & 20000 & 8 & 160,000 & & & & & & & & \\
\hline Manager & 100000 & 1 & 100,000 & & & & & & & & \\
\hline Secretaries & 20000 & 5 & 100,000 & & & & & & & & \\
\hline Total Salaries & & & $|1,574,000|$ & & 1.574 & 1.57 & 3.02 & 1.68 & 3.23 & & \\
\hline & & & & & & & & & & & \\
\hline $\mathrm{t}$ & & $60 \%$ & 944,400 & & 0.944 & 0.94 & 1.81 & 0.94 & $1.81 \mathrm{c}$ & \multicolumn{2}{|l|}{ of Labor \& Supervison } \\
\hline Maintenance & & $2 \%$ & $2,700,501$ & & 2.701 & 2.70 & 5.17 & 2.70 & $5.17 \mathrm{I}$ & \multicolumn{2}{|l|}{ Installed Eq. Cost } \\
\hline Taxes & & $1.5 \%$ & $2,154,492$ & & 2.154 & 2.15 & 4.13 & 2.15 & $4.13 \mathrm{c}$ & of Total Installed Cost & \\
\hline Operating & & & & & 7 & 7.37 & 14.12 & 7.48 & 14.34 & & \\
\hline & & & & & & & & & & & \\
\hline & & & & & & & & & & & \\
\hline Cost & & & & & & 32.42 & 62.10 & 32.62 & 62.48 & & \\
\hline & & & & & & & & & & & \\
\hline \multicolumn{2}{|c|}{ Annual Capital Charge } & & & & & 41.15 & 78.84 & 41.15 & 78.84 & & \\
\hline & & & & & & & & & & & \\
\hline Denatured & & & & & & 73.57 & 140.94 & 73.77 & 141.32 & & \\
\hline & & & $100 \%$ Conv & version to $\mathrm{E}$ & Ethanol & & & & & & \\
\hline & & $\mathrm{Kg} / \mathrm{hr}$ & $\mathrm{Kg} / \mathrm{hr}$ & $\mathrm{MM}$ & & & & & & & \\
\hline Feed Cellulose & ZCIOIFLW & 35,556 & 20,205 & 56.8 & & & & & & & \\
\hline Feed Xylan & ZXI01FLW & 15,879 & 9,228 & 26.0 & & & & & & & \\
\hline Feed Arabinan & ZAI0IFLW & 658 & 382 & 1.1 & & & & & & & \\
\hline Feed Mannan & ZMI0IFLW & 3,274 & 1,860 & 5.2 & & & & & & & \\
\hline
\end{tabular}




\section{Appendix E}

Comparison of Experimentally Measured and Modeled Information 
Comparison of Experimentally Measured and Modeled Information

Table E-1 shows pretreatment yields as measured in experimentally (Reference 17) and modeled in the base case. Overall yeilds were improved to account for near term research improvements. The primary improvement is in xylan to xylose yield. The other xylan products were reduced to allow for a higher xylose yield. Mannan, galactan, and arabinan to monomer yields were modified to match the xylan yields, but those three components are converted to little ethanol even in out year cases.

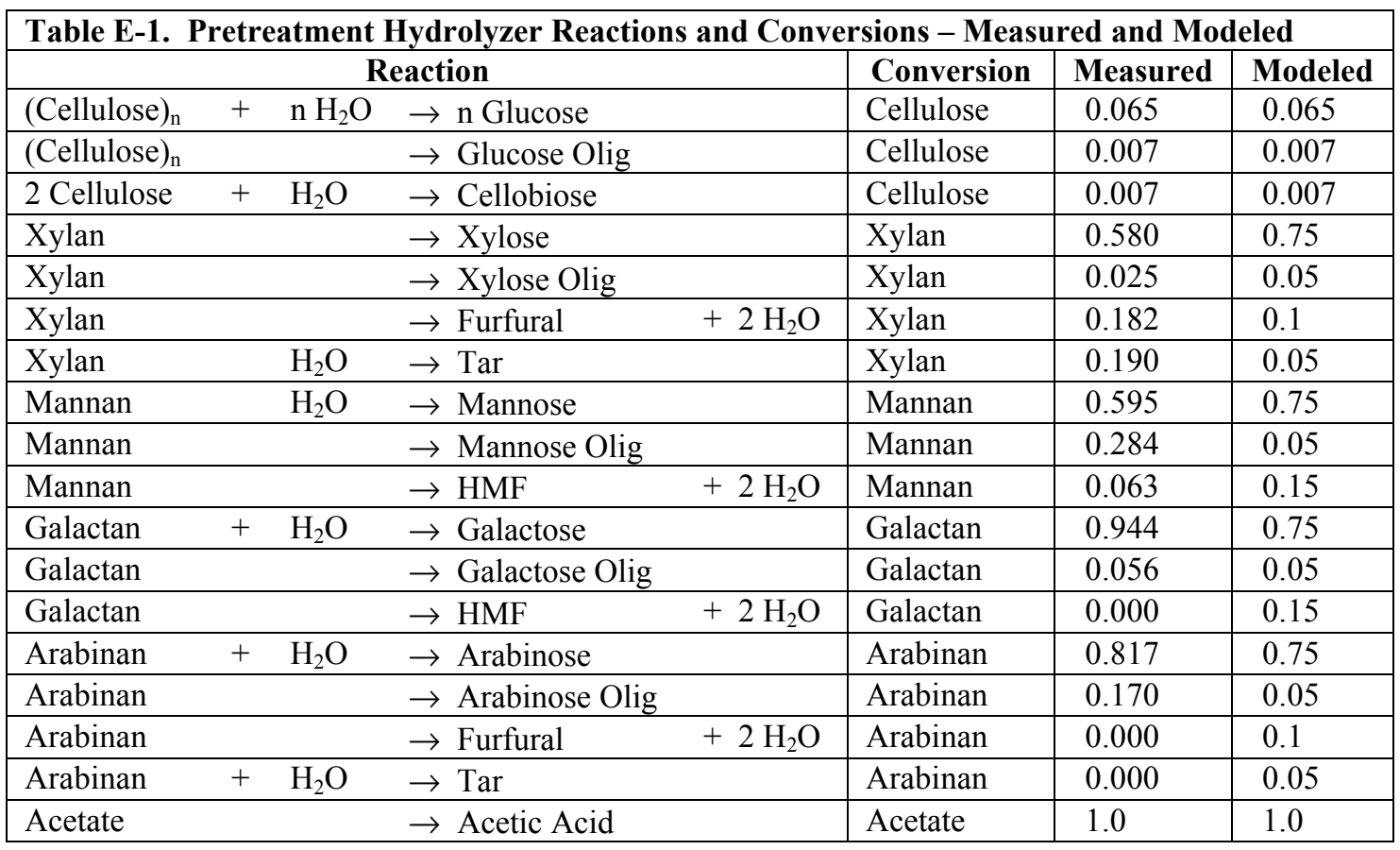

Tables E-2 and E-3 show saccharification and fermentation yields, respectively, as measured experimentally (Reference 27) and modeled in the base case. Overall yields were improved to account for near term research improvements. An increased cellulose to glucose yield is considered achievable with a $15 \mathrm{FPU} / \mathrm{g}$ cellulose enzyme loading. The experiment was run using only $12 \mathrm{FPU} / \mathrm{g}$ cellulose. The glucose to ethanol yield is the most important fermentation yield and a $92 \%$ yield is considered achievable with an optimized organism. However, that optimized organism may not achieve xylose to ethanol yield of greater than $85 \%$. The measured xylose to ethanol yield may be high due to experimental error. Arabinose, galactose, and mannose are not considered fermentable in the base case.

Table E-2 Production SSCF Saccharification Reactions and Conversions

\begin{tabular}{|c|c|c|c|c|c|c|}
\hline \multicolumn{4}{|c|}{ Reaction } & Conversion & Measured & Modeled \\
\hline Cellulose & & & $\rightarrow$ Glucose Olig & Cellulose & 0.068 & 0.068 \\
\hline 2 Cellulose & + & $\mathrm{H}_{2} \mathrm{O}$ & $\rightarrow$ Cellobiose & Cellulose & 0.012 & 0.012 \\
\hline Cellulose & + & $\mathrm{H}_{2} \mathrm{O}$ & $\rightarrow$ Glucose & Cellulose & 0.745 & 0.8 \\
\hline Cellobiose & + & $\mathrm{H}_{2} \mathrm{O}$ & $\rightarrow 2$ Glucose & Cellobiose & 1.0 & 1.0 \\
\hline
\end{tabular}


Table E-3 SSCF Fermentation Reactions and Conversions

\begin{tabular}{|c|c|c|c|c|c|c|}
\hline \multicolumn{4}{|c|}{ Reaction } & Conversion & Measured & Modeled \\
\hline Glucose & & $\rightarrow$ Ethanol & $+2 \mathrm{CO}_{2}$ & Glucose & 0.853 & 0.92 \\
\hline Glucose & $+\quad 1.2 \mathrm{NH}_{3}$ & $\rightarrow 6$ Z. Mobilis & $+2.4 \mathrm{H}_{2} \mathrm{O}+0.3 \mathrm{O}_{2}$ & Glucose & 0.027 & 0.027 \\
\hline Glucose & $+2 \mathrm{H}_{2} \mathrm{O}$ & $\rightarrow 2$ Glycerol & $+\mathrm{O}_{2}$ & Glucose & 0.002 & 0.002 \\
\hline Glucose & $+2 \mathrm{CO}_{2}$ & $\rightarrow 2$ Succinic Acid & $+\mathrm{O}_{2}$ & Glucose & 0.008 & 0.008 \\
\hline Glucose & & $\rightarrow 3$ Acetic Acid & & Glucose & 0.022 & 0.022 \\
\hline Glucose & & $\rightarrow 2$ Lactic Acid & & Glucose & 0.013 & 0.013 \\
\hline 3 Xylose & & $\rightarrow 5$ Ethanol & $+5 \mathrm{CO}_{2}$ & Xylose & 0.916 & 0.85 \\
\hline Xylose & $+\mathrm{NH}_{3}$ & $\rightarrow 5$ Z. Mobilis & $+0.25 \mathrm{O}_{2}$ & Xylose & 0.029 & 0.029 \\
\hline 3 Xylose & $+5 \mathrm{H}_{2} \mathrm{O}$ & $\rightarrow 5$ Glycerol & $+2.5 \mathrm{O}_{2}$ & Xylose & 0.002 & 0.002 \\
\hline Xylose & $+\mathrm{H}_{2} \mathrm{O}$ & $\rightarrow$ Xylitol & $+0.5 \mathrm{O}_{2}$ & Xylose & 0.006 & 0.006 \\
\hline 3 Xylose & $+5 \mathrm{CO}_{2}$ & $\rightarrow 5$ Succinic Acid & $+2.5 \mathrm{O}_{2}$ & Xylose & 0.009 & 0.009 \\
\hline 2 Xylose & & $\rightarrow 5$ Acetic Acid & & Xylose & 0.024 & 0.024 \\
\hline 3 Xylose & & $\rightarrow 5$ Lactic Acid & & Xylose & 0.014 & 0.014 \\
\hline
\end{tabular}




\section{Appendix F}

\section{Other Summary Model Results}




\begin{tabular}{|c|c|c|c|c|c|}
\hline \multicolumn{6}{|c|}{ Summary of Yields, Rates and Conversion Costs } \\
\hline Case & $\begin{array}{l}\text { NREL } \\
\text { Near } \\
\text { Term }\end{array}$ & $\begin{array}{l}\text { Near } \\
\text { Term } \\
\text { Best of }\end{array}$ & $\begin{array}{l}\text { Year } \\
2005\end{array}$ & $\begin{array}{l}\text { Year } \\
2010\end{array}$ & $\begin{array}{l}\text { Year } \\
2015\end{array}$ \\
\hline Feedstock Rate (dry metric tons/day) to $\mathrm{d}$ & 2000 & 2000 & 2000 & 2000 & 2000 \\
\hline Feedstock Rate (dry metric tons/day) to P & 2000 & 2000 & 2000 & 2000 & 2215 \\
\hline Ethanol Production (MM gal//yr) & 52.2 & 58.8 & 62.2 & 72.2 & 87.5 \\
\hline Ethanol Yield (Gal/dry ton (US) feedstock & 68.0 & 76.0 & 81.0 & 94.0 & 112.0 \\
\hline Ethanol Yield Overall (Gal/dry ton (US) fe & 68.0 & 76.0 & 81.0 & 94.0 & 99.0 \\
\hline Total Equipment Cost (1995 MM\$) & 135.0 & 119.1 & 98.4 & 90.7 & 92.4 \\
\hline Total Project Investment (1995 MM\$) & 233.8 & 205.3 & 169.4 & 156.1 & 159.3 \\
\hline Non-feedstock Raw Matl. (1995 MM\$ / yr) & 9.0 & 10.2 & 7.6 & 7.3 & 7.6 \\
\hline Waste Disposal (1995 MM\$/yr) & 0.6 & 0.6 & 1.5 & 1.5 & 1.6 \\
\hline Fixed Costs (1995 MM\$/ yr) & 7.5 & 6.9 & 6.2 & 5.9 & 5.9 \\
\hline Excess Electricity Generated (kWH/gal Et & 1.76 & 2.66 & 2.80 & 1.22 & 0.0 \\
\hline On-Line Time (hr/yr) & 8406 & 8406 & 8406 & 8406 & 8478 \\
\hline Case ID & R9906A & R9906B & R9906C & R9906D & R9906E \\
\hline
\end{tabular}




\section{Appendix G}

\section{Process Flow Diagrams}

Note: Larger format (11" x 17") versions of these Process Flow Diagrams are available upon request from rwooley@nrel.gov. 


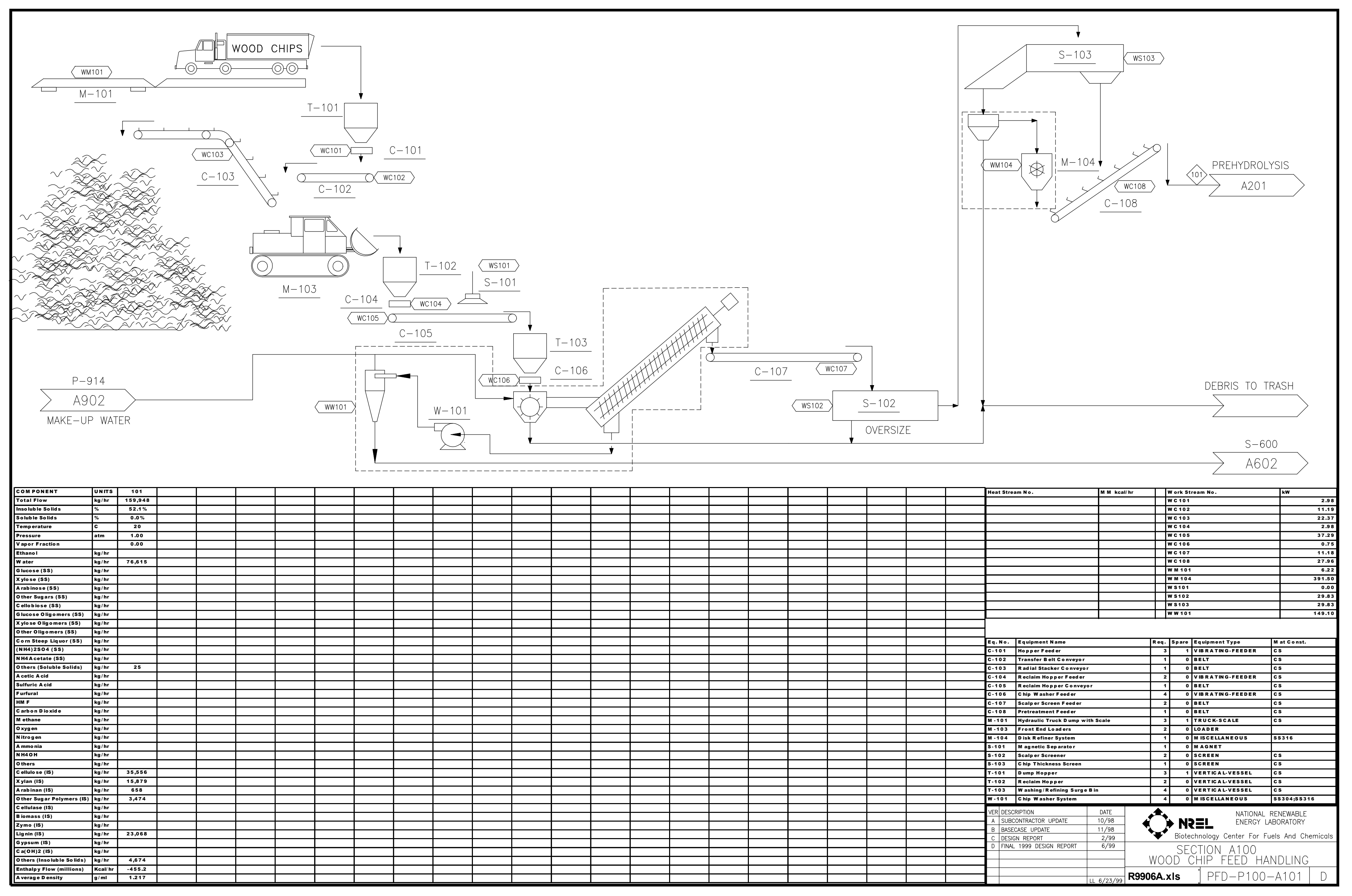




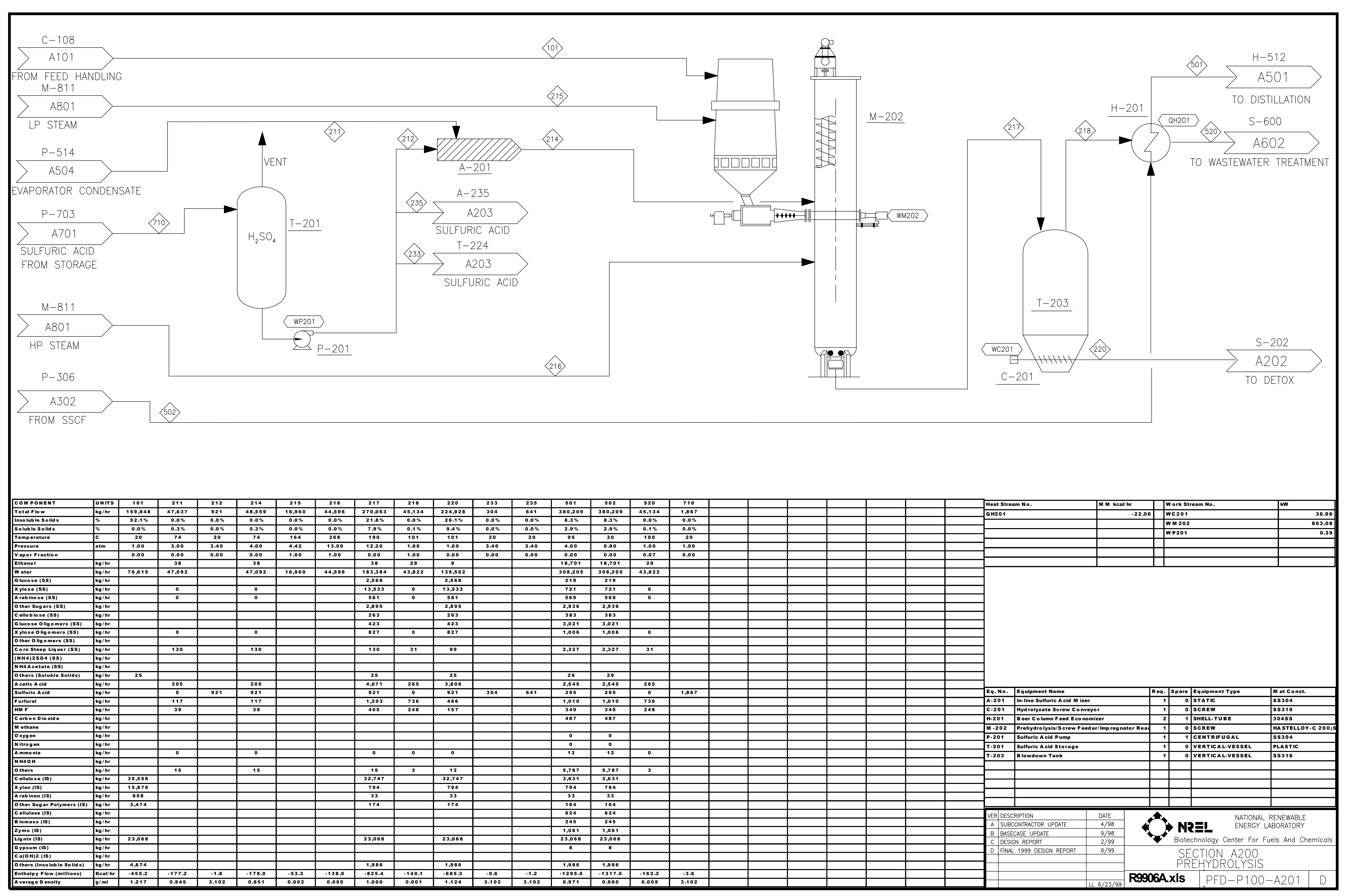




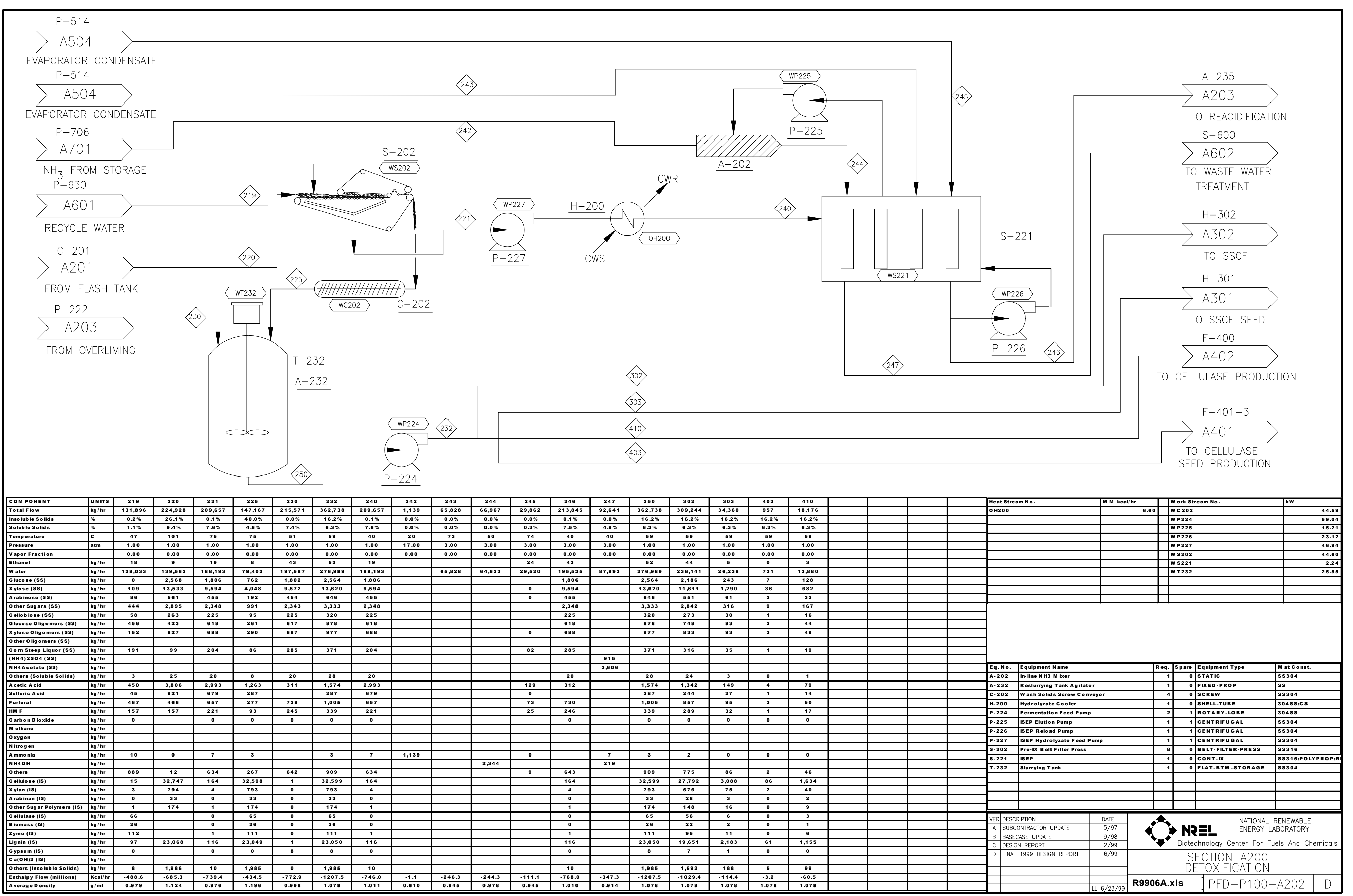




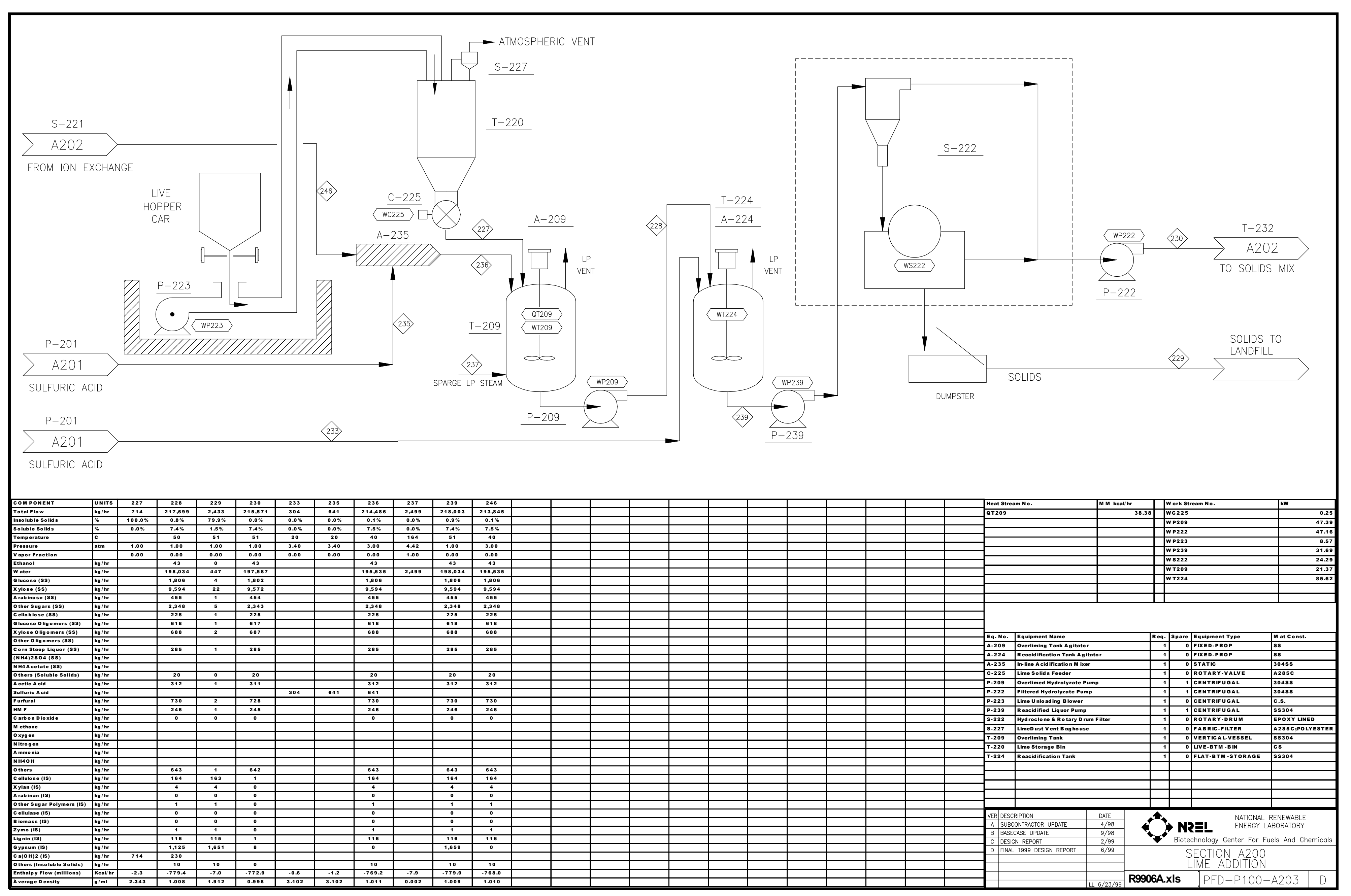



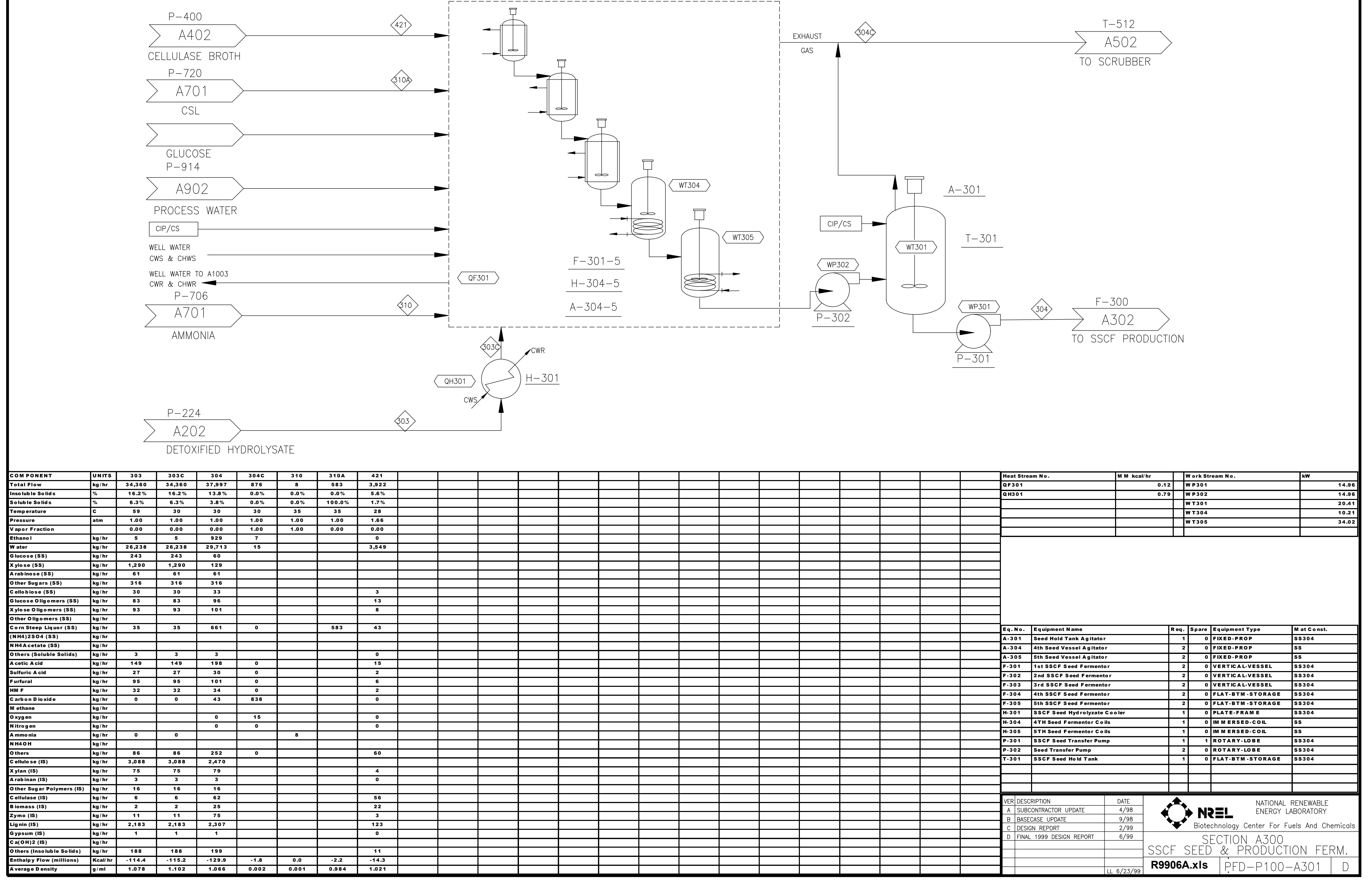

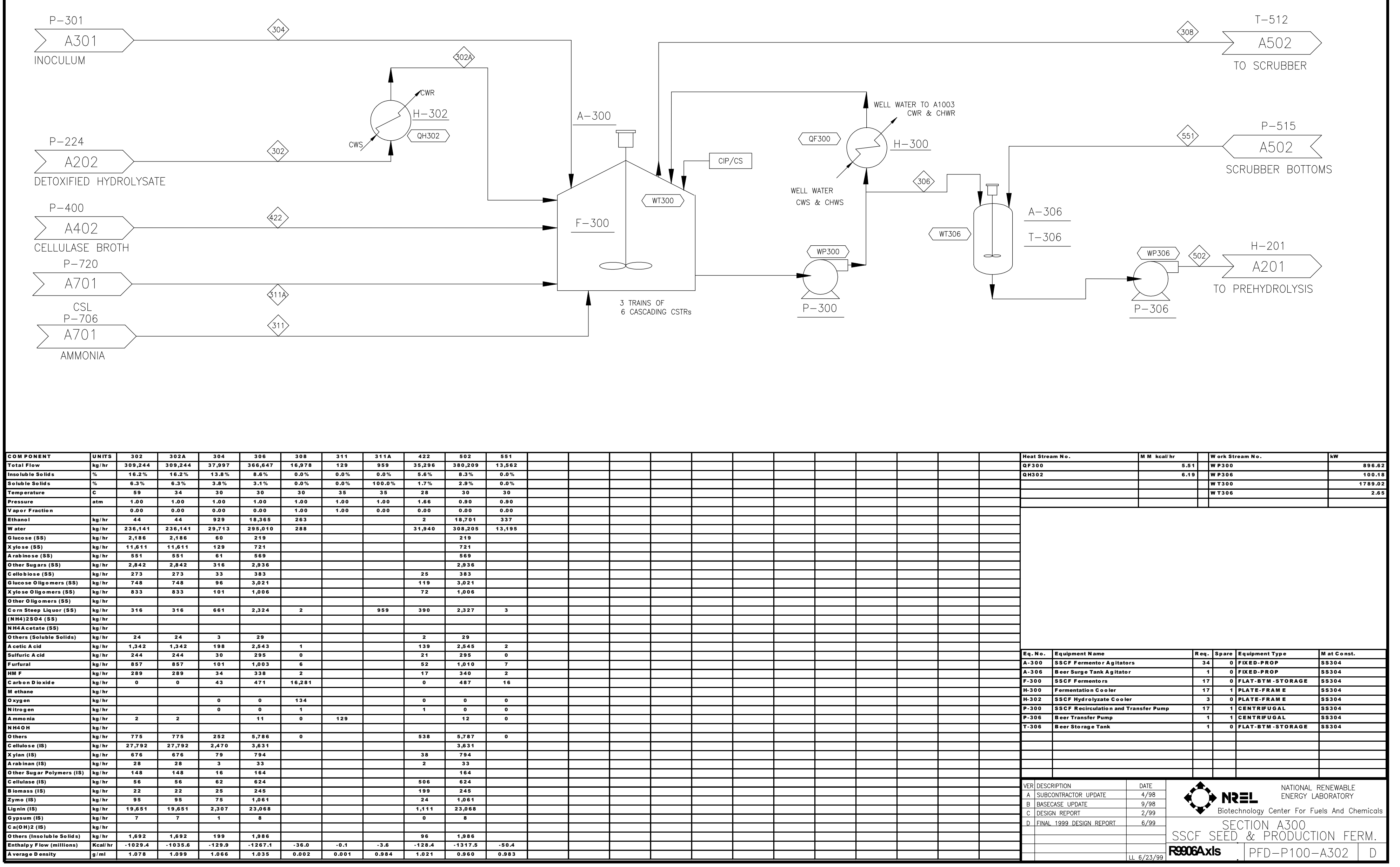


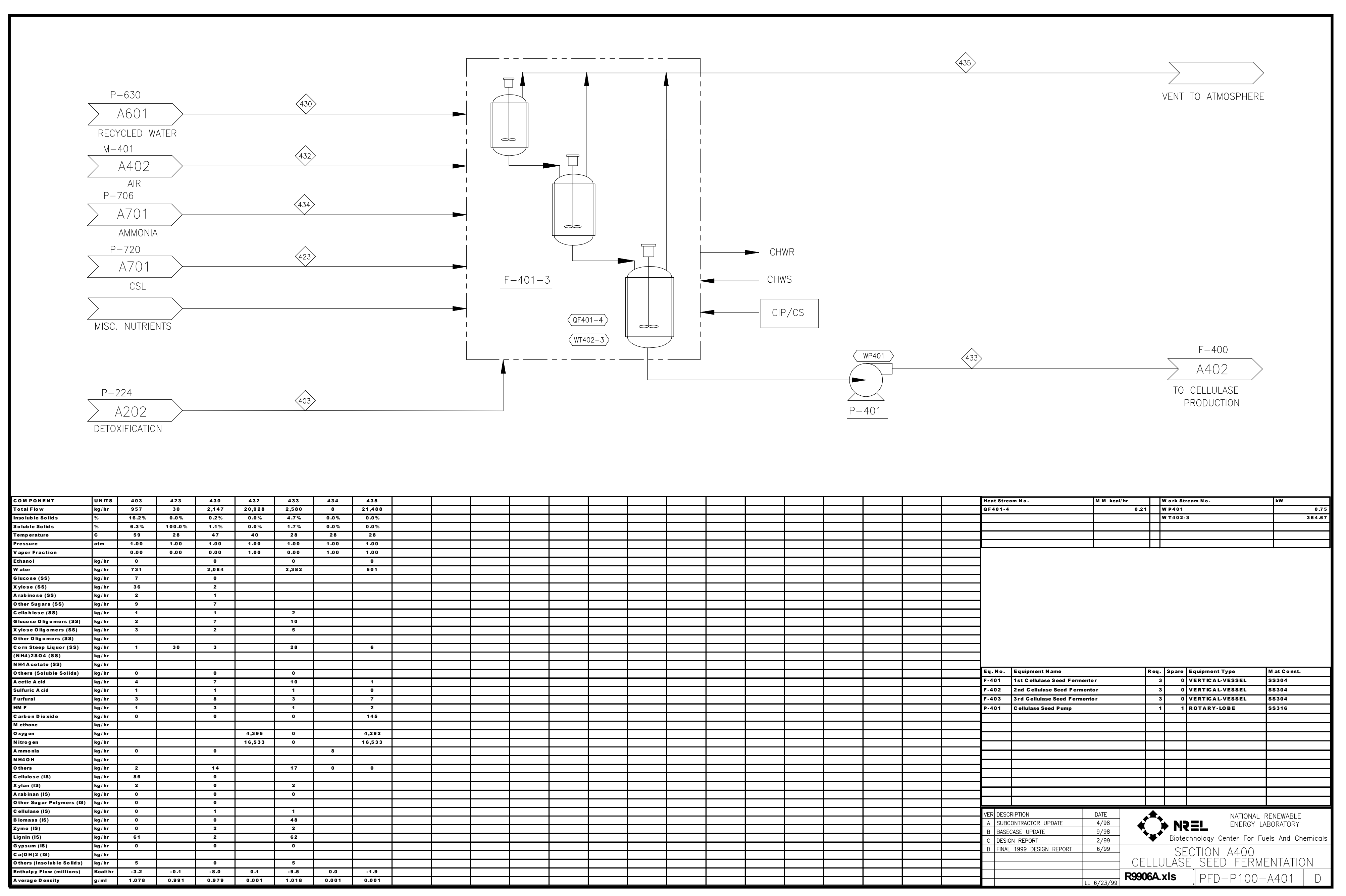




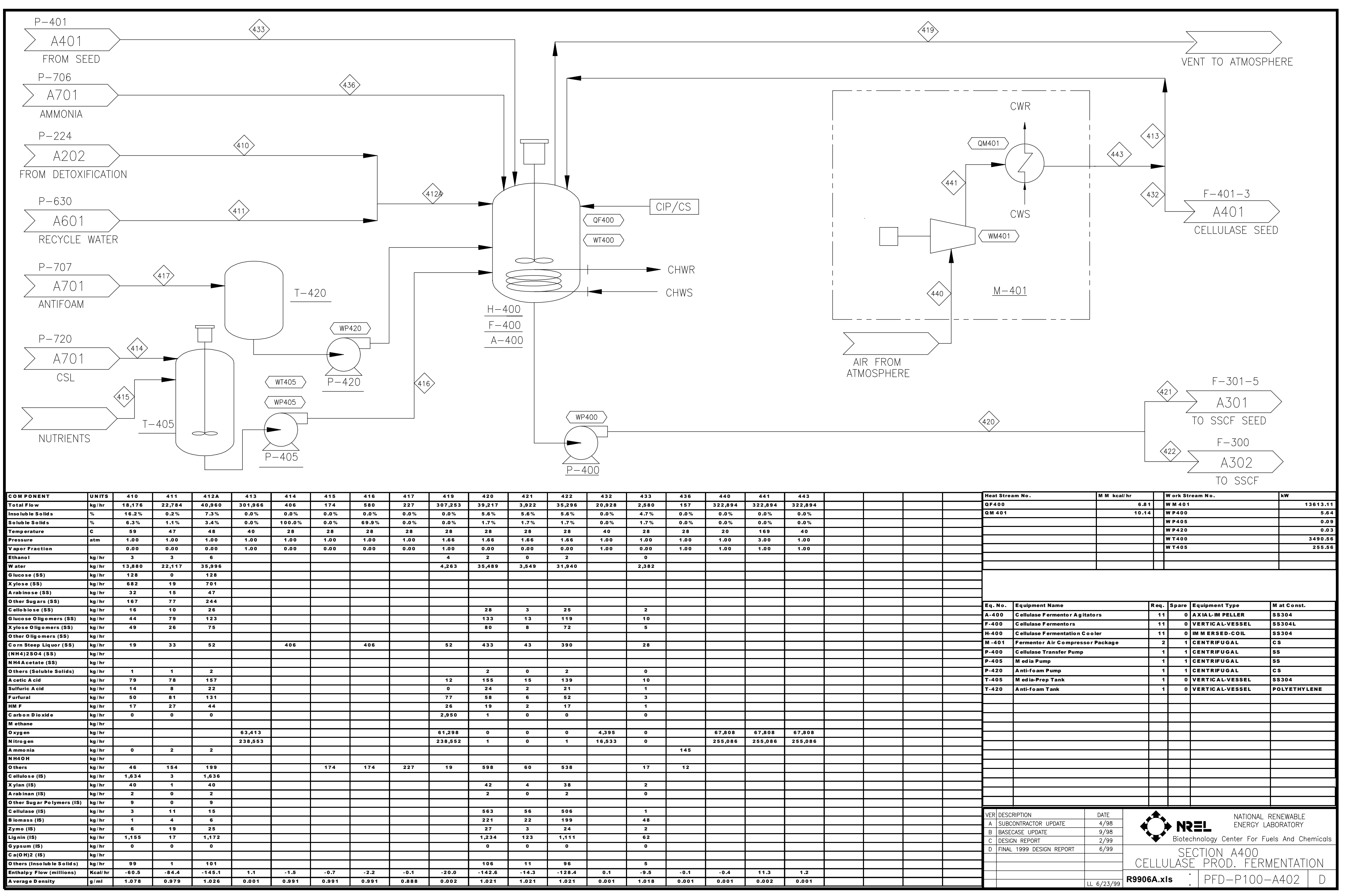




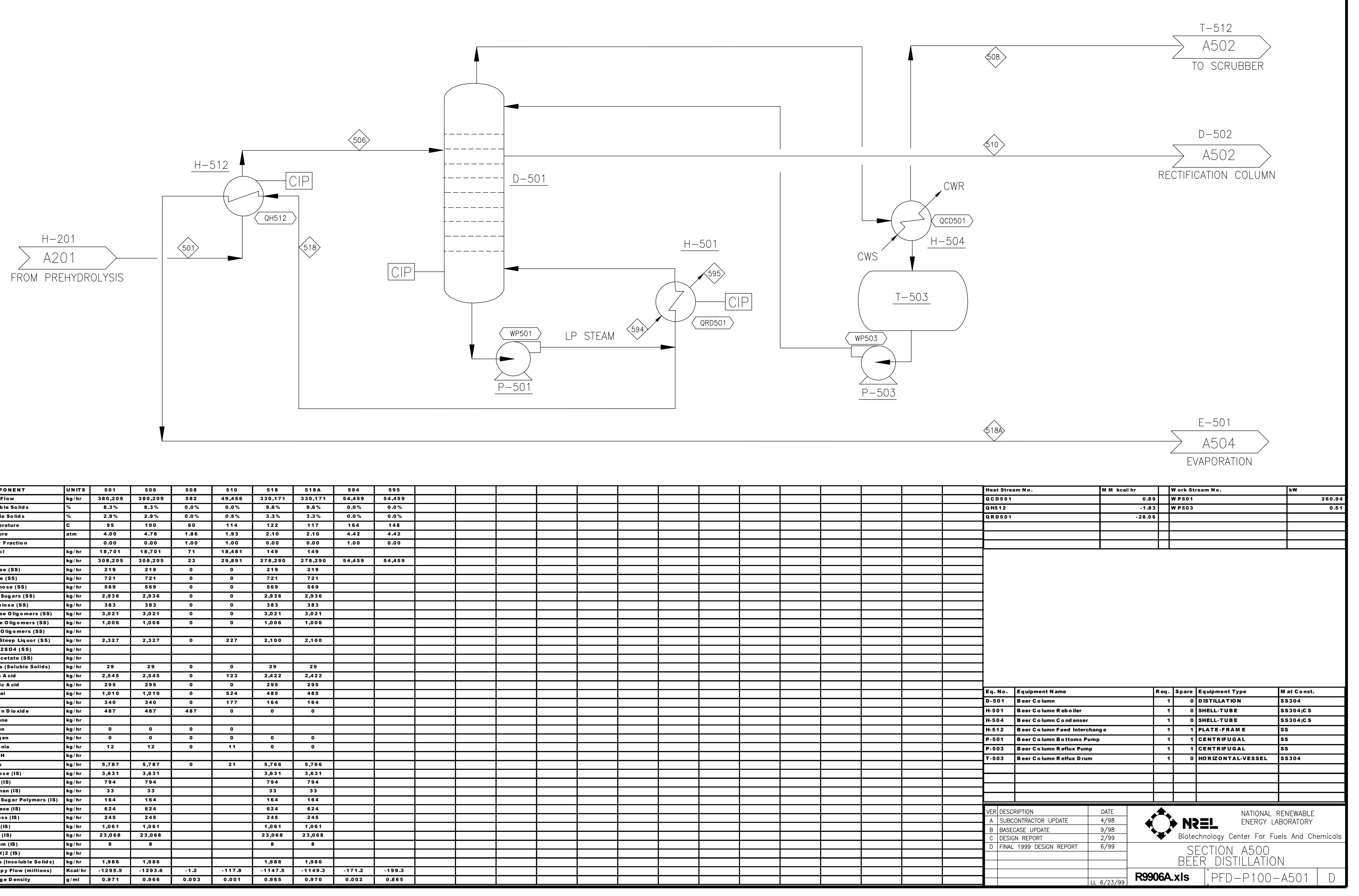




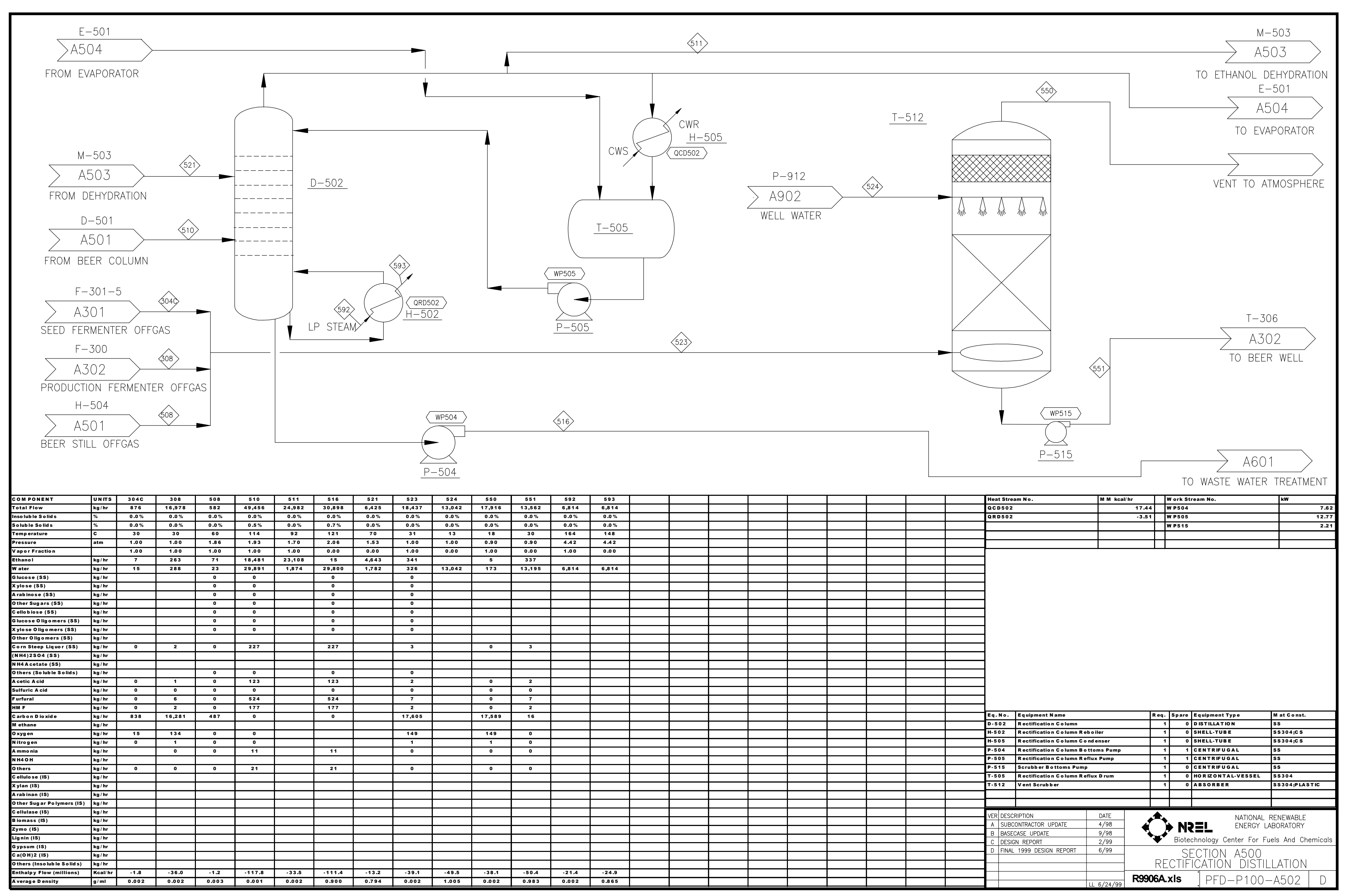




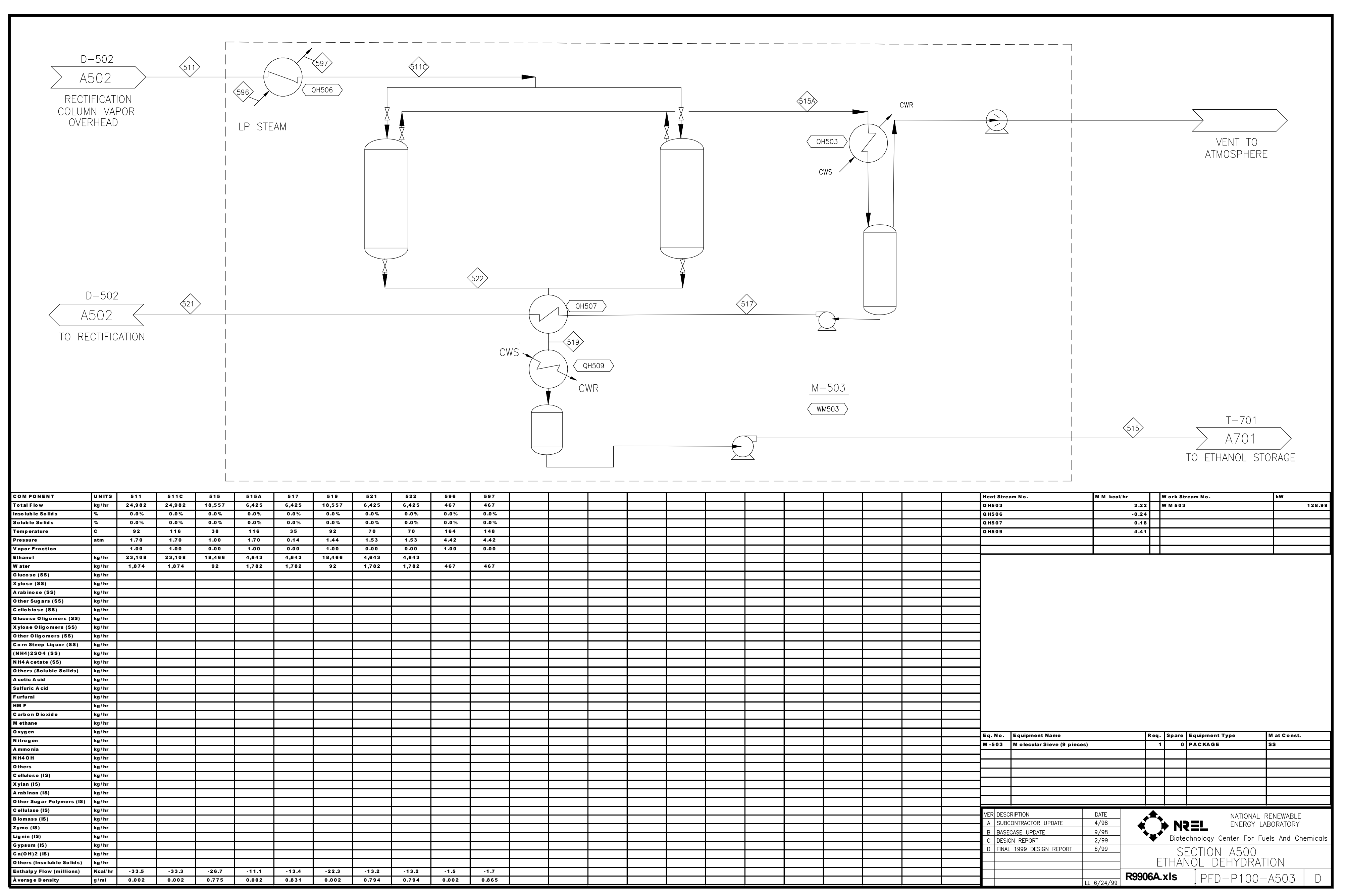




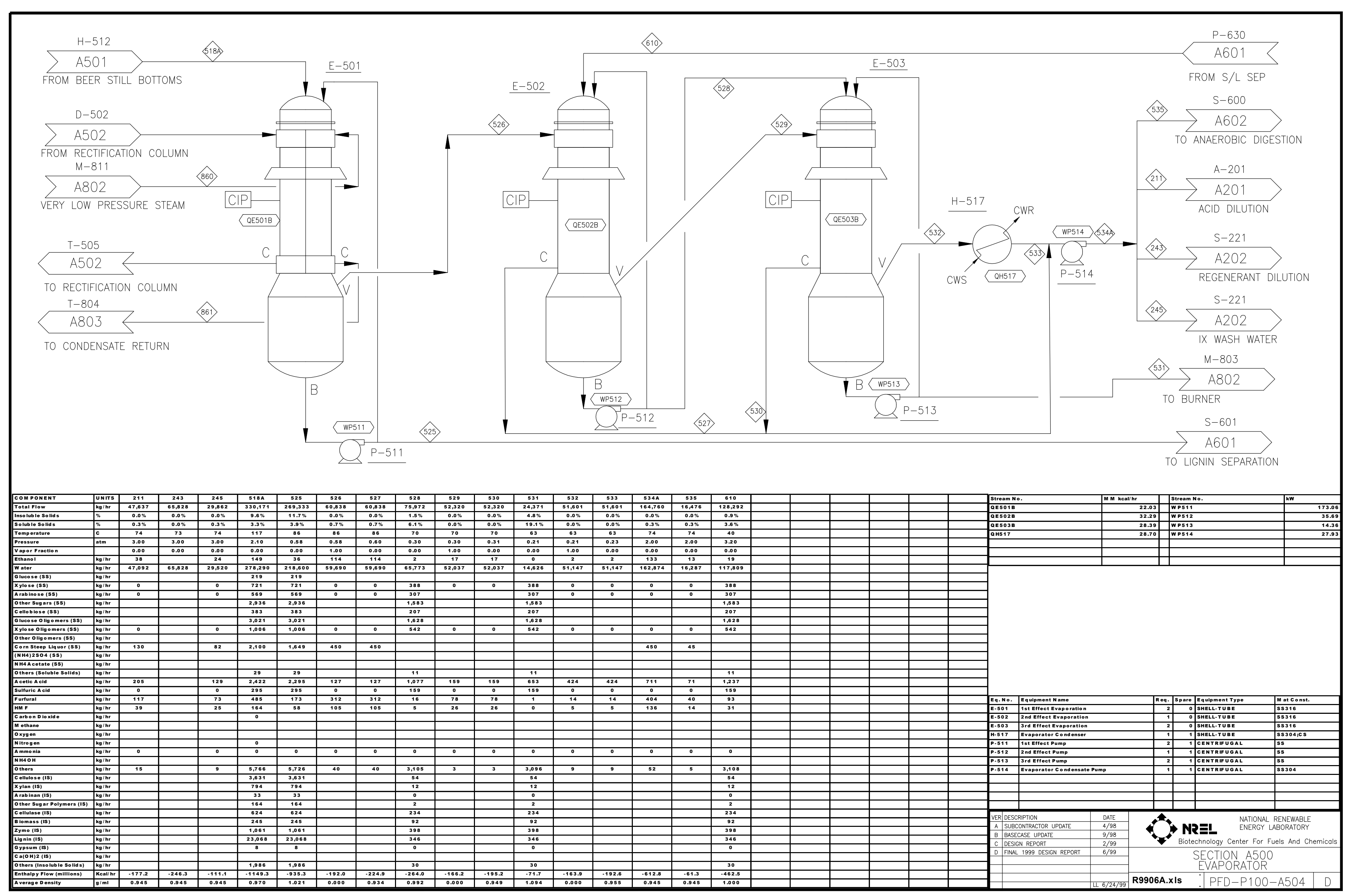




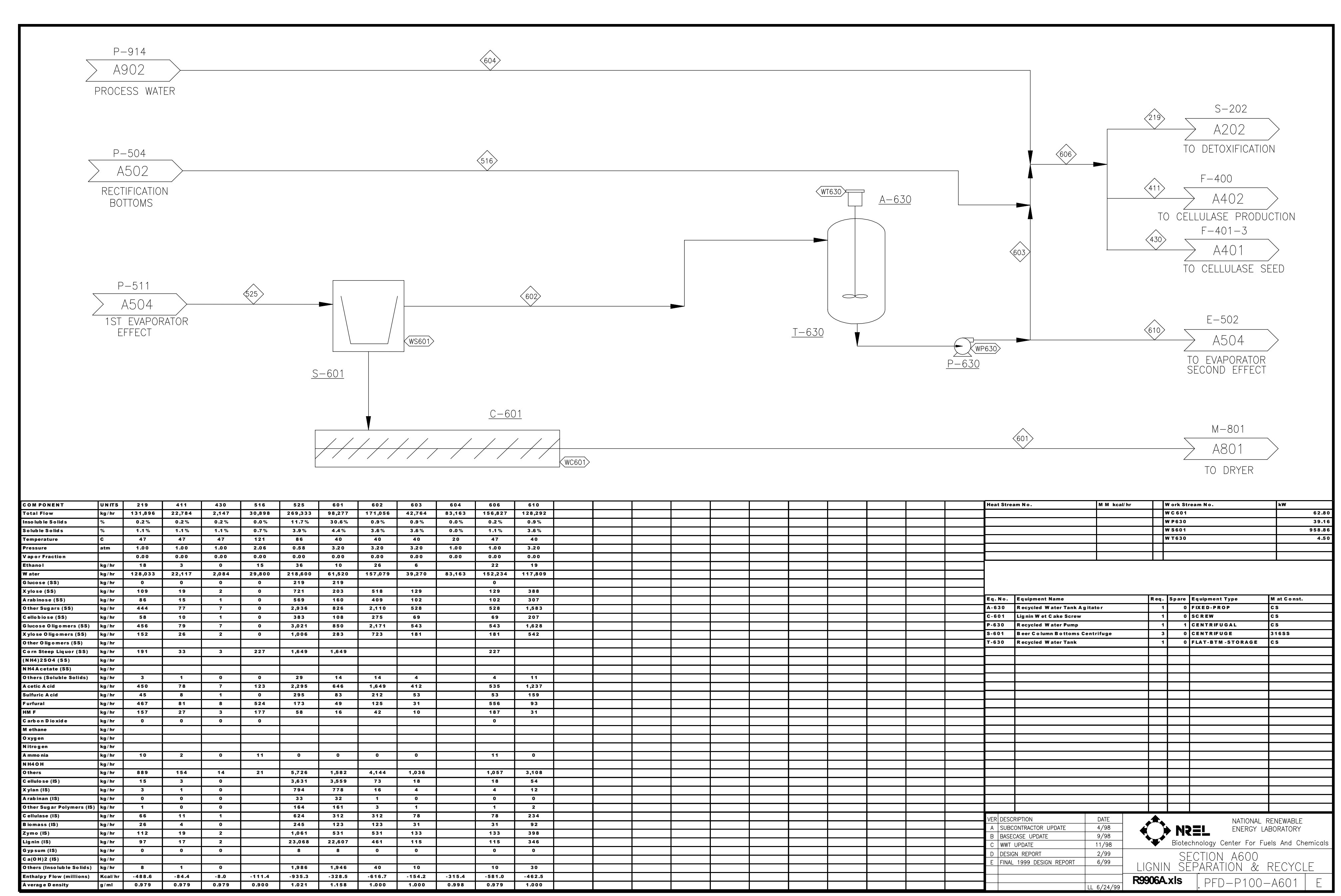




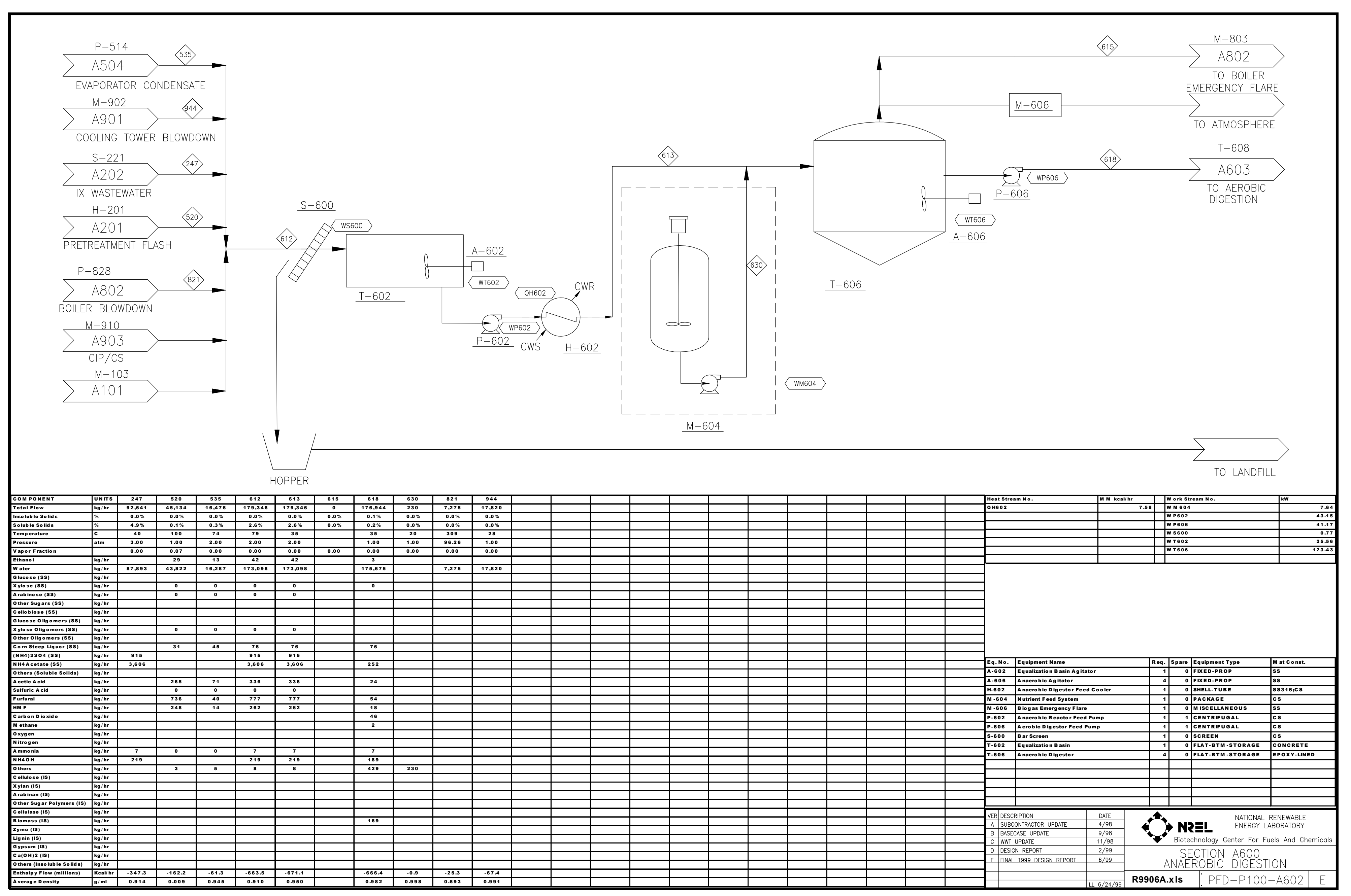




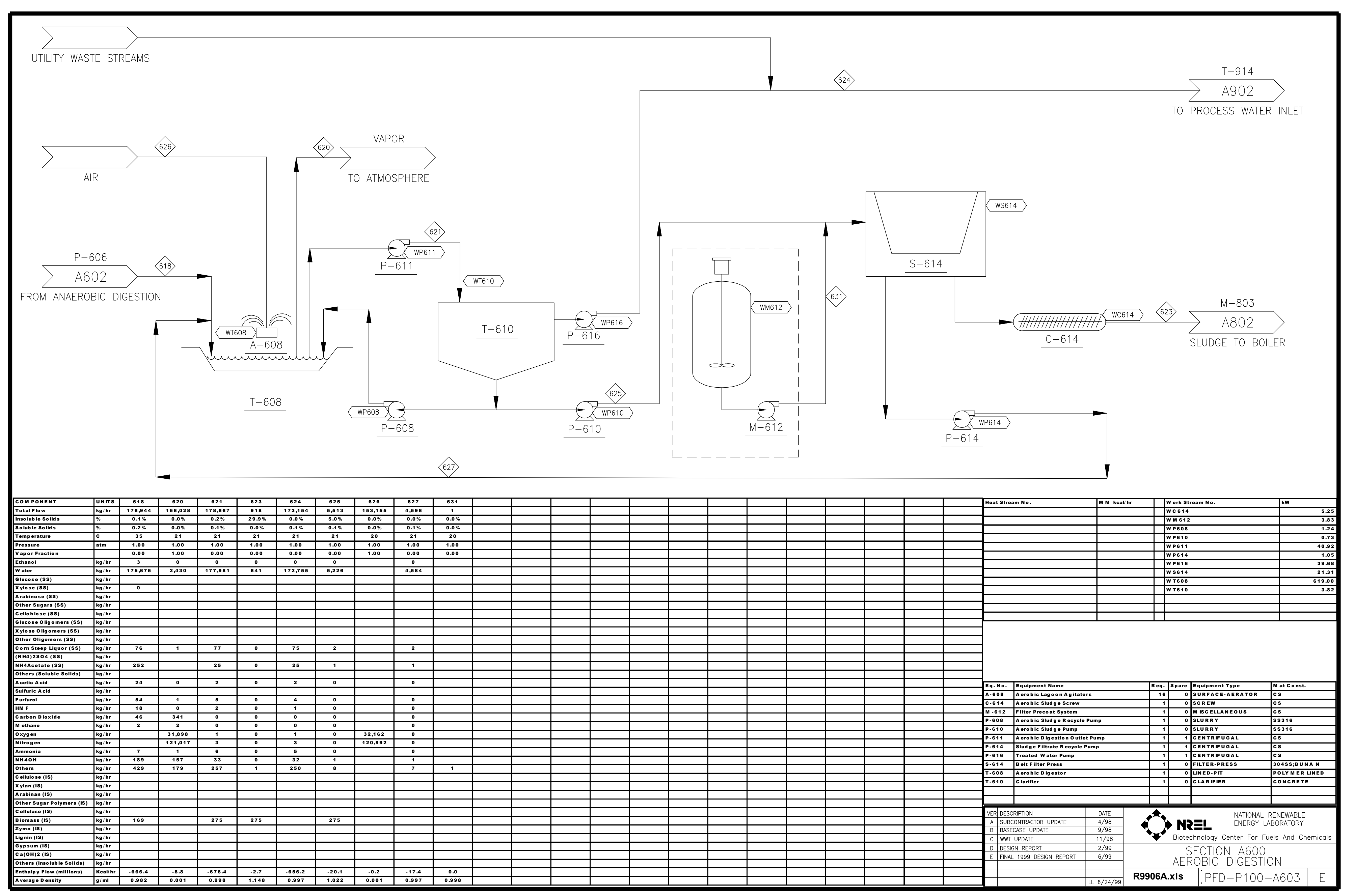




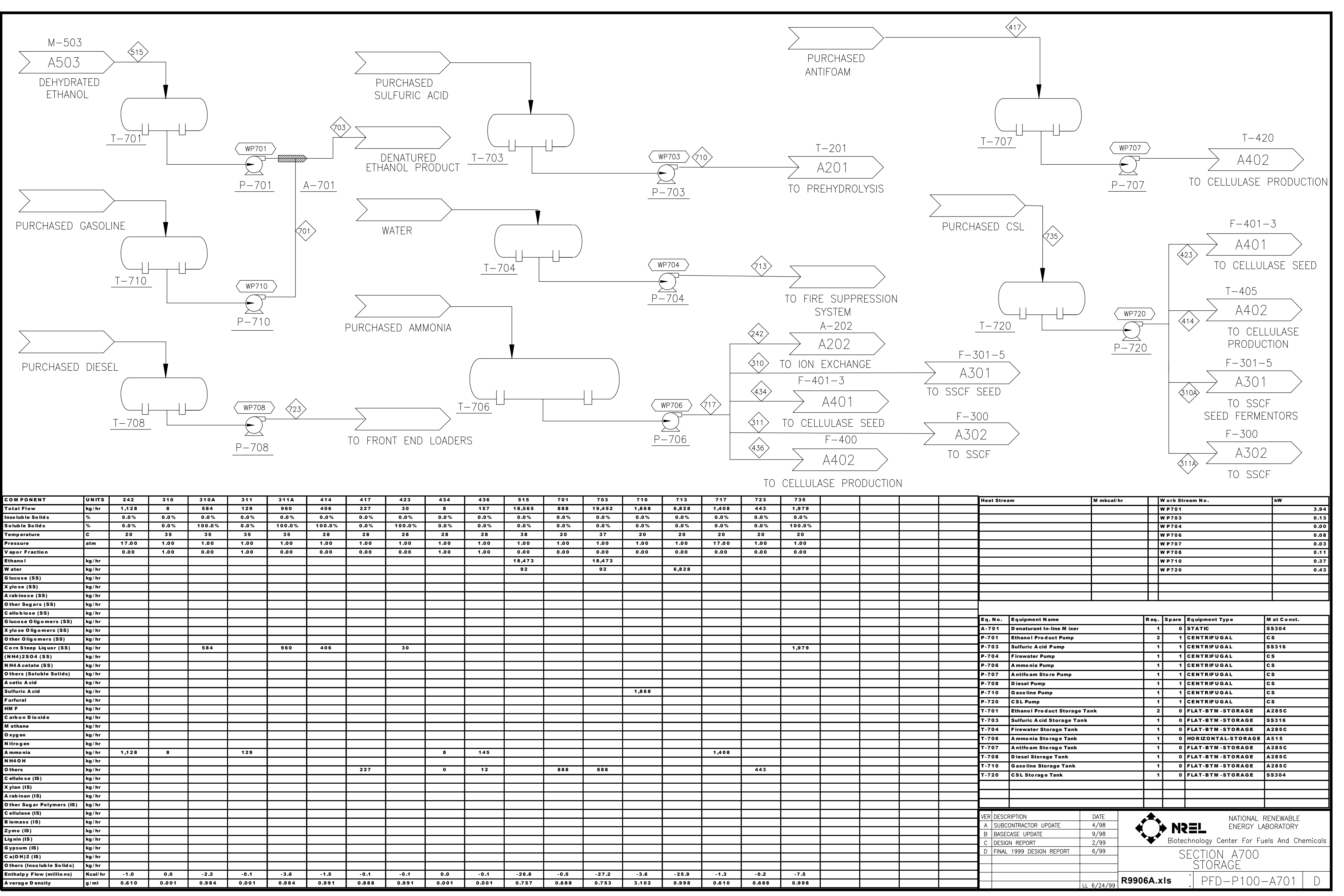




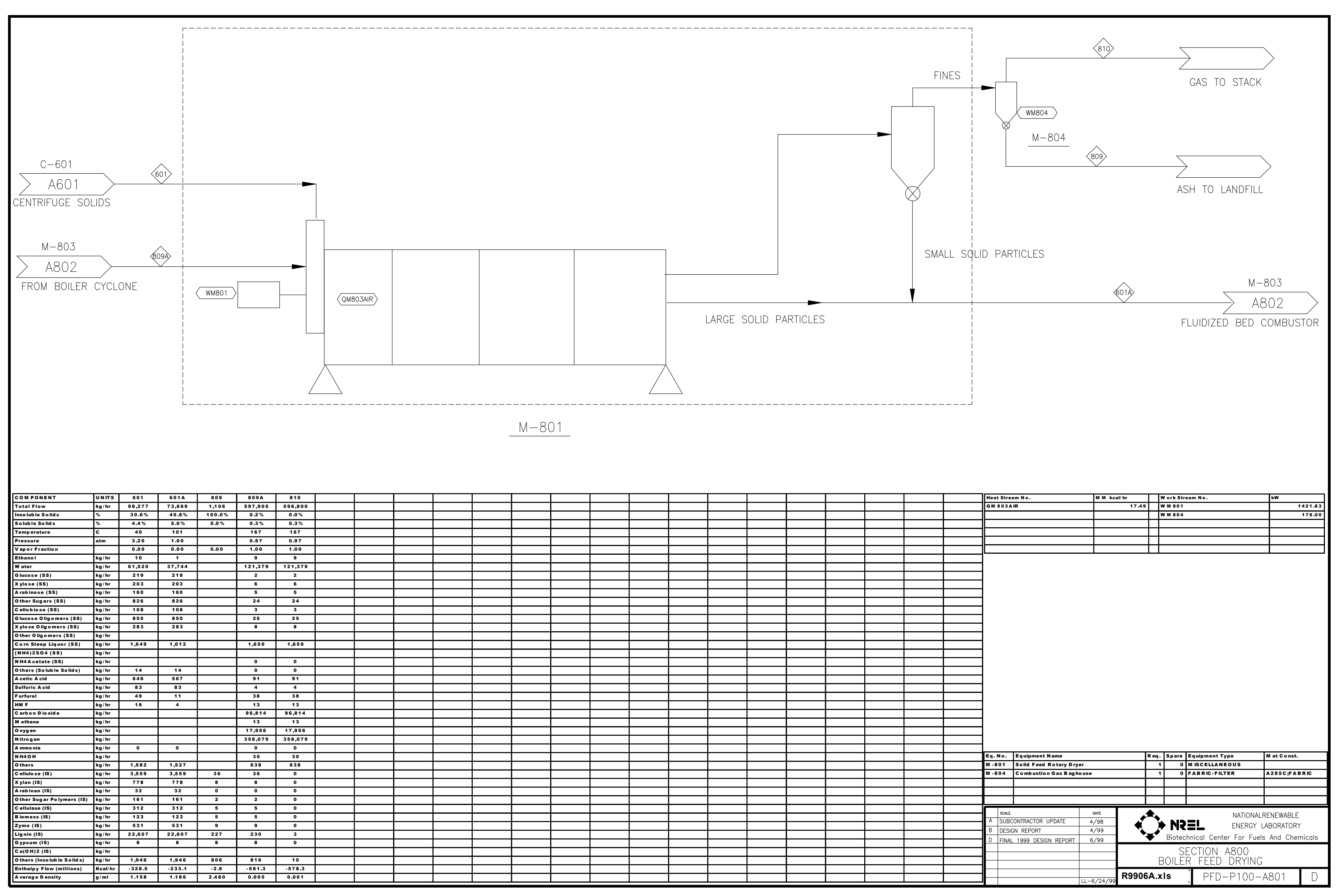




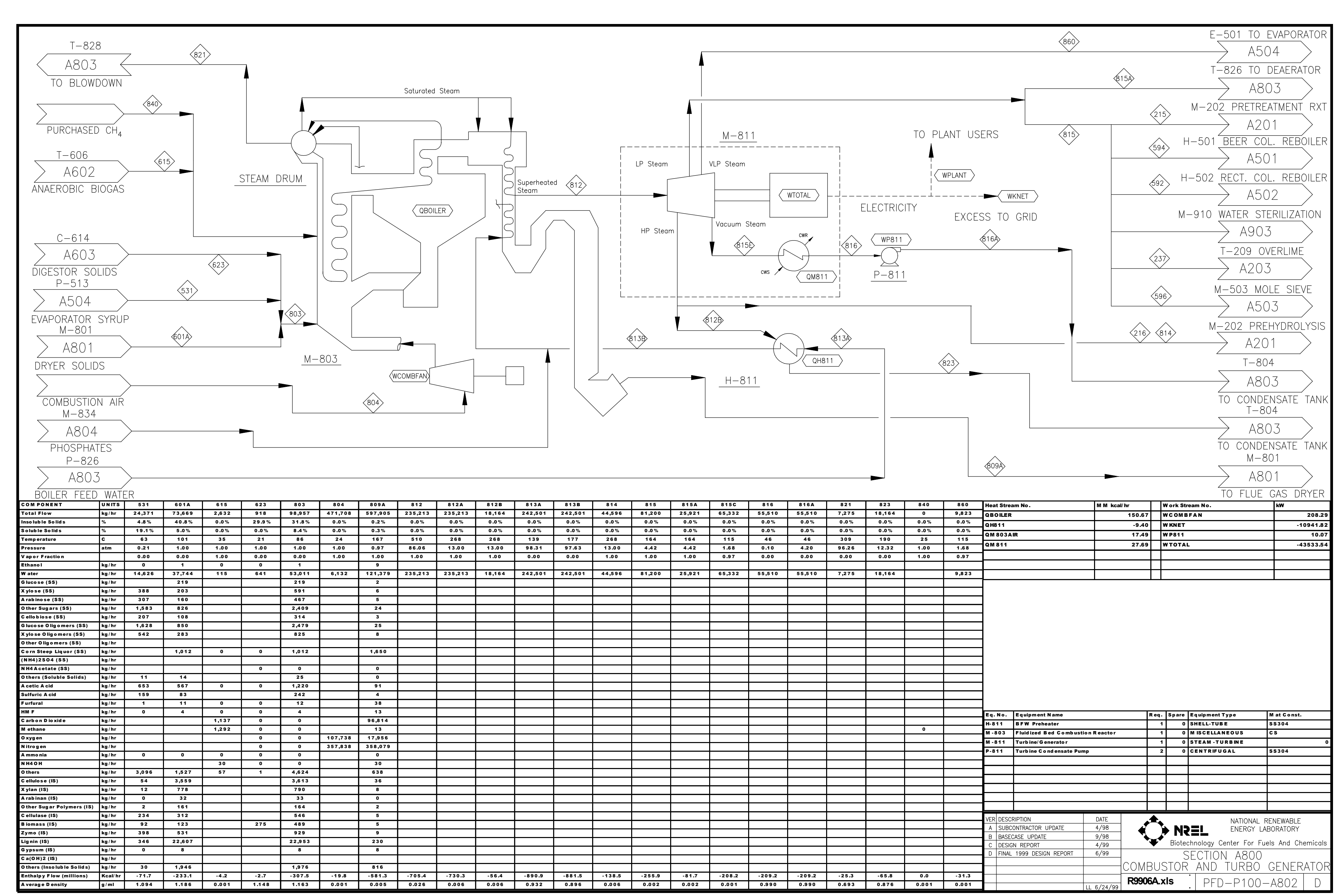




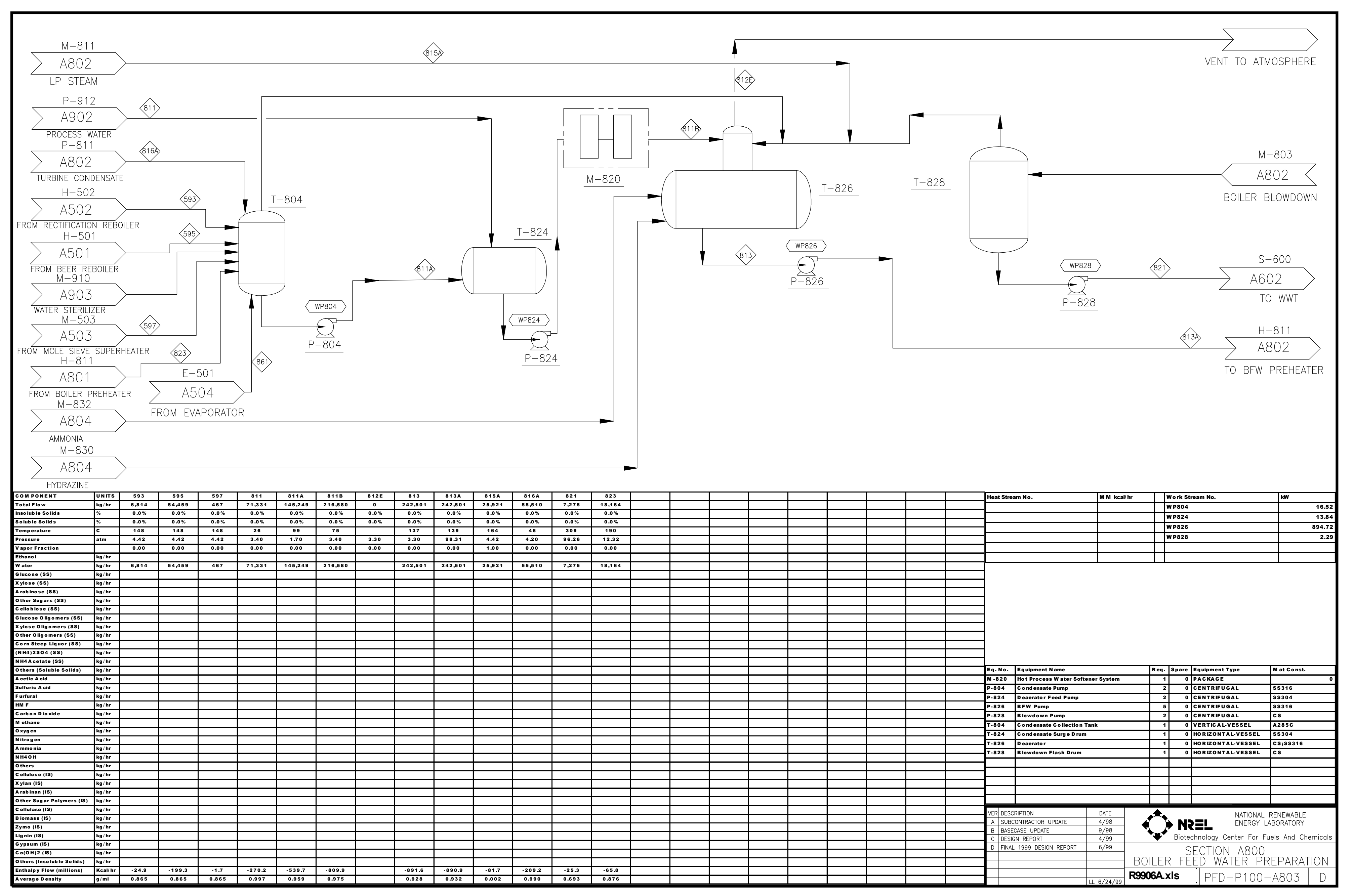




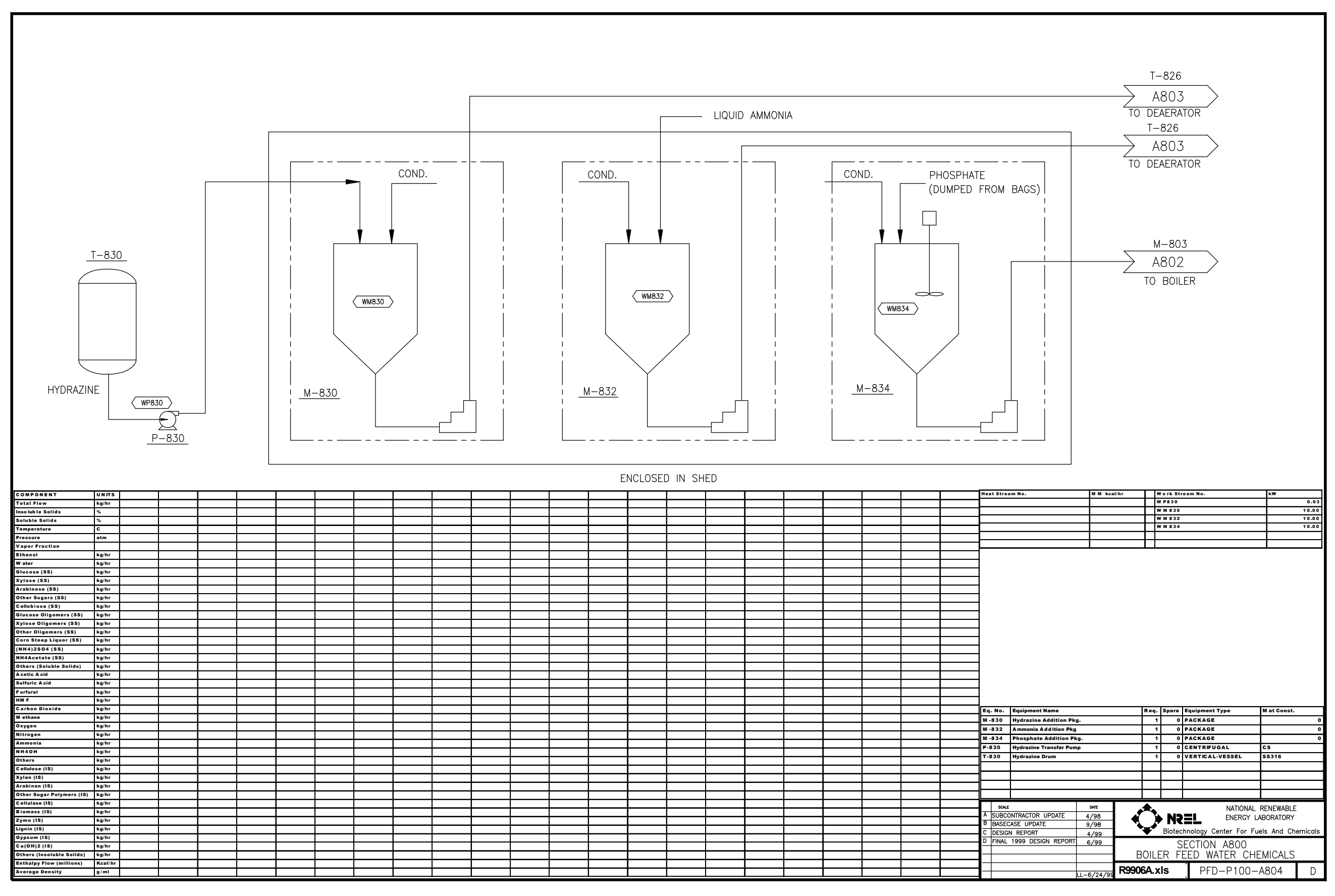



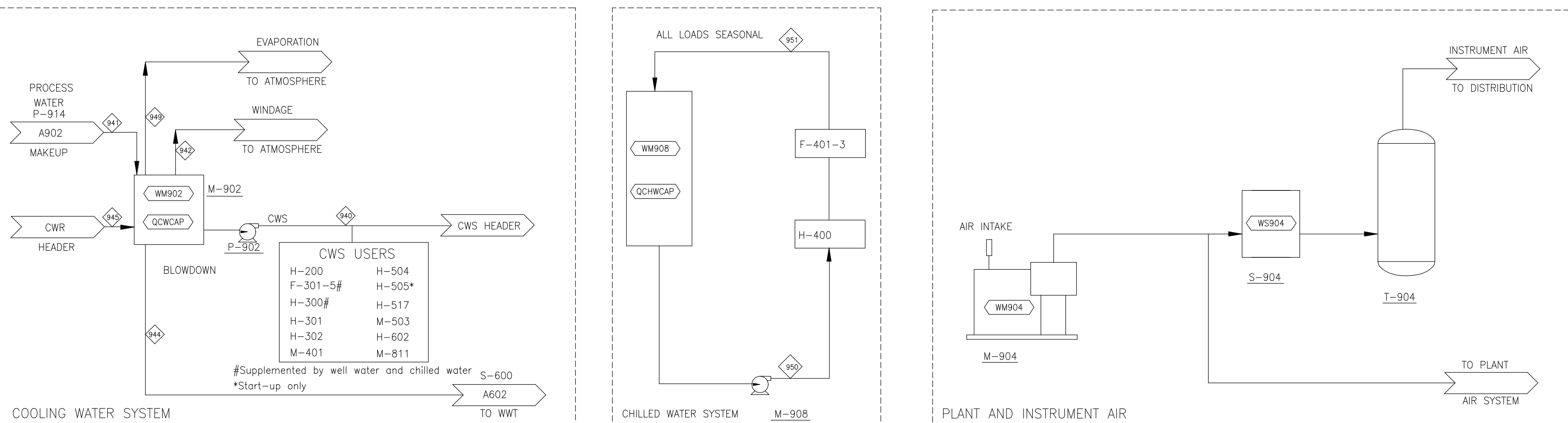

COOLING WATER SYSTEM TO WW

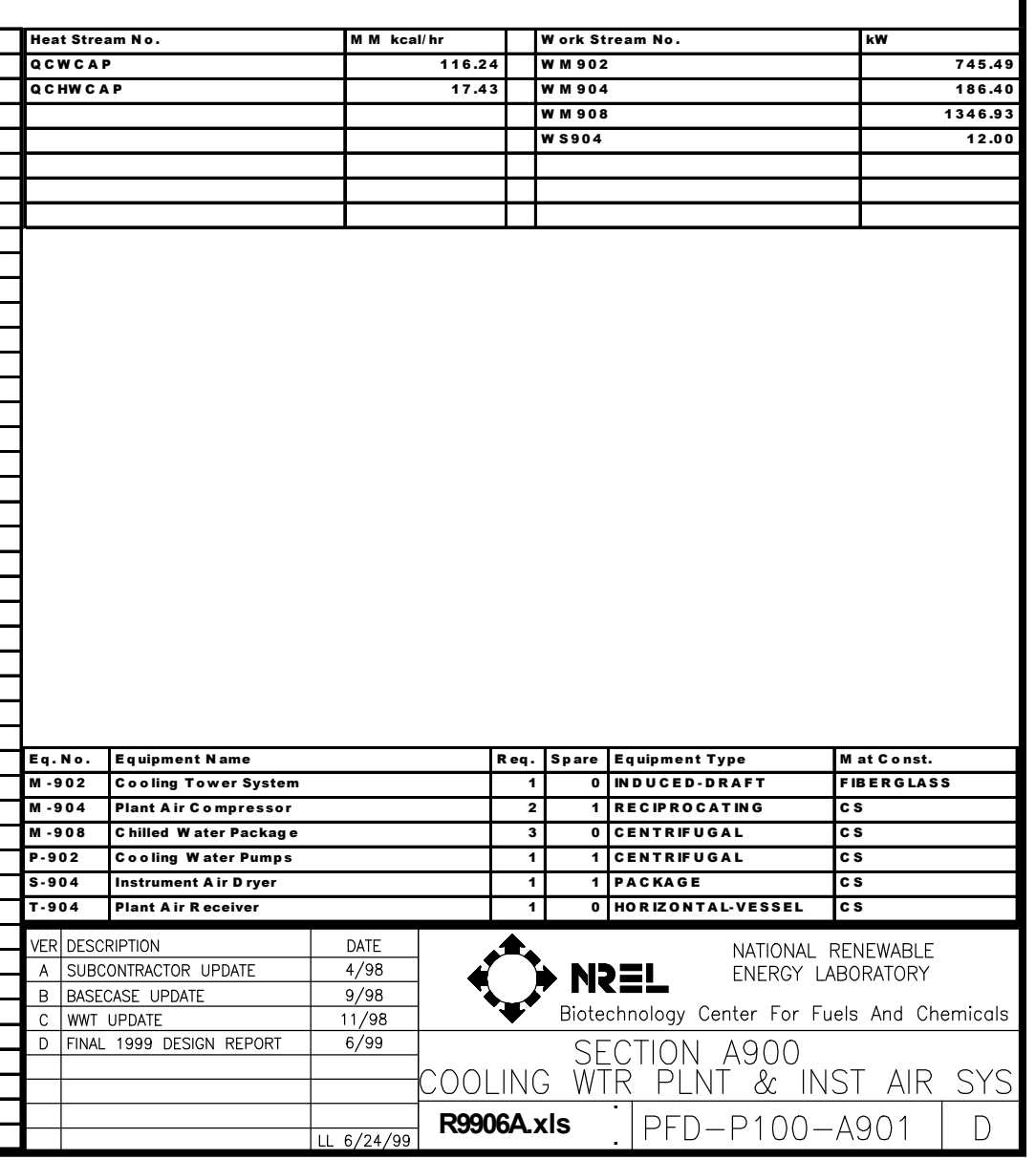




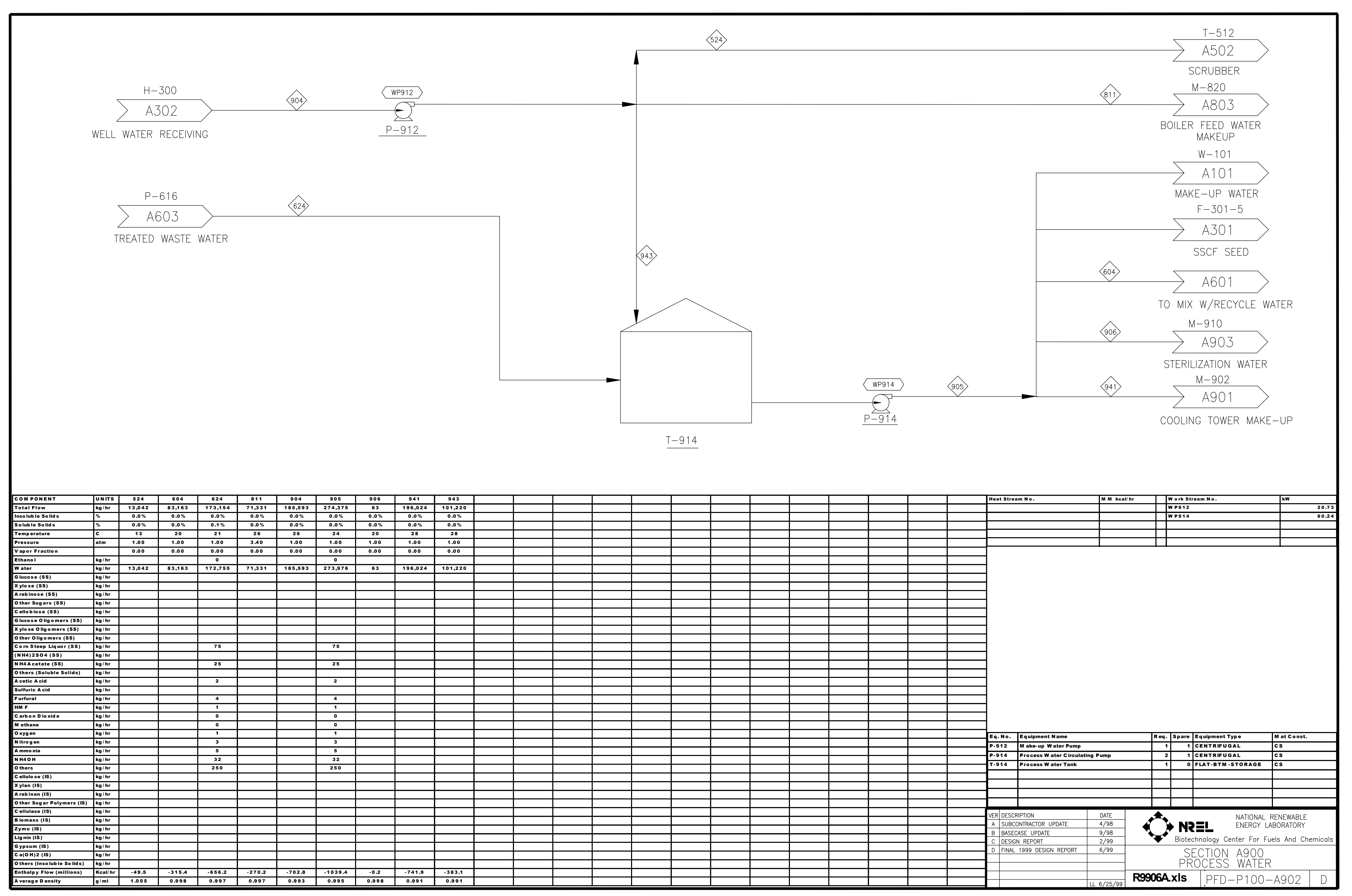




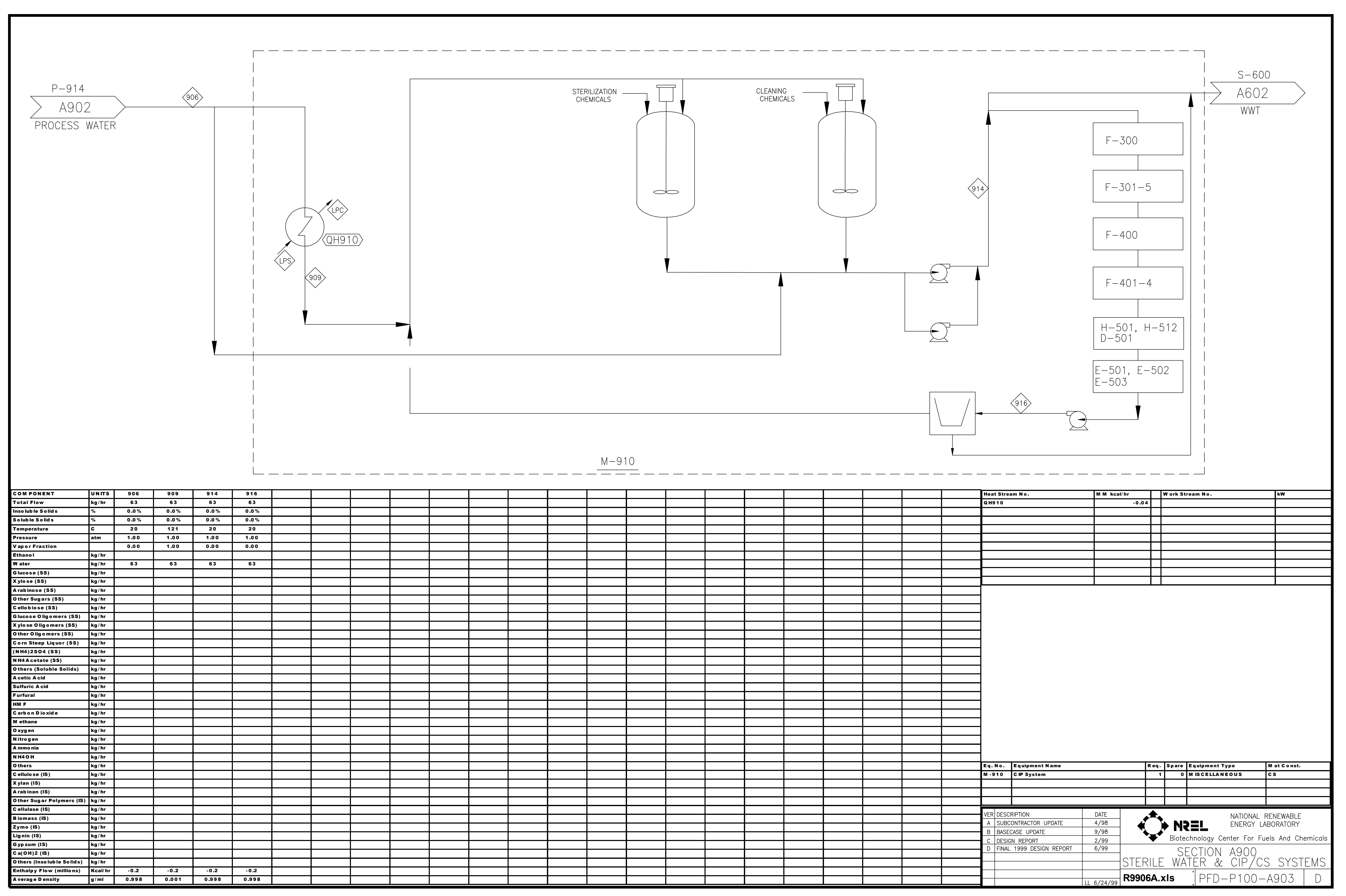


Public reporting burden for this collection of information is estimated to average 1 hour per response, including the time for reviewing instructions, searching existing data sources, gathering and maintaining the data needed, and completing and reviewing the collection of information. Send comments regarding this burden estimate or any other aspect of this collection of information, including suggestions for reducing this burden, to Washington Headquarters Services, Directorate for Information Operations and Reports, 1215 Jefferson Davis Highway, Suite 1204, Arlington, VA 22202-4302, and to the Office of Management and Budget, Paperwork Reduction Project (07040188), Washington, DC 20503.

1. AGENCY USE ONLY (Leave blank)

\section{REPORT DATE \\ July 1999}

\section{REPORT TYPE AND DATES COVERED}

Technical Report

4. TITLE AND SUBTITLE

Lignocelluloais Biomass to Ethanol Process Design and Economics Utilizing Co-Current Dilute Acid Prehydrolysis and Enzymatic Hydrolysis Current and Futuristic Scenarios

6. AUTHOR(S)

R. Wooley, M. Ruth, J. Sheehan, K. Ibsen

H. Majdeski, A. Galvez

7. PERFORMING ORGANIZATION NAME(S) AND ADDRESS(ES)

National Renewable Energy Laboratory, 1617 Cole Boulevard, Golden, CO 80401-3393

Delta-T Corporation, 460 McLaws Circle - \#150, Williamsburg, VA 23185

8. PERFORMING ORGANIZATION

9. SPONSORING/MONITORING AGENCY NAME(S) AND ADDRESS(ES)

National Renewable Energy Laboratory

1617 Cole Blvd.

Golden, CO 80401-3393 REPORT NUMBER

NREL/TP-580-26157

5. FUNDING NUMBERS

BF882251

10. SPONSORING/MONITORING AGENCY REPORT NUMBER

\section{SUPPLEMENTARY NOTES}

NREL Technical Monitor:

12a. DISTRIBUTION/AVAILABILITY STATEMENT

National Technical Information Service

12b. DISTRIBUTION CODE

U.S. Department of Commerce

5285 Port Royal Road

Springfield, VA 22161

13. ABSTRACT (Maximum 200 words)

The National Renewable Energy Laboratory (NREL) has undertaken a complete review and update of the process design and economic model for the biomass-to-ethanol enzymatic based process. The process design includes the core technologies being researched by the U.S. Department of Energy (DOE): prehydrolysis, simultaneous saccharification and co-fermentation, and cellulase enzyme production. In addition, all ancillary areas - feed handling, product recovery and purification, wastewater treatment lignin burner and boiler-turbogenerator, and utilities - are included. NREL engaged Delta-T Corporation to assist in the process design evaluation, equipment costing, and overall plant integration. The process design and costing for the lignin burner and boiler turbogenerator has been reviewed by Reaction Engineering Inc. and the wastewater treatment by Merrick \& Company. An overview of both reviews is included here.

The purpose of this update was to ensure that the process design and equipment costs were reasonable and consistent with good engineering practice for plants of this type using available technical data.

This work has resulted in an economic model that can be used to predict the cost of producing ethanol from cellulosic biomass using this technology if a plant were to be built in the next few years. The model was also extended using technology improvements that are expected to be developed based on the current DOE research plan. Future process designs and cost estimates are given for the years 2005, 2010, and 2015 .

14. SUBJECT TERMS

Ethanol; Process Design; Economic Evaluation; Cost Estimation; Pretreatment; Fermentation; Waste Water Pretreatment; Lignin Burner Distillation; Molecular Sieve

17. SECURITY CLASSIFICATION OF REPORT
18. SECURITY CLASSIFICATION OF THIS PAGE
19. SECURITY CLASSIFICATION OF ABSTRACT
15. NUMBER OF PAGES 128

16. PRICE CODE 